\title{
WestVirginiaUniversity
}

THE RESEARCH REPOSITORY @ WVU

Graduate Theses, Dissertations, and Problem Reports

2003

\section{Modeling the international competitiveness of Botswana's coal}

\author{
Khaulani Fichani \\ West Virginia University
}

Follow this and additional works at: https://researchrepository.wvu.edu/etd

\section{Recommended Citation}

Fichani, Khaulani, "Modeling the international competitiveness of Botswana's coal" (2003). Graduate Theses, Dissertations, and Problem Reports. 1827.

https://researchrepository.wvu.edu/etd/1827

This Dissertation is protected by copyright and/or related rights. It has been brought to you by the The Research Repository @ WVU with permission from the rights-holder(s). You are free to use this Dissertation in any way that is permitted by the copyright and related rights legislation that applies to your use. For other uses you must obtain permission from the rights-holder(s) directly, unless additional rights are indicated by a Creative Commons license in the record and/ or on the work itself. This Dissertation has been accepted for inclusion in WVU Graduate Theses, Dissertations, and Problem Reports collection by an authorized administrator of The Research Repository @ WVU.

For more information, please contact researchrepository@mail.wvu.edu. 


\title{
MODELING THE INTERNATIONAL COMPETITIVENESS OF BOTSWANA'S COAL
}

\author{
Khaulani Fichani \\ Dissertation submitted to the \\ Davis College of Agriculture, Forestry and Consumer Sciences \\ at West Virginia University \\ in partial fulfillment of the requirements \\ for the Degree of
}

\author{
Doctor of Philosophy \\ in \\ Natural Resource Economics \\ Walter C. Labys, Ph.D., Chair \\ Calvin O. Masilela, Ph.D. \\ Jerald J. Fletcher, Ph. D. \\ Stratford Douglas, Ph.D. \\ Tim Phipps, Ph.D.
}

Division of Resource Management

\author{
Morgantown, West Virginia \\ 2003
}

Keywords: International Steam Coal Trade Model, Botswana's Coal Resources, Econometric Forecasting, Spatial and Dynamic Optimization, Long Run Marginal Cost Function

Copyright 2003 Khaulani Fichani 


\section{ABSTRACT \\ Modeling the International Competitiveness of Botswana's Coal}

\section{Khaulani Fichani}

Botswana has vast proven deposits of steam coal, which for a long time it has wanted to develop but without much success. The main objectives of this study are: 1) to analyze the time schedule of coal exports likely to be forthcoming from Botswana and the land routes for these exports 2) to determine the competitiveness of Botswana's coal in the world steam coal markets and 3) to make recommendations on the appropriate policy for the exploitation of this coal. To accomplish these objectives, we construct a model of the seaborne steam coal trade consisting of exporters and importers with a substantial share in this trade. We econometrically estimate the long run marginal cost functions for net exporters and employ these to construct a spatial and dynamic model of the world steam coal trade with elastic supply and inelastic demand. This model is applied to simulate Botswana's competitiveness in this trade over the period 1995 to 2010 from a 1990 base year with a decision criterion that minimizes the sum of discounted capital costs of mine development, variable supply costs, rail and maritime transportation costs. Finally, we employ the model to forecast the likely optimal size of mine, timing of production capacity and choice of export port for Botswana's coal for the years 2005 and 2010. The base year for the forecast is 2000. The simulation results indicate that Botswana's coal would have been competitive in the steam coal markets of Western Europe and Asia. The forecast results indicate that Botswana's coal would also be competitive in these markets in the future. These results are least sensitive to changes in rail transportation and variable supply costs but are sensitive to capital costs for mine development. 


\section{ACKNOWLEDGEMENTS}

The subject of this dissertation work has been of great interest to me for many years and I was very fortunate to find an equally high level of enthusiasm on this topic from members of my Ph.D. committee. I would like to specifically thank my advisor and committee chair, Dr. Walter Labys, for the assistance and direction he gave on this work. It was a privilege for me to have worked and shared in his experience on international commodity modeling.

I was also very fortunate to have on my committee, Dr. Jerry Fletcher, Dr. Calvin, O. Masilela, Dr. Tim Phipps and Dr. Stratford Douglas who were there for that unplanned brainstorm that in many ways cleared my thinking just at the right time. I know that things would not have been as easy without the GIS "piece job" and, for this, my family and I are extremely grateful.

I would also like to thank Mr. Jacob Thamage, Director of Minerals Affairs in the Ministry of Minerals, Energy and Water Affairs in Botswana for his prompt responses with very useful background information on the geology, size and location of Botswana's coal deposits.

Finally, I would like to thank my beautiful wife, Mmama, whom I dearly love, and the children, Madalla, Tlhomamo and Senzeni and my sister-in-law, Itumeleng, for their support especially in the critical days of this dissertation. I dedicate this dissertation to my wife and the children. 


\section{TABLE OF CONTENTS}

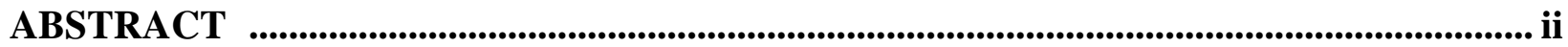

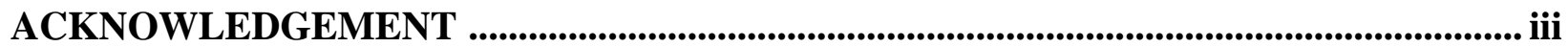

LIST OF TABLES ........................................................................................................................... vii

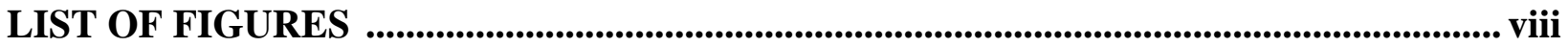

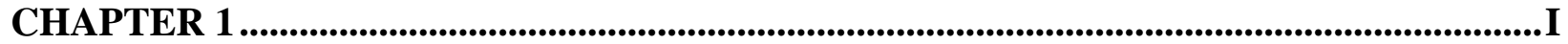

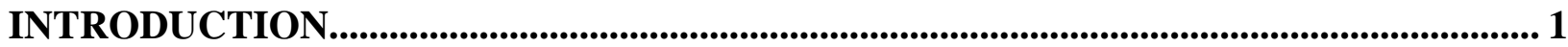

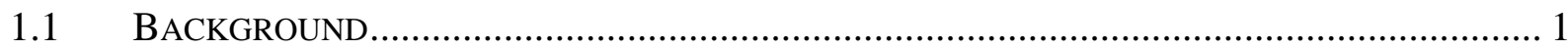

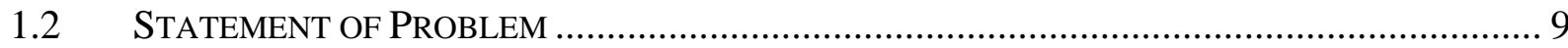

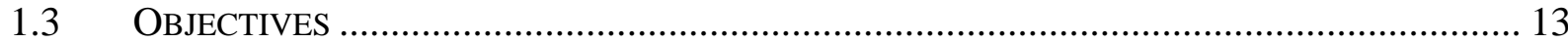

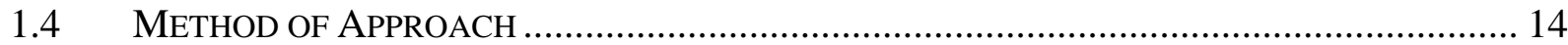

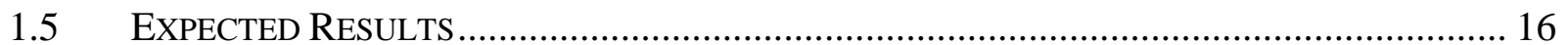

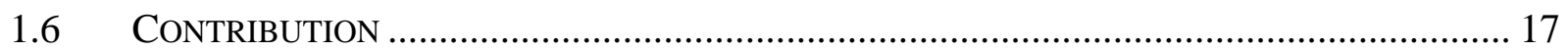

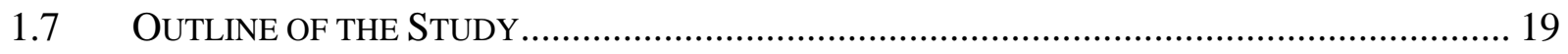

CHAPTER 2

THE INTERNATIONAL STEAM COAL TRADE ....................................................... 22

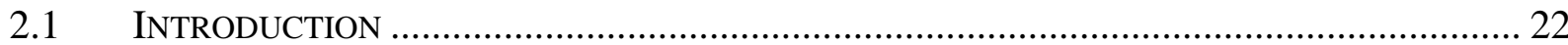

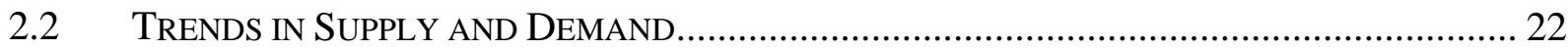

2.3 TRENDS IN RAIL TRANSPORTATION COSTS .............................................................. 33

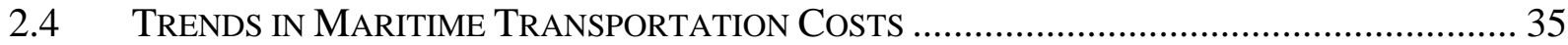

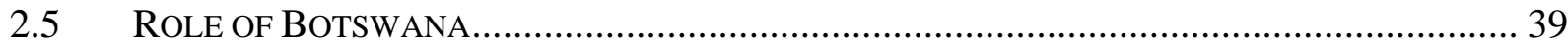

2.5.1 Taking Advantage of Botswana's Geographical Location ................................... 40

2.5.2 Framework for Regional Cooperation on Transport Infrastructure .................... 41

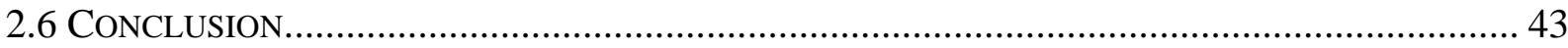

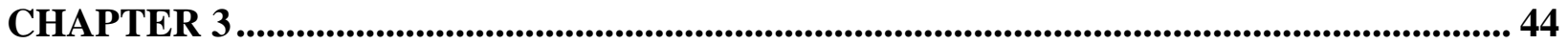

COAL TRADE MODELS IN RETROSPECT .............................................................. 44

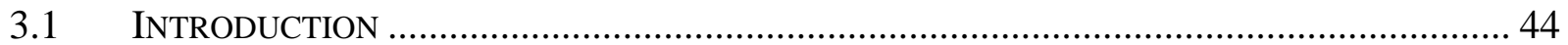

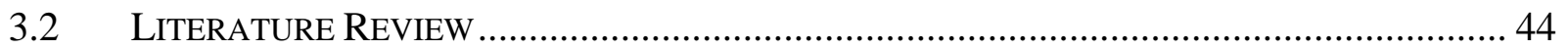

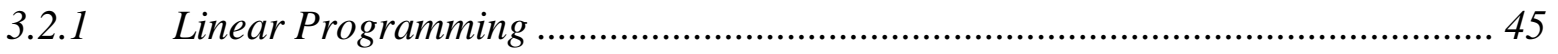

3.2.2 Nonlinear Programming ............................................................................... 46

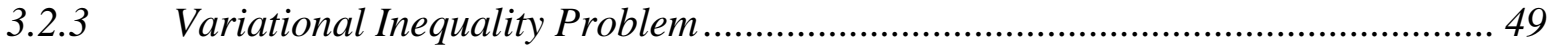

3.2.4 Mixed Integer Programming......................................................................... 54

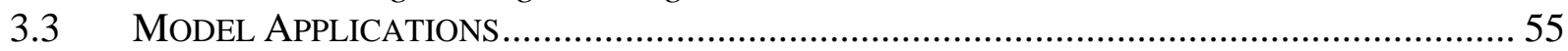

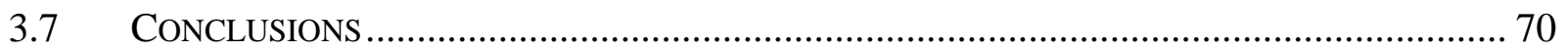

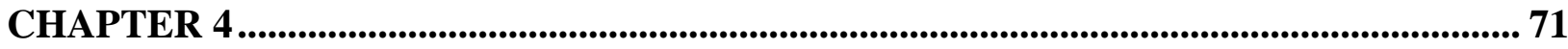

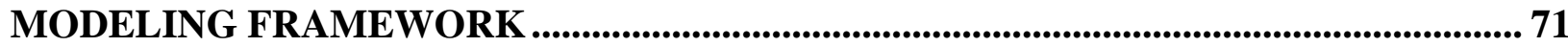

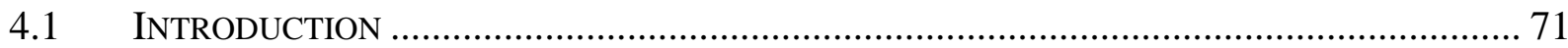

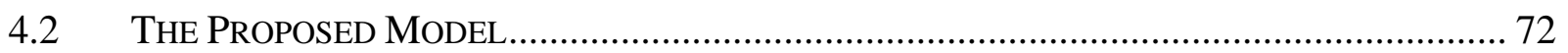


4.3 AsSumptions About the World SteAm Coal Trade......................................... 73

4.4 THE CHOICE OF COUNTRIES FOR THE MODEL ................................................... 74

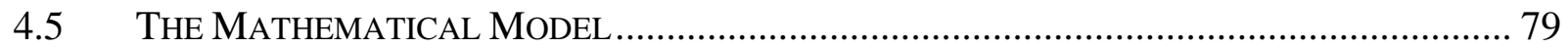

4.5.1 The Kuhn-Tucker Conditions ........................................................................ 83

4.5.2 Economic Interpretation of the Kuhn-Tucker Conditions ................................ 84

4.6 FORMULATION OF THE EMPIRICAL MODEL ............................................................. 85

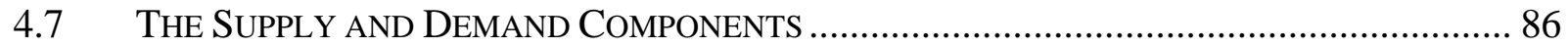

4.7.1 Specification of Country Supply and Demand Functions ................................ 86

4.7.2 Estimation of Country Supply and Demand Functions..................................... 87

4.7.3 Estimation of the Long Run Marginal Cost Functions ...................................... 91

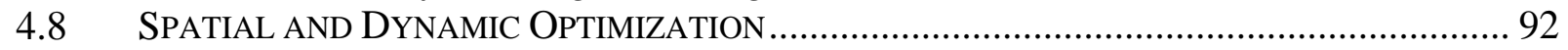

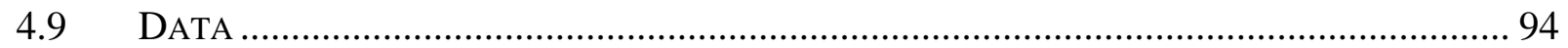

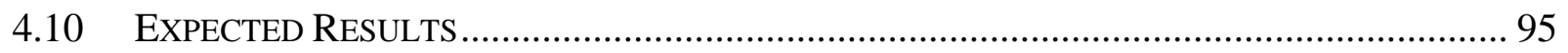

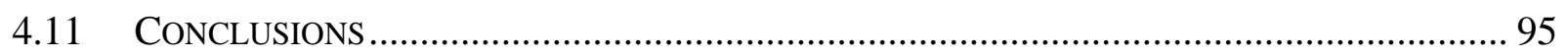

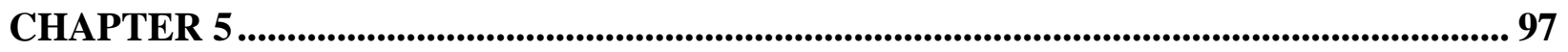

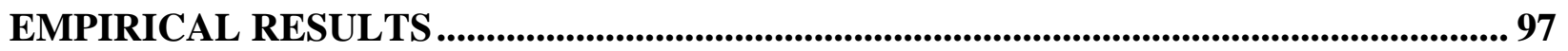

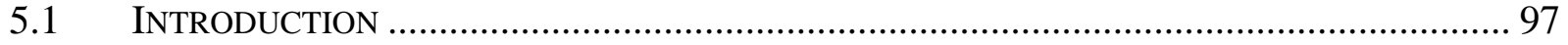

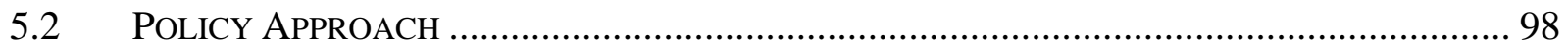

5.3 RESULTS OF THE ESTIMATION OF COUNTRY SUPPLY AND DEMAND FUNCTIONS ........... 99

5.4 VALIDATION OF THE RESUltS FOR COUNTRY SUPPLY AND DEMAND FUNCTIONS ....... 100

5.5 RESUltS AND VALIDATION OF THE LONG Run MARginal COST FunCTIONS............. 107

5.6 Simulation With the SPATIAL AND Dynamic Optimization ModEL ................... 110

5.6.1 Base Case Simulation ................................................................................... 112

5.6.2 Assumptions for the Base Case .................................................................... 112

5.6.3 The Two Simulated Routes for Botswana's Coal Exports ............................... 114

5.6.4 Results of the Base Case Simulation .............................................................. 114

5.6.5 Validation of the Results of the Base Case Simulation Scenario....................... 120

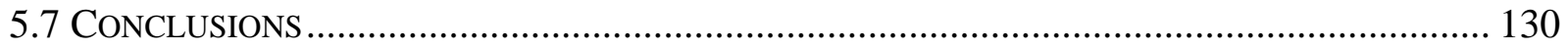

CHAPTER 6 ................................................................................................................. 131

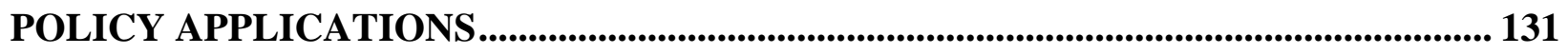

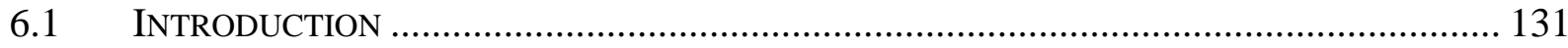

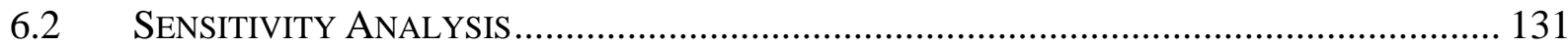

6.3 RESUlts OF THE SENSITIVITY ANALYSIS OF THE BASE CASE SCENARIO SiMULATION 132

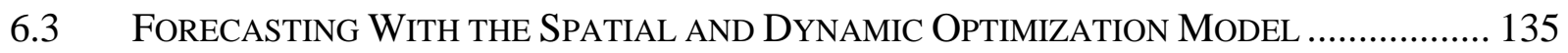

6.3.1 Results of the Base Case Forecast Scenario..................................................... 136

6.3.2 Sensitivity Analysis of the Base Case Forecast Results ................................... 139

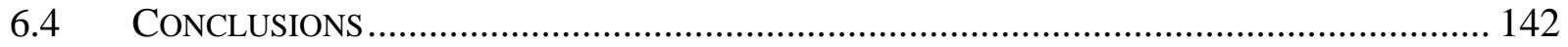

CHAPTER 7 ................................................................................................................... 143

CONCLUSIONS AND FUTURE RESEARCH........................................................ 143

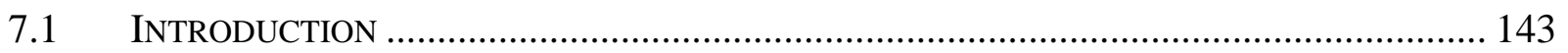

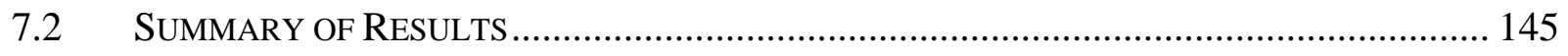

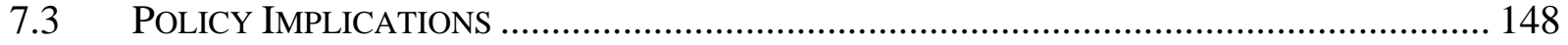

7.3.1 Public Provision of Infrastructure in Botswana ................................................ 149 
7.3.2 The Role of the SADC Protocol on Transport, Communications and Meteorology.. 150

7.3.3 Role of Mineral Policy Makers ........................................................................... 151

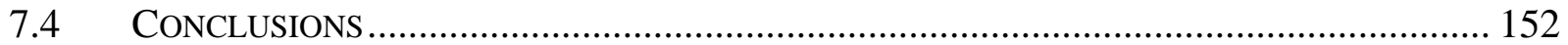

7.5 RECOMMENDATIONS FOR FUTURE RESEARCH .................................................. 153

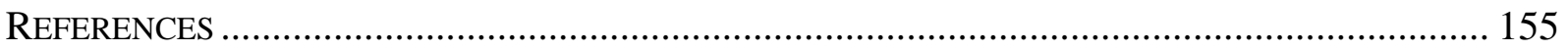

APPENDIX A. RESULTS OF THE ECONOMETRIC ESTIMATION OF THE COUNTRY SUPPLY AND

DEMAND FUNCTIONS FOR STEAM COAL (ALL VARIABLES IN LOG FIRST DIFFERENCES)......... 160 APPENDIX B. RESULTS OF THE ECONOMETRIC ESTIMATION OF THE LONG RUN MARGINAL COST FUNCTIONS FOR STEAM COAL (1980-1997) (ALL VARIABLES IN FIRST DIFFERENCES) ............ 164 ApPEndix C. Results For Time SERIEs Estimation of SEA Freight Costs Along Trade Routes for SEA Vessels of Size Greater Than 100000 DeAD Weight Tons (All VARIABLES IN LOG DIFFERENCES EXCEPT FOR USA WHICH IS IN LOGS) 165 APPENDIX D. SENSITIVITY RESULTS OF THE ECONOMETRIC ESTIMATION OF THE LONG RUN MARGINAL COST FUNCTIONS FOR STEAM COAL (1983 - 2000) (ALL VARIABLES IN FIRST DIFFERENCES) 165

APPENDIX E. BASE CASE ForECAST RESIDUAL MARKET SHARES FOR EXPORTERS . 166 APPEndix F. The Resultant Market Shares With Botswana's Capital Costs at 20\% ABOVE THEIR BASE CASE FORECAST LEVELS 167

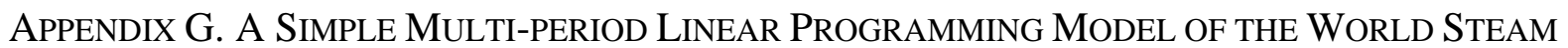
COAL TRADE 168

APPENDiX H. THE GAMS CODE AND OUTPUT FOR THE BASE CASE Simulation SCENARIO OF SPATIAL AND DyNAMiC OPTIMIZATION MODEL OF THE WORLD STEAM COAL TRADE 173 VITA 193 


\section{LIST OF TABLES}

Table 1.1 Hard Coal Resources of Africa (Million mtce) ................................................

Table 1.2 Gross Heat Content for Selected Countries (MJ/kg) .........................................

Table 1.3 Characteristics of Coals on Botswana's Major Coalfields ................................4

Table 4.1 Steam Coal Supply and Demand Patterns for Countries

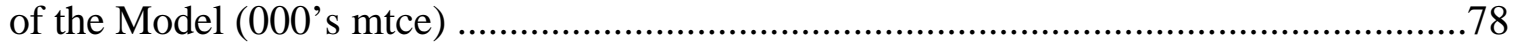

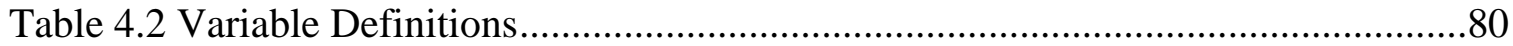

Table 4.3 Sources of Data for the Model .......................................................................94

Table 5.1 Actual and Forecast Steam Coal Demand and Supply in Net

Importing Countries of the Model (000's mtce) ...........................................................104

Table 5.2 Actual and Forecast Steam Coal Demand and Supply in Net Exporting

Countries of the Model (000's mtce) .105

Table 5.3 Comparative Forecasts of Steam Coal Exports With Other

Models (000's mtce)

Table 5.4 Comparative Forecasts of Steam Coal Imports With Other

Models (000's mtce) 106

Table 5.5 Transformed Long Run Marginal Cost Functions (1980 to 1997) ..................108

Table 5.6 Indicative Rail Transportation Costs (in year 2000 US \$ per mtce)................111

Table 5.7 Maritime Transportation Costs (in year 2000 US \$ per mtce) ........................111

Table 5.8 Simulated Gross Steam Coal Exports (000's mtce).......................................117

Table 5.9 Simulated Flow of Steam Coal From Mine to Export Seaport (000's mtce) ..117

Table 5.10 Simulated Flow of Steam Coal From Export to Import Port(000's mtce)....117

Table 5.11 Transformed Long Run Marginal Cost Functions (1983 to 2000) ................122

Table 5.12 Simulated Gross Steam Coal Exports Excluding Botswana (000's mtce) ....122

Table 5.13 Simulated Seaborne Steam Coal Flows Excluding Botswana(000's mtce) 123

Table 5.14 Factor Level Ratios to Base Case ............................................................126

Table 5.15 A $2{ }^{4}$ Simulation Experiment for Botswana's Annual Steam Coal

Exports (for the period 1995 to 2010 in Decimal \%) ....................................................126

Table 5.16 Analysis of Variance for the $2^{4}$ Simulation Experiment ..............................126

Table 6.1 Scenarios for Sensitivity Analysis of the Base Case Simulation Results .......134

Table 6.2 Sensitivity of Trade Flows to Changes in Botswana's Capital Costs .............134

Table 6.3 Forecast Results of the Base Case Showing Exporters' Market Shares ..........138

Table 6.4 Relative Competitiveness of F.O.B. Prices for Net Exporters

(year 2000 US \$ per mtce) ......................................................................................138

Table 6.5 Scenarios for Sensitivity Analysis of the Base Case Forecast Results ............138

Table 6.6 Distribution of the Residual Market Share in Asia Due to

Changes in Botswana's Capital Costs (\%)

Table 6.7 Distribution of the Residual Market Shares in Western Europe Due to

Changes in Botswana's Capital Costs (\%) 


\section{LIST OF FIGURES}

Figure 1.1 The Coal Deposits of Interest and Their Approximate Location Relative to the Railway Network of Southern Africa ......................................................5

Figure 2.1 Selected Country Percentage Share in the International Seaborne

Steam Coal Trade

Figure 2.2 Selected Country Percentage Share in the International Seaborne

Steam Coal Trade 25

Figure 2.3 Trends in the Combined Percentage Share of Selected Steam Coal Exporting

Countries in the Model Against the Growth Index in the Seaborne Steam Coal Trade ...26

Figure 2.4 Trends in the Seaborne Steam Coal Demand for the Major Markets

in the Model .29

Figure 2.5 Trends in the Percent Shares by the Major Markets for the Seaborne Steam Coal Trade

Figure 2.6 Trends in the Japanese Price Ratios of Other Fossil Fuels to Coal ..................31

Figure 2.7 Trends in the UK Price Ratios of Other Fossil Fuels to Coal .........................32

Figure 2.8 Trends in Rail Transportation Costs for Exporters in the Model .....................34

Figure 2.9 Trends in Marginal Supply Costs for Exporters in the Model .........................36

Figure 2.10 Trends in Sea Freight Costs for Selected Exporters to Markets in Asia ........37

Figure 2.11 Trends in Sea Freight Costs for Selected Exporters to Markets in

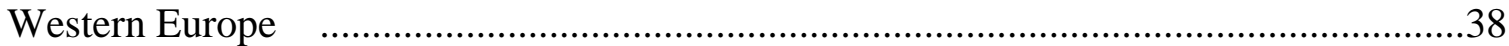

Figure 4.1 The Seaborne Steam Coal Trade Among Countries of Supply and Demand...77

Figure 5.1 Transformed Long Run Marginal Cost Functions for Exporters .................108

Figure 5.2 Simulated Railway Lines (bold dashed pattern) to Seaports and the Existing

Railway Network of Southern Africa ...................................................................116

Figure 5.3 Simulation Results for the Base Case Scenario for the Exporters' Residual

Market Shares in Asia

Figure 5.4 Simulation Results for the Base Case Scenario for the Exporters' Residual

Market Shares in Western Europe

Figure 5.5 Simulation Results for the Base Case Scenario for the Exporters' Market

Shares in the World Seaborne Steam Coal Trade

Figure 5.6(a) Main Effects of Capital Costs on Botswana's Simulated Steam

Coal Exports

Figure 5.6(b) Capital and Rail Costs Interaction Effects on Botswana's Simulated

Steam Coal Exports

Figure 5.6(c) The Response Surface for Botswana's Simulated Steam Coal Exports ....129 


\section{CHAPTER 1}

\section{INTRODUCTION}

\subsection{Background}

Botswana has vast deposits of coal; it has wanted for a long time to exploit them but without much success. For a long time the country was considered a potential exporter of coal due to its abundant reserves, some of which are strippable (WOCOL 1980, Abbey and Kolstad 1983 and Raschke 1986). In a 1984 report by the US Bureau of Mines, it was estimated that Botswana would by the end of the decade be in a position to export 5 million to 10 million metric tons of steam coal to Western Europe. Factors that may have weighed heavily against the success of efforts to exploit these coal deposits take a variety of forms, such as: the lack of a domestic market for coal, the great distance from sea ports (at the time the only option was railway line to the port of Walvis Bay in Namibia, a distance of about for a $1600 \mathrm{~km}$ ), political instability in the region which for a long time limited the available options for regional spatial developments in the goods transport sector, and also existing barriers to entry into the coal export business due to the concentrated nature of this industry in South Africa, where the coal export facilities were and still are privately owned by coal exporters. Other factors that may explain the lack of exploitation of Botswana's coal may have a lot to do with the characteristics of the world steam coal trade, such as, the conduct of this trade through long-term contracts and also the concerns by importers over security of supply issues.

The development of coal in Botswana has, therefore, been very meager and directly linked to the domestic demand for electricity. The country's only colliery is located on the Morupule coalfield, which has proven reserves of some 8.0 billion metric tons coalfield (see Table 1.3). It has a capacity of some one million metric tons per year, with most of this coal used 
for power generation by the Botswana Power Corporation's mine-mouth power plant with a rated capacity of $132 \mathrm{MW}$.

In a 1980 report of the World Coal Study (WOCOL), Botswana is shown to hold close to two-thirds of the coal resources in the African continent at some 100 billion metric tons of coal equivalent, ahead of South Africa at 57.6 billion (see Table 1.1). The quality of these resources is good and compares very favorably with steam coal from other coal producing countries, which have a developed steam coal export industry (see Tables 1.2 and 1.3). In spite of this endowment, it is South Africa that has both a thriving domestic and export coal industry from mines located on the Witbank region of one of its provinces, Mpumalanga. There is also a mine located near the town of Ellisras in the Northern Province, a distance of not much more than a hundred kilometers from the Botswana border, the Grootgeluk colliery, that produces coal for both the domestic and export markets. This colliery is close to the Mmamabula coal deposits, which occur on a coalfield that straddles the Botswana and South Africa border and is known as the Waterberg on the South African side (see Figure 1.1). This coalfield is estimated to hold over one third of South Africa's coal reserves. The quality of this coal makes it suitable for other uses such as in the production of synthetic fuels (para 2, "Future developments", n.d.). 
Table 1.1 Hard Coal Resources of Africa ( Million mtce)

\begin{tabular}{lc}
\hline Country & Coal Resources \\
\hline Botswana, Republic of & 100,000 \\
\hline Morocco & 200 \\
\hline Mozambique & 400 \\
\hline South Africa, Republic of & 57,566 \\
\hline Swaziland & 5,000 \\
\hline Democratic Rep. of Congo (DRC) & 808 \\
\hline Zambia & 228 \\
\hline Zimbabwe & 7,130 \\
\hline Others & 1,560 \\
\hline Total & 172,892 \\
\hline
\end{tabular}

Source: Greene, R.P. and Gallagher, J.M. (Ed), Future Coal Prospects: Country and Regional Assessments, Report of the World Coal Study (WOCOL), 1980, Nimrod Press, Boston, p561.

Table 1.2 Gross Heat Content for Selected Steam Countries (MJ/kg)

\begin{tabular}{lll}
\hline Country & Gross Heat Content & Sulfur Content (\%) \\
\hline Botswana & $24.20-27.73$ & $0.8-1.16$ \\
\hline South Africa & $16.8-31.9$ & $0.23-1.84$ \\
\hline Indonesia & $26.2-33.5$ & $0.3-1.0$ \\
\hline Australia & $23.0-33.0$ & $0.3-0.8$ \\
\hline Poland & $23.88-24.02$ & $1.0-2.0$ \\
\hline U.S.A. & $27.54-34.92$ & $0.41-4.29$ \\
\hline
\end{tabular}

Source: International Coal, 1999-2000, National Coal Association, Washington, D.C., p I-3. 
Table 1.3 Characteristics of Coals on Botswana's Major Coalfields

\begin{tabular}{|c|c|c|c|c|c|c|}
\hline Coalfield & $\begin{array}{l}\text { Reserves } \\
(000 \text { s m. tons })\end{array}$ & $\begin{array}{l}\text { Thickness } \\
\text { (Meters) }\end{array}$ & $\begin{array}{l}\text { Depth } \\
\text { (Meters) }\end{array}$ & $\begin{array}{l}\% \\
\text { Yield }^{\mathrm{a}}\end{array}$ & $\begin{array}{l}\text { GCV } \\
\text { (MJ / kg) }\end{array}$ & $\begin{array}{l}\% \text { Sulfur } \\
\text { (Washed) }\end{array}$ \\
\hline Morupule & 7910000 & $6.5-9.5$ & $40-300$ & 46.9 & 27.9 & 0.66 \\
\hline $\begin{array}{l}\text { Mmamabula } \\
\text { Central Block }\end{array}$ & 442943 & & & & & \\
\hline $\begin{array}{l}\text { : Upper } \\
\text { : Middle } \\
\text { : Lower } \\
\end{array}$ & $\begin{array}{r}70923 \\
212769 \\
159251 \\
\end{array}$ & $\begin{array}{l}2.07 \\
5.39 \\
2.83 \\
\end{array}$ & $\begin{array}{l}2.5-32.5 \\
12.5-42.5 \\
30.0-60.0\end{array}$ & $\begin{array}{l}30 \\
46 \\
80 \\
\end{array}$ & $\begin{array}{l}28.24 \\
27.76 \\
27.35 \\
\end{array}$ & $\begin{array}{l}0.42 \\
0.41 \\
0.44 \\
\end{array}$ \\
\hline $\begin{array}{l}\text { Mmamabula } \\
\text { South Block }\end{array}$ & 2440000 & $2.07-5.39$ & $82.5-160$ & n.a. & n.a. & n.a. \\
\hline $\begin{array}{l}\text { Rest of } \\
\text { Mmamabula }\end{array}$ & 2292057 & $\begin{array}{l}\text { Similar to } \\
\text { Central } \\
\text { Block }\end{array}$ & $\begin{array}{l}\text { Similar to } \\
\text { South Block }\end{array}$ & n.a. & n.a. & n.a. \\
\hline $\begin{array}{l}\text { Letlhakeng } \\
\text { : E2b } \\
\text { : G1 }\end{array}$ & $\begin{array}{l}3530000 \\
325800 \\
679274\end{array}$ & $\begin{array}{l}1.45-3.16 \\
2.9-7.4\end{array}$ & $\begin{array}{l}60-200 \\
80-220\end{array}$ & $\begin{array}{l}74.0 \\
52.3\end{array}$ & $\begin{array}{l}28.66 \\
28.25\end{array}$ & $\begin{array}{l}0.41 \\
0.36\end{array}$ \\
\hline Rest of Letlhaken & 2524926 & n.a. & n.a. & n.a. & n.a. & n.a. \\
\hline Dutlwe & 2000000 & $1.5-4.0$ & $<300$ & 50.0 & 26.88 & 0.60 \\
\hline S.W. Moijabana & 1300000 & $\begin{array}{l}\text { same as } \\
\text { Morupule }\end{array}$ & $\begin{array}{l}\text { same as } \\
\text { Morupule }\end{array}$ & n.a. & n.a. & n.a. \\
\hline
\end{tabular}

\begin{tabular}{ll}
\hline Total & 19915000
\end{tabular}

Source: Clark, G.C., Lock, N. P. and Smith, R. S., The Coal Resources of Botswana, n.d., Department of Geological Survey, Lobatse, Botswana.

Note: ${ }^{\text {(a) }}$ - The yield $\%$ is from coal washability tests at an S.G. of 1.5 


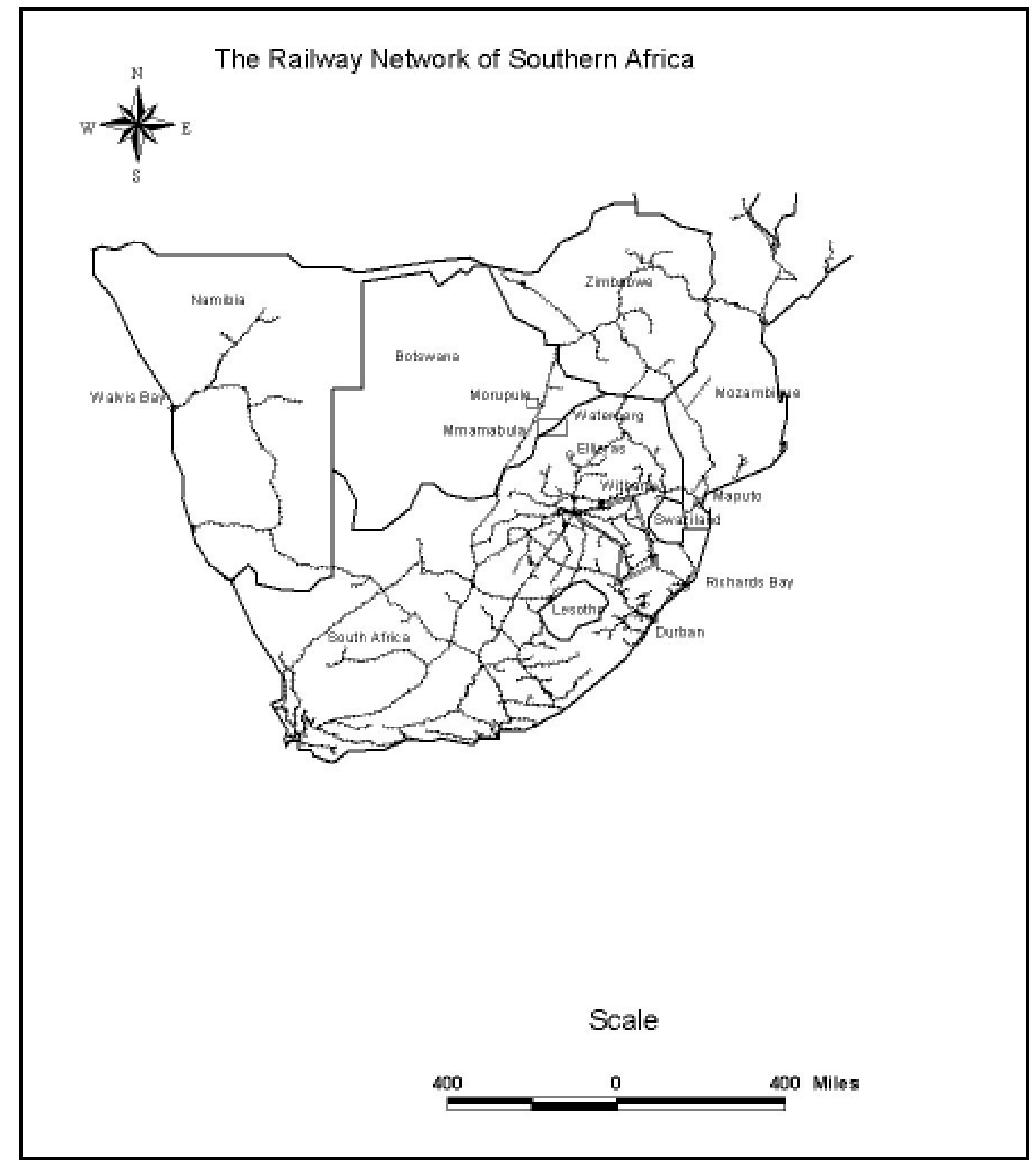

Figure 1.1 The Coal Deposits of Interest and Their Approximate Location Relative to the Railway Network of Southern Africa

Source: Compiled by author from GIS database files retrieved on April 19 ${ }^{\text {th }}, 2002$ from: http://www.maproom.psu.edu/dcw/

Note: Coal deposits location is not geo-referenced and is therefore only illustrative. 
In the year 2001, South Africa was ranked fifth in world bituminous coal production after Australia, India, the United States and China but was the second largest coal exporter after Australia ${ }^{1}$. During the same year, South Africa produced 224.2 million metric tons of coal, out of which a total of 218.68 million metric tons was saleable coal valued at R25.814 billion (about US $\$ 2.87$ billion at an average exchange of about R9.00 to US $\$ 1.00$ for 2001). Export coal, at 66.7 million metric tons, was just under one third of total sales tons but contributed R16.27 billion (about US $\$ 1.81$ billion) to total sales, representing about $63 \%$ of total revenue, thus highlighting the role of exports to the South African coal industry ${ }^{2}$. Most of South Africa's steam coal exports are destined for markets in Western Europe. The continued growth in steam coal exports reflects the country's cost competitiveness as a supplier of steam coal to international markets. There have been recent reports that the South African government, out of concern for its diminishing coal reserves, has embarked on a study to take inventory of its reserves. This concern was highlighted by a recent report by the government that the country's coal reserves were sufficient for another forty years at current extraction rates. It is therefore likely that the export coal capacity will peak at some 85 million metric tons, which is the estimated export handling capacity of the Richards Bay coal terminal after the current phase of expansion ${ }^{3}$. This would present an opportunity for Botswana to build up capacity so that it could, in addition to

\footnotetext{
${ }^{1}$ Table 5.3 World Coal Production, $1992-2001$ (Million short tons). Retrieved March $10^{\text {th }}$, 2003, from the Energy Information Administration world wide web: http://www.eia.doe.gov/pub/international/ieapdf/t05_03.pdf

${ }^{2}$ South African Mining Industry Statistical Tables, 2001. Retrieved on February $28^{\text {th }}, 2002$, from the Chamber of Mines of South Africa world wide web: http://www.bullion.org.za/bulza/publications/Stats2001/StatsTables.pdf

${ }^{3}$ Bain, J., "About $20 \%$ of the Coal Will be Left Unmined", Business Day, February $20^{\text {th }}$, 2002. Retrieved on March $23^{\text {rd }}, 2002$ from: http://www.bday.co.za/bday/content/direct/1,3523,1027499-6078-0.00.html. This article reports that South Africa's proven coal reserves stand at 34.4 billion metric tons and that expansion of the RBCT will lead to some 82 million tons of rated capacity in 2004 but with a safety to reach 85 million metric tons without major capital investment. The port of Matola is expected to increase its capacity from 1 million to 6.5 million by 2005 .
} 
any market share that it would gain away from the present suppliers, take up any future supply shortfall from Southern Africa as a result of this binding constraint on South Africa's exports.

The existence of large deposits of coal in Botswana and their lack of exploitation has always been a worrisome issue for policy makers. This concern led to government sponsored pre-feasibility type investigations into options for exploiting these coal deposits. From a project completed in 1983 and designed to investigate the feasibility of an export coal mine to produce steam coal for sale in the international market, it was concluded that the single most important factor contributing to the project's unfavorable economics was the cost of rail transportation from the Kgaswe coalfield to Walvis Bay in Namibia, a distance of about 1600 kilometers. A feasibility study was conducted in 1992 for a coal-fired power station to generate electricity from Mmamabula coal for sale to South Africa. This project too was found to be uneconomic at the time, as it would have produced electricity at a price that was then higher than the rates in South Africa.

The Southern Africa region has seen substantial progress in the areas of political stability and regional cooperation on spatial development initiatives covering infrastructure projects that embrace a regional as opposed to only national government objectives in the wake of a democratically elected government in South Africa in 1994. These developments justify renewed interest by policy makers in Botswana to explore the options that can be pursued to facilitate the exploitation of the country's coal deposits. There has also been growth in cooperation among Southern African countries in the selling and buying of electricity, which has been facilitated by the formalization of the Southern Africa Power Pool (SAPP) in 1995. This has resulted in interconnections between national grids in the region. The significance of the SAPP is that it is only the third of its kind in the world after those in Europe and the United States. This has reduced the 
risk of loss of load, lowered capacity and reserve requirements by national utilities, reduced fuel costs, and raised the efficiency of utilization of the regions hydropower (O'Leary, Charpentier and Minogue, June 1998). The region's projected investment in power generation to meet demand for electricity over a period till 2025 shows that even under modest load projections, the scale of investment in new capacity would be very substantial (Dingley, 2000).

Following on the wave of deregulations of the electricity industry, a maneuver devised first in the United Kingdom and then adopted in other European countries and recently in the United States, South Africa has also joined the growing list of countries with a deregulated electricity generating market (see Green and Newbury, 1992). This projected growth in electricity demand is likely to be met from coal fired power plants, whose location within the region may also depend on the ability of national governments to provide financing as project partners, thus placing Botswana, which is a capital surplus country, in a very favorable position to develop its coal reserves for power generation to meet the projected regional demand in electricity.

There has long been curiosity on the relationship between electricity consumption and economic growth arising out of the dual role of electricity as both an infrastructure good as well as input that raises firm productivities and living standards. Murry and Nan (1994) conducted causality tests on a cross-section of countries and concluded that for those countries with fast expanding electrification programs, there is a two-way causality between electrification and economic growth. Burney (1995) conducts a similar study but using the random coefficient method and concludes that socio-economic factors such as literacy, urbanization, industrialization are key determinants of the demand for electricity and therefore need to be included in any estimation of electricity consumption. The region is therefore projected to 
expand its residential electricity demand resulting from projects such as those of the accelerated housing delivery in South Africa, where some two million households were added to the grid in the first half of the 1990's and a further four million are estimated to be added in the next decade or so. In Botswana, the rural electrification project has improved access in rural areas. Some 72 villages have been connected to the national grid and it is foreseen that in the period from 2002 onwards, 14 villages would be connected every year (Budget Speech, 2002). All of these projects are likely to increase the regional consumption of coal, thus raising the need for capacity expansion or new mine development for the regional market. A clear policy to take advantage of economies of scale in mine production could result in the entry of Botswana into the world steam coal trade.

The foregoing possibilities only confirm the soundness of past studies that identify the potential for the exploitation of Botswana's coal deposits as: 1) to develop these for the international steam coal markets, and 2) to invest in power plants to meet projected demand growth in both the domestic and regional electricity markets. In this study only the international competitiveness of Botswana coal, paying much emphasis to the likely time phasing of production capacity and the land routes to seaports will be modeled.

\subsection{Statement of Problem}

The Botswana government has sponsored two major studies, one in 1983 for an export coal mine and the other in 1992 for an export power station. In the intervening period and also since 1992, there have been smaller investigations aimed at determining the local demand potential for coal. Pre-feasibility type studies are costly and the usefulness of their results is not long lived. This means that the policy maker in Botswana has to make ad-hoc decisions to study 
whether conditions have sufficiently improved to justify the detailed feasibility type studies on ways to exploit the country's coal deposits. For instance, in 2002, the government once again indicated its intention to re-investigate the potential for exploiting the country's coal deposits.

One way to avoid this ad-hoc decision making would be to develop a simple and user friendly spatial and dynamic optimization model of the world steam coal trade upon which policy makers would rely to gain some insight about whether economic factors favored the development of Botswana's coal deposits for the export markets. This would provide a means to determine the likely competitiveness of a possible export coal mine to exploit Botswana's coal. Such a model would also provide information on the likely role of government policy regarding provision of support infrastructure for an export coal mine development. For these reasons there is justification for developing a steam coal model that policy makers can rely on for decision making on energy development and infrastructure issues related to coal.

The improved regional stability and increased cooperation in spatial development projects presents an opportunity for policy makers in Botswana to investigate options for alternative export ports to facilitate the development of the country's coal deposits. There is need to objectively determine the factors that impede the development of an export coal industry instead of attributing this failure to distance from seaports. A 1993 study by the US Bureau of Mines comparing the costs of selected coal mines in Australia, Canada, Colombia, South Africa and the United States found that South African coal mines had the second lowest delivered steam coal costs for markets in Europe and the U.S. Gulf Coast region after Columbia ${ }^{4}$. Mines from

\footnotetext{
4 _ A Cost Comparison of Selected Coal Mines from Australia, Canada, Colombia, South Africa, and the United States", United States Department of the Interior, U.S. Bureau of Mines, August 1993.

Case VI: European Electric Utility Delivered Costs are: Columbia $-\$ 28.85, \mathrm{RSA}-\$ 32.36-42.20$,

Australia - \$32.64 -54.33 and USA - \$44.91-51.21

Case VII: Japanese Electric Utility Delivered Costs are:

RSA- \$28.01-37.85, Australia - \$28.92-35.20 and USA - \$46.04-67.52
} 
Australia and the United States were ranked in third and fourth positions respectively. In the Japanese steam coal market, South Africa had the lowest delivered costs followed by Australia and then the United States. In a 1996 study by Ames Minerals Research as cited in Coal Age (1996), South Africa and Indonesia were found to have the lowest f.o.b. cash costs at US $\$ 22.80$ per metric ton of steam coal exported. The study further observed that the growing cost disadvantage that Australia suffered would most likely rule out any new mine development in the steam or semi-coking coal category for the next 5 to 10 years. The cost advantage enjoyed by South Africa is further helped by its depreciating currency against the U.S. Dollar.

This advantage in costs is likely to apply to all mines within the Southern African region as it derives mainly from the low costs of mining. The country's low wage rates and the geology of the coal deposits contribute to these low per unit costs of coal supply and since the region as a whole also has low wage rates and, to some extent, similar geology (Clark, Lock and Smith, n.d.) this cost advantage can be extended to all existing and potential coal suppliers from Botswana's coalfields. In other words, an assumption of a single regional supply function would be justified. Even with this assumption, there is flexibility to have differing levels of profitability for the individual mines as the regional export price may be in excess of that required by the mine with the highest marginal costs. In the demand regions, the price paid to suppliers is not necessarily that which equals the marginal costs of the highest producer. Suppliers are willing to accept any price that exceeds their own marginal costs but less than that paid to the supplier with the highest marginal cost. This practice leads to infra-marginal pricing based on marginal supply costs (Kolstad, Bivins and Abbey, 1983 and Elliot-Jones, 1986).

Case IX: U.S. Gulf Coast Electric Utility Delivered Costs are: Columbia -\$29.70, RSA - \$33.41-40.40, Australia \$55.73-58.28 and USA - \$35.04-61.30

All costs figures are in January 1989 \$ /short ton saleable coal. 
On the issue of distance, and hence, rail transportation costs to export ports, Iscor's Grootgeluk mine located near Ellisras in the Northern Province is only about a hundred kilometers from one of the major coalfields, Mmamabula on the Botswana side of the border and Waterberg, on the South African side, and, therefore, is at a distance from the seaport of Richards Bay that is comparable to a would be a mine located on the Mmamabula coalfield. This distance would be much reduced if a railway line were built along the same route indicated under a spatial development initiative project for the Northern Province to link it to the coal handling port of Matola, Mozambique. It is doubtful whether the short distance separating Grootgeluk and Mmamabula would lead to rail transportation costs that would be so large as to erode the cost advantage that South African coal, and therefore coal from the region, would enjoy on international steam coal markets.

The existence of barriers to entry into the South African coal export industry manifests itself in the close control that the coal exporting companies have over the privately owned coal handling and export facilities at the Richard's Bay Coal Terminal (RBCT). The coal companies controlling the RBCT allocate themselves export quotas that are proportional to their shareholding in the export facility. Botswana has built a very good reputation in its dealings with foreign investors and it is a successful mining country. The country should be able to take advantage of its existing joint venture partnerships with South African transnational corporations to lessen the barriers to entry into the international steam coal trade.

The role of distance in rail transportation costs needs to be viewed in comparison with hauling distances in other world regions such as western Canada and the Illinois Basin of the United States, which have similar, if not longer, distances to seaports. It is most likely that the rail tariff structures in the Southern Africa region, which can vary substantially across borders, 
acts as a serious deterrent to the regional freight business and it is this selfish rent-seeking behavior that in the past, could also have affected the profitability of a would be export coal mine from Botswana. This situation is expected to change under the provisions of the 1996 Southern African Development Community's (SADC) protocol on Transport, Communications and Meteorology.

\subsection{Objectives}

This study has two main objectives: 1) to analyze the time schedule of coal exports likely to be forthcoming from Botswana and the land routes for these exports from among the existing and simulated railway lines to seaports at Matola (Mozambique), Richards Bay coal terminal (Republic of South Africa) and Walvis Bay (Namibia), and 2) to provide input towards the development of an appropriate policy on the development of coal export infrastructure that would encourage investment in projects to exploit the country's coal reserves. To accomplish these objectives, it is necessary to conduct the following research:

(i) to construct a spatial and dynamic optimization model of the world steam coal trade that is capable of analyzing a number of issues;

(ii) to determine the time phasing and capacity of production that is likely from Botswana coalfields;

(iii) to identify possible land routes for exporting Botswana coal, and

(iv) to forecast the spatial and temporal distribution of the international steam coal trade, to simulate the share of Botswana coals in this trade, and to make policy recommendations regarding the provision of railway infrastructure to encourage Botswana's coal exports. 


\subsection{Method of Approach}

The majority of spatial price equilibrium models for trade in fuel and energy minerals are static and differ only in their treatment of supply and demand. For instance, the U.S. coal model by Zimmerman (1981), the world steam coal trade model by Dutton (1982) and the US Department of Energy's international coal trade model (ICTM) of 1982, all use marginal supply functions that are derived from engineering cost data, where data availability permits, and inelastic estimates where there is paucity of such data. The demand used in these models is estimated exogenously. In the early non-linear coal trade models such as the Argonne Coal Model by Macal (1979), the supply function used differs from the cumulative cost function approach by Zimmerman and Dutton and, instead, is derived through a simple econometric model that regresses unit production costs on production. The demand is still exogenously estimated. In the regional models, the demand for coal is estimated from two step models of energy demand in which the first step is to estimate the total regional energy for residential and commercial users on the one hand and industrial users on the other and secondly, to employ a conditional logit model for the choice of fuels to meet the estimated energy demands (Baughman, Joskow and Kamat, 1979). In the non-linear regional trade models with both elastic supply and demand functions included in the model, the estimation of the supply and demand equations invokes the regional market equilibrium conditions that supply should equal to demand (see Labys and Yang, 1980).

The objective function for the spatial and dynamic optimization model for this study consists of four terms: capital expenditure costs, rail transportation costs, maritime transportation costs and variable supply costs. The constraints conditions consist of both domestic demands in the net exporting countries and import demands in the net importing countries. For a study of this 
type, two possible approaches to modeling the import demands exist. The first involves the estimation of steady state regional export supply and import demand functions (Lord, 1991). The two step procedure in estimating the import demand functions is as follows: first, the total import demand for a commodity is determined from the usual utility maximization between imports and a composite or numeraire good subject to a nominal level of income in the importing region. The first order conditions provide conditional demand functions for the import good and the composite good. The second step is another utility maximization to select from among the available exporters subject to an import budget constraint to satisfy the demand for imports estimated from the first step. The resulting conditional import and export demand functions are expressed as functions of real income, relative prices between the pair of countries exporting and importing and market share. The choice of functional form is the log-linear as it readily provides price elasticities for both export demand and import demand. These models use only relative prices, market share and income levels to explain trade and prove to be too restrictive, as they do not allow for the possibility of substitution (Lord 1991). This approach was not adopted for this study as its non-linear functions do not readily lend themselves to the quadratic programming that is widely applied in spatial price equilibrium models.

The second approach begins with the econometric estimation of country supply and demand functions. Some authors have invoked assumptions of inelastic supply with the result that only the demand functions are econometrically estimated using ordinary least squares (OLS) estimation. Examples include Hashimoto's (1979) world iron and steel economy (wise) model and Toweh and Newcomb's (1991) spatial equilibrium analysis of the world iron ore trade. In this study, we estimate the supply and demand functions for countries in the model using the appropriate methods after the data has been tested to avoid the main pitfalls such as simultaneity, 
non-stationarity and co-integration. The estimation of supply and demand functions for the countries in the model follows the approaches by Meyers, Devados and Helmar (1989) and Labson (1997), where in the latter it was applied in modeling the world steel and iron ore trade.

The spatial and dynamic optimization model developed in this study will determine the time phasing and size of production capacity for Botswana's coal. This is the model upon which forecasts and policy simulations will be based. The application in this work will add a spatial, temporal and time phasing component to the approaches used by Labson (1997) and Meyers, Devados and Helmar (1989).

A simple multi-period linear programming model of the world seaborne steam coal trade will precede this optimization model. The purpose of this linear programming model would be to determine whether rail and sea freight costs impede the development of Botswana's steam coal deposits for the export market. The interpretation of the marginal values, which are the shadow prices associated with the supply of coal or transportation costs along both existing and simulated routes, obtained from this model will provide some very useful insights about whether or not Botswana's coal would not have been competitive in the world markets in the past and their likely competitiveness in the future. This model is described together with its results in Appendix G.

\subsection{Expected Results}

The spatial and dynamic optimization model, which is formulated as a quadratic, temporal and spatial allocation model, is expected to provide useful information on the likely timing and size of coal development on Botswana coalfields. The expected results are for inclusion of coal from these fields in the world steam coal trade but in the event that the results 
show no immediate cost advantage for these coals, it is expected that within the forecast horizon, coals from Botswana would become competitive. The marginal values from this optimization would provide useful insights on the appropriate policy and level of intervention that would be necessary to encourage the development of Botswana coal for the export market. As the model is dynamic, it will find use in conducting sensitivity analyses. For instance, in the event that the base case forecast fails to include Botswana coal, then a sensitivity analysis of the forecast demand growth would indicate the likely timing of development of these coals. The advantage of this model is that it attempts to replace the adhoc policy decisions on when to revisit the issue of exploiting these huge coal deposits with a systematic approach that informs the policy maker about whether economic conditions existing at any point in time are sufficiently favorable to justify detailed investigations of projects for developing Botswana's coal deposits.

\subsection{Contribution}

The international steam coal trade only began advancing in the late 1970's; and when the first coal trade models emerged in the early 1980's, there was a general paucity of time series data, which precluded the estimation of the temporal characteristics of this trade. This paucity of data led to the reliance on engineering cost methods to estimate marginal supply functions and trade theory methods to estimate steady-state export and import demand functions for use in these static spatial price equilibrium models. In some models, there is reliance on expert opinion as to the levels of supply and demand to use in the forecasts, thus exposing these models to subjective judgments. The trade theoretic approaches to the estimation of import demands tend to ignore the substitution effects between fossil fuels in their use for power generation. 
Our contribution in this work is that we take advantage of the appearance of data on the international steam coal trade to estimate country supply and demand functions econometrically for countries within the model. This approach leads to the computation of the import demand quantities in these countries as the residual of domestic supply and demand. We apply microeconomic theory in the specification of the derived demand for steam coal for electricity generation and, therefore, take into account substitution effects among the fossil fuels for electricity generation. While existing regional studies that have employed econometrically estimated supply functions (Yang, Hwang and Sohng, 2002, Yang and Labys, 1991 and 1980), these have tended to concentrate on the short run marginal supply functions as opposed to those for the long run. In this study, we estimate the long run marginal cost functions for the net exporting countries within the model and these are then used in the spatial and dynamic optimization model both to simulate and to forecast the temporal and spatial distribution of the seaborne steam coal trade. This approach relies on publicly available data, which should make the model easy to maintain. The model also has the advantages of quadratic programming such as endogenously determining the temporal supply quantities, capacity additions, trade flows, and supply prices.

This study represents an application of the Spatial Temporal and Price Allocation (STPA) methodology that focuses on development aspects of Botswana's steam coal deposits. This provides an alternative approach for analyzing the competitiveness of Botswana's steam coal in the international markets as opposed to project evaluation approaches. The advantage of this method over the project evaluation approaches is that, where there are increasing returns to scale such as in mining operations, this approach selects the scale of operations that minimizes supply costs since the scale of operations also impacts on project profitability. 
Lastly, the modeling approach has the following advantages over the feasibility study approach: 1) it provides the Botswana government with an alternative to ad-hoc decisions relying on feasibility studies to determine the country's competitiveness as a steam coal exporter, 2) it presents an opportunity for the Botswana government to explore policy approaches to provide for railway infrastructure to seaports and 3) it provides a basis upon which the Botswana government could present a case for a regional approach towards the development of rail and port infrastructure under the Southern African Development Community's (SADC) protocol on Transport, Communications and Meteorology.

\subsection{Outline of the Study}

This study is divided into six chapters with the first primarily made up of the introduction. Chapter 2 provides a review of the international steam coal trade with special emphasis on 1) trends in supply and demand, 2) transportation, which is discussed separately for rail and maritime transportation costs and 3) the role of Botswana.

In chapter 3, a review of the literature on spatial price equilibrium models in the modeling of the mineral and energy trade includes: linear programming, non-linear programming the variational inequality problem and mixed integer programming. The chapter also reviews applications of these models in both international and regional trade in steam coal.

Chapter 4 presents the modeling framework, which involves both econometric and optimization techniques. The main subsections are: 1) the proposed model, 2) assumptions about the world steam coal trade, 3) the choice of countries for the model, 4) the mathematical model, 5) formulation of the empirical model, 6) the supply and demand components under which the specification and estimation of the long run marginal cost functions for the net exporters of the 
model are presented, 7) spatial and dynamic optimization and finally, 8) data sources for the model.

In Chapter 5, we present the empirical results. The main subsections for this chapter are as follows: 1) policy approach, 2) results of the estimation of the country supply and demand functions, 3) validation of the results for country supply and demand functions, 4) results and validation of the long run marginal cost functions and 5) simulation with the spatial and dynamic optimization model. In the last subsection, we also provide the validation of the spatial and dynamic optimization model through two approaches. The first is a comparison of the model's optimal values with the historical values for supply, exports and imports for the countries of the model. The second approach is that of an experimental design approach to test which factors have a significant impact on the changes in Botswana's exports.

Chapter 6 is concerned with the sensitivity analysis of the base case simulation scenario and also with applying the model towards forecasting Botswana's future steam coal exports. The sensitivity analysis is also applied to the base case forecast results to determine the responsiveness in Botswana's steam coal exports to changes in rail transportation costs, capital costs and changes in demand.

Finally, chapter 7 provides summary of the study, results, policy implications, conclusions and recommendations for future research. The Appendix presents results of the econometric estimations, the simple multi-period linear programming model and the GAMS code and a partial output from the base case simulation scenario. The description of the appendices follows below:

1. Appendix A - Results from the econometric estimation of country supply and demand functions; 
2. Appendix B - Results from the econometric estimation of the long run marginal cost functions for net exporters in the model;

3. Appendix C - Results of the time series estimation of sea freight costs;

4. Appendix D - Sensitivity results of the long run marginal cost functions;

5. Appendix E-Graphical comparison of market shares;

6. Appendix F - The Resultant Market Shares With Botswana's Capital Costs at 20\% Above Their Base Case Forecast Levels;

7. Appendix G - A simple Multi-Period Linear Programming Model of the World Steam Coal Trade, and

8. Appendix H - The GAMS Code and Output for the Base Case Simulation Scenario of the Spatial and Dynamic Optimization Model of the World Steam Coal Trade. 


\section{CHAPTER 2}

\section{THE INTERNATIONAL STEAM COAL TRADE}

\subsection{Introduction}

The international seaborne trade in hard coal consists of trade in two categories of coal, coking coal and steam coal. Coking coal has applications in the steel industry while steam coal is used in any one of the following three ways: generating steam for electricity generation; production of heat and steam for final end use such as in the residential and transportation sectors, and as pulverized injection coal (PCI) that is used together with coking coal in the steel industry (Coal Information 2001, p I.87). Towards the end of the 1970's, the reporting of separate trade data for the seaborne steam coal trade began (Coal Information, 1996). This chapter analyses the growth in the seaborne steam coal trade over the period beginning in 1980 and ending in 2000. This period is also relevant as it coincides with the period in which the prefeasibility study on the viability of an export coal mine on the Kgaswe coal field, one of several major coal fields in Botswana, was carried out. The chapter goes on to look at trends in supply and demand, the role of transportation on the seaborne trade, focusing specifically on developments in the rail and maritime transportation costs and finally reviews the regional political situation in Southern Africa and how this shapes a role for Botswana in this trade.

\subsection{Trends in Supply and Demand}

Figure 2.1 depicts the growth trend in the seaborne steam coal trade and shows that this has increased by slightly more than 3.5 times in the period 1980 to 2000 . As a percentage of the total seaborne hard coal trade, steam coal has shown consistent growth from about $46 \%$ in 1980 to about $66 \%$ in 2000 . In figure 2.2 , the share of the steam coal exporting countries under study 
is shown. The United States has always been a major producer of steam coal, second only to China, which has been left out of the model in the class of the rest of world supply. The position of the United States as a marginal producer for the international steam coal market is only sustainable due to the substantial demand for coal in the domestic market. This has placed the United States, with both its productive and transportation capacity, in a position to respond quickly to offset any supply shocks from lower cost producers. This happened in the early 1980's when there was a disruption of supply of steam coal from Poland destined for Western European markets. The graph depicts a spike in United States' steam coal exports that raised their share of this trade from about $27 \%$ in 1980 and to $42 \%$ in 1981 . By the time the disruptions to coal supply from British collieries occurred in 1984-85, Australia and South Africa were in a position to compete for this increase in import demand with the United States (Coal Information, 1996, pp I.20).

In the second half of the 80 's decade, new supply came on stream from countries outside of this model, such as Indonesia, Colombia and Venezuela. These new exporters began to play a significant role at the start of the 90's decade. The impact of new entrants would as expected be highest on the United States, as they are the marginal supplier. Figure 2.2 shows that in 1990, the market shares held by the United States, Australia and South Africa were 19\%, 23\% and 23\% respectively. These countries had a combined share of $65 \%$ of this trade. By the year 2000 , the United States' market share had declined substantially to about 7\% while Australia and South Africa still commanded $23 \%$ and $20 \%$ respectively. In the intervening period, Australia's share reached a high of $27 \%$ while that of South Africa peaked at $25 \%$. The three countries still commanded a market share of 50\% in the year 2000 (see Fig. 2.3). 


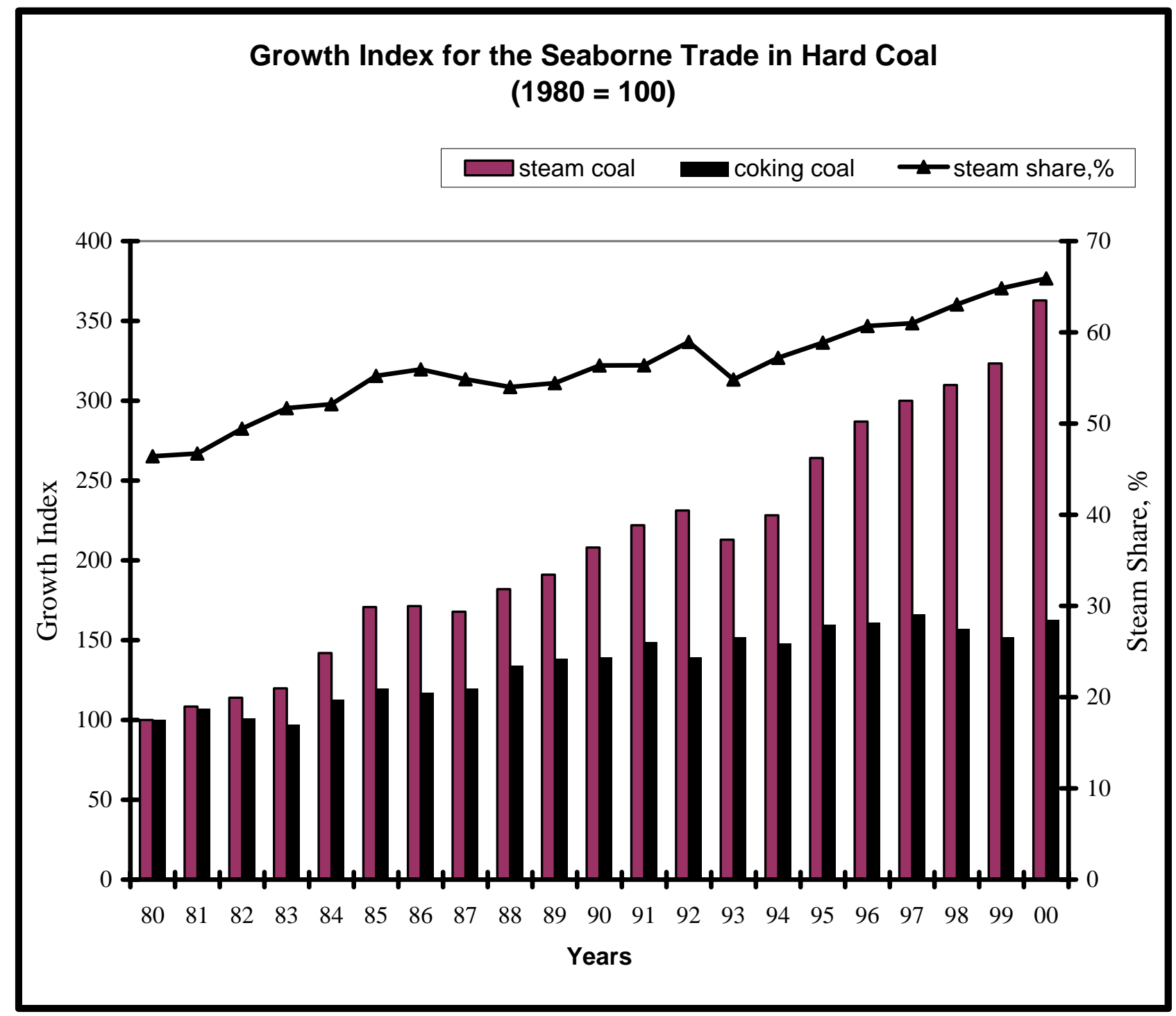

Figure 2.1 Selected Country Percent Shares in the World Seaborne Steam Coal Trade Source: Coal Information, 2001, International Energy Agency / OECD, Paris, p I.150. 


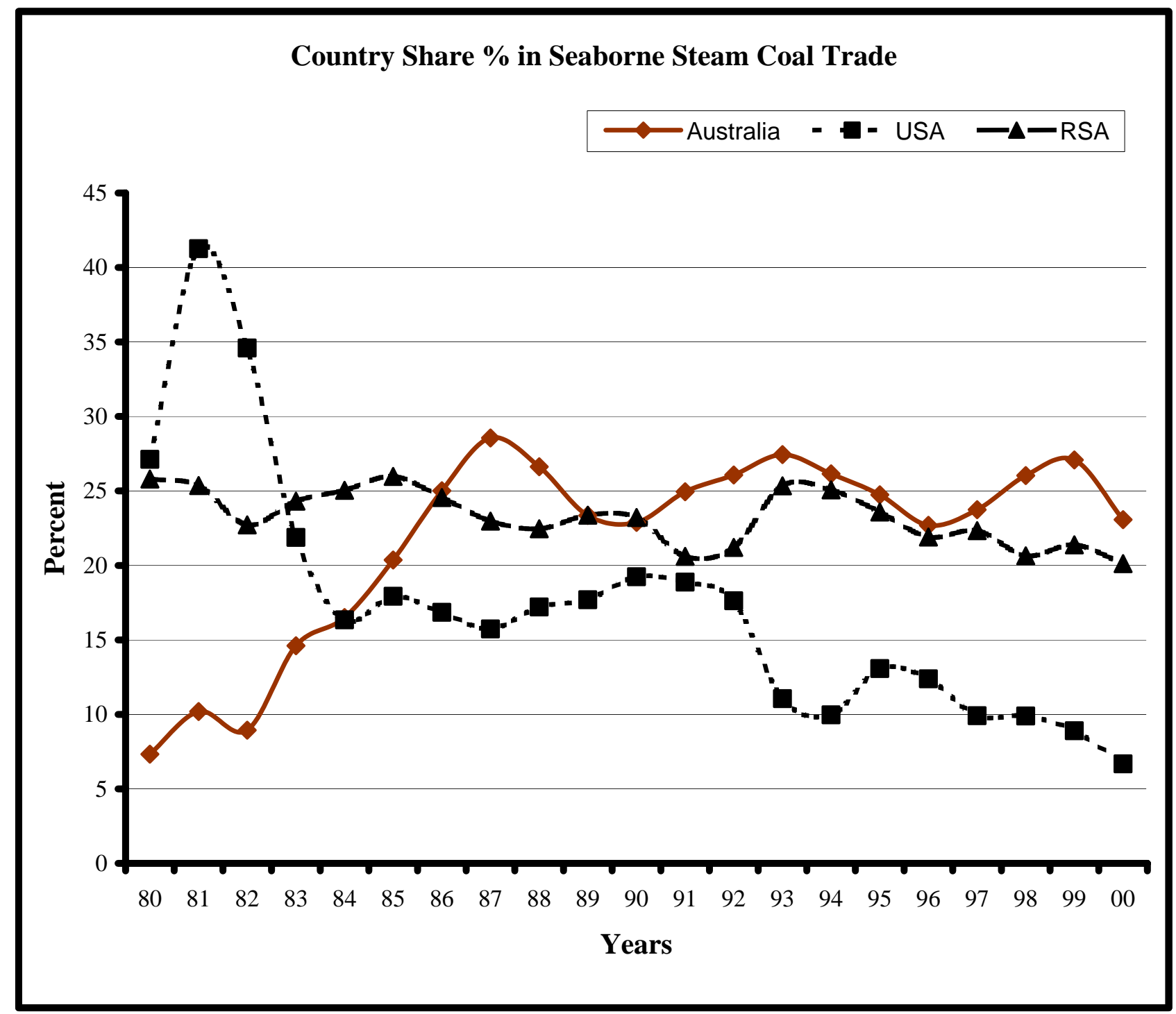

Figure 2.2 Selected Country Percentage Share in the International Seaborne Steam Coal Trade

Source: Coal Information, 2001, International Energy Agency / OECD, Paris, p I.150. 


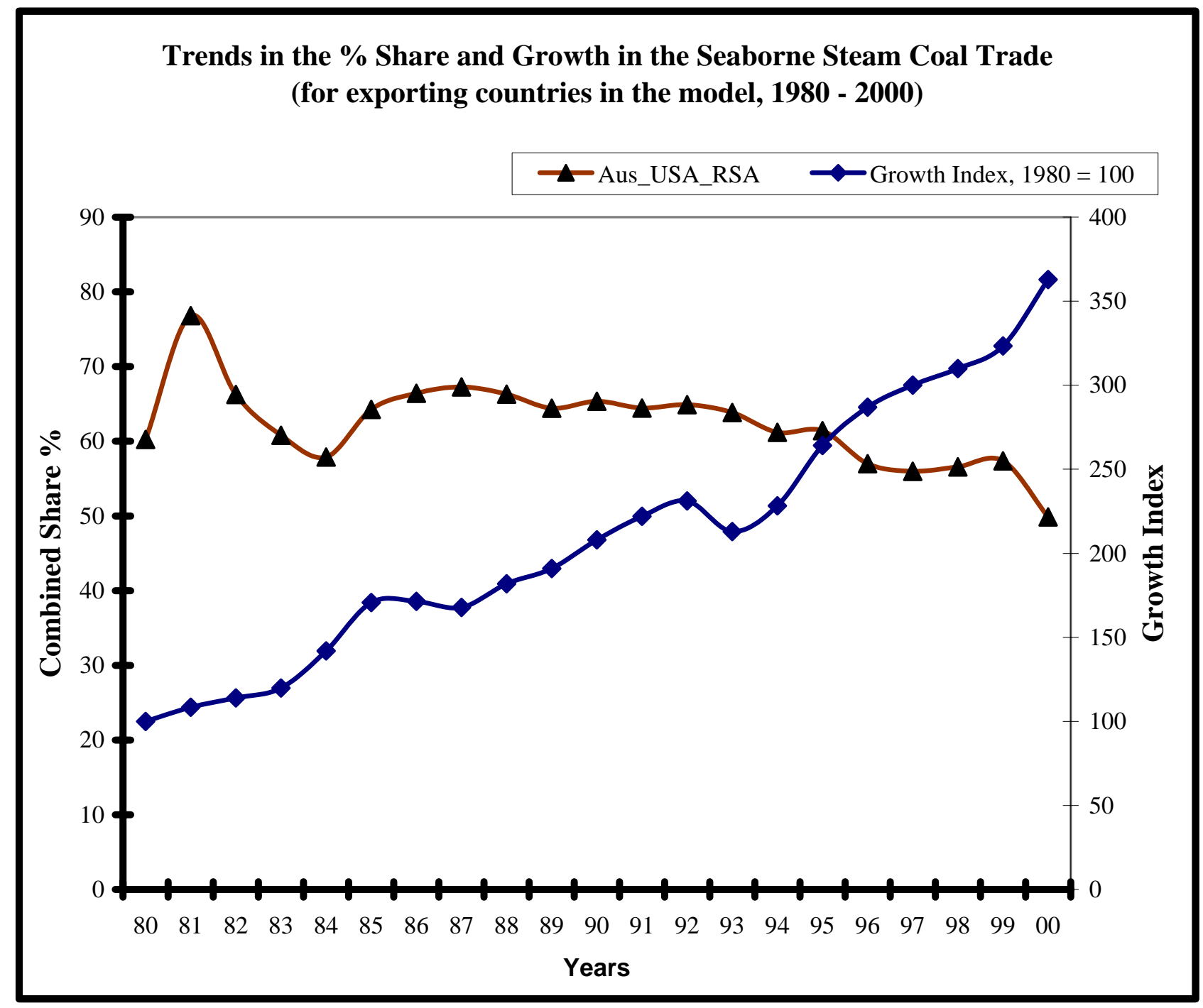

Figure 2.3 Trends in the combined percentage share of selected steam coal exporting countries in the model against the growth index in sea borne steam coal trade

Source: Coal Information, 2001, International Energy Agency / OECD, Paris, p I.150. 
The major markets for seaborne steam coal are in two geographic regions, Asia and Western Europe. In this study only a few countries in each of these regions have been included as the demand countries in the model. The market in Western Europe is made up of Belgium, Germany, France, Italy, Netherlands, Spain and the United Kingdom while that of Asia includes only Japan and South Korea. The rate of growth in these markets, relative to a 1980 base year, is shown in Figure 2.4. The demand for steam coal in the Asian market grew eleven fold in the period 1980 to 2000 while in Western Europe it just about doubled over the same period. Figure 2.5 shows the trend in the individual and combined market shares for these regions. The latter has remained at about $60 \%$ in the 1990s. The individual market shares for these regions have trended in opposite directions, with the share for Western Europe declining by almost one-half between 1980 and 2000 to about 30\%. The Asian market grew over the period by about three and one-half times to $35 \%$. Long term projections for steam coal demand in these markets all show an increase in coal demand. For the period 2005 to 2010, steam coal demand Western European is projected to grow by $3.4 \%$ while in Asia it is $3.6 \%$. For the period 2010 to 2020 , the growth in demand is projected to increases to $7.3 \%$ and $19.6 \%$ for Western European and Asian markets respectively (Coal Information, 2001 p I.102).

Figures 2.7 and 2.8 show the price ratios of heavy fuel oil and natural gas to coal in their use in electricity generation for the leading steam coal importing countries in their respective market groupings, the United Kingdom and Japan, in the Western Europe and Asia market respectively. The natural gas to steam coal price ratio for the United Kingdom over the years 1995 to 2000 averaged out at 1.44. For other countries in this market, such as Germany, Netherlands and Spain for instance, the ratio of the gas price to that of steam coal averaged in the range 1.91 to 2.73 . This may help justify the level of aggregation in the model at the country 
level instead of the regional level, as a country's demand for steam coal will depend on the relative prices of other fuels for electricity generation. These ratios also help explain why steam coal is the fuel of choice for electricity generation in the Asian market.

The concerns on green house gas emissions from the burning of fossil fuels and their impact on global warming has led to technological initiatives to burn these fuels in much cleaner and efficient processes. The options available for complying with environmental regulations for lower green house gas emissions include burning fuel that produces less carbon dioxide per unit of heat, using more efficient generation technology and adopting more energy efficient policies in the consumption of electricity. Some progress has been made in adopting more efficient generation technology, or what is commonly referred to as advanced clean coal technologies. These consist mainly of the integrated gasification combined cycle (IGCC), the pressurized fluidized bed combustors (PFBC), the circulating fluidized bed combustors (CFBC) and the supercritical / ultra-supercritical pulverized coal (SC/USC) (see Coal Information 2001). These technologies improve efficiency for electricity generation and therefore lower the emission of both green house gases and sulfur dioxide, which are the main pollutants from the burning of fossil fuels. The trend in the ratios of the oil and gas prices to the price of coal indicates that the latter remains cost competitive while the progress in advanced clean coal technologies bodes well for the continued use of steam coal in the generation of electricity. 


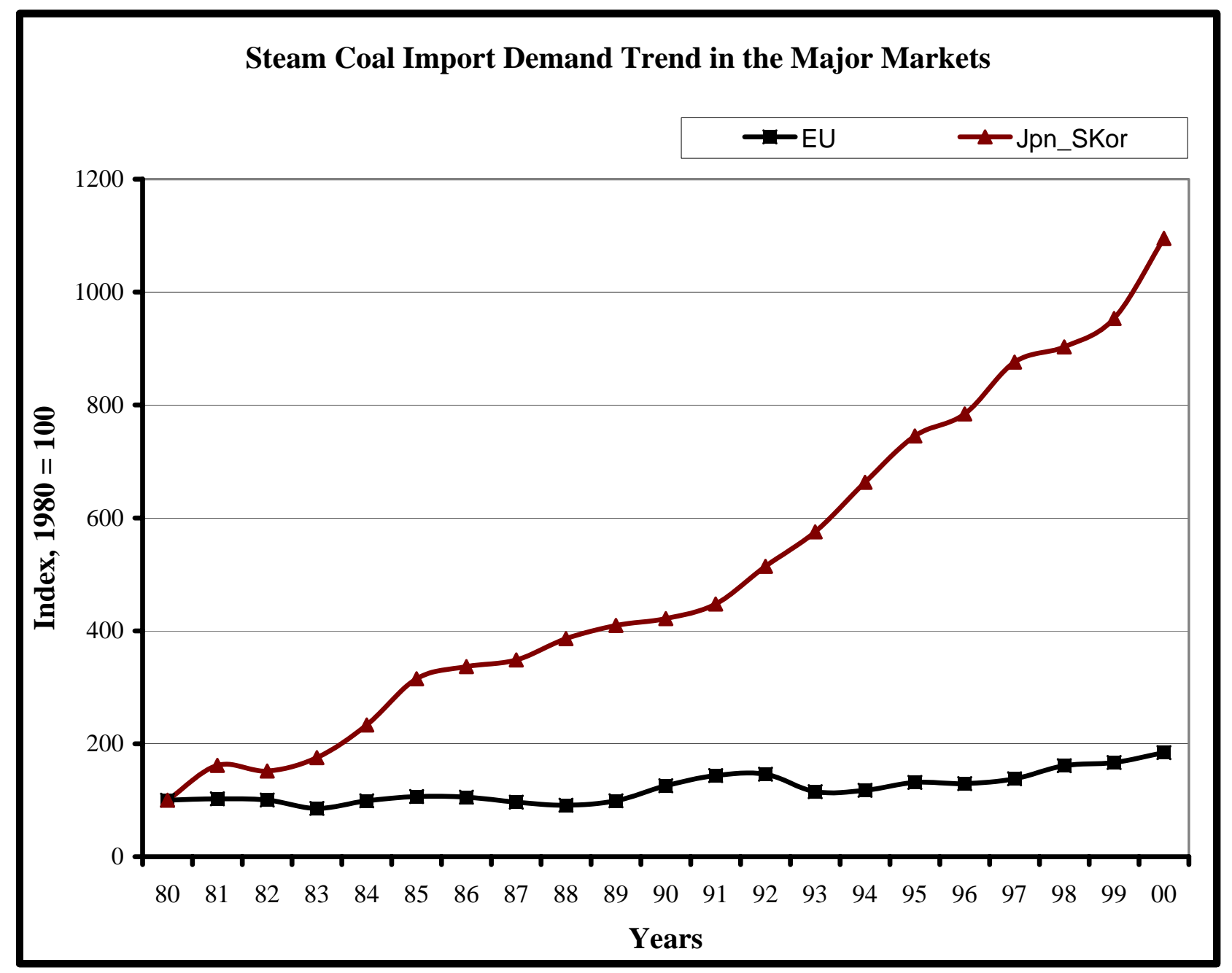

Figure 2.4 Trends in Seaborne Steam Coal Demand for the Major Markets in the Model Source: Coal Information, 2001, International Energy Agency / OECD, Paris, p I.54. 


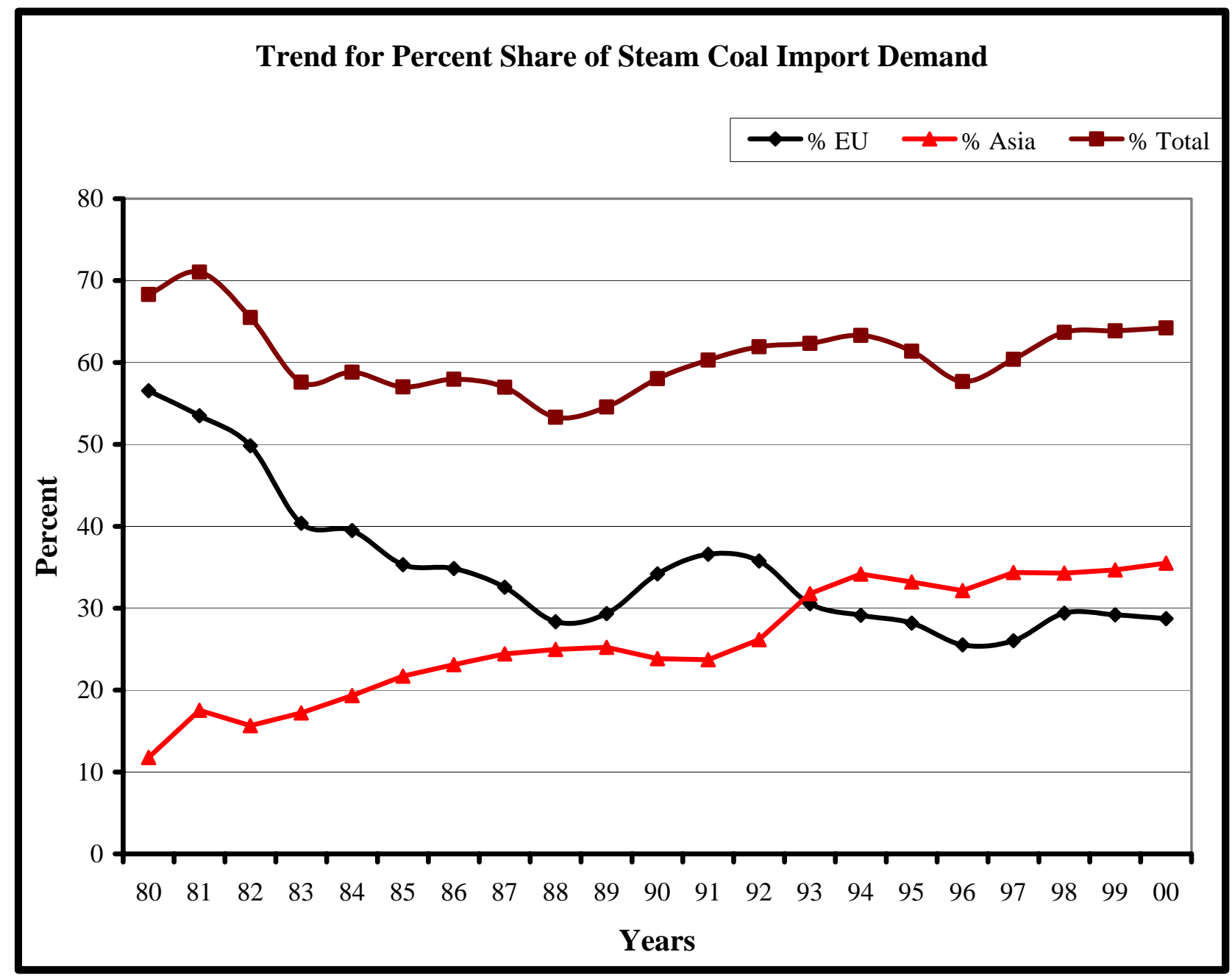

Figure 2.5 Trends in the Percent Shares by the Major Markets for the Seaborne Steam Coal Trade

Source: Coal Information, 2001, International Energy Agency / OECD, Paris, p I.54. 


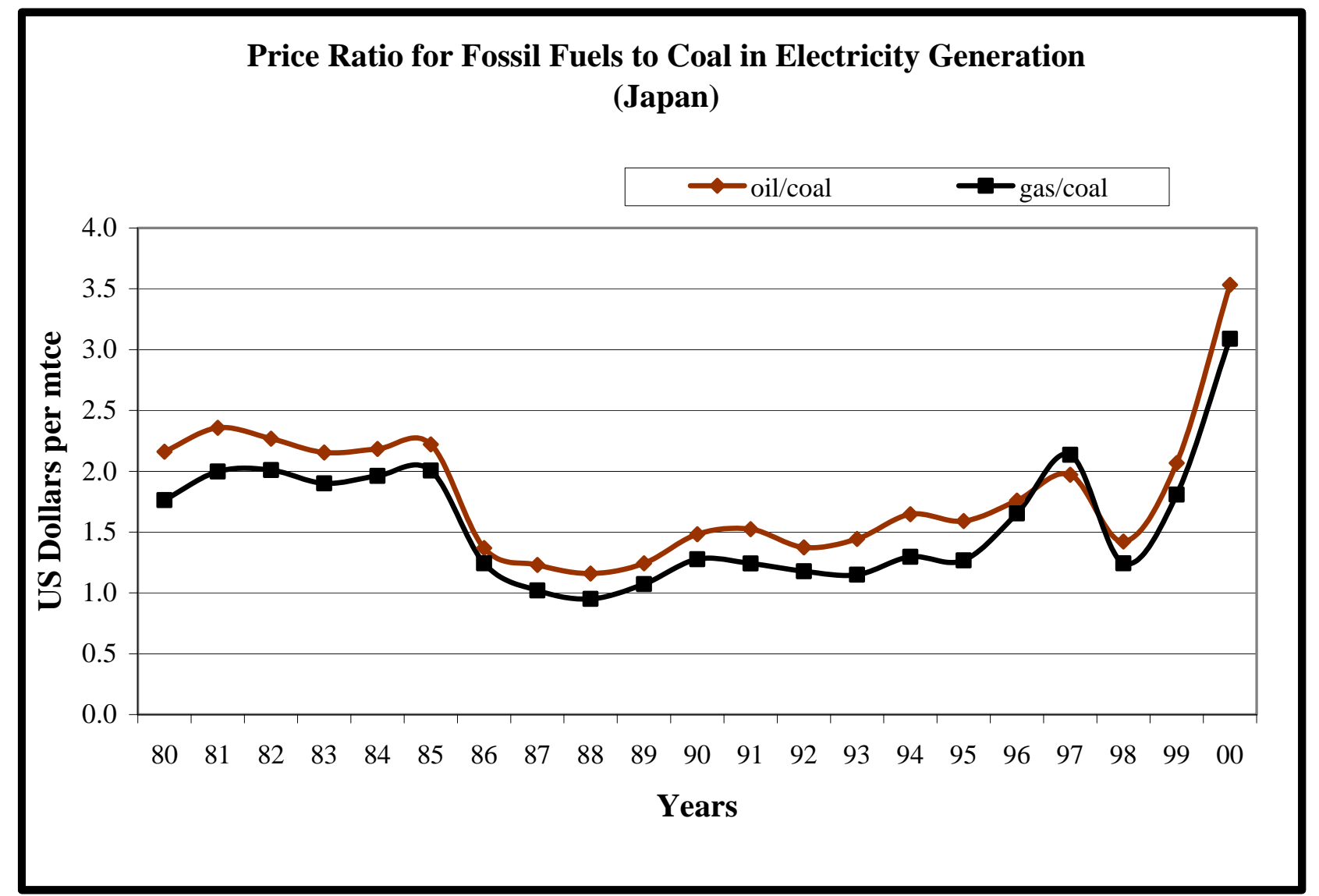

Figure 2.6 Trends in the Japanese Price Ratios of Other Fossil Fuels to Coal

Source: 1) Coal Information, 1990,1996 and 2001, International Energy Agency / OECD, Paris.

2) Energy Prices and Taxes, Quarterly Statistics, Second Quarter 2001, International Energy Agency / OECD, Paris. 


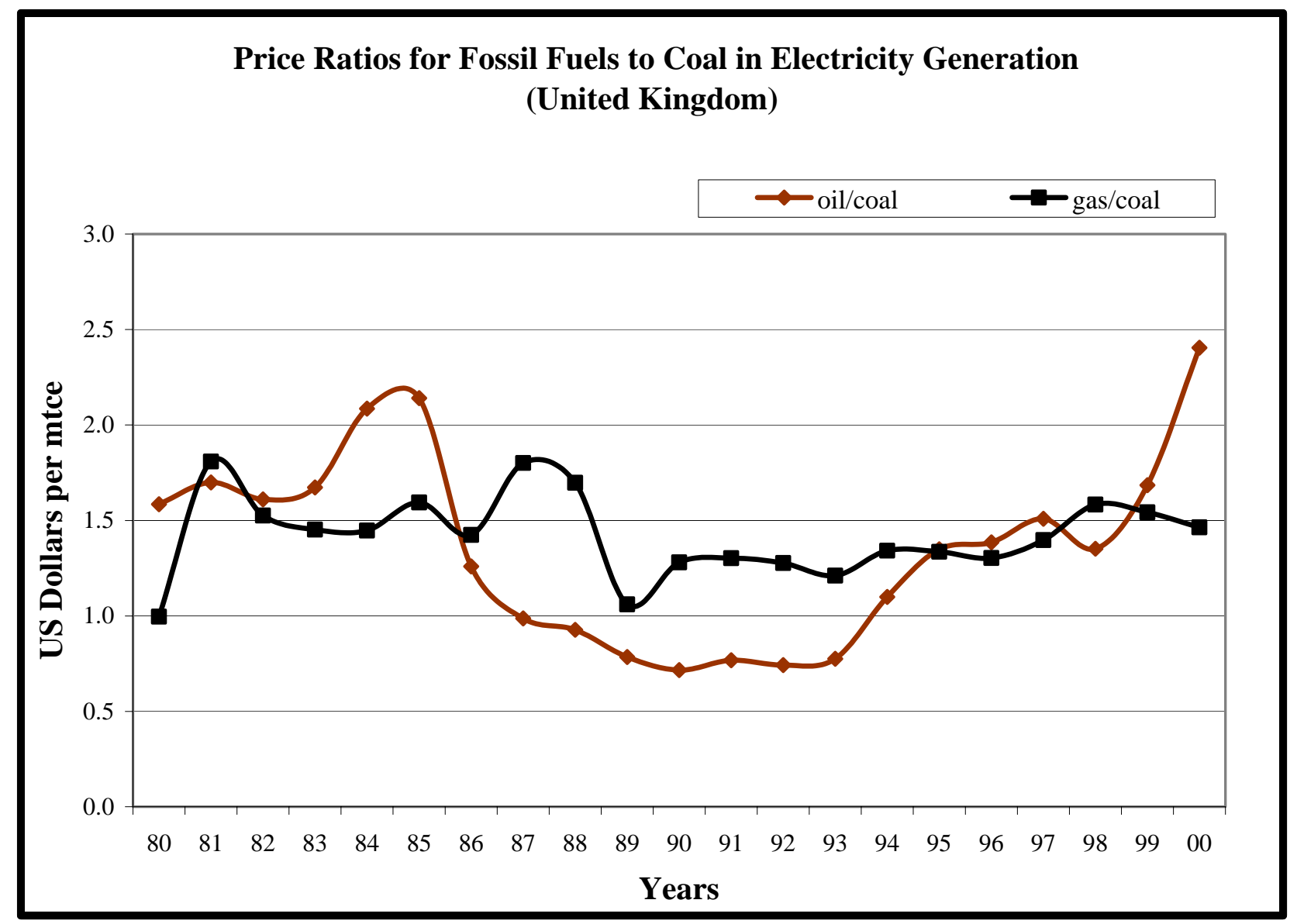

Figure 2.7 Trends in the UK Price Ratios of Other Fossil Fuels to Coal

Source: 1) Coal Information, 1990,1996 and 2001, International Energy Agency / OECD, Paris.

2) Energy Prices and Taxes, Quarterly Statistics, Second Quarter 2001, International Energy Agency / OECD, Paris. 


\subsection{Trends in Rail Transportation Costs}

The competitiveness of rail transportation costs in the exporting countries in the model depends on the hauling distances to seaports. Among these countries, Australia has the shortest hauling distances to two of its major ports, Gladstone and Newcastle, of 280-380 km and 80-120 $\mathrm{km}$ respectively (Coal Information 2001, Table $5.6 \mathrm{p}$ I.183). The main railway operator, Queensland rail is government owned. In South Africa, the distance from Witbank to the Richards Bay coal terminal is $625 \mathrm{~km}$. Coal is also railed from ISCOR's Grootegelug mine, located about $100 \mathrm{~km}$ from the Mmamabula coalfield, to the seaport of Durban, some $1100 \mathrm{~km}$ away. The rail operator, Spoornet is government owned. In the United States, the hauling distances for mines located in Appalachia exceed those in South Africa. For instance mines located in central Appalachia, which is the region assumed for this study, face rail distances of $700 \mathrm{~km}-1350 \mathrm{~km}$ to the seaport of Hampton Roads in Virginia. Some coals from Wyoming and Montana are railed to the Canadian seaport of Roberts Bank, a distance of $2250 \mathrm{~km}-2330 \mathrm{~km}$ (Coal Information, 2001, Table 5.7, p I.185). There is competition in the provision of rail transportation services in the United States, a factor that facilitates the country's position as a marginal supplier of steam coal to the world markets.

Figure 2.6 shows that rail transportation costs have been declining over the period 1980 to 2000. In the five-year period 1995 to 2000, rail transportation costs for Australia fell by $43 \%$ from $\$ 10.29$ to $\$ 6.05$ per mtce and those for South Africa fell $43 \%$ to $\$ 7.28$ from $\$ 12.83$ per mtce. In the United States, rates only fell marginally by 5\% to $\$ 19.16$ from $\$ 20.24$ per mtce in 1995. The decline in rail costs for Australia and South Africa may be explained in part by the depreciation of these countries' currencies against the U.S. Dollar. 


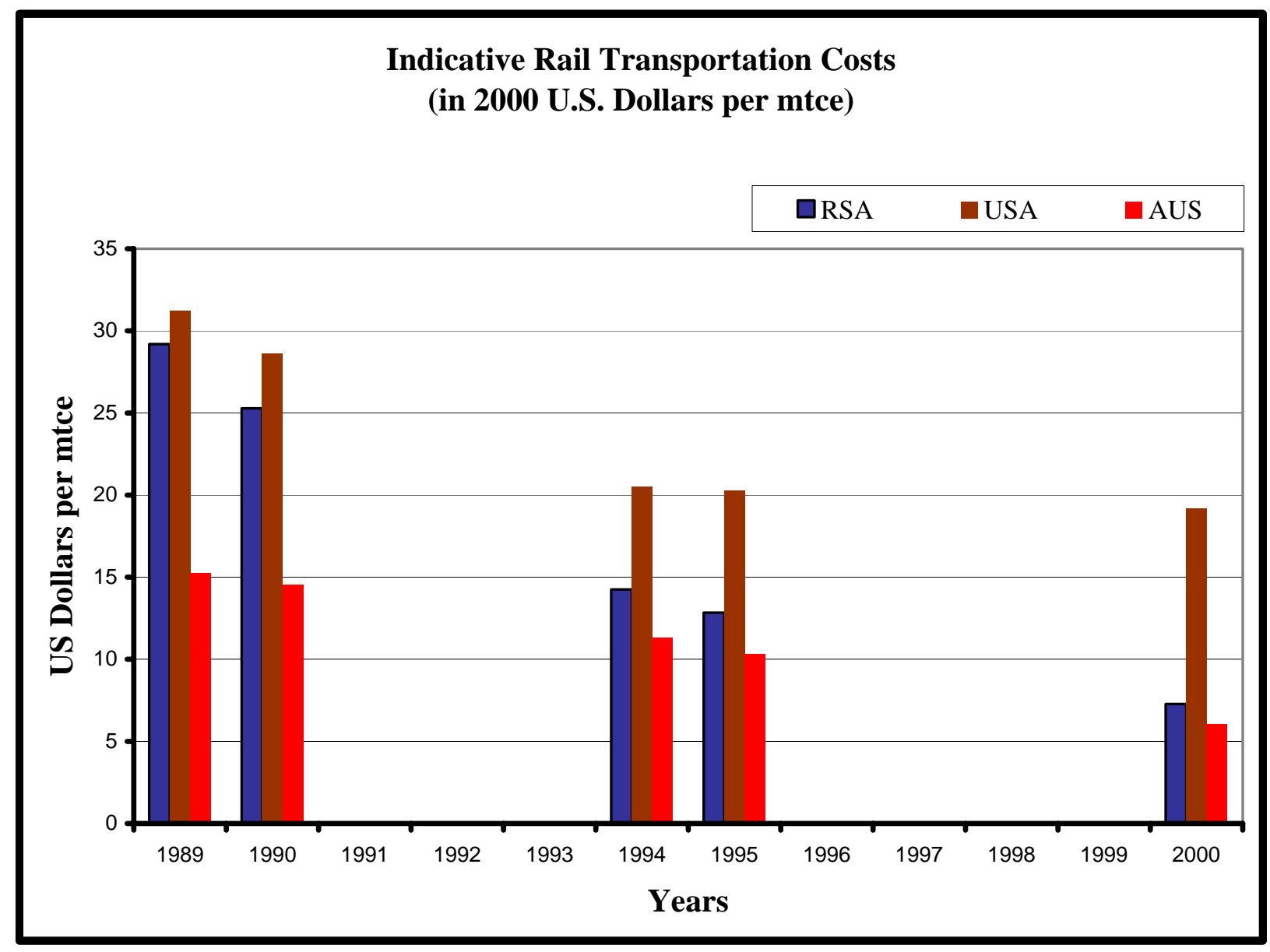

Figure 2.8 Trends in Rail Transportation Costs for Exporters in the Model

Source: 1) Coal Information, 1990, International Energy Agency / OECD, Paris, p26.

2) Coal Information, 1996, International Energy Agency / OECD, Paris, p I.148.

3) Coal Information, 2001, International Energy Agency / OECD, Paris, p I.183 and I.185 


\subsection{Trends in Maritime Transportation Costs}

The seaborne trade in steam coal can be characterized as having two major markets, one in Western Europe and the other in Asia. If we imagine the imposition of prohibitive maritime transportation costs or if the price of coal were to decline to levels that would discourage the seaborne steam coal trade, then we would end up with truly regional markets. These would be in the Americas, Western Europe, Southern Africa and the Pacific. In the existing geographic definition of these markets, it is necessary to determine the cost competitiveness of suppliers to these markets and thus help to define which supplier would have cost advantages in which markets.

Figure 2.7 shows trends in the marginal supply costs for exporters in the model. All exporters show a consistent decline in their marginal supply costs. Figure 2.8 demonstrates that in the Asian markets, Australia faces the lowest unit maritime transportation costs followed by South Africa. The U.S., on the other hand, faces higher maritime transportation costs. In the Western European market, the U.S. has the lowest unit maritime transportation costs followed by South Africa (see Figure 2.9). The competition picture that emerges, then, is that of South Africa being the main link between these two major markets. It competes with Australia in the Asian markets and with the United States in the Western European markets. In this model, therefore, both Australia and the United States individually assume the role of marginal supplier in the Western Europe and Asian markets respectively while South Africa is a significant supplier to both markets. Maritime transportation costs have been on the decline as depicted in figures 2.8 and 2.9. The seaborne trade in major dry bulk commodities such as coal, metal concentrates and grains has seen a shift towards the use of larger sea going vessels in the size ranges exceeding 100000 metric tons as these are more profitable to operate (Coal Information, 2001, p I.160). 


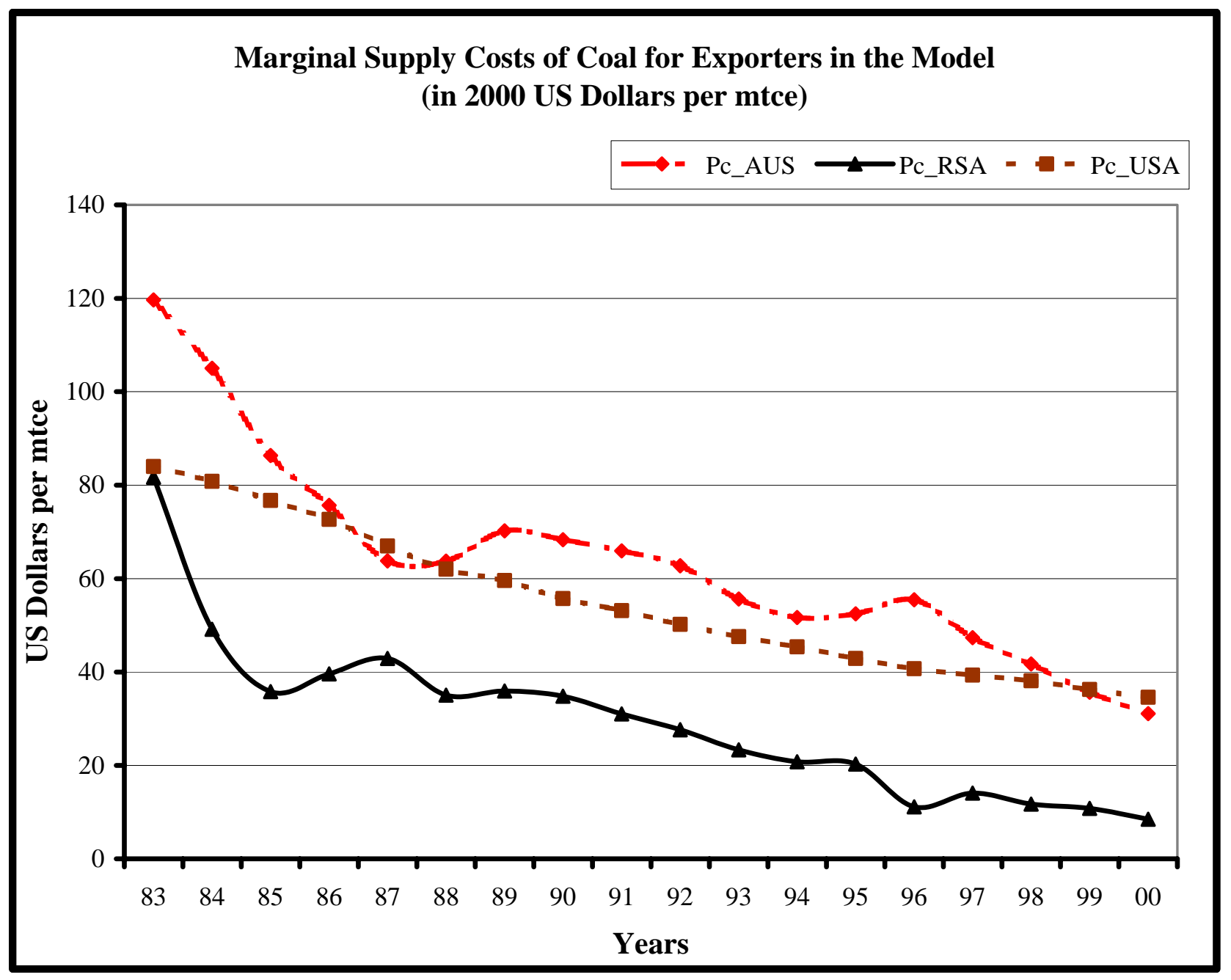

Figure 2.9 Trends in Marginal Supply Costs for Exporters in the Model

Source: Based on authors computation based on data from Coal Information 1990, 1996 and 2001, and Energy Prices and Taxes, Quarterly Statistics, Second Quarter 2001.

Note: Australia is f.o.b. price. 


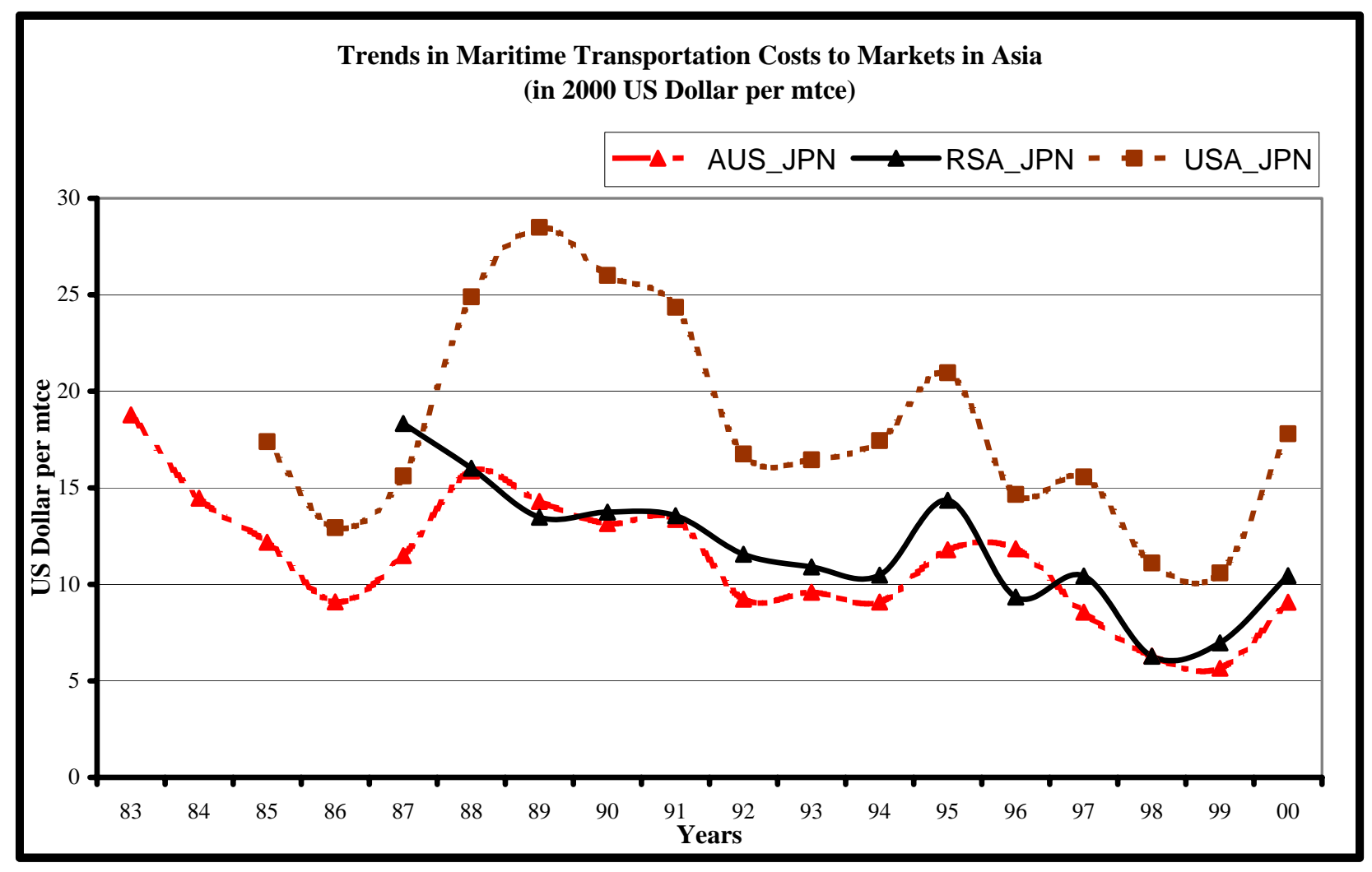

Figure 2.10 Trends in Maritime Transportation Costs for Selected Exporters to Markets in Asia

Source: Based on authors computation based on data from Coal Trade Freight Report, Rodriguez Sons Co. as cited in International Coal Review Monthly. 


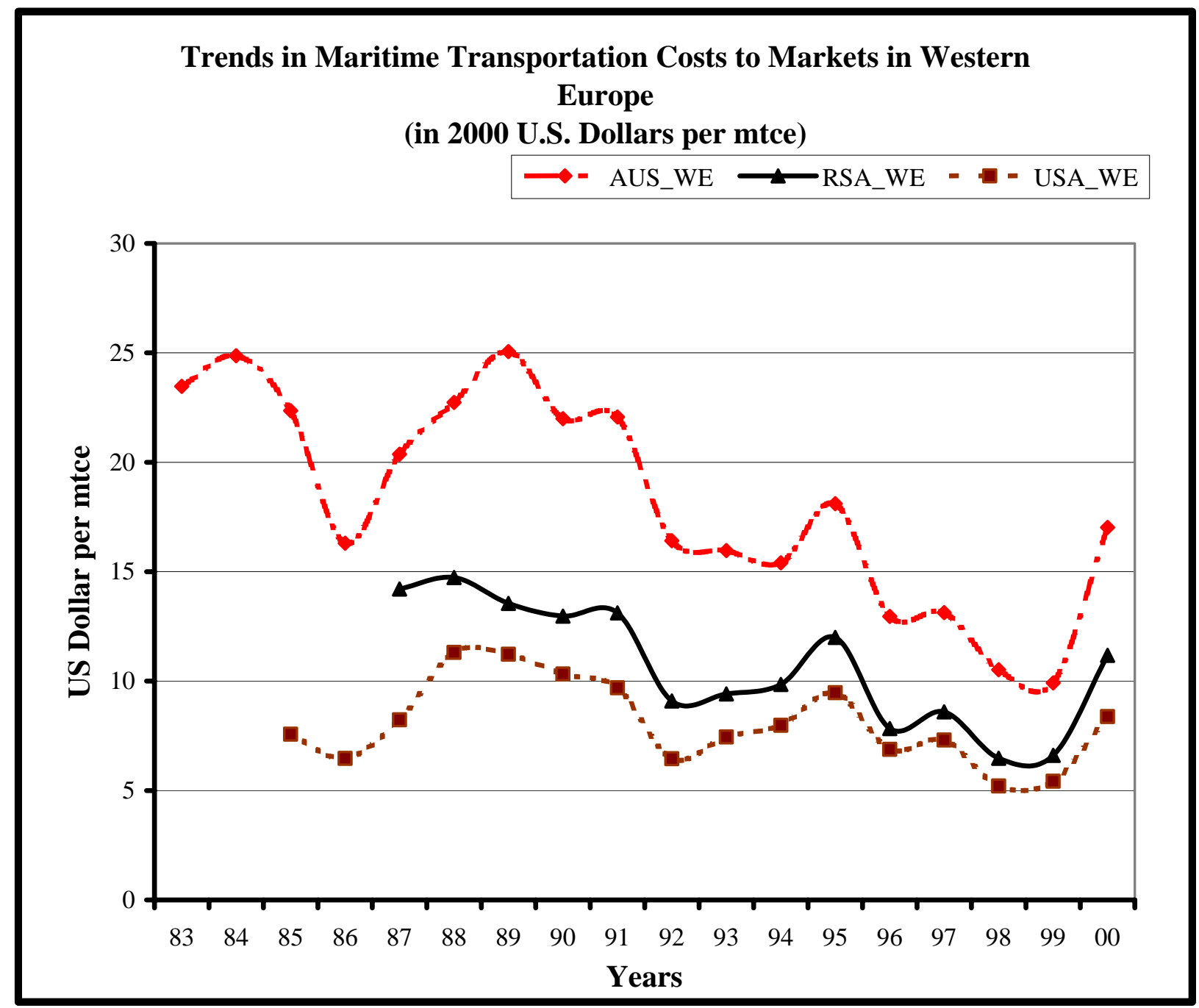

Figure 2.11 Trends in Maritime Transportation Costs for Selected Exporters to Markets in Western Europe

Source: Based on authors computation based on data from Coal Trade Freight Report, Rodriguez Sons Co. as cited in International Coal Review Monthly. 


\subsection{Role of Botswana}

An analysis of steam coal exports from the United States and Australia to those markets in which these countries face high maritime transportation costs provides an indication of the annual tonnages that these countries control in their role as marginal suppliers to these markets. In the first half of the 1990s, Australia's steam coal exports to markets in Western Europe averaged some 8.776 million metric tons. These fell in the second half of the decade to 6.952 million metric tons. In the Asian markets, steam coal exports from the United States rose from an average of 3.445 million metric tons in the first half of the 1990s to 4.080 million metric tons in the second half. The total tonnage controlled by Australia and the United States in those markets in which they play the role of marginal supplier, Western Europe and Asia, respectively, provides an indication of the tonnage that could be won away by a new entrant facing an overall cost advantage in these markets over these marginal suppliers. The average tonnage controlled by these marginal suppliers in the second half of the 1990s was some 11.0 million metric tons.

The regional export coal supply in Southern Africa is concentrated in the Republic of South Africa (RSA). Most of these collieries exploit coals on the Witbank coalfield in the Mpumalanga province. There is one large-scale colliery, Grootgeluk, in the Northern province near Ellisras, and therefore also in the general vicinity of a would be mine on the Mmamabula coalfield, that produces coal for both the domestic and export markets. South Africa's steam coal is transported by rail from Witbank to the Indian Ocean sea port of Richards Bay, where a private coal handling export terminal by the same name and is operated by the coal exporting companies, provides access to the only high volume dedicated coal handling terminal in the region. Botswana's role is further discussed in the following two sub-sections that emphasize the country's geographical location relative to the world's major steam coal markets and the 
improved conditions for regional cooperation citing a specific framework for regional cooperation on transport infrastructure and related issues.

\subsubsection{Taking Advantage of Botswana's Geographical Location}

The landlocked nature of Botswana has in the past meant that rail transportation costs to seaports rendered high volume low value exports such as coal unprofitable. When one views the geographical location of Botswana in relation to the main supply and demand regions for seaborne steam coal trade, it then becomes apparent that the country is almost equi-distant between the two major world markets for seaborne steam coal, Western Europe and Asia. This presents possibilities for the country to be cost competitive in these markets. For instance, Figures 2.8 and 2.9 respectively show that in a three country or region competition, the Southern Africa region would be in competition with Australia in the Asian market and with the United States in the Western European market.

The question then is whether or not steam coal from Botswana can gain market share from the United States on the Asian markets and from Australia in the Western European market. Figure 2.7 also shows that the supply price for steam coal in Southern Africa is the lowest among the three countries selected for this study. Figure 2.6 shows that railway costs have been declining in real terms and in some regional markets, and as discussed under the section on rail transportation above, hauling distances would be comparable to those faced by Botswana's coal exports. Botswana should seek ways by which it would take advantage of its geographical location relative to the world's main steam coal markets and explore further possibilities for gaining market share away from those countries / regions farthest away from these markets. 


\subsubsection{Framework for Regional Cooperation on Transport Infrastructure}

There have been substantial changes in the Southern Africa region and these justify a renewed interest by policy makers in Botswana to explore the options that can be pursued to move towards exploiting the country's coal deposits. Some of these changes are in the area of political stability and the increased regional cooperation that has come about with a democratically elected government in South Africa in 1994. A framework for regional cooperation in the area of transport has been devised and formalized under the regional economic body, the Southern African Development Community's (SADC) Protocol on Transport, Communications and Meteorology, that was signed by the Heads of State and government of the SADC countries in August 1996. Some of the transport specific issues that the protocol deals with are found in Articles 3.3 and 3.5, dealing with transport infrastructure and institutional framework respectively. The intention is to have cross-border corridor planning committees drawn from both the government and private sectors and who will be tasked with, among other things, the identification of regional corridors and their prioritization for integrated development (SADC, 1996). In view of these regional efforts at integration, there is justification for simulating rail transport routes across regional borders to sea ports in the region as will be done in this study. The simulation of a railway line to link Mmamabula with the port of Walvis Bay in Namibia could be viewed in the regional context as satisfying the need for faster delivery times for steam coal and other products to the European market. There would also be possibilities for shorter access routes to the ocean through links from Mmamabula to the Witbank-Maputo railway line for the high steam coal demand growth markets in the Asia Pacific countries.

There have since been regional spatial development initiatives on infrastructure projects along these defined concepts. Some examples include an agreement between the governments of 
South Africa and Mozambique under the Maputo Development Corridor over the rehabilitation and management of the Ressano Garcia railway line between Witbank and the ports of Matola and Maputo ${ }^{5}$. The Ressano Garcia Railway Company would be majority owned by a consortium led by Spoornet of South Africa (51\%), the Mozambique railway company, CFM (33\%) and regional interests including Mozambique $(16 \%)^{6}$. There has also been close cooperation between regional railway lines such as that between Botswana Railways and Spoornet of South Africa involving the operation of a dry port in Botswana's capital, Gaborone. Proposals that have been put forward for the development of the ports of Maputo and Matola, under the Maputo Corridor Company, would require an ownership structure that includes the governments of South Africa, Botswana, South Africa, Swaziland, Mozambique and Zimbabwe on the one hand and a private sector investor on the other. Such an export port would offer an alternative to coal mines located in Botswana and even South Africa itself as the existing export facilities at the Richard's Bay Coal Terminal are privately owned and operated by the existing consortium of South African coal exporting companies. Other developments in the regional rail transport sector show SADC governments' policy of encouragement of private sector participation in the transportation infrastructure projects. ${ }^{7}$

\footnotetext{
${ }^{5}$ Maputo Development Corridor, Update of Key Investment Opportunities, June 1996. Retrieved on January $27^{\text {th }}$, 2002, from the South Africa Department of Transport: http://www.transport.gov.za/library/index.html ${ }^{6}$ Additional investments in the coal terminal at Matola would increase port capacity to more than 4.3 million tons. As with the coal link line from Witbank to the Richard's Bay Coal Terminal, the section of the Ressano Garcia line between Komatipoort and Maputo is considered for electrification. Retrieved on January $28^{\text {th }}, 2002$ from: http://www.businessday.co.za/bday/content/direct/1,3523,1004048-6078-0,00.html.

${ }^{7}$ The Beitbridge Bulawayo Railway Company was awarded a concession by the Zimbabwean government to rehabilitate and operate the $350 \mathrm{~km}$ of railway line from, Beitbridge, South Africa to Bulawayo, Zimbabwe. The project took 16 moths and cost US $\$ 85$ million. The President of Zimbabwe commissioned the line on September 1 , 1999. The company has been given other concessions to operate more railway lines in Zimbabwe. This project is in line with the SADC protocol as cited here as "... increasing private sector involvement in railways investment with a view to improving railway work and service standards." Retrieved on January $28^{\text {th }}, 2002$ from the New Limpopo Projects Investment: http://nlpi.main-server.co.uk/bot_projects.html
} 
It is therefore helpful that there is some level of success with regional cooperation and it may be that this success will help sustain the political will for an integrated regional infrastructure for transportation.

\subsection{Conclusion}

This chapter reviewed the seaborne international steam coal trade, placing emphasis on the trends in: supply and demand, rail transportation costs, maritime transportation costs, and marginal supply costs for steam coal. We then went further to define the role for Botswana, by recognizing the geographic advantage that the country enjoys relative to the United States and Australia in the Asian and Western European steam coal markets respectively. The prospects for Botswana as a major steam coal producer also rely on regional cooperation in matters of regional infrastructure provision. Here too, we demonstrated that regional cooperation now exists as may be read from other regional cooperation initiatives such as those of the Southern African Power Pool, that between the rail authority of South Africa, Spoornet, and Mozambique, to operate the rail link from Witbank to Maputo, and more generally, those provisions of the SADC protocol on Transport, Communications and Meteorology, which recognize the need to approach infrastructure development on a regional rather than country basis. 


\section{CHAPTER 3}

\section{COAL TRADE MODELS IN RETROSPECT}

\subsection{Introduction}

This chapter reviews the literature on spatial price equilibrium models that have been applied to model the trade in coal. The types of models reviewed are discussed under section 3.2, literature review, and under specific headings of: 1) linear programming, 2) non-linear programming, 3) the variational inequality problem and 4) mixed integer programming. Subsection 3.2.2, on non-linear programming, provides a detailed theoretical treatment of the spatial, temporal and price allocation (STPA) model of Samuelson (1952) and Takayama and Judge (1971). The variational inequality problem is presented with the aim of emphasizing the link between this type of problem with the STPA model under given conditions. In subsection 3.2.4, mixed integer programming, the approach is to define the conditions that justify the use of this model type and therefore any optimization model that is geared towards project selection as opposed to capital budgeting methods used in project evaluation. The chapter then proceeds to provide examples of the applications of these models under section 3.3 and finally, section 3.4 concludes this chapter.

\subsection{Literature Review}

Spatial price equilibrium models have found plenty of application in models to explain the pattern in both the regional and international trade in mineral, energy and agricultural commodities (see van den Bergh, Nijkamp and Rietveld, 1995, Labys, Takayama and Uri, 1991, Labys and Yang, 1991, for a review of mineral and energy models; and Koo and Larson (1985) 
for a review of agriculture models). This review covers linear programming, quadratic programming, which is a type of non-linear programming, variational inequality and mixed integer programming, which can be linear or non-linear. The complexity of these models increases from the linear to the mixed integer type models.

\subsubsection{Linear Programming}

The logical starting point for spatial price equilibrium models is the transport problem, which, in its primal form, is concerned with minimizing the total cost of transporting a commodity between supply and demand regions subject to physical supply and demand constraints and also to non-negativity constraints on all variables. The linear programming model has both a linear objective function and linear constraints. In such a model, the following variables are given: 1) unit transportation costs between each possible pair of supply and demand, $c_{i j}$, 2) available quantities in supply regions, $q_{i}$, and 3) quantity demanded in the market regions, $q_{j}$. The model determines the optimal quantities shipped between supply and demand regions, $q_{i j}$.

$$
\begin{aligned}
& \text { Min TC }=\sum_{i=1}^{n} \sum_{j=1}^{m} c_{i j} q_{i j} \\
& \text { s.t. } \quad-\sum_{j=1}^{m} q_{i j} \geq-q_{i} \text { for all } i \text { in } n ; \\
& \sum_{i=1}^{n} q_{i j} \geq q_{j} \quad \text { for all } j \text { in } m ;
\end{aligned}
$$

The constraint condition in equation 3.1 is material availability constraint and it ensures that total shipments cannot exceed available supply for a given source $i$. At the destination points, total inflows should at least be greater than demand. This is expressed through constraint condition 
3.2, which reads that demand in region $j$ must be less than or equal to total quantities shipped from all regions in $i$ or that there should be no shortage at the destination points.

The dual of the cost minimizing transportation problem is the maximization of value added between supply and demand markets. In this formulation, the given variables are: 1) prices in the supply and demand regions, 2) available quantities in supply regions and 3) quantity demanded in the market regions. In either of these formulations, the locational price equilibrium condition demands that the price differential between the supply and demand regions should be at least greater than or equal to the unit transportation cost between these regions for there to be a positive shipment between such pair of supply and demand regions. The model permits the flow of trade from the supply to the demand region for as long as demand exists. In linear programming the sum of supply from all the sources must be exactly equal to demand.

\subsubsection{Nonlinear Programming}

The nonlinear programming model discussed here is the quadratic programming model. The credit for defining the excess supply in a region as a linear function of the difference between the equilibrium price with trade and that under autarky is attributed to Enke (1951). At this time, it was only possible to solve spatial price equilibrium models consisting of a maximum of three regions by first determining the role of the region with the median autarky price. The resulting trade possibilities set was either for one export and two import regions or the reverse. Enke devised a solution for the n-region problem by applying an electrical analogue where each circuit represented a region while the voltage and current represented pre-trade equilibrium prices and quantities respectively. When measured across these circuits, the voltage and current then represented equilibrium price and quantities with trade. 
In his 1952 paper, Samuelson applied Enke's representation of the excess supply function to the classic Koopmans-Hitchcock transportation problem, which is a linear programming problem such as the one described above. He defined the social pay-off for a region as the area under its excess demand function, and as excess demand is simply the negative of excess supply, it could also be defined as the negative of the area under the excess supply function. He went on to define the net social pay-off as the sum of the producer surplus in the exporting region plus the consumer surplus in the importing region less the fixed per unit transportation costs between the regions and showed that the original cost minimization problem could be re-stated, equivalently, as that of maximizing net social pay-off. This required the formulation of a quadratic programming model with a nonlinear objective function and linear constraints. The objective function is shown below in the quantity formulation, wherein the inverse demand and supply functions are expressed as a function of demand and supply quantities respectively.

$$
\begin{aligned}
& \text { Max Net Social Payoff }=\quad \sum_{j=1}^{m} \int_{0}^{q_{j}} P_{j}\left(q_{j}\right) d q_{j}-\sum_{i=1}^{n} \int_{0}^{q_{i}} P_{i}\left(q_{i}\right) d q_{i}-\sum_{i=1}^{n} \sum_{j=1}^{m} c_{i j} q_{i j} \\
& \text { s.t. }-\sum_{j=1}^{m} q_{i j} \geq q_{i} \text { for all } i \text { in } n ; \\
& \qquad \sum_{i=1}^{n} q_{i j} \geq q_{j} \quad \text { for all } j \text { in } m ;
\end{aligned}
$$

Samuelson did not advance a formal solution to this maximization problem apart from that by trial and error involving different values of quantities traded that lead to a maximization of the net social pay-off (Samuelson 1952, p292).

The modern formulation of the spatial price equilibrium model, as a maximization problem, is attributed to Samuelson (see Takayama and Judge, 1964, Florian and Los, 1982, 
Nagurney, 1987 and Labys and Yang, 1991). Takayama and Judge (1964) converted the Samuelson-Enke problem into a quadratic programming problem by making assumptions of linear regional supply and demand functions. They went further to devise a simplex algorithm for the solution of this quadratic problem and then proved the existence, uniqueness and regularity of the optimal solution for this problem. The significance of these proofs for uniqueness, existence and regularity means that the Kuhn-Tucker conditions are both necessary and sufficient conditions for the optimization problem. This problem was improved to include the temporal dimension with examples of short-term optimization problems in which inventories could be carried forward to future periods. This became known as the spatial, temporal and price allocation model or STPA (Takayama and Judge, 1971). The advantage of the quadratic model is its ability to endogenously solve for the optimum prices, supply and demand quantities and optimal trade flows between supply and demand regions.

In their 1971 book, Takayama and Judge give further theoretical treatment of the quadratic programming model and demonstrate, among other things, the equivalence of the Kuhn-Tucker conditions to those for a general space-less equilibrium under microeconomic theory. These conditions require, for instance, that: (1) the price differential between the importing and exporting regions be equal to the interregional unit transportation costs; (2) there be a unique regional price; (3) there be no excess demand in any region, and (4) a uniform per unit transportation costs along a transportation leg (Takayama and Judge, 1971, p28). The equivalence of the spatial equilibrium conditions to those for a space-less economy provides the assurance that under the assumption of perfect competition, these will also be Pareto efficient. This book lays the theoretical foundation for spatial price equilibrium models beginning with the simple and static single commodity model to inter-temporal multi-commodity models under 
assumptions that mix both fixed and linear demand and supply functions. In addition, it also develops theoretical treatment of different market conditions and trade policy instruments such as import tariffs, export subsidies, import and export quotas, and ad valorem tariffs. There has been some empirical application of some of these theoretical models and those from the energy and minerals sectors will be discussed under section 3.4 below.

\subsubsection{Variational Inequality Problem}

We begin by re-stating the mathematical formulation of the STPA model in equation 3.3 as that for a cost minimization problem and then show how this can be re-cast as a variational inequality problem. We consider a bipartite spatial price equilibrium model with the following: supply price, $p_{i}=p_{i}\left(s_{i}\right), i=1,2, \ldots m$; demand price, $p_{j}=p_{j}\left(d_{j}\right), j=1,2, \ldots n ; c_{i j}=$ fixed unit cost for transporting a quantity, $q_{i j}$ between an origin-destination pair; $p_{\mathrm{i}}$ is a continuous and increasing monotonic function of $s_{i}$, while $p_{\mathrm{j}}$, is a continuous and decreasing function of $d_{j}$ and with non-negativity conditions on all variables. The optimization form of this problem is then given by:

$$
\begin{gathered}
\min f\left(s_{i}, q_{i j}, d_{j}\right)=\sum_{i} \int_{0}^{s_{i}} p_{i}(x) d x+\sum_{i} \sum_{j} c_{i j} q_{i j}-\sum_{j} \int_{0}^{d_{j}} p_{j}(y) d y \\
\text { s.t. } \quad \sum_{i} q_{i j} \leq s_{i} \\
\sum_{j} q_{i j} \geq d_{j}
\end{gathered}
$$

The constraint conditions for this minimization problem are identical to those for the maximization problem and only repeated here for clarity. The Kuhn-Tucker conditions for this problem are easily derived and represent the spatial price equilibrium conditions for this problem. These conditions are: 


$$
\begin{array}{cccc}
p i(s i)+c i j=0 & \text { if } q_{i j}>0 & \text { and } \quad p i(s i)+c i j \geq 0 & \text { if } q_{i j}=0 \\
\sum_{i} q_{i j}=s_{i} & \text { and } \quad & \sum_{j} q_{i j}=d_{j} &
\end{array}
$$

The approach by Florian and Los (1982) took advantage of the equilibrium conditions in equation 3.10, which define both the optimal supply and demand quantities by substituting for these expressions into the objective function and then solving the resulting modified objective function subject only to non-negativity conditions on the quantity flow, $q_{i j}$. The authors employed the Frank-Wolfe algorithm, which is a linear approximation method for the solution of this convex programming problem. The algorithm computes the descent path and applies a minimization procedure to select the step length for the next iteration.

The equivalence of the spatial price equilibrium problem to both a variational inequality and a nonlinear complementarity problem is attributed separately to Florian and Los (1982) and Friesz, Harker and Tobin (1981) (see Florian and Los, 1982, Friesz, Harker and Tobin, 1984, Nagurney, 1987). The following general definitions of the variational inequality and nonlinear complementarity problems are taken from Friesz, Harker and Tobin (1984, p483) and Nagurney (1999, p6). A variational inequality, VI (F, K) is defined as:

$$
\text { Find } x^{*} \in K \text { such that } \mathrm{F}\left(\mathrm{x}^{*}\right)^{\mathrm{T}} \cdot\left(\mathrm{x}-\mathrm{x}^{*}\right) \geq 0 \mathrm{~A} \times \mathrm{E} \mathrm{K}
$$

where $F(x)=\nabla f$ and $f$ is continuously differentiable with $K$ a closed convex set, while $x$ is a column vector of supply, quantity flows and demand.

The solution to this variational inequality problem also satisfies the spatial equilibrium conditions stated in equations 3.9 and 3.11 above. In the special case where the supply, transportation cost and demand functions are separable, the objective function has a symmetric Jacobian that is also positive definite. This collapses the variational inequality problem into that 
of the standard STPA model shown above in equation 3.6. We can further define the variational inequality in terms of the STPA variables in equation 3.6 above as follows:

$$
\text { Let } \quad x \equiv(s, q, d) \in R^{m+m n+n}
$$

and $\quad F(x)=\nabla f(x)$, then

$$
F(x)^{T} \equiv\left(p_{i}\left(s_{i}\right), c_{i j}, p_{j}\left(d_{j}\right)\right) \text { maps } R^{m+m n+n} \text { into itself. }
$$

Theorem 3.2 (Nagurney, 1999, p96) states that $F(x)$ is monotone, strictly monotone or strongly monotone if and only if $p_{i}\left(s_{i}\right), \mathrm{c}_{\mathrm{ij}}, \mathrm{p}_{\mathrm{j}}\left(\mathrm{d}_{\mathrm{j}}\right)$ are each monotone, strictly monotone or strongly monotone in $s_{i}, q_{i j}$, and $d_{j}$ respectively. The existence of a unique optimal vector $x$ is guaranteed if these strong monotonicity conditions are met. The above optimization can then be transformed into the following variational inequality problem ( see Nagurney, 1999, p99):

Find $\left(s^{*}, q^{*}, d^{*}\right)$ in $K$

$$
\text { such that }\left(p\left(s^{*}\right) \cdot\left(s-s^{*}\right)+c .\left(q-q^{*}\right)-p\left(d^{*}\right) \cdot\left(d-d^{*}\right) \geq 0 \quad \forall(s, q, d) \in K\right.
$$

The spatial price equilibrium optimization problem can also be formulated as non-linear complementarity, NCP, as follows (see Friesz, Harker and Tobin (1984, p483) and Nagurney, 1999, p9).

Find $x^{*} \geq 0$

$$
\text { such that } F\left(x^{*}\right)^{T} \cdot x^{*}=0, F(x) \geq 0, \quad \text { and where } F \text { maps } R^{n} \text { into } R^{n}
$$

The case for a linear complementarity problem is obtained when $\mathrm{F}(\mathrm{x})$ produces an affine mapping, which is defined below:

$$
F(x)=M x+b \text { with } M=n x n \text { and } b=n x l
$$


There have been other demonstrations of the relationship between linear, quadratic, linear complementarity, nonlinear complementarity and the variational inequality problems (see Takayama and Hashimoto 1989, Yang and Labys, 1989, Cottle, Pang and Stone, 1992 and Nagurney, 1987 and 1999). These works demonstrate that the quadratic programming problem is a subset of the linear complementarity problem, which in turn is a subset of the nonlinear complementarity and which, similarly, is a subset of the variational inequality problem. Cottle, Pang and Stone (1992) extensively cover solution algorithms for the linear and nonlinear complementarity problem. In general these algorithms rely on pivoting techniques.

There is a special relationship between the extremal formulation of the Samuelson (1952) and Takayama and Judge (1971) spatial price equilibrium model and linear complementarity programming. Where the supply, transportation and demand functions are separable, the Jacobians of supply, transportation costs and demand are symmetric and the Kuhn-Tucker conditions are equivalent to the linear complementarity conditions (Cottle, Pang and Stone, 1992, Florian and Los, 1982 and Takayama and Judge, 1971). The symmetry condition is met only in cases where there are no market interactions in supply, transportation and demand. In reality, other models such as the Stackelberg and Nash-Cournot competition may explain the market behavior regarding supply and demand while transportation costs may depend on quantity flows between other supply-demand pairs and may also take into consideration the disutility from congestion (see Nagurney and Dong, 2002, Miller, Tobin, and Friesz, 1991, Nagurney, 1987, and Florian and Los, 1982). When the symmetry condition is not met, there is no equivalent optimization of the problem in the standard form of the STPA model. Such a condition requires the use of variational inequality algorithms to solve the spatial price equilibrium model. 
The algorithms for variational inequality problems are intended to convert the problem into a quadratic programming problem with separable supply, transportation cost and demand functions. Nagurney (1987 and 1999) provides descriptions for the linearization methods, namely, the Gauss-Seidel linearization and the projection methods, and the equilibriation algorithms for solution of the linearized or standard quadratic programming problem of Samuelson, Takayama and Judge. The Gauss-Seidel approach is a diagonalization method that can be used to decompose the problem by supply, demand and supply and demand pairs to arrive at the quadratic programming problem (Nagurney, 1987). The projection method also re-defines supply, transportation costs and demand functions such that interactions with other supplydemand pairs are eliminated. In both cases, the resulting problem results in symmetric and positive definite Jacobians for these components, and thus the problem lends itself to solution by quadratic programming solution algorithms such as the Frank-Wolfe algorithm. The author concludes that the combination of the Gauss-Seidel linearization with the equilibration algorithms far out-perform the Frank-Wolfe algorithm in computing time.

Other solution algorithms include the reduced gradient algorithm that improves on that of Frank-Wolfe. This algorithm was developed into the well-known MINOS solver by Murtaugh and Saunders (Friesz, Harker and Tobin, 1984). Even at its early stages, the MINOS algorithm, which was designed for the solution of large and non-linear programming problems with linear and sparse constraints, was quite impressive (Rowse, 1981 p67). Drissi-Kaitouni and Florian (1991) propose a Gauss-Seidel-Newton projection algorithm combined with some restrictions and apply it to the solution of the standard spatial price equilibrium problem. Recent work in spatial price equilibrium modeling is increasingly attempting to make realistic assumptions about the market behavior wherein the interactions that exist between supply and demand markets and 
the demand for transportation also take into account both costs and delivery times (Nagurney and Dong, 2002 and Liu and Boyce, 2002). Some of the latest applications of variational inequality can be found in Nagurney, Ding and Dong (2002), where the authors extend the work in Nagurney and Dong (2002) by analyzing the dynamic adjustment to quantities shipped and demand prices. The authors propose a solution algorithm that is based on the Euler discretization method of the continuous time dynamics (p92) to solve the variational inequality problem. The solution algorithms are coded in the FORTRAN programming language and as yet no commercial solution packages are available.

\subsubsection{Mixed Integer Programming}

The question to ask, naturally, is how to decide on whether to use conventional financial and economic decision methods that rely on single project specific profitability criteria such as net present value and discounted cash flow rate of return on the one hand or a project selection method such as mixed integer programming on the other. Kendrick and Stoutjesdijk (1978) offer as a guide that, where a project exhibits economies of scale, there exists a simultaneous relationship between price and quantity as the scale of operations affects costs and is itself affected by demand, thus linking the marginal costs to the level of demand. This further links project profitability to the scale of operations and makes conventional project evaluation inappropriate in such a case.

A detailed description of the mixed integer programming method is found in Kendrick and Stoutjesdijk (1978) where the authors present it as a tool for selecting industrial projects (project selection model) that show economies of scale and have sectoral interdependencies. Other descriptions of this same model are found in Labys (1999), Labys and Yang (1991) and Labys, Takayama and Uri (1989). The model is multi-period, multi-product, and made up of the 
following components: (1) the transport problem, (2) production costs, (3) a process model and (4) an investment model. The objective function is to minimize discounted total costs, now defined to include all costs, such as those of production, transportation of all inputs and outputs, annualized costs of capital, and operation and maintenance on new units of equipment, over a given planning horizon and for a desired level of the discount rate. The constraints are similar to those for spatial equilibrium models but now augmented with those for material balance at the process level, intermediate product stage, and a binary variable for whether or not an investment in additional or new capacity is made. The model also deals with both intermediate and final products with the latter sold both locally and in export markets. The various components of the model lead to its ability to determine optimal values for location of plant, size of plant, time phasing of new or additional capacity, process technology to be used, and product mix. The production process is disaggregated to the process level, which requires that input-output coefficients for all processes and over all time periods be known in advance. The data requirements for the full project selection model tends to make it difficult to apply in regions where there may be a paucity of data (Kendrick and Stoutjesdijk, 1978, p80).

\subsection{Model Applications}

The discussion begins with linear programming models of coal supply, transportation and demand in the United States and then progresses to models used to study the international trade in steam coal and, finally, provides examples of model applications for mixed integer programming. There has been a great interest in modeling the energy-economy interactions in the United States as is evident from models such as the Federal Energy Administration's Project Independent Evaluation System (PIES) (see MIT Energy Laboratory Policy Study Group, 1975 
and Hausmann, 1975). PIES is a large-scale model with sub-models for fuel specific supply, demand and transportation. Gabriel, Kydes and Whitman (1999) provide a brief chronological development of this large- scale model into the Intermediate Future Forecasting System (IFFS) and finally into the current National Energy Modeling System (NEMS). Instead of reviewing these large-scale energy economy models, only the development of the coal sub-model in its use to forecast U.S. supply, demand, and the distribution of the coal trade will be reviewed here. The development of models for supply, transportation and demand for coal in the United States has been dominated by projects funded by agencies of the U.S. government, most notably, the Energy Information Administration. Some of these models are: (1) the National Coal Model (EIA, 1983), (2) Coal Supply and Transportation Model (EIA, 1983), (3) Argonne Coal Market (ACM) model (Macal, 1979), (4) The International Coal Trade Model (EIA, 1982) and (5) the World Steam Coal Trade model by Kolstad, Abbey and Bivins (1982). Interested readers may consult the references provided for details on these models. There have also been independent studies on both the regional and international steam coal trade such as those by Labys and Yang (1980), Zimmerman (1981), and, Senf and Fruin (1986). A review of the application of spatial price equilibrium models in the mineral and energy sectors can be found in Labys, Takayama and Uri (1989), while the use of spatial equilibrium models in the 1990's can be found in and Labys and Yang (1991) and van den Burgh, Nijkamp and Rietveld (1995).

One of the major shortcomings in the coal supply and demand module in the PIES model was that the production mix from the U.S. supply regions was set based on professional judgment as opposed to a cost minimization criterion as would be the case in a linear programming problem. The resulting regional supply curves were step functions reflecting the regional minimum acceptable selling price (MASP) for a mine life of twenty years and a 
discount rate of 15\% (Hausmann, 1975, p27). There was therefore need for a model that would endogenize the supply function. One such model is that by Zimmerman (1981), which is a linear programming model that minimizes the delivered cost of coal to end-users in the electric utility and non-electric user industries. The model has the usual components of production, transportation and demand. The production component determines long run marginal costs for coal supply for both underground and surface mines. These costs are derived from regressions of costs on the production rate and geological properties of the coal (coal thickness and depth of overburden) and represent the minimum price for bringing such coal reserves into production. The coal reserves are then classified according to geological characteristics and as costs are defined in terms of these, a cumulative cost curve is constructed. This approach has not found widespread use in models at the EIA where the coal supply model used is similar to that used in the National Coal Model (Wood and Mason, 1982).

The demand for coal is a derived demand arising out of that for electricity. The method of estimation is that used in the regionalized energy model (REM) by Baughman, Joskow and Kamat (Chapter 4, 1979). The approach uses a two-step procedure in which energy consumption in both the residential-commercial and industrial sectors is first estimated using a flowadjustment model. A fuel choice demand model is then used to determine the fuel split among gas, coal and natural gas to meet this energy demand. This latter estimation of fuel proportions is achieved through a multinomial logit model.

The transportation cost equation for this model expresses rate per ton as a linear function of hauling distance, quantity hauled, difference between the price of natural gas and the f.o.b. coal price, loading plus unloading time and a dummy variable for the eastern region. Elements of this model appear in some of the EIA models, which are described next. 
The National Coal Model came out in 1983 and it is a linear programming model that connects the coal supply and the electric utility industries. The model is long term and static. The objective function minimizes the total costs, defined to include, costs of coal production, transportation, and electricity generation and distribution. The f.o.b., mine gate, price of coal is estimated from the resource allocation and mine costing (RAMC) model. This essentially assigns long run marginal cost of production over a given life of mine and for existing coal reserves that are not committed and then creates a stepwise supply function for a given case year. This stepwise function is linearized to obtain a marginal supply function for an increment in output as opposed to the cumulative quantity approach used by Zimmerman. The linearization avoids lumpy additions that exceed the typical mine size (Macal, 1979). A further economic reasoning is that the price would have to be at least greater than these long run marginal costs for these reserves to be exploited. This price is then the minimum acceptable selling price, MASP, as previously defined. The exploitation of these reserves then proceeds sequentially starting with those with the lowest cost of production.

The exogenous variables to the National Coal Model are transportation rates and coal demands. The RAMC model determines the MASP for all regions whose coals become part of the solution depending on their satisfaction of the objective function of cost minimization. The 1983 Coal Supply and Transportation Model extends this model into a nonlinear programming model. The extension is in the formulation of transport costs as a quadratic function of the coal quantity traded.

The National Coal Model and the Coal Supply and Transportation Model were used to answer "what if" questions on actions that impact on the supply and demand for coal in the United States. These actions may be: changing government regulation, changing structure of the 
coal industry, and technological improvements, and any other actions that affect the demand for electricity, and hence that of coal. The models database has some 40 coal types, 5 heat content levels, 8 sulfur content levels, 31 supply regions, 44 demand regions, 9 mine types with 5 and 4 sub-classes for open pit and underground mining respectively and reserve information (National Coal Model, 1982).

Some applications of nonlinear programming models in the U.S. coal industry are the Argonne Coal Market model by Macal (1979) and the quadratic model of the Appalachian steam coal trade by Labys and Yang (1980). The Argonne Coal Market model differs from those by Zimmerman and the National Coal Model in that it has a quadratic objective function. This is in the supply function, which is expressed as a linear function of production. The objective function minimizes the cost of production, transportation and emission reduction. The demand is determined exogenously from the regional electricity model, just as in the National Coal Model and that by Zimmerman. The model was used to test the impact of the 1977 Clean Air Act Amendment's best available control technology on the interregional coal trade. At the time the target reduction levels had not yet been set, so this model evaluated the impact of several scenarios regarding these and demonstrated that in the long run, there was to be a shift in coal supply that favored sources in the west central region of the United States.

In their application of quadratic programming models for the regional trade in coal, Labys and Yang (1980) used this approach to model the Appalachian steam coal trade and concluded that the optimal trade pattern was in line with what prevailed in reality. They also found that their regional quadratic programming model could be used as policy tool to determine the optimal levels of policy intervention, for instance, taxation, and the impact of exogenous shocks such as transportation cost increases, on the likely magnitude of the welfare changes. The 
quadratic programming model leads readily to the determination of the components of this welfare change in terms of consumer (electric utilities) and producer (coal producers) surpluses.

At the international coal trade level, there has been application of both linear and nonlinear programming models. The International Coal Trade Model's (ICTM) spatial price equilibrating model is described in a publication by the U.S. Department of Energy (September, 1982) as a medium to long-term multi-product (more than one coal type) quadratic programming model that was used to project the likely distribution of the international trade in coal for three coal types (premium or coking coal, low sulfur steam and high sulfur steam). The model relies on sub-models that produce projections about regional supply, sea transportation and demand, and then applies the spatial price-equilibrating sub-model based on both elastic demand and supply relationships for the OECD countries and inelastic supply and demands in other markets for a projected base year to obtain a solution.

The ICTM model has 18 supply and 6 demand regions with nodes placed at exit and entry ports for the coal respectively for these regions. It therefore deals only with the sea borne spatial distribution of the international coal trade. The model could be used to answer comparative static questions on the likely magnitude and direction of trade that would result from regional policies that affect demand, factor input costs in the coal supply regions or costs for both land and sea transportation. It requires detailed supply functions from engineering cost estimates and where these are not available, fixed estimates of the likely supply are estimated outside the model. The demand component is treated a little differently from the usual econometric demand function for each region and instead, a regional condensed import demand equation is used ${ }^{8}$. Two models released at about the same time as the ICTM and both dealing

\footnotetext{
${ }^{8}$ See Description of the International Coal Trade Model (September 1982). The import coal demand for the OECD region is given by the following equation (equation 1, p29):
} 
with international trade in steam coal are those by Dutton (July, 1982) and Kolstad, Abbey and Bivins (January, 1983).

The model by Dutton, which is named an Allocation Model, maximizes net social pay-off and is as defined below (see Dutton, 1982, p 88):

$$
\operatorname{Max} \mathrm{W}_{\mathrm{t}}=-\sum_{i=1}^{n}\left\{S_{i}\left(X_{i t-1}+\sum_{T=t-1}^{t} X_{i T}\right) X_{i t}\right\}-\sum_{i=1}^{n} \sum_{j=1}^{m} C_{i j} X_{i j}
$$

s.t. $\quad \sum_{i=1}^{n} K_{i} X_{i j t} \geq Y_{j t}$;

where $K_{i}$ is calorific value (GJ / metric ton) of region $i$ coal;

$$
\sum_{j=1}^{m} X_{i j t} \leq X_{i t}-Y_{i t}
$$

where $X_{i t}$ and $Y_{i t}$ are supply and demand in region i for year t

$$
\sum_{i=1}^{n} 2 S C_{i} X_{i j t} \leq S E_{j} Y_{j t}
$$

where $S C_{i}$ is sulfur content for coal from region $\mathrm{i}$;

$$
\sum_{i=1}^{n}\left(S P_{j}-S G\right) X_{i j} \geq 0
$$

where $S P_{j}$ is upper limit for coal burned in region $\mathrm{j}$.

and where also: $\quad X_{i j t}=$ quantity shipped from supply I to demand $\mathrm{j}$ in year $\mathrm{t}$.

$S_{i}()=$. linearized marginal cost function from the cumulative cost curve.

$D_{c}^{\prime}(t)=D_{c}^{r}(t) *\left[P_{c}^{\prime}(t) / P^{r}(t)\right]^{G}$

where: $\quad D_{c}^{\prime}(t)=$ the computed base year value of demand for coal quality, $c$

$\mathrm{P}_{\mathrm{c}}^{\prime}(\mathrm{t}) \quad=$ current delivered price of coal quality, $\mathrm{c}$, in the base year, $\mathrm{t}$ and

$\mathrm{r} \quad=$ the values of demand and price at the reference coal type, and

$\mathrm{G} \quad=$ import elasticity of demand. 
This model differs from the ICTM model in two respects. First, it is a short term model, meaning that it can be used to model the impact of increases in prices of competing fuels for generation such as oil and gas which will determine what units are deployed for generation. The second difference is that it deals only with steam coal while retaining the constraint conditions for levels of sulfur dioxide but without allowing for blending at the demand point to achieve these constraint conditions. The model differs from the standard STPA with fixed demand only in the supply function, which is derived by a linearization of the regional (country level) cumulative cost curve.

The technical relationship between coal output and the driving variables is estimated by regressions of output from three different mining methods on geological characteristics of the coal such as thickness, depth of overburden cover and technical factors, such as face length and manning levels. This cumulative cost curve is a schedule based on extraction of the cheapest resources first, which means that the graph will generally trend upward or it can be viewed as generally monotonic. The mechanics of the linearization is to graphically approximate the total cost function between two adjacent output levels corresponding to the desired time periods by a straight line. It is this approximated linear marginal cost function that is then used in the STPA model in place of the usual econometrically estimated supply function. Other assumptions of the model are in-elastic demand and constant long run marginal costs of maritime transportation. Like the other models of this type, this model is also used to conduct sensitivity analysis by varying the level of future coal demand and then observing the resulting optimal values for supply prices, quantities and trade flows (p. 87).

The allocation model has 9 supply and demand regions. Projections for the allocation of the world trade in steam coal from this model and for the period 1985-2000 show Australia 
supplying East Asian markets except Japan, South Africa supplying the market in Western Europe and the U.S. supplying steam coal to Canada while Japan is supplied by a combination of sources that include the United States, South Africa and Canada (Dutton, 1982, p99).

In their model of the international steam coal trade, which they named the World Coal Trade model, Kolstad, Abbey and Bivins (1982) state as their primary objective, the need to have a forecasting model for the international steam coal trade and also a tool that could be used to test U.S. government policy on a variety of issues such as the elimination of import tariffs and quotas, applying domestic subsidies to investments to deepen export ports to handle larger vessels and any other legislation that would place US coal at an advantage in this trade. The authors depart from the STPA model and instead adopt a general equilibrium model that assumes an n-country oligopoly of both consumers and producers that maximizes the objective functions of representative agents subject to feasible physical constraints. The optimality conditions for consumer, producer and tax revenue maximization conditions are repeated here as follows (see Kolstad, Abbey and Bivins, 1983 p44-46): The first order conditions for utility firms (consumers) are:

$$
u_{j t}=\left\{\sum_{k}^{K} \sum_{i}^{n} a_{i k} q_{i j k t}-d_{j t}\left(p_{j t}\right)\right\} \text { and } u_{j t} * p_{j t}=0 \text {; where } q_{i j k t} \text { is coal from I to } j
$$

In the case of producers, their first order conditions for profit maximization are:

$$
w_{i k t}=\left\{c_{i k t}\left(s_{i k t}\right)-p_{i k t}\right\} \text { and } w_{i k t} * s_{i k t}=0 ;
$$

where $p_{i k t}$ supply price for coal type $\mathrm{k}$

$$
v_{i k t}=s_{i k t}-\sum_{j=1}^{m} q_{i j k t} \geq 0 \text { and } \quad v_{i k t} * p_{i k t}=0
$$

where $c_{i k t}\left(s_{i k t}\right)$ is marginal cost of supply. 
The objective function for governments is the maximization of the present value of export tax revenues and is given in the equations below:

$$
\operatorname{Re}^{\text {venue }_{i}}=\sum_{t}(1+\rho)^{-t} \sum_{k} \sum_{j} \pi_{i j k t} * q_{i j k t} ;
$$

where $\pi_{i j k t}$ is unit tax on coal type $\mathrm{k}$ shipped from I to $\mathrm{j}$

$$
\begin{aligned}
& \text { F.O.C. } y_{i j k t}=\sum_{\bar{t}}(1+\rho)^{-\bar{t}} \sum_{k} \pi_{i j \bar{k} t} * \frac{\partial q_{i j \bar{k}}}{\partial \pi_{i j k t}} \geq 0 \text { and } y_{i j k t} * \pi_{i j k t}=0 \\
& \text { and where } \frac{\partial q_{i j \bar{k} \bar{t}}}{\partial \pi_{i j k t}}=\frac{1}{\left(1+r_{i j}\right) \alpha_{i k} \alpha_{i \bar{k}}}\left(\frac{\partial d_{j \bar{t}}}{\partial p_{j t}}\right)
\end{aligned}
$$

which for $r_{i j}=0$ under Cournot-Nash, simplifies to:

$$
y_{i j k t}=-\left\{q_{i j k t}+d_{j t}^{\prime} \frac{\pi_{i j k t}}{\left(\alpha_{i k}\right)^{2}}\right\} \geq 0 \text { and } y_{i j k t} * \pi_{i j k t}=0
$$

The spatial price efficiency conditions are:

$$
z_{i j k t}=\left(p_{i k t}+\tau_{i j t}+\pi_{i j k t}-\alpha_{i k} p_{j t}\right) \geq 0 \text { and } z_{i j k t} * q_{i j k t}=0
$$

This model is similar to the ICTM in many respects, such as supply, transportation and demand components, but differs in the market conduct assumption. For the supply component, the over-land transportation costs are added to the mine-mouth unit production costs to arrive at a price free on board port of export. It is these price and quantity figures that are fitted to obtain a marginal cost of supply curve for a region (see Kolstad, Abbey and Bivins, 1982, Table A-II, p56). On the demand side, the authors used projected price and quantity data from forecasts by the U.S. Department of Energy to fit a constant elasticity of demand function for those regions with elastic demand and relied on expert opinion for other regions where demand is fixed. The transportation cost component was estimated from cost functions that are specific to size of 
colliers. Unlike in the STPA model where the objective function is the maximization of net social pay-off, this model includes the following specific steps: 1) defining an objective and strategy for each agent, 2) defining a constraint set for each agent and 3) a simultaneous solution for equilibrium prices and quantities for all agents (p40). The advantage of this general equilibrium approach is that it embodies the full range of possibilities for market conduct which can be realized by the type of assumptions made about the $i^{\text {th }}$ oligopolist's conjectural variation, which in the case of a coal producer government, is its perception of how other governments will respond to its change in coal exports. The equations used in this model are derived from the following: consumer utility maximizing conditions; profit maximizing conditions for the producers; tax revenue maximizing conditions for the governments, and price efficiency conditions between the regions. The authors use the world coal trade model to test the likely market structure for the international steam coal trade. They make the basic assumption of a Cournot-Nash competition, which means that the $i^{\text {th }}$ country's conjectural variation is zero and further that countries take the level of exports from their competitors as fixed when deciding on their own export tax levels. The choice variable for governments is the export tax, which is chosen to maximize revenues. The market conduct assumptions are: 1) a South African monopoly with all other producers in a competitive fringe; 2) a non-cooperative duopoly among Australian and South African producers while all other countries face perfect competition conditions and 3) all producers face perfect competition. The model assumes imperfect competition among utility firms in the importing countries.

The model results are for the projected steam coal trade in 1990 and show that the cases for a South African monopoly and that for pure competition fail to include both the United States and Canada in the solution and it is only in the non-cooperative duopoly case between South 
Africa and Australia that both of the North American producers enter into solution to reproduce market shares that are close to those observed in reality. The results for the pure competition case are similar to those by Dutton (1982). The authors acknowledge the model to have a weakness in that it cannot be applied to answer short to medium term policy issues just like the ICTM model and is therefore used to project long run equilibrium in the international steam coal trade. The other weakness is that it is not an econometric model and therefore fails to account for the substitution that exists between coal, oil and natural gas in their use as fuels for generating electricity (Kolstad, Abbey and Bivins, 1982, p51).

The solution of quadratic models is now readily achieved through the use of software such as GAMS, which have options for solving non-linear problems. The world coal trade model by Kolstad, Abbey and Bivins was solved using a linear complementarity programming algorithm.

In their study, Senf and Fruin (1986) use a linear programming model to determine the cost competitiveness of two Great Lakes ports, port Duluth in Minnesota and port Superior in Wisconsin, for exporting coal from Montana and Wyoming to the world steam coal markets. The authors employ a model in which the objective function is to minimize the total delivered cost of coal under two scenarios about the level of world coal demand and for three case years, 1985, 1990 and 2000. The linear programming model used has 19 coal supply regions in thirteen countries and 25 coal importing countries. There are also 65 export and 52 import ports in the model. The authors conclude that under the low demand scenario and by the case year 2000 demand projections, South Africa and Australia would account for about half the world steam coal trade while a quarter of this trade would be captured by emerging export coal countries such as China, Colombia and Canada (Senf and Fruin, 1986, p72). 
The above models on the international trade in steam coal consistently show supply from South Africa as a part of the projected steam coal trade. More recent studies (USBM, 1990 and 1993, Mining Engineering, April 2001 p11) still place South African coal producers at a cost advantage ahead of Australia and the United States but behind Indonesia and Colombia.

Two exact applications of the project selection model of Kendrick and Stoutjesdijk can be found in Dammert (in Labys, Nadiri and Nunez del Arco, 1980) where it was used to study investments in Latin America's copper sector in competition with the rest of the world and also in Suh (1981), who applied it to the Korean oil refining and petrochemicals industry. The model by Dammert considered all operational stages from mining and up to semi-manufacturing of copper for final use and thus has both scale economies and interdependence between product stages. The model was able to provide intuitive results that showed that mining development would occur in regions of high ore grades while the location of semi-manufacturing depended more on the costs of transportation and labor (Dammert, 1980, p82).

Suh used the model to study investment planning in the Korean oil refining and petrochemical industries. He specifically wanted to determine the time phasing of new or expansion capacity and also to explore ways of dealing with stricter environmental regulation to control pollution. This application has both the economies of scale and interdependence properties between the oil refining and petro-chemical industries. The author concludes, among other things, that because these two industries were studied together under this model, the resulting high inter-industry business reduced costs and thus the economies of scale became the most important factor ahead of transportation costs in the selection of sites for new or expansion capacity (Suh, 1981, p308). 
Another model that used mixed integer programming is that by Kang (1981) in which the objective was to determine the optimal time phasing, location and size of electricity generating plants to meet Korea's demand for electricity under conditions of uncertainty of either reliability or expansion capacity. The presence of uncertainty in the reliability constraint introduced nonlinearity and therefore ruled out the direct application of the linear mixed integer programming algorithm but the author was able to solve the model by a combination of a nonlinear programming code and branch-and-bound algorithm to arrive at integer solutions. The author concludes that uncertainty in either the level of reliability or expansion capacity significantly affects the investment planning decision.

There have been two recent applications of mixed integer programming modeling in the coal trade, one by Lai and Chen (1996), and the other by Suwala and Labys (1998). Lai and Chen use a mixed integer programming model to minimize the cost of imported coal for the Taiwan power company subject to environmental constraints that are met through blending of coals from the company's coal yards. The authors conclude that their model can be used to plan future coal imports by source to minimize investment costs on blending facilities.

Suwala and Labys apply mixed integer programming to model the impact of structural adjustments on the Polish coal industry. These changes arose as a result of the country's movement towards a market economy with its attendant requirement for competition and market determined product prices. The objective of the study was to evaluate policies to restructure the Polish coal industry. The study adopts a two-model approach in which the first model defines an objective function in a manner much similar to the project selection model of Kendrick and Stoutjesdijk, where discounted costs are minimized. These costs are wide ranging and include costs of imported coal, mine closure costs and environmental costs. This model identifies mines 
at which investments in capacity can be made and those that need to be shutdown. The second model uses the supply functions from the first model to identify the spatial distribution of the coal trade using the STPA model in which the objective function is the maximization of net social pay-off. The study uses a highly disaggregated approach with supply being at the mine level and demand at the sector level, for instance, power generation, householders and steel plants (coke ovens). The authors conclude that their model succeeds in producing results that coincide with what is expected in reality. Some of these realities include the fact that as long as local coal is more expensive than imported coal, then the share of the latter will continue to grow and that the impact of stricter environmental standards has not been a major factor in the closure of low quality coal mines.

In their U.S. Regional Ferrous Scrap Model, Giarratani, Gruver and Richmond (2002) model the spatial behavior of the US ferrous scrap industry using a static, non-linear programming model that accounts for the substitution that exists between the two grades of scrap. The model is highly disaggregated, dealing with supplies at the county level and demand at the steel mill level. The model consists of 1212 counties and 240 steel mills. The non-linearity in the model derives from the definition of a supplier's market share as a logistic function of the normalized f.o.b. price of scrap. This approach makes the supplier's market share to be endogenous to the model and to depend on the size of the county and the netted back mill prices to arrive at the f.o.b. price at the county level. The authors go further to provide a solution algorithm for their model, which basically is an iteration procedure that begins with the selection of the mill price, calculation of the total demand, suppliers' share, and total supply. The model then checks for market clearance by comparing total supply to total demand and adjusts excess 
demand to pick a new mill price to re-start the iteration. This model has been able to correctly simulate some of the steel mill prices and the flow of trade in US ferrous scrap.

\subsection{Conclusions}

This chapter reviewed the theoretical basis for spatial price equilibrium models and provided examples of their applications in the minerals and energy sectors. These models have been applied as a medium to long term tool to determine the distribution of the steam coal trade for a given base year. In many cases, demand and supply functions have been determined outside of these models. The extension of these models to incorporate mixed integer programming has resulted in these models being used to determine the optimal investment in capacity in addition to its other uses in selecting plant locations and their capacities. The purposes to which these models have been put include the analysis of government policies regarding energy and environmental policy issues, the determination of the relative competitiveness of countries in the world steam coal trade and as a tool for projecting the growth in the world steam coal trade. 


\section{CHAPTER 4}

\section{MODELING FRAMEWORK}

\subsection{Introduction}

This chapter provides the following: a description of the proposed model of the world steam coal trade; the behavioral assumptions for firms involved in this trade; the criterion used for selecting countries to be included in the model, and the components of the model, which includes the mathematical formulation of the model and the derivation of the elements of the objective function. The modeling framework proceeds in two stages. The first stage is the estimation of the country supply, demand and long run marginal cost functions, with the latter estimated only for net exporters in the model. This modeling is done within the structure of a non-spatial econometric model of the world steam coal trade by adopting approaches by Labson (1997) and Meyers, Devados and Helmar (1989). In the second stage, the forecast domestic and import demand quantities from the first stage are exogenous to the spatial and dynamic optimization model which, due to the inclusion of capital expenditure costs, long run marginal costs, rail transportation costs and maritime transportation costs, is capable of solving for the following: capacity additions in the exporting countries of the model, supply prices, domestic supply in the net exporting countries in the model, and trade flows over time and space.

A simple multi-period transport model of the world steam coal trade precedes the spatial and dynamic optimization model. The purpose of the transport model is to determine whether coal from Botswana can be competitively delivered to markets in Western Europe and Asia when only the rail and maritime transportation costs are considered. A detailed description of this problem and its results and their interpretation are presented in Appendix G. The advantage from this approach is that a multi-period linear programming approach can easily give some insights 
into the likely distribution of this trade in time as a result of declining costs of rail and maritime transport. The proposed model is discussed next.

\subsection{The Proposed Model}

There is a need for the Botswana government to employ a modeling approach that identifies factors concerning the exploitation of the country's coal deposits and to provide useful policy insights regarding future developments of the coal industry. This model would indicate whether or not conditions that have been identified in the past as preventing the development of the country's coal deposits continue to exist or have diminished. Such a model would also assist in policy decisions with respect to the provision of railway infrastructure as any new mine development is likely to require a rail link to existing railway lines in South Africa or Namibia. The objectives of this model are as follows:

1. To apply the model to forecast the optimal size of export mine located on the Mmamabula coalfield in Botswana and the land routes for these exports for the years 2005 and 2010 from a base year of 2000 ;

2. To conduct sensitivity analysis on the optimal forecast values to determine their responsiveness to changes in capital costs for mine development, rail transportation costs, and changes in demand in the net importing countries of the model;

3. To validate the model by simulating the world steam coal trade over the period 1995 to 2000 beginning from a base year of 1990 and then to determine whether Botswana's coal would have been competitive in the world steam coal markets in the past, and

4. To apply an experimental design approach to determine the significance of the effects of cost factors to be minimized in the optimization model, which consist of capital costs, variable supply costs, rail transportation and maritime transportation costs on changes in Botswana's steam coal exports.

In order to build this model the following are required: a model optimization framework, capital expenditure cost equations for mine development, forecast quantities of domestic steam coal demand in the net exporting countries and import demand in the net importing countries, regressions for long run marginal cost functions in the net exporting countries, rail transportation 
costs and sea freight costs. The forecast maritime transportation costs along each major trading route are obtained by time series methods while those for rail transportation are projections. The regressions for capital expenditure are exogenous to this model. This leaves us with the main task of forecasting domestic and import demands for steam coal for countries of the model. It is usual in models of this type to apply a linear marginal cost function that is derived from engineering cost data but in our case the lack of this data leads us to employ a marginal cost function that is derived from an econometric model of the long run marginal cost function based on publicly available information relevant to the coal industries of countries included in the model.

\subsection{Assumptions About the World Steam Coal Trade}

The following main assumptions about the market behavior of the world steam coal trade are made:

1. All net exporting countries in the model start from a base year supply capacity of 2000 and can only increase supply by carrying out capital expenditure programs for capacity additions. The capacity added in this way is only available at five-year intervals beginning with the first expansion period of 2005 to 2010.

2. We assume a perfectly competitive market in which the net exporters in the model respond to increases in exogenous steam coal demand by supplying steam coal after the necessary capital expenditure on capacity has been made. This is done through a cost minimization decision criterion in which the sum of the discounted capital costs, variable supply costs, rail transportation costs and maritime transportation costs are minimized over a give time horizon.

3. Each of the net exporters in the model has a minimum acceptable selling price (MASP) that is represented by its long run marginal cost function. The MASP is transmitted through to market prices in the markets of Western Europe and Asia after unit rail and maritime transportation costs have been added, and

4. Finally, we assume an increasing cost industry to reflect the positive slope of the steam coal industry aggregate supply curve and also to accommodate the non-negativity requirement on the slope coefficient for the long run marginal cost functions for each individual producer. 


\subsection{The Choice of Countries for the Model}

The model divides the global steam coal trade into four geographic areas, North America, Southern Africa, Western Europe and Asia-Pacific, which includes Australia (see Figure 4.1 below). The Western European region is further divided at the country level to focus on the countries that have featured consistently among the major steam coal importers in the region. These are: Belgium, Germany, France, Italy, the Netherlands, Spain and the United Kingdom. In the North American region, only the United States is included as it is generally taken to be the marginal producer of steam coal for exports due to its high mine-mouth production costs (e.g. see Abbey and Kolstad, 1983, and USBM, 1993). In the main, the countries selected represent a substantial portion of the export and import share of the seaborne steam coal trade (e.g. see Dutton, 1982, the US Department of Energy's International Coal Trade Model, 1982 and Senf and Fruin, 1986).

For a study such as this one, it would have been useful to include the emerging exporters such as Colombia, Indonesia and China but it was beyond our capacity to obtain meaningful data for these countries. The export growth potential of these countries is widely reported in mining industry journals (for instance Coal Age, Mining Journal and Mining Annual Review). These reports project that even though China is becoming the marginal supplier to the world steam coal trade, it does not pose a threat to Australia's ranking as the leading steam coal exporter to markets in Asia. The reason cited for this is the concern about quality and security of supply, issues that favor Australia over China. In the Asian market, Australia's steam coal exports are projected to grow further in response to growing demand in the region. China would also need to invest in infrastructure for the domestic distribution of coal to meet rising domestic demand as well as exports. The political uncertainty in Indonesia, coupled with increasing domestic 
demand, creates an uncertain scenario for the growth of Indonesia's exports. In the region, the continued growth in electricity demand is credited for the growth in steam coal production and exports. In South America, Colombia's exports are projected to double from their current levels of about 37 million metric tons to 70.0 million metric tons by 2010 . Colombia competes against South Africa for market share in the U.S. Gulf states as well as in Western Europe. The latter is also projected to increase its exports to 80 million metric tons by 2010 .

Later in this study (Table 6.4), we provide the relative competitiveness of f.o.b. prices for steam coal for the year 2000 and in U.S. Dollars per mtce. This ranking is as follows: 1) Indonesia (\$24.22), South Africa (\$26.84), Colombia (\$28.10), Botswana (\$28.89), Australia (\$31.10) and the United States (\$38.08). In the Western European steam coal markets, coal from South Africa enjoys a cost advantage over Colombian coal (South African Coal Report, 2002). This model rationally excludes some exporters and importers and these are dealt with as the rest of the world. The question to ask, then, is whether or not Botswana coal can compete favorably against coals from Australia, South Africa and the United States in Western Europe and Asia?

We select model mines and their locations in each of the geographic regions. For the Southern Africa region, coal exports from South Africa derive from Witbank and are exported through Richards Bay, while those from Botswana are from Mmamabula and are exported through Richards Bay (and other possible routes to seaports at Matola, in Mozambique and Walvis Bay in Namibia). For the United States, the model mine is assumed to be in Central Appalachia and exporting through the Hampton Roads port in Virginia. This assumption is valid and does not place exports from the United States at a disadvantage, as there has been consistently a premium in the range $\$ 0.50$ - $\$ 2.50$ per long ton of coal exported from U.S. Gulf ports destined for markets in Western Europe (International Coal Review Monthly). For 
Australia, we make the assumption that end user prices and f.o.b. for steam are the same. In line with the maritime transportation costs data referencing, the export port is assumed to be mid-way between Gladstone and New Castle (IEA/OECD, 1984 and International Coal Review Monthly). 


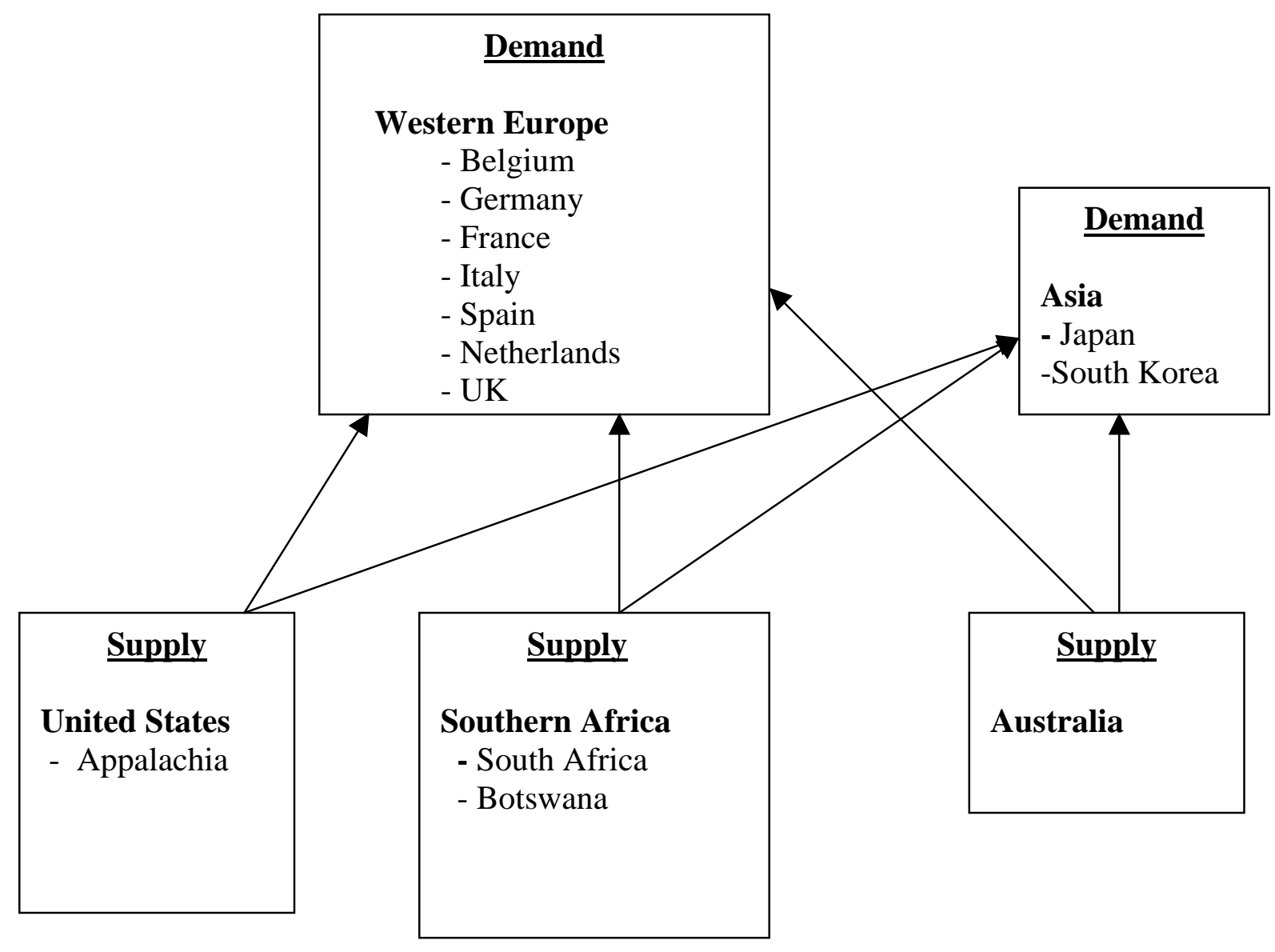

Figure 4.1 The Seaborne Steam Coal Trade Among Countries of Supply and Demand 
Table 4.1 Steam Coal Supply and Demand Patterns for Countries of the Model (000's metric tons)

\begin{tabular}{|c|c|c|c|c|c|c|c|c|c|}
\hline Country & 1980 & 1985 & 1990 & 1995 & 1996 & 1997 & 1998 & 1999 & 2000 \\
\hline \multicolumn{10}{|l|}{ Japan } \\
\hline Demand & 17496 & 35935 & 45044 & 63829 & 67073 & 69469 & 69998 & 74315 & 83391 \\
\hline Supply & 11084 & 12460 & 8152 & 6261 & 6480 & 4275 & 3665 & 3906 & 3148 \\
\hline Imports & 6412 & 23475 & 36892 & 57568 & 60593 & 65194 & 66333 & 70409 & 80243 \\
\hline South Korea & 4927 & 11300 & 11500 & 26734 & 27600 & 34652 & 35607 & 37342 & 42777 \\
\hline \multicolumn{10}{|l|}{ Belgium } \\
\hline Demand & 8994 & 7490 & 8996 & 7657 & 7541 & 7608 & 7480 & 6081 & 7004 \\
\hline Supply & 3982 & 4182 & 2357 & 637 & 560 & 427 & 312 & 364 & 375 \\
\hline Imports & 5012 & 3308 & 6639 & 7020 & 6981 & 7181 & 7168 & 5717 & 6629 \\
\hline \multicolumn{10}{|l|}{ Germany } \\
\hline Demand & 46092 & 45641 & 44749 & 40231 & 44845 & 42660 & 42558 & 39839 & 37890 \\
\hline Supply & 38456 & 37448 & 31976 & 27172 & 24385 & 24184 & 21708 & 20027 & 18515 \\
\hline Imports & 7636 & 8193 & 12773 & 13059 & 20460 & 18476 & 20850 & 19812 & 19375 \\
\hline \multicolumn{10}{|l|}{ France } \\
\hline Demand & 33510 & 25175 & 19122 & 14872 & 16371 & 13440 & 17561 & 15167 & 15940 \\
\hline Supply & 16076 & 13667 & 9378 & 8056 & 7755 & 6286 & 5375 & 5130 & 4442 \\
\hline Imports & 17434 & 11508 & 9744 & 6816 & 8616 & 7154 & 12186 & 10037 & 11498 \\
\hline Italy & 5820 & 11965 & 11797 & 11433 & 9971 & 8439 & 9436 & 10430 & 11817 \\
\hline Netherlands & 3757 & 6879 & 12837 & 12234 & 11946 & 14749 & 16856 & 14532 & 17431 \\
\hline \multicolumn{10}{|l|}{ Spain } \\
\hline Demand & 11124 & 20290 & 21861 & 24331 & 19997 & 24525 & 23477 & 28092 & 28589 \\
\hline Supply & 11505 & 15184 & 14603 & 13652 & 13674 & 13804 & 12300 & 11772 & 11317 \\
\hline Imports & -381 & 5106 & 7258 & 10679 & 6323 & 10721 & 11177 & 16320 & 17272 \\
\hline \multicolumn{10}{|l|}{ UK } \\
\hline Demand & 111982 & 94667 & 98236 & 70856 & 62040 & 53882 & 53624 & 47544 & 50846 \\
\hline Supply & 120047 & 91438 & 92797 & 53956 & 49379 & 47419 & 40589 & 36809 & 31704 \\
\hline Imports & -8065 & 3229 & 5439 & 16900 & 12661 & 6463 & 13035 & 10735 & 19142 \\
\hline Total Imports & 42552 & 84963 & 114879 & 162443 & 165151 & 173029 & 192648 & 195334 & 226184 \\
\hline \multicolumn{10}{|l|}{ Australia } \\
\hline Demand & 27373 & 34504 & 43367 & 45865 & 50616 & 51486 & 53616 & 55267 & 58808 \\
\hline Supply & 29646 & 61571 & 93564 & 111352 & 110943 & 116794 & 131827 & 125904 & 133970 \\
\hline Exports & 2273 & 27067 & 50197 & 65487 & 60327 & 65308 & 78211 & 70637 & 75162 \\
\hline \multicolumn{10}{|l|}{ S. Africa } \\
\hline Demand & 79803 & 119870 & 119225 & 142985 & 145442 & 149781 & 147288 & 154017 & 150692 \\
\hline Supply & 104515 & 162358 & 165492 & 202351 & 202829 & 216426 & 220806 & 221928 & 223394 \\
\hline Exports & 24712 & 42488 & 46267 & 59366 & 57387 & 66645 & 73518 & 67911 & 72702 \\
\hline \multicolumn{10}{|l|}{ United States } \\
\hline Demand & 546581 & 645325 & 697253 & 743161 & 783995 & 837782 & 857406 & 858534 & 861484 \\
\hline Supply & 592462 & 649381 & 760388 & 781448 & 808401 & 836721 & 868545 & 862342 & 842859 \\
\hline Exports $^{(a)}$ & 24898 & 27562 & 35895 & 26541 & 27576 & 21682 & 22558 & 20443 & 13502 \\
\hline \multicolumn{10}{|l|}{ Botswana } \\
\hline Demand & 324 & 382 & 693 & 898 & 739 & 717 & 856 & 872 & 886 \\
\hline Supply & 324 & 382 & 693 & 898 & 739 & 717 & 856 & 872 & 886 \\
\hline Exports & 0 & 0 & 0 & 0 & 0 & 0 & 0 & 0 & 0 \\
\hline Total Exports & 51883 & 97117 & 132359 & 151394 & 145290 & 153635 & 174287 & 158991 & 161366 \\
\hline Tot. Seaborne Trade & 95800 & 163600 & 199300 & 253000 & 274900 & 287400 & 296900 & 309800 & 347600 \\
\hline
\end{tabular}

Source: Compiled mainly from Coal Information 2001, International Energy Agency, Paris, p I.52

Notes: ${ }^{(a)}$ - US exports are reported exports less reported imports. 


\subsection{The Mathematical Model}

This model is formulated as a minimization problem in which the objective function minimizes the sum of the present value of annualized capital expenditure costs for mine capacity additions, variable supply costs, rail transportation costs, and maritime transportation costs over a given time horizon. These discounted costs are minimized subject to resource availability constraints; port capacity constraints for the Southern Africa region; conservation of flow constraints for the transshipment ports in two of the three net exporting regions of the model, that is, Southern Africa and the United States, and market demand constraints, which require supply to equal or exceed demand at the chosen world level of aggregation and for all time periods. The model applied is a variation of the STPA (Takayama and Judge, 1971) model (see Table 4.2 below for Variable Definitions). The objective function is as given in equation 4.1 below.

Min Total Discounted Present Value Costs $(P V C)=\sum_{t=1}^{T} \delta_{t}\left(\phi_{k t}+\phi_{f t}+\phi_{s t}\right)$

$$
\text { where } \quad \phi_{k t}=\sum_{\tau=1}^{t} \sum_{i=1}^{N} \sigma\left(\operatorname{Capex}_{i t}\left(H_{i t}\right)\right)
$$

Amortized $=$ sum of $\mathrm{CRF}^{*}($ Capital expenditure for new capacity addition $)$ Capital costs

The equation for capital expenditure costs, Capex $_{i t}\left(H_{i t}\right)$ is obtained from the U.S. Bureau of Mines Cost Estimating System (1995) and has the following three components, where $Y_{i t}$ is the capacity expansion in metric tons per day for a mechanized room and pillar mining operation with a production rate in the range $20000-25000$ metric tons per day and operating on two production shifts using continuous miners. The variable $H_{i t}$ is converted to $Y_{i t}$, which is in metric tons per day for computing the components of capital costs from the equations given below. 


\section{Table 4.2 Variable Definitions}

\begin{tabular}{|c|c|}
\hline Variable & Definition \\
\hline \multicolumn{2}{|l|}{ Sets } \\
\hline I & $\begin{array}{l}\text { Set of net exporting countries, } i \text {, in the model (Australia, South Africa, Botswana and the United } \\
\text { States }\end{array}$ \\
\hline $\mathrm{K}$ & $\begin{array}{l}\text { Set of export ports, } k \text {, for the set of I exporting countries: Australia - Gladstone, South Africa }- \\
\text { Richards Bay, United States - Hampton Roads and Botswana - (Matola, Walvis Bay and Richards } \\
\text { Bay) }\end{array}$ \\
\hline $\mathbf{J}$ & $\begin{array}{l}\text { Set of import ports, } j \text {, in Western Europe (Antwerp, Rotterdam and Amsterdam) and Asia } \\
\text { (Yokohama) }\end{array}$ \\
\hline $\mathrm{T}$ & $\begin{array}{l}\text { Time period for expansion, } t \text {, is } 2005 \text { and } 2010 \text { for the forecast from a base year of } 2000 \text { and } 1995 \text {, } \\
2000,2005 \text { and } 2010 \text { from a base year of } 1990 \text { for the simulation; }\end{array}$ \\
\hline \multicolumn{2}{|l|}{$\frac{\text { Endogenous }}{\text { Variable }}$} \\
\hline $\mathrm{q}_{\mathrm{it}}$ & Domestic supply of steam coal at mine in exporting country I in period T $(000 \mathrm{~s}$ mtce $)$ \\
\hline $\mathrm{q}_{\mathrm{ikt}}$ & Steam coal exports from mine I to port $\mathrm{K}$ in time period $\mathrm{T}(000 \mathrm{~s}$ mtce $)$ \\
\hline $\mathrm{q}_{\mathrm{kjt}}$ & Steam coal shipped form export port $\mathrm{K}$ to import port $\mathrm{J}$ in time period $\mathrm{T}(000 \mathrm{~s} \mathrm{mtce})$ \\
\hline $\mathrm{H}_{\mathrm{it}}$ & Expansion capacity at mine I in period $\mathrm{T}(000 \mathrm{~s}$ mtce $)$ \\
\hline \multicolumn{2}{|l|}{$\begin{array}{l}\text { Exogenous } \\
\text { Variable }\end{array}$} \\
\hline Dit & $\begin{array}{l}\text { Domestic demand in exporting country I, including exports to the rest of the world markets in time } \\
\text { period T }(000 \mathrm{~s} \text { mtce })\end{array}$ \\
\hline Djt & Total steam coal import demand by market $\mathrm{J}$ in time period $\mathrm{T}$ (000s mtce) \\
\hline $\mathrm{C}_{\mathrm{ikt}}$ & Rail costs from mine I to port K in time period T (in 2000 US Dollar / mtce) \\
\hline $\mathrm{C}_{\mathrm{kjt}}$ & $\begin{array}{l}\text { Sea freight costs from export port } \mathrm{K} \text { to import port } \mathrm{J} \text { in time period } \mathrm{T} \text { and for vessels greater than } \\
100 \mathrm{~K} \text { tons deadweight (in } 2000 \text { US Dollar / mtce) }\end{array}$ \\
\hline \multicolumn{2}{|l|}{$\frac{\text { Shadow }}{\text { Values }}$} \\
\hline$\lambda_{\text {Sit }}$ & Optimal market price for steam coal in exporting country I in period T (in 2000 US Dollar /mtce) \\
\hline$\lambda_{V k, t}$ & Shadow value for port capacity for Southern African ports only (in 2000 US Dollar /mtce) \\
\hline$\lambda_{T r, t}$ & Optimal market price at port of exit (optimal f.o.b. price in US 2000 / mtce) \\
\hline$\lambda_{D j t}$ & Optimal market price for steam coal in importing in country $\mathrm{J}$ in period T (in 2000 US Dollar /mtce) \\
\hline
\end{tabular}




$$
\begin{array}{ll}
\operatorname{Cost}_{\mathrm{E}}=2943 * Y_{i t}^{0.901} & \text { equipment capital costs } \\
\operatorname{Cost}_{L}=405.8^{*} Y_{i t}^{0.941} & \text { labor capital costs } \\
\operatorname{Cost}_{S}=390.7 * Y_{i t}^{0.904} & \text { supply capital costs }
\end{array}
$$

The total capital expenditure cost is the sum of the three components. The cost estimate was updated to the base year 2000 from that of 1994 using mining cost indices for coal operations published by Western Mine Engineering Inc. (2002). The labor component of the capital expenditure is normalized relative to wages in the United States.

$$
\phi_{f t}=\sum_{i=1}^{N} \sum_{k=1}^{K} c_{i k t} q_{i k t}+\sum_{k=1}^{K} \sum_{j=1}^{M} c_{k j t} q_{k j t}
$$

Equation 4.6 expresses transportation costs as the sum of rail plus maritime transportation costs.

$$
\begin{aligned}
& \qquad \phi_{s t}=\int_{0}^{q_{i t}}\left(\alpha_{i t}+\beta_{i} q_{i t}\right) d q_{i t} \\
& \text { where } \quad q_{i t}=q_{i 0}+\sum_{\tau=1}^{t} H_{i t} \\
& =\alpha_{i t}\left(q_{i 0}+\alpha \sum_{\tau=1}^{t} H_{i t}\right)+0.5 \beta_{i}\left(q_{i 0}+\sum_{\tau=1}^{t} H_{i t}\right)^{2}
\end{aligned}
$$

Equations 4.7, 4.8 and 4.9 derive the variable cost of supply function and demonstrate how the model gets its quadratic cost structure. They show that the total variable supply cost for each producer and for a given period is obtained by integrating over the linear long run marginal cost function over the limits from zero to the cumulative quantity supplied by such producer.

$$
\delta_{t}=\sum_{\tau=1}^{\theta}(1+\rho)^{-\theta(t-1)-\tau}
$$


The discount factor for period $t$, where $\theta$ is equal to the number of years per time period and $\rho$ is the discount rate, is given by equation 4.11 .

The capital recovery factor (CRF) is given by:

$$
\sigma=\frac{\rho}{1-(1+\rho)^{-T}} \quad \text { where } T \text { is the life of project. }
$$

The above objective function is minimized subject to the following constraint conditions:

Condition 1: This condition requires defining a set, $I K$, which matches producing countries to export ports to eliminate non-feasible links. The constraint says that for the set $I K$, exports should not exceed the available net supply, which is the difference between demand and base period supply plus sum of capacity additions to the present period.

$$
-\sum_{k=1}^{K} q_{i k t} \geq D_{i t}-q_{i 0}-\sum_{\tau=1}^{t} H_{i t} \text { for all } i, \text { in } I K \text { and } t
$$

Condition 2: This equality states that at the transshipment nodes, coal inflows and outflows should balance out. This applies to the Southern Africa region and the United States. The condition does not exist for Australia as the long run marginal cost function is based on export prices that already include rail transportation costs to export ports.

$$
\sum_{i=1}^{N} q_{i k t}=\sum_{j=1}^{m} q_{k j t} \quad \text { for all } k \text { and } t
$$

Condition 3: This inequality requires that the sum of supplies from transshipment ports must be greater than or equal to demand in region $j$. Even though the entry ports are not the final demand points, the final distribution costs in the importing regions will be common to all coal regardless of their origins and therefore would not affect the results of the model in determining the spatial and temporal distribution of this trade.

$$
\sum_{k=1}^{K} q_{k j t} \geq D_{j t} \quad \text { for all } j \text { and } t
$$

Condition 4: This inequality is relevant for those producers that may face a binding port capacity constraint. This applies to both existing and simulated ports in Southern Africa. In the simulation scenario, the simulated port capacity is assumed to grow at rates that would mimic the growth of exports once a starting base has been selected.

$$
-\sum_{i=1}^{N} q_{i k t} \geq-V_{k t} \text { for all } k \text { and } t
$$




\subsubsection{The Kuhn-Tucker Conditions}

The Kuhn-Tucker conditions (K-T) for this problem are shown below:

$$
\begin{aligned}
& L_{H i t}=\frac{\partial \operatorname{Capex}_{i t}\left(H_{i t}\right)}{\partial H_{i t}}+\alpha_{i t}+\beta_{i}\left(q_{i 0}+H_{i t}\right)-\lambda_{S i t} \geq 0 \\
& L_{H i t} * H_{i t}=0 \\
& L_{q_{i k t}}=c_{i k t}+\lambda_{S i t}+\lambda_{V k, t}-\lambda_{T r, t} \geq 0 \\
& L_{q_{i k t}} * q_{i k t}=0 \\
& L_{q_{k j t}}=c_{k j t}+\lambda_{T r, t}-\lambda_{D j, t} \geq 0 \\
& L_{q_{k j t}} * q_{k j t}=0 \\
& L_{\lambda s i t}=D_{i t}-q_{i 0}-\sum_{\tau=1}^{t} H_{i t}+\sum_{k=1}^{K} q_{i k t} \leq 0 \\
& L \lambda_{S i t} * \lambda_{S i t}=0 \\
& L \lambda_{D_{j t}}=D_{j t}-\sum_{k=1}^{K} q_{k j t} \leq 0 \\
& L \lambda_{D_{j t}} * \lambda_{D_{j t}}=0 \\
& L \lambda_{T r, t}=\sum_{i=1}^{N} q_{i k t}-\sum_{j=1}^{M} q_{k j t}=0 \\
& L \lambda_{v k, t}=-V_{k t}+\sum_{i=1}^{N} q_{i k t} \leq 0 \\
& L \lambda_{V k, t} * \lambda_{V k, t}=0
\end{aligned}
$$




\subsubsection{Economic Interpretation of the Kuhn-Tucker Conditions}

The economic interpretation of K-T conditions relies on the definition of the marginal values, which in this study are the optimal market prices in both the net exporting and importing countries of the model. The component wise interpretation of these K-T conditions leads to relationships that govern optimal expressions for production, consumption, quantity flows and efficient market pricing conditions. Conditions 4.16 and 4.17 deal with optimum production with the latter showing that if there is positive production, which means that condition 4.16 is binding, then the sum of the marginal cost of new capacity plus marginal cost of production must be equal to the market price in that country. The interpretation of the K-T conditions 4.16 and 4.17 , therefore make economic sense as they indicate that the sum of marginal costs should be greater than or equal to the optimal market price for capacity expansion and production to take place in a country. In the event production is zero, it must be that a country's supply price exceeds the market price in that country.

The optimum consumption condition is given by equations 4.20 and 4.21 . If consumption is positive, equation 4.21 implies that 4.20 is binding and the delivered price of coal in the importing country is equal to the optimal market price. If quantity demanded is zero, this means that 4.20 is not binding and the market price is greater than the price in the importing country or region. A more intuitive interpretation of this condition is to begin by noticing that when equation 4.20 is binding, this means that the marginal benefit from a unit of consumption is equal to its shadow price. In the event that consumption is zero, then it must be that the market price is greater than the marginal benefit from a unit of steam coal imported. A simple manipulation of equations 4.18 and 4.20 leads to the locational price equilibrium condition that says that the optimal market price differential between two spatially separated markets must equal the cost of transportation for any positive quantity shipped and is less than these costs for a zero shipment. 
This condition rules out arbitrageurs or speculators who would not find it profitable to buy the product in one market and sell it in another market as all of their profit margin would be used up to pay for transportation costs. The locational price equilibrium condition is shown in equation 4.29.

$$
\left(c_{i k t}+c_{k j t}\right)+\lambda_{S i t}+\lambda_{V k, t} \geq \lambda_{D_{j t}}
$$

The pair of equations 4.22 and 4.23 , and 4.24 and 4.25 are efficient market pricing conditions. The interpretation of these conditions is that a positive market price induces production that is both for the domestic and export markets. In the event the market price is zero, then there exists an excess of supply of exports in the region. In the importing countries, a positive price ensures that condition 4.25 is binding and imports are in balance with demand. If the price is zero, this condition would no longer be binding and hence there would be excess supply.

\subsection{Formulation of the Empirical Model}

The formulation of the empirical model is that of a model with elastic supply and inelastic demand. The elastic supply functions are derived from the estimation of long run marginal cost functions for net exporters of steam coal in the model while the inelastic demand is the forecast quantities of steam coal imports by the net importing countries in the model and the forecast domestic demand for steam coal by the net exporting countries. The existing international steam coal trade models are based on marginal cost functions that are derived from engineering cost data that normally are not readily available to researchers. The spatial and dynamic model developed in this work employs time series data specific to the supply of and demand for steam coal in the selected countries in the model to estimate the long run marginal cost functions for the net exporters in the model. This function is then transformed into the 
quantity formulation for incorporation into the objective function of the spatial and dynamic model. Integration over the linear long run marginal cost function yields the variable supply cost, which is quadratic in the quantity supplied (see equation 4.9 above). The advantage of using a quadratic programming approach is that the model solves endogenously for optimal supply quantities, capacity additions, trade flows and supply prices, across space and time.

\subsection{The Supply and Demand Components}

In this section we present the specification and estimation of the country supply and demand functions and the long run marginal cost functions for the net exporting countries of the model.

\subsubsection{Specification of Country Supply and Demand Functions}

There are two possible approaches for modeling the export supply and import demand quantities for steam coal. The first involves the direct estimation of steady state regional export supply and import demand functions (see Lord 1991). Such an approach results in non-linear supply and demand functions that do not readily lend themselves to the quadratic programming approach that is widely applied in spatial price equilibrium models. The second approach begins with the econometric estimation of country supply and demand functions. In this approach, some researchers have invoked assumptions of inelastic supply with the result that the demand functions are then estimated using ordinary least squares (OLS) methods. Examples include Hashimoto's (1979) model of world iron and steel economy, econometric model of the copper industry (Bozdogan and Hartman, 1979, Mikesell, 1979, and Fisher, Cootner and Bailey, 1972) and Toweh and Newcomb's (1991) model dealing with the spatial equilibrium analysis of the world iron ore trade. 
In this study, we estimate the country supply and demand functions under the context of a non-spatial time dependent econometric model of the world steam coal trade following similar approaches to those by Labson (1997) and Meyers, Devados and Helmar (1989). The purpose of this non-spatial econometric model approach is two-fold: 1) to model the domestic demand and supply functions for all countries to determine the forecast demands in the net exporting countries and also the forecast import demands in the net importing countries of the model, and 2) to model the long run marginal cost of steam coal supply in the net exporting countries of the model. The forecast domestic and import demands are then used in the spatial and dynamic model to determine which countries would respond by adding production capacity under a decision criterion that minimizes the discounted sum of capital costs, variable supply costs, rail transportation and maritime transportation costs over a given time horizon. This model is applied towards analyzing a variety of coal trade issues relevant to policy decisions in Botswana.

The model differentiates coal only on the basis of its heat content (Btu) and for this reason the coal supply and demand data are converted to metric tons of coal equivalent (mtce). Similarly, all price and cost variables are reported on a per mtce basis.

\subsubsection{Estimation of Country Supply and Demand Functions}

Microeconomic theory informs us that the supply function for a firm is derived from the first order conditions for a profit maximizing firm. In the short run, when the firm is faced with a fixed level of capacity, the quantity supplied is explained by input and output prices. In the long run, however, the firm is able to adjust its capacity to meet increased demand. This means that a properly specified model of the long run supply function should include a variable for capacity as provided in equation 4.30 below. The long run marginal cost functions for each of the net exporters are obtained by estimating the inverse long run supply functions as specified in 
equation 4.33 below. In this form, each net exporter's long run marginal cost function is obtained by a regression of the steam coal price on input prices, output supply and production capacity.

The demand for steam coal, like all input demands, is a derived demand. Such demand equation is obtained from the first order conditions for cost minimization by a firm subject to a given level of output. In this case, we are considering the demand for steam coal in electricity generation, and this is derived from the first order conditions for a cost minimization problem in which electric utilities choose levels of fossil fuels to minimize total costs of generating electricity. The demand equations to be estimated are specified in equation 4.31 below.

The supply, demand and long run marginal cost functions are specified within the structure of a non-spatial econometric model of the world steam coal trade. This is the approach used by Labson (1997) and Meyers, Devados and Helmar (1987). The market clearing condition in equation 4.32 is not invoked in the econometric modeling of the supply, demand and long run marginal cost functions and is presented here for the sake of completeness of the non-spatial econometric model only. For each of the countries in the model, the supply and demand equations that will be estimated are of the form:

$$
\begin{array}{cl}
\text { Country Supply: } & S_{i t}=g_{i}\left(W_{i t}, R_{i t}, P_{i t}, S_{i t-1,}, K_{i t},\right) \\
\text { Country Demand: } & D_{i t}=f_{i}\left(P_{i t}, P_{\text {oil }, t} P_{\text {gas }, t}, D_{i t-1}, G D P_{i t}, \text { Trend }\right) \\
\text { World Steam Coal Market Clearance: } & \sum_{i=1}^{n+m} S_{i t}+S_{R O W}=\sum_{i=1}^{n+m} D_{i t}+D_{R O W} \\
\text { Sum of supply }= & \text { Sum ofdemand }
\end{array}
$$

where: $P_{i t}$ - is the end user real price of coal in country $i$ and year $t$ in base year 2000

in US Dollars per metric ton of coal equivalent (mtce). Australia data assumed export and end user prices are the same; 
$D_{i t}, D_{i t-1}$ - domestic demand for coal in mtce for region $i$ for periods $t$ and $t-1$ (000s mtce)

$S_{i t}, S_{i t-1}$ - domestic supply of coal in mtce for region $i$ for period $t$ and $t-1$ (000s mtce)

$S_{\text {ROWit }}$ - rest of world supply in period $\mathrm{t}(000 \mathrm{~s}$ mtce)

$D_{\text {ROWit }}$ - rest of world demand in period $\mathrm{t}(000 \mathrm{~s}$ mtce)

$W_{i t} \quad$ - is the real hourly mine labor wage in year 2000 US $\$$ for country $i$ in period $t$;

$R_{i t,} \quad$ - is the real cost of capital, (real interest rate) in period $t$;

$P_{o i l, t} \quad$ - is the end user price of oil in year 2000 US $\$$ per mtce in period $t$;

$P_{\text {gas }, t}$ - is the end user price of gas in year 2000 US $\$$ per mtce in period $t$;

$G D P_{i t}$ - is the real gross domestic product for country $i$ in time period $t$, (US $\$ 2000$ )

$K_{i t} \quad$ - is the coal production capacity in exporting country $i$ in period $t$ in (000's mtce)

$(n+m)$ - total of countries in the model (net exporters plus net importers), and

Trend - is the time trend.

The above econometric model is dynamic but not spatial. This means that it does not estimate trade flows among countries in the model. The difference in estimated values for domestic supply and demand indicate each country's position as either a net exporter or importer of steam coal.

For each country in the model, equations 4.30 and 4.31 are estimated using data for the period 1980 to 1997 . The ex-post forecast period is 1998 to 2000, while the ex-ante period is 2000 to 2010. In any econometric forecasting, the performance of a model can be measured by the goodness of fit for the within-sample period as interpreted from significance of the adjusted R-squared, low forecast error for the out-of-sample period and other parametric and non- 
parametric tests. As we plan to employ the models to forecast future values, our priority in this study is to select a model with good explanatory power and low forecast error.

The minerals industry has been modeled frequently using partial adjustment models to take into account the slow speed of adjustments due to both supply and demand side rigidities (Fisher, Cootner and Bailey, 1972, Bozdogan and Hartman, 1979 and Mikesell, 1979). Supply side rigidities derive from the long time required to build capacity, which, once it is in place, presents certain operational constraints of its own. For instance, during periods of depressed prices, a mine will maintain its output as long as this price is equal to the short run average variable cost of production. On the demand side, there are rigidities in the adoption of processes that employ substitutes in the production of final goods. There is therefore a difference in elasticities between the short and long run periods. For these reasons, the models estimated would combine both the structural and partial adjustment form to include variables that provide the model with economic explanation as well as accounting for the slow speed of adjustment between the short and long run periods. It has been found that the simple autoregressive models sometimes out-perform multivariate models in forecasting. We keep this fact in mind when selecting the best models for estimating country supply and demand functions.

There is need to pre-test the data series for stationarity before we can estimate equations 4.30, 4.31 and 4.33. This is done to avoid spurious regression of one trending variable on one or more trending variables as well as more severe problems. This testing is easily achieved by running the Augmented Dickey-Fuller (ADF) unit root tests on the data variables for each country in the model. There has been an evolution of the approaches that can be used to correct trended data series to achieve stationarity (see Hunt, Judge and Ninomiya, 2003, Harvey 1997 
and Gujarat 1995). All variables of the econometric model are first differenced and the ADF unit root test is conducted once again on the differenced series to confirm stationarity.

\subsubsection{Estimation of the Long Run Marginal Cost Functions}

The inverse long run marginal supply function described above is as shown below in equation 4.33 with the explanation of the variables as already provided. In the event there is simultaneity between price and quantity at the country level, this equation can be estimated with equation 4.31 with the identity shown in equation 4.32 above using two stage least squares, otherwise it is estimable as a single equation for each net exporting country.

$$
P_{i t}=f_{i}\left(W_{i t}, R_{i t}, S_{i t}, P_{i t-1,} K_{i t}\right)
$$

The estimated linear long run marginal cost functions, with all other identifying variables collapsed into the intercept term, are of the form shown below with the constraint that both $\alpha_{i t}$ and $\beta_{i}$ be non-negative.

$$
P_{i t}=\alpha_{i t}+\beta_{i *} q_{i t}
$$

In this study, we consider the marginal cost function in the long run when the firm can adjust its capacity to meet changes in demand. For this reason, there is a need to model variation in capacity over time. Since such capacity data are lacking, a surrogate was devised based on the observation that in any year during which prices are high or there is a disruption in supply from other exporters, the level of operation would be near full capacity. Since data were not available for all years, the missing observations had to be estimated. The years for which full capacity is assumed together with a brief explanation for their selection are as follows:

1. 1981/82 - The strike by Polish coal miners in 1981 disrupted Poland's coal exports to Western Europe, such that US steam coal exports expanded to fill the gap. (Coal Information 1996, p I.20),

2. 1984/85 - The strike by UK coal miners led to all the major steam coal exporters increasing their exports to Western Europe to fill the gap, 
3. 1992 - Industrial action in the US affected steam coal exports and therefore other exporters expanded to fill the gap (Coal Information 1996, p I.20), and

4. 2000 - the matching of demand and supply at full capacity led to a recovery in steam coal prices (Coal Information 2001, p I.130).

In using the long run marginal cost function, we make the assumption that this is equal to the minimum acceptable selling price of steam coal for each of the net exporters in the model. This assumption means that no producer is earning any rent. This assumption has also been invoked in coal trade models by the Macal (1979) and Dutton (1982) and derives from economic theory that in the long run all economic factors are paid their market price and firms realize zero economic profit.

\subsection{Spatial and Dynamic Optimization}

The second stage of this model incorporates the transformed long run marginal cost functions from the first stage into a spatial and dynamic optimization model of the world steam coal trade that has a quadratic objective function. In the second stage, we rely on a cost minimization decision criterion to determine which exporters would expand their production capacities to meet the exogenous demand for steam coal. The forecast demand for steam coal facing the net exporters in the model includes both the domestic and export demand.

The estimated long run marginal cost functions are transformed into a quantity formulation (see equation 4.34 above) and incorporated into the objective function of the spatial and dynamic optimization model. The other terms of this objective are: capital expenditure costs, variable supply costs, rail transportation and sea freight costs. Appendix $\mathrm{H}$ provides the indicative and estimated costs for rail and maritime costs respectively. The model is solved using the GAMS MINOS 5.5 solver (Brooke et. al., 1998). The salient features of this model are:

1. inelastic domestic demand in the net exporting countries of the model, 
2. inelastic import demand in the net importing counties of the model,

3. elastic supply functions for net exporters derived from their estimated long run marginal cost functions, and

4. a quadratic objective function which derives from the variable supply costs which are quadratic in quantity supplied for each of the net exporters in the model.

This model is therefore capable of solving for the optimal values of capacity additions over the given simulation or forecast periods, optimal supply quantities by the net exporters, export and import quantities, optimal trade flows, and supply prices over space and time. 


\subsection{Data}

The data sources for this study are presented in table 4.3 below.

\section{Table 4.3 Sources of Data for the Model}

\begin{tabular}{ll}
\hline Data Variables & Source \\
\hline $\begin{array}{l}\text { Steam coal production, consumption, exports, } \\
\text { imports }\end{array}$ & Coal Information, 1988, 1990, 1996 and 2001 \\
\hline $\begin{array}{l}\text { End user prices for steam coal, natural gas and } \\
\text { heavy fuel oil }\end{array}$ & $\begin{array}{l}\text { 1) Coal Information, 1988, 1990, 1996 and 2001 } \\
\text { 2) Energy Prices and Taxes, Quarterly Statistics, 2 } \\
\text { Quarter 2001 }\end{array}$ \\
\hline Maritime freight rates & $\begin{array}{l}\text { Coal Trade Freight Report, Rodriguez and Sons Co. } \\
\text { cited in International Coal Review Monthly }\end{array}$ \\
\hline Rail transportation costs & Coal Information, 1988, 1990, 1996 and 2001 \\
\hline $\begin{array}{l}\text { Macro data on real gdp, interest rates, exchange } \\
\text { rates and CPI }\end{array}$ & International Financial Statistics, May 2001. \\
\hline Hourly wage rates & $\begin{array}{l}\text { International Labor Organization's Washington } \\
\text { branch web site: http://us.ilo.org }\end{array}$ \\
\hline Heat content of coals & $\begin{array}{l}\text { US Energy Information Administration's web site } \\
\text { www.eia.doe.gov }\end{array}$ \\
\hline
\end{tabular}




\subsection{Expected Results}

The spatial and dynamic optimization model is expected to provide useful information on the likely timing and scale of new coal development in Botswana's Mmamabula coalfield. The results of the multi-period spatial linear programming model show that there exist opportunities for coal production from the Mmamabula coal field would be competitive in the world markets. Specifically, if Botswana had capacity and rail links already in place, then these results show that the country's coal would have been traded internationally in the year 2000. The main model will then determine whether this advantage ceases to exist once order of magnitude cost estimates for capacity additions are included in the model. In the event that the results show no immediate cost advantage for Botswana coals, it is expected that within the forecast horizon, coals from Botswana would become competitive as indicated by the linear programming model, which indicates that the port of Walvis Bay would have long term cost advantages in the Western European steam coal market.

\subsection{Conclusions}

This chapter has provided the theoretical approach to modeling the competitiveness of Botswana's coal in the seaborne steam coal trade. This approach relies first on the econometric modeling of the world steam coal trade to obtain the following: forecast domestic demand for steam coal in net exporting countries, the derived steam coal imports in the net importing countries and finally, long run marginal cost functions for each of the net exporting countries in the model. As we are dealing with time series data, each country's data series was tested for stationarity using the Augmented Dickey-Fuller unit root test. These tests are necessary to avoid spurious regressions in which the models might give high levels of goodness of fit even when there is no ruling economic relationship. 
The second stage of the proposed model involves spatial and dynamic optimization in which the objective function is to minimize the discounted sum of capital costs, variable supply costs, rail transportation costs and maritime transportation costs over a given time horizon.

A simple multi-period linear spatial allocation model was simulated to determine the impact of the declining rail and sea freight costs on the competitiveness of Botswana's coal (Appendix G). The results from this model demonstrate that if the rail transportation rates charged on South African coal exports are applied to steam coal exports from Botswana, and if there were railway lines to Matola and Walvis Bay for transporting this coal, then Botswana's coal would be competitive in the world steam coal markets. This simple transportation model also demonstrates that in 2000, Botswana's coal would have been competitive for exporting through Richards Bay. These results are very encouraging and justify a furthering of the model to include capital costs for capacity additions and variable costs of supply in the spatial and dynamic optimization model. The mathematical formulation of this model was developed and the Kuhn-Tucker conditions interpreted to confirm the proper formulation of the problem. 


\section{CHAPTER 5}

\section{EMPIRICAL RESULTS}

\subsection{Introduction}

In chapter 4, we presented the modeling approach as that which has two stages: the first stage presents an econometric estimation of the supply and demand functions for each of the countries in the model and the long run marginal cost function for exporters in the model, and the second stage features a simulation framework consisting of a spatial and dynamic optimization model that has a quadratic objective function in variable supply costs. In the second stage, the import demand quantities from the first stage are exogenous to the optimization model which due to the inclusion of capital expenditure costs, long run marginal costs, rail transportation costs and sea freight costs is capable of solving for the following: capacity additions in the exporting countries of the model, supply prices, domestic demand, and trade flows over time and space. The model covers the periods 1995, 2000, 2005 and 2010. The results of the econometric model of the world steam coal trade are validated by both parametric and non-parametric methods. In the latter approach the computed values for exports and imports are validated by comparing the export or import quantities for each country with those from other models.

In the second stage of this study, we solve the spatial and dynamic optimization model of the world steam coal trade model to determine which of the exporting countries, with Botswana included as a possible exporter, would have responded to the import demand in the past, in 1995 and 2000, and which are likely to respond to the estimated import demand in the future, in 2005 and 2010, under a decision criterion that minimizes the sum of the discounted costs of capacity additions, variable costs of supply, rail transportation and sea freight costs. The model is then 
used to forecast the future of Botswana's coal for the years 2005 and 2010 from a base year of 2000.

\subsection{Policy Approach}

The use of coal models in formulating and evaluating energy policy has long been the accepted way of utilizing these models. In the United States, for instance, there has been a reliance on energy-economy models like the national coal model and its simpler versions such as the coal supply model in the formulation of environmental policy on coal use (Holloway, 1982, Wood and Mason 1982). Currently, the US Energy Information Administration's National Energy Modeling System consists of a Coal Market Module that is capable of producing forecasts relying on an engineering based marginal cost function. In this study, the policy focus is that of defining the obstacles to the development of an export coal industry in Botswana. As the country is landlocked, the burden of providing for rail infrastructure might present a real barrier to the development of an export coal industry. The Botswana government's policy on infrastructure provision for mining projects has always been that it would provide it and then charge user fees to recover the cost of provision over a stipulated period. In chapter 2, we gave a description of the regional initiative under the SADC protocol on Transport, Communications and Meteorology in which the region aims to approach infrastructure provision on a regional instead of an individual country basis. The mechanics of this regional cooperation include the prioritization of projects that have a regional benefit. A study like this one, could, therefore, provide economic justification for the prioritizations of rail and port infrastructure in those export corridors that offer the lowest transportation cost for exported coal.

Botswana has a long history of large scale mining and it recently revised its mining law to make it more comprehensive and investor friendly. This should provide comfort to any 
security of supply concerns in the markets in Western Europe and Asia. This model aims to provide a tool for the policy maker to model the likely competitiveness of Botswana's coal and to be in a position to anticipate possible future developments in world energy markets that may bear some opportunities for the development of the country's coal deposits. It is hoped that the output from this model would simplify the decision making process about whether or not conditions in the world energy markets justify much more detailed investigations at the project investment level.

\subsection{Results of the Estimation of Country Supply and Demand Functions}

The country level data series for steam coal demand and supply, hourly wages for the mining industry, real interest rates, real gross domestic product, end user prices for steam coal, natural gas, and crude oil, were tested for stationarity using the augmented Dickey-Fuller unit root test. The presence of a unit root and therefore, non-stationarity was detected in all the variables. These test results indicate that ordinary least squares regression would lead to spurious results due to the regressing of a trending variable on one or more trending explanatory variables. The existence of non-stationarity may also be accompanied by co-integration, a condition in which one or more variables have a long term equilibrium relationship and therefore share a similar trend. There are basically two approaches of handling non-stationary time series data: first differencing and if the variables are co-integrated, an approach that uses the error correction mechanism in the representation of the model for estimation. As the focus of this study is to forecast instead of establishing a relationship between the above variables in their levels form, the first differencing approach is used (see Gujarat, 1995 and Hunt, Judge and Ninomiya, 2003). All the data series were, therefore, first-differenced and the transformed series once again 
checked for stationarity. As expected, the first differencing eliminated the stochastic trend. Finally the results from the Hausmann specification test for each country's supply and demand function as represented in equations 4.31 and 4.32 indicated that there was no simultaneity between the steam coal supply price and quantity demanded or supplied. This was the expected result as the price formation in the international steam coal trade occurs at the international as opposed to the national level. In agreement with the general approach in model estimation, where it may be too restricting to assume a linear relationship between variables, in this study, a model, non-linear in the parameters, was used in estimating the country supply and demand functions. Also this non-linear functional form was transformed into a log-log form to end up with a linear in the parameters model. The results of the econometric modeling of the country supply and demand functions are presented in appendix A.

\subsection{Validation of the Results for Country Supply and Demand Functions}

There exist a variety of tests for validating econometric models of the type used in this study and these fall generally into two classes, parametric and non-parametric tests (see Pindyck and Rubinfeld, 1991 and Labys 1982 and 1973). The former relies on significance of the estimated parameters and the adjusted R-squared, which measures a model's goodness of fit. In addition, the estimated parameters may be shocked to simulate changes in policy variables. For instance a shock to the intercept term could simulate the imposition of taxes and consumption subsidies that affect the inverse supply and demand functions respectively. The slope parameters may also be shocked by half of the standard estimation error as suggested by Rubinfeld and Pindyck and the resulting values of the endogenous variable observed.

The performance of a model can be measured for both the with-in-sample and out-ofsample periods. Where the intention is to utilize the model for conducting out-of-sample 
forecasts, non-parametric tests, such as the root mean squared error, RMS, the mean absolute percent error, MAPE, and the Theil inequality coefficient, $\mathrm{U}$, which is a ratio of the root mean squared error to the sum of the root mean squared values of the simulated and actual values of the endogenous variable are used to measure a model's forecasting ability. The value of the U ratio falls between 0 and 1 , with values closer to zero depicting good out-of-sample performance and those nearer to 1 indicating poor model performance (Pindyck and Rubinfeld, 1991). Econometric models can also be checked for how well the models simulate turning points in the data by a graphical approach. Another approach involves a comparison of the forecast endogenous variables to those from other models.

The preceding discussion on validation approaches point to the need for the modeler to identify the kinds of tests that are suitable for the purposes of the model. If the objective is to obtain forecast values of the endogenous variable, then a low forecast error for the model takes precedence over the individual significance of the estimated parameters. This is the priority pursued in this modeling exercise. The validation of the country supply and demand functions therefore, proceeds as follows: reporting results from tests on MAPE, $\mathrm{U}$, and the interpretation of bias component of $\mathrm{U}$ in the context of the suitability of a model for long range forecasting and comparing the forecast values for exports and imports computed from the country supply and demand equations with those from other models.

The econometric models for the country supply and demand functions were evaluated for their performance in the out-of-sample period of the data from 1997 to 2000 only, due to the limited time series data. The test statistics are reported in full in Appendix A. In this study, the import demands are computed as differences in domestic supply and demand. Next, we present 
only the statistics on the demand side, that is, for the net importing countries, to demonstrate the validity of the model and its usefulness for long range forecasting.

The adopted forecasting approach is the one step ahead forecast. This is relevant in this study as it allows actual data points to be used for solving for the predicted or forecast values. This is in contrast with the dynamic approach which forecasts future values based on forecast values from earlier periods. Obviously, in a model with low forecasting ability, the dynamically forecasted values are likely to diverge from actual values, leading to high forecast errors. For the demand equations, the MAPE is as follows: Japan (5.05\%), Belgium (25.85\%), France (23.62\%), Germany (7.40\%), Italy (12.22\%), Netherlands (22.72\%), Spain (12.97\%) and the UK (7.87\%).

These statistics infer that where there is significant steam coal consumption, there may be better reporting of data, which may explain the low errors for Germany, Japan, Spain and the UK. The high forecast error for France can be explained by the much diminished role for steam coal in electricity generation, while those for the Netherlands and Belgium may be due to the fact that these countries are entry points for steam coal imports and therefore the data may not be accurately reporting the re-exports to other Western European destinations. The Theil coefficient, $\mathrm{U}$ is as follows: Japan (0.03), Belgium (0.13), France (0.14), Germany (0.04), Italy (0.08), Netherlands (0.11), Spain (0.08) and the UK (0.06). These models have good explanatory power in the major demand countries of the model as indicated by the relatively high values for the adjusted R-squared. These are as follows: Japan (0.56), Belgium (0.30), France (0.10), Germany (0.49), Italy (0.29), Netherlands (0.25), Spain (0.21) and the UK (0.36). Once again, the low adjusted R-squared value for France may be an indication of the lesser role that steam coal plays in electricity generation as the country relies more on nuclear powered generation. The supply equations show values generally similar to those for the demand. While the Theil 
inequality coefficient values are relatively low, the existence of bias components of the $U$ coefficient in excess of 0.2 (see Appendix A), alerts us to the limited usefulness of projecting with this model too far into the future

The next validation test for the country supply and demand models is a comparison of the computed export and import volumes with results from other models for the forecast years 2005 and 2010. In the Western European markets, the model's forecast steam coal imports are $15 \%$ and $9 \%$ below those by the International Energy Agency, while in the Asian markets, the forecasts are 7\% and $13 \%$ above, for 2005 and 2010 respectively (see Table 5.4). The small difference between the model's forecast and those by the International Energy Agency provides some level of comfort in using these values in the second stage of the analysis, where the seaborne steam coal trade is simulated. The model's forecasts of exports are compared with those by three other agencies, EIA, IEA and WEFA on Table 5.3. The difference in the model's forecasts of exports and those by the EIA in the year 2005 are as follows: Australia (-5\%), South Africa (+19\%) and the United States (+34\%). In 2010, these are: Australia (+5\%), South Africa $(+38 \%)$ and the United States $(+67 \%)$. A comparison with the IEA projections, which do not have values for South Africa, shows the following differences in 2005: Australia (-9\%) and the United States (+13\%), while in 2010 these are as follows: Australia (+6\%) and the Unite States $(+39 \%)$. These results once again point to the fact that the country supply and demand functions estimated in this study are best suited for short forecast periods. 


\section{Table 5.1 Actual and Forecast Steam Coal Demand and Supply Quantities in Net Importing Countries of the Model (000's mtce)}

\begin{tabular}{|c|c|c|c|c|c|c|c|}
\hline \multicolumn{4}{|c|}{ Historical Period } & \multicolumn{4}{|c|}{ Forecast Period } \\
\hline Country & 1990 & 1995 & 2000 & 2005 & 2010 & 2015 & 2020 \\
\hline \multicolumn{8}{|l|}{ Japan } \\
\hline Demand & 32751 & 49644 & 66933 & 75453 & 88659 & 103121 & 119053 \\
\hline Supply & 6824 & 4928 & 2602 & 1556 & 871 & 480 & 262 \\
\hline Imports & 25928 & 44716 & 64332 & 73897 & 87788 & 102641 & 118791 \\
\hline \multicolumn{8}{|l|}{ South Korea } \\
\hline Demand $^{\text {(a) }}$ & 76554 & 54501 & 39597 & 52740 & 61140 & 70878 & 82167 \\
\hline Net Imp. Asia & 102482 & 99217 & 103929 & 126637 & 148928 & 173519 & 200958 \\
\hline \multicolumn{8}{|l|}{ Belgium } \\
\hline Demand & 6977 & 6897 & 5238 & 6709 & 8398 & 10511 & 13155 \\
\hline Supply & 1611 & 436 & 296 & 144 & 68 & 32 & 15 \\
\hline Imports & 5365 & 6460 & 4942 & 6565 & 8330 & 10479 & 13140 \\
\hline \multicolumn{8}{|l|}{ Germany } \\
\hline Demand & 24596 & 21440 & 21846 & 19285 & 16476 & 14075 & 12410 \\
\hline Supply & 16787 & 11867 & 7745 & 5406 & 3595 & 2366 & 1548 \\
\hline Imports & 7809 & 9573 & 14101 & 13879 & 12881 & 11710 & 10862 \\
\hline \multicolumn{8}{|l|}{ France } \\
\hline Demand & 14509 & 11088 & 12336 & 10016 & 7923 & 6149 & 4709 \\
\hline Supply & 8443 & 6946 & 4006 & 2905 & 2093 & 1501 & 1073 \\
\hline Imports & 6067 & 4142 & 8330 & 7111 & 5830 & 4648 & 3636 \\
\hline \multicolumn{8}{|l|}{ Italy } \\
\hline Demand & 9614 & 9220 & 10214 & 8317 & 6561 & 5061 & 3841 \\
\hline \multicolumn{8}{|l|}{ Netherlands } \\
\hline Demand & 8001 & 7338 & 8057 & 7308 & 6281 & 5391 & 4628 \\
\hline \multicolumn{8}{|l|}{ Spain } \\
\hline Demand & 12891 & 14639 & 19253 & 19192 & 18559 & 17746 & 16829 \\
\hline Supply & 13147 & 11771 & 10206 & 10514 & 11904 & 13529 & 15376 \\
\hline Imports & (256) & 2868 & 9046 & 8679 & 6655 & 4217 & 1453 \\
\hline \multicolumn{8}{|l|}{ UK } \\
\hline Demand & 86892 & 53228 & 41135 & 35906 & 43252 & 50494 & 59276 \\
\hline Supply & 83543 & 46521 & 28592 & 18119 & 13032 & 9241 & 6484 \\
\hline Imports & 3350 & 6707 & 12542 & 17789 & 30220 & 41254 & 52791 \\
\hline & 39950 & & & & 72533 & 83004 & \\
\hline Imports Europe & & 46308 & 67233 & 64843 & & & 93583 \\
\hline & 142431 & 145525 & & & & 256525 & \\
\hline Model Imports & & & 171162 & 191480 & 221460 & & 294541 \\
\hline
\end{tabular}

Source: Based on models estimated by the author.

Notes: (a) - South Korea's demand estimates are projections based on 5.9\% growth rate from 2000 as cited in Coal Information 2001, p I.140. 
Table 5.2 Actual and Forecast Steam Coal Demand and Supply Quantities in Net Exporting Countries of the Model (000's mtce)

\begin{tabular}{lrrr|rrrr}
\hline Historical Period & & & & Forecast Period & & \\
\hline Country & $\mathbf{1 9 9 0}$ & $\mathbf{1 9 9 5}$ & $\mathbf{2 0 0 0}$ & $\mathbf{2 0 0 5}$ & $\mathbf{2 0 1 0}$ & $\mathbf{2 0 1 5}$ & $\mathbf{2 0 2 0}$ \\
\hline Australia & & & & & & & \\
$\quad$ Demand & 30243 & 33643 & 45910 & 56230 & 69600 & 86311 & 107182 \\
$\quad$ Supply & 65248 & 81680 & 104588 & 136907 & 179700 & 233138 & 299877 \\
$\quad$ Exports & 35006 & 48036 & 58678 & 80677 & 110100 & 146827 & 192696 \\
\hline RSA & & & & & & & \\
$\quad$ Demand & 96692 & 115407 & 129710 & 142060 & 151355 & 160463 & 169498 \\
$\quad$ Supply & 134215 & 163678 & 188836 & 213187 & 239526 & 269118 & 302367 \\
$\quad$ Exports & 37523 & 48271 & 59126 & 71127 & 88171 & 108655 & 132868 \\
\hline U.S.A. & & & & & & & \\
$\quad$ Demand & 627375 & 638844 & 693489 & 774799 & 848535 & 942735 & 1029330 \\
$\quad$ Supply & 658449 & 661305 & 704779 & 799063 & 874326 & 971221 & 1060258 \\
$\quad$ Exports & 31074 & 22460 & 11290 & 24265 & 25791 & 28485 & 30928 \\
& & & & & & & \\
\hline Model & 103603 & 118768 & 129093 & 176069 & 224061 & 283968 & 356492 \\
\hline Exports & & & &
\end{tabular}

Source: Based on models estimated by the author.

Table 5.3 Comparative Forecasts of Steam Coal Exports With Other Models (000's mtce)

\begin{tabular}{lr|rr}
\hline Historical Period & & \multicolumn{2}{|c}{ Forecast Period } \\
\hline & $\mathbf{2 0 0 0}$ & $\mathbf{2 0 0 5}$ & $\mathbf{2 0 1 0}$ \\
\hline Model & & & \\
$:$ Australia & 58678 & 80677 & 110100 \\
: RSA & 59126 & 71127 & 88171 \\
: USA & 11290 & 24265 & 25791 \\
\hline EIA $^{(1)}$ & & & \\
$:$ Australia & 72734 & 84987 & 95256 \\
$:$ RSA & 57130 & 59814 & 63648 \\
: USA & 19268 & 18130 & 15475 \\
\hline WEFA & & & \\
$:$ Australia & NA & 92123 & 106956 \\
$:$ RSA & NA & 75232 & 76077 \\
$:$ USA & NA & 9198 & 9198 \\
\hline IEA & & & \\
$:$ Australia & 73400 & 88600 & 103700 \\
$:$ RSA & NA & NA & NA \\
$:$ USA & 24600 & 21400 & 18500 \\
\hline
\end{tabular}

Source: Model values based on estimation by the author.

Notes: ${ }^{(1)}$ - Table 103. World Steam Coal Flows by Importing Regions and Exporting Countries, Energy

Information Administration, Annual Energy Outlook 2002, National Energy Modeling System, pp 214-215.

(2) - Table 4.8 Comparative Forecasts of World Hard Coal Exports: 2000/2010, Coal Information 2001, Part

I, pp I. 156.

(3) - Table 4.7 IEA Projected Coal Trade (Mtce), Coal Information 2001, Part I, pp I. 154. The above projections for 2000 are actually for 1999. 
Table 5.4 Comparative Forecasts of Steam Coal Imports With Other Models (000's mtce)

\begin{tabular}{lr|rr}
\hline Historical Period & & Forecast Period & \\
\hline & $\mathbf{2 0 0 0}$ & $\mathbf{2 0 0 5}$ & $\mathbf{2 0 1 0}$ \\
\hline Model & & \\
: Belgium & & & \\
: France & 4942 & 6565 & 6565 \\
: Germany & 8330 & 7111 & 5830 \\
: Italy & 14101 & 11321 & 7910 \\
: Netherlands & 10214 & 8317 & 6561 \\
: Spain & 8057 & 7308 & 6281 \\
: UK & 9046 & 3875 & 4195 \\
& 12542 & 17789 & 30220 \\
\hline Sub-total Europe & 67233 & 64843 & 72533 \\
\hline : Japan & 64332 & 73897 & 87788 \\
: S. Korea & 39597 & 52740 & 61140 \\
\hline Sub-total Asia & 103929 & 126637 & 148928 \\
\hline IEA & & & \\
: Belgium & 6900 & 7100 & 7100 \\
: France & 9200 & 5400 & 5900 \\
: Germany & 16500 & 22100 & 22800 \\
: Italy & 9500 & 8400 & 8900 \\
: Netherlands & 12400 & 8000 & 6400 \\
: Spain & 12400 & 8600 & 8800 \\
: UK & 11200 & 16200 & 19400 \\
\hline Sub-total Europe & 78100 & 75800 & 79300 \\
\hline : Japan & 59000 & 63200 & 62700 \\
: S. Korea & 31600 & 55100 & 69200 \\
\hline Sub-total Asia & 90600 & 118300 & 131900 \\
\hline
\end{tabular}

Source: Model values based on estimation by the author.

Notes: ${ }^{(1)}$ - Table 4.7 IEA Projected Coal Trade (Mtce), Coal Information 2001, Part I, pp I. 154. The above projections for 2000 are actually for 1999. 


\subsection{Results and Validation of the Long Run Marginal Cost Functions}

The second stage of this modeling exercise depends greatly on the validity of the estimated long run marginal cost functions for the net exporters in the model. The results of the estimation of the long run marginal cost functions are presented in Appendix B. The transformed long run marginal cost functions are provided in Table 5.1 below. The results for South Africa, and therefore, Botswana are the lowest of the four exporting countries in the model. This means that if one were to construct an industry supply curve for all countries in the model, South Africa and Botswana would occupy a position at the lower cost end of such an industry supply curve. For this reason, any sensitivity analysis on the demand side would not impact negatively the competitiveness of these low cost producers.

The validation of these models, therefore proceeds as follows: reporting results from tests on MAPE, $U$, and the interpretation of bias component of $U$ in the context of the suitability of a model for long range forecasting. Lastly, we vary the starting date for the long run marginal cost function to 1983 from 1980. This last achieves a parametric variation of both the intercept and slope terms for the long run marginal cost function to check for the model's stability over time.

The MAPE for each exporting country is as follows: Australia (19.32\%), South Africa (3.26\%) and the United States (2.03\%). The long run marginal cost function for South Africa is applied also to coal supplies from Botswana. The Theil inequality coefficients are: Australia (0.16), South Africa (0.03), and the United States (0.01). The bias proportion of the Theil inequality coefficient in excess of 0.2 indicates that these models are not suitable for long range forecasts. 
Table 5.5 Transformed Long Run Marginal Cost Functions (1980 to 1997)

\begin{tabular}{cc}
\hline Period 1991-1995: & \\
Australia: & $\mathrm{P}=50.90+7.06 \times 10^{-5} \mathrm{Q}^{\mathrm{s}}$ \\
South Africa: & $\mathrm{P}=15.54+6.51 \times 10^{-5} \mathrm{Q}^{\mathrm{s}}$ \\
Botswana: & $\mathrm{P}=15.54+6.51 \times 10^{-5} \mathrm{Q}^{\mathrm{s}}$ \\
U.S.A.: & $\mathrm{P}=42.97+7.32 \times 10^{-6} \mathrm{Q}^{\mathrm{s}}$ \\
\hline Period 1996-2000: & \\
Australia: & $\mathrm{P}=32.31+7.06 \times 10^{-5} \mathrm{Q}^{\mathrm{s}}$ \\
South Africa: & $\mathrm{P}=5.01+6.51 \times 10^{-5} \mathrm{Q}^{\mathrm{s}}$ \\
Botswana: & $\mathrm{P}=5.01+6.51 \times 10^{-5} \mathrm{Q}^{\mathrm{s}}$ \\
U.S.A.: & $\mathrm{P}=32.19+7.32 \times 10^{-6} \mathrm{Q}^{\mathrm{s}}$ \\
\hline
\end{tabular}

Source: Model values based on estimation by the author.

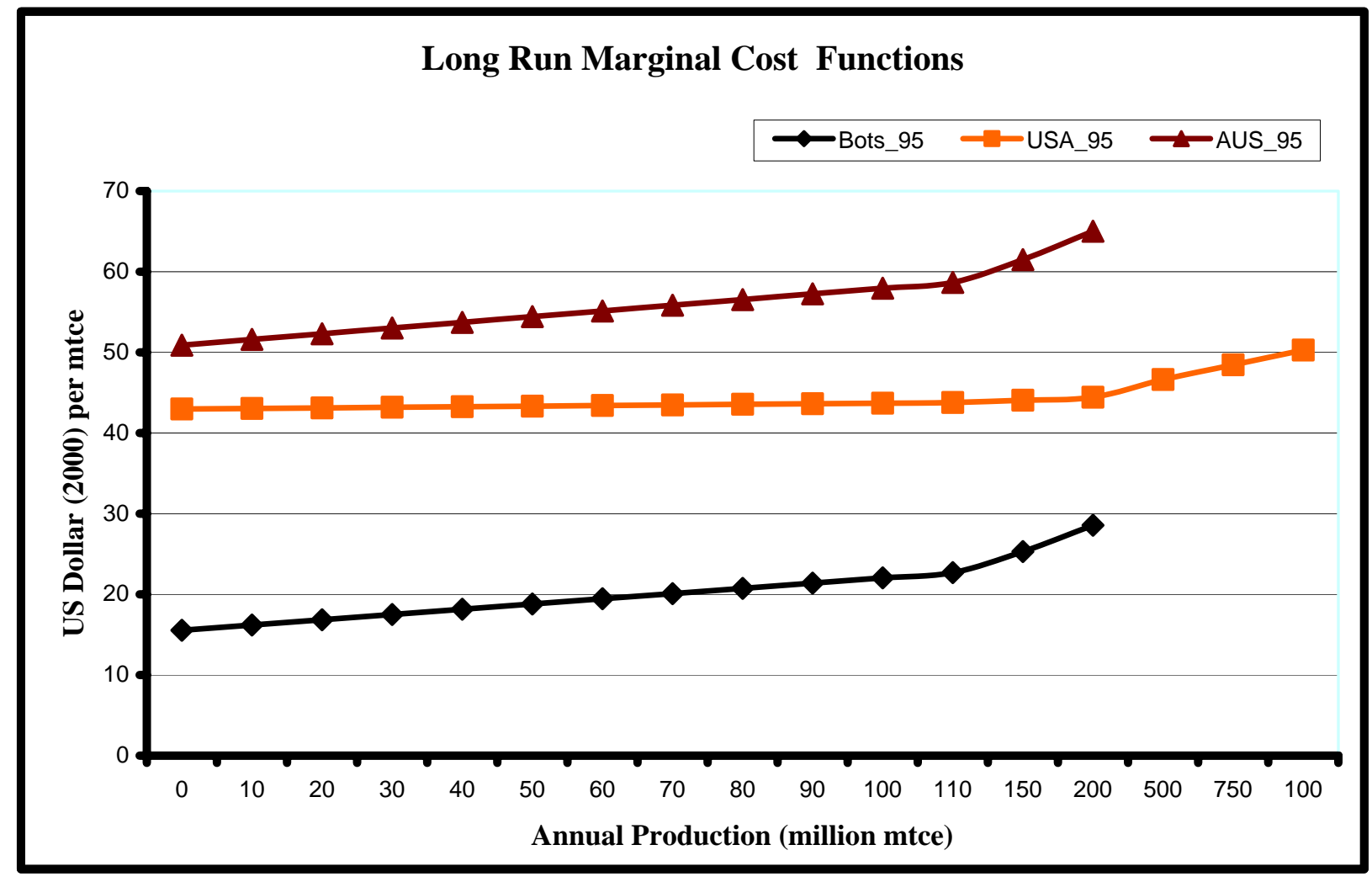

Figure 5.1 Transformed Long Run Marginal Cost Functions for Exporters

Source: Based on model estimation by the author

Note: Botswana's function is the same as that for South Africa. 
The non-negativity constraint on both the intercept and slope terms of the long run marginal cost function is observed to hold only during the sample period. For this reason, the transformed functions during the sample period are used for future periods in the model simulation and forecast stages, which is equivalent to making a further assumption that there are no supply shifts in the long run marginal cost function over the forecast period.

The validity of the long run marginal cost function is critical to the acceptance of the results of the model simulation as it determines the supply competitiveness of each of the net exporters in the model. For this reason the relatively high values for the adjusted R-squared, Australia (0.42), South Africa (0.61) and the United States (0.32), indicate that the model has good explanatory power. The parametric variation of both the intercept and slope terms for the long run marginal cost functions is achieved by varying the starting date for the long run marginal cost function to 1983 from 1980. The resulting sample period is 18 years, which is similar to the length of the original period 1980 to 1997 . The varying of the start date tests the robustness of the estimated parameters over time to determine if they will maintain their signs. This method is preferred over the variation of the intercept and slope coefficients as the estimated long run marginal cost function for South Africa, and therefore, Botswana, result in the lowest intercept terms for these producers and any variation of the transformed intercept and slope variables would have to be of magnitudes that are not easy to justify in a policy context.

The sensitivity results for the long run marginal cost of supply function over the new sample period 1983-2000 are provided in Appendix B. Their adjusted R-squared values are: Australia (0.25), South Africa (0.61) and the United States (0.49). These compare very favorably with those in the original estimation. The coefficients on the supply quantity variable maintain their positive sign, which shows that the model is stable over this period and 18 observations. 


\subsection{Simulation With the Spatial and Dynamic Optimization Model}

We now proceed to the second stage of our analysis in which we apply the spatial and dynamic optimization model of the world steam coal trade to simulate this trade and obtain the results of the base case scenario. The price equations used in this model are shown on Table 5.5 above. The rail transportation costs are the actual values for 1995 and 2000 while those for 2005 were projected from the actual values in 2000 . The projected rates for 2005 were applied to 2010. Maritime transportation costs were estimated by using time series data on costs along each major seaborne steam coal trading route. This involved ordinary least squares regressions of sea freight costs per mtce on the price of crude oil, which were used as a proxy for the price of bunker fuel oil, annual steam coal quantities exported between each pair of export and import port along each route and finally on the scale of the seaborne steam coal trade. The results of this estimation are shown in Appendix C. The values for rail and maritime transportation costs are presented on Tables 5.6 and 5.7 below. This section presents the purpose of the base case simulation, the assumption for the base case, the two simulated routes for Botswana's steam coal exports, and the results of the base case simulation and their validation. 
Table 5.6 Indicative Rail Transportation Costs ( in year 2000 US \$ per mtce)

\begin{tabular}{|c|c|c|c|c|c|c|}
\hline & \multicolumn{4}{|c|}{ Historical Period } & \multicolumn{2}{|c|}{ Forecast Period } \\
\hline Mine to Port & $\begin{array}{l}\text { Distance } \\
(\mathrm{Km})\end{array}$ & 1990 & 1995 & 2000 & 2005 & 2010 \\
\hline Australia & $280-380$ & 14.54 & 10.29 & 6.05 & 3.81 & 3.81 \\
\hline \multicolumn{7}{|l|}{ Witbank } \\
\hline : Richards Bay & 635 & 25.28 & 12.83 & 7.28 & 4.31 & 4.31 \\
\hline : Matola & 453 & 18.03 & 9.16 & 5.19 & 3.07 & 3.07 \\
\hline : Walvis Bay & 2000 & 79.61 & 40.42 & 22.91 & 13.56 & 8.03 \\
\hline \multicolumn{7}{|l|}{ Mmamabula } \\
\hline : Richards Bay & 1255 & 46.41 & 20.52 & 13.18 & 7.80 & 7.80 \\
\hline : Matola & 1100 & 40.68 & 17.98 & 11.55 & 6.84 & 6.84 \\
\hline : Walvis Bay & 1500 & 55.47 & 24.52 & 15.75 & 9.32 & 9.32 \\
\hline \multicolumn{7}{|l|}{ Appalachia } \\
\hline : Hampton Roads & 700 & 28.60 & 20.24 & 19.16 & 17.87 & 17.87 \\
\hline
\end{tabular}

Source: Compiled from Coal Information, 1990, 1996 and 2001, International Energy Agency, Paris.

Table 5.7 Maritime Transportation Costs ( in year 2000 US \$ per mtce)

\begin{tabular}{|c|c|c|c|c|c|c|}
\hline & \multicolumn{4}{|c|}{ Historical Period } & \multicolumn{2}{|c|}{ Forecast Period } \\
\hline Export to Import Port & $\begin{array}{l}\text { Distance } \\
\text { (Nautical miles) }\end{array}$ & 1990 & 1995 & 2000 & 2005 & 2010 \\
\hline $\begin{array}{l}\text { Gladstone } \\
\text { : ARA } \\
\text { : Yokohama }\end{array}$ & $\begin{array}{r}13900 \\
4200\end{array}$ & $\begin{array}{r}16.68 \\
9.98\end{array}$ & $\begin{array}{l}16.03 \\
10.44\end{array}$ & $\begin{array}{r}17.02 \\
9.08\end{array}$ & $\begin{array}{r}13.34 \\
8.95\end{array}$ & $\begin{array}{r}13.30 \\
9.35\end{array}$ \\
\hline $\begin{array}{l}\text { Richard's Bay } \\
\text { : ARA } \\
\text { : Yokohama }\end{array}$ & $\begin{array}{l}7400 \\
7600\end{array}$ & $\begin{array}{l}12.97 \\
13.74\end{array}$ & $\begin{array}{l}12.00 \\
14.36\end{array}$ & $\begin{array}{l}11.18 \\
10.45\end{array}$ & $\begin{array}{l}7.94 \\
8.27\end{array}$ & $\begin{array}{l}7.44 \\
7.63\end{array}$ \\
\hline $\begin{array}{l}\text { Hampton Roads } \\
\text { : ARA } \\
\text { : Yokohama } \\
\end{array}$ & $\begin{array}{l}3900 \\
9500 \\
\end{array}$ & $\begin{array}{l}10.33 \\
26.00\end{array}$ & $\begin{array}{r}9.47 \\
20.96 \\
\end{array}$ & $\begin{array}{r}8.37 \\
17.80 \\
\end{array}$ & $\begin{array}{r}7.19 \\
15.92 \\
\end{array}$ & $\begin{array}{r}7.36 \\
16.50 \\
\end{array}$ \\
\hline $\begin{array}{l}\text { Matola } \\
\text { : ARA } \\
\text { : Yokohama }\end{array}$ & $\begin{array}{l}7400 \\
7600\end{array}$ & $\begin{array}{l}12.97 \\
13.74\end{array}$ & $\begin{array}{l}12.00 \\
14.36\end{array}$ & $\begin{array}{l}11.18 \\
10.45\end{array}$ & $\begin{array}{l}7.94 \\
8.27\end{array}$ & $\begin{array}{l}7.44 \\
7.63\end{array}$ \\
\hline $\begin{array}{l}\text { Walvis Bay } \\
\text { : ARA } \\
\text { : Yokohama }\end{array}$ & $\begin{array}{l}5900 \\
9100\end{array}$ & $\begin{array}{l}10.34 \\
16.45\end{array}$ & $\begin{array}{r}9.57 \\
17.19\end{array}$ & $\begin{array}{r}8.91 \\
12.51\end{array}$ & $\begin{array}{l}6.33 \\
9.91\end{array}$ & $\begin{array}{l}5.93 \\
9.14\end{array}$ \\
\hline
\end{tabular}

Source: 1) International Coal Review Monthly, National Mining Association, 1983 to 2000, Washington, D.C., Table 17, Single Trip Ocean Freight Rates per Long Ton of Coal

2) Shipping distances are from Mining Cost Services, March 2002, Western Mining Engineering, p TR C4

Notes: Maritime transportation costs are converted by author to US \$ per mtce. The $1990-2000$ values are actual values while those for 2005 and 2010 are econometrically predicted. 


\subsubsection{Base Case Simulation}

The objective of the base case simulation is to determine whether or not coal from Botswana is competitive in the world steam coal markets of Asia and Western Europe, and further, to define both the temporal and spatial distribution of steam coal exports from Botswana that would have been likely in the past and also in the future. The scenario seeks to identify export routes to seaports for Botswana's coal exports and then to determine whether or not there is economic justification for the provision of rail and port infrastructure in the event that the model solution includes coal exports from Botswana.

\subsubsection{Assumptions for the Base Case}

The competitiveness of Botswana as an exporter of steam coal to markets in Asia and Western Europe is simulated against that of Australia, South Africa and the United States. The approach involves a reconstruction of the coal industries in these four countries beginning in 1990 and simulating the growth in production through the development of new capacity to meet both domestic and export demand for steam coal. The forecast domestic demand in the net exporting countries and import demand in the net importing countries were obtained from the econometric model of the world steam coal trade and are therefore exogenous to the spatial and dynamic optimization model. The production from new capacity is assumed to start in the fifth year in each of the five-year periods, 1991-1995, 1996-2000, 2001-2005 and 2006-2010. The model is then used to determine which countries in the model will respond by developing coal production capacity to meet both domestic and export demand for steam coal.

The spatial and dynamic optimization model has a quadratic objective function in which the objective is to minimize the sum of discounted annualized capital expenditure costs for capacity additions, long run marginal costs, both rail transportation and maritime transportation 
costs of internationally traded steam coal. The specific assumptions for the base case scenario are that:

1. exporters in the model build capacity to meet domestic demand and rest of world export demand first;

2. exporters face a residual demand equal to their combined market share in both of the two markets of Western Europe and Asia computed from historical data to be $62 \%$;

3. exporters' market share in the rest of the world markets are treated in the same way as domestic demand in that they are given zero transportation costs and do not appear in the trade flows;

4. steam coal exports from Botswana are assumed to begin at 10.0 million mtce in 1995 and to follow a trajectory similar to that realized in other exporting countries such as South Africa and Australia where these grew, on average, at about 10 million mtce every five years; the port capacity constraint for the simulated ports of Walvis Bay and Matola are assumed to grow in line with Botswana's coal exports and in fact are the ones set exogenous to the model while the model solves endogenously for the addition of production capacity from Botswana's coal fields;

5. the capital cost estimate is valid for a room and pillar operation using continuous miners and rated between 2000 and 25000 metric tons per day of coal. This translates into a mine size of 7.5 million metric tons of coal per annum. The capital cost estimate for each exporter assumes the development of multiple coal mine operations of this size to meet increased demand and therefore ignores any scale economies beyond this maximum size;

6. the real rate of discount is $15 \%$ and this applies on investment projects with a fixed life of mine of 20 years;

7. South Africa's coal exports use the Richard's Bay coal terminal even though the Matola port would be at a cost advantage because of its shorter hauling distance, and the maximum port capacity is 82 million metric tons per annum;

8. the share of rest of world exporters to the importing countries in the model is assumed to fill up the remaining share of the demand and does not enter the model;

9. the long run marginal cost of supply function is equal to the breakeven price or the minimum acceptable selling price, which means that exporters realize zero economic profits, and

10. the total export port capacity for the two simulated ports constraints rises from 10 million mtce in 1995 to 40 million in 2010 in equal increments of 10 million mtce in each five year period. 


\subsubsection{The Two Simulated Routes for Botswana's Coal Exports}

The two simulated routes are: 1) Mmamabula - Lobatse - Ghanzi - Gobabis - Walvis Bay, in Namibia, and 2) Mmamabula - Ellisras - Pretoria - Matola in Maputo, Mozambique. The first route would use existing rail from Mmamabula to Lobatse, a distance of about 200km and a simulated railway line from Lobatse to Ghanzi, along the same corridor as the TransKalahari Highway on the Botswana side, a distance of about $700 \mathrm{~km}$ and that from Ghanzi to Gobabis to join an existing railway line in Namibia. The total estimated length of this haul would be $1500 \mathrm{~km}$. The second route links Mmamabula to the line that is currently being used to export steam coal from ISCOR's Grootegelug mine near Ellisras. The approximate total length of this haul is $1100 \mathrm{~km}$. These routes are shown in Figure 5.2 below.

The routes from export to import ports are assumed to be the same as those for South Africa's coal exports to Western Europe and Asia. The Richard's Bay port is approximately equidistant from markets in Asia and Western Europe at 7400 and 7600 nautical miles respectively (Western Mining, 2002, Table 6 p. TR C4). A computation of the reduction in the sea voyage from using Walvis Bay instead of the East facing ports of Southern Africa shows that this would be about 20\%. A port such as Walvis Bay would, therefore, be about the same distance from the Western European steam coal markets as exports ports for South American exporters.

\subsubsection{Results of the Base Case Simulation}

The results of the base case simulation scenario are shown below in Tables 5.8, 5.9 and 5.10. These results show that Botswana would have ranked first in competitiveness in the Western European steam coal market, followed by South Africa, the United States and finally 
Australia. In the Asian market, Botswana would have ranked third after Australia and South Africa but ahead of the United States. The market shares for Botswana in Western Europe, expressed as a percentage of total model exports to this market, would have been $35 \%$ in 1995 , $48 \%$ in 2000, 0\% in 2005 and $62 \%$ in 2010. South Africa's market share would have risen from $27 \%$ in 1995 to $52 \%$ in 2000, 100\% in 2005 and $0 \%$ in 2010. The US' market share in Western Europe would have begun at $38 \%$ in 1995 , declined to zero in the intervening years and rebounded to $38 \%$ by 2010 .

The loss of market share by South Africa in Western Europe is made up for by the gain of market share in Asia, where its share would have risen from $47 \%$ in 1995 to $62 \%$ in 2010 at the expense of that for Australia, which would have declined from 54\% in 1995 to $21 \%$ in 2010. Botswana's share of the Asian market would have been $39 \%$ in 2005 and $17 \%$ in 2010 (see Figures 5.3 and 5.4). The base case assumes a residual demand of $62 \%$ to be faced by the four exporters in the model. It is therefore a straightforward exercise to express the resulting simulated market shares in terms of the world seaborne steam coal trade. The market shares reported on this basis are given on Figure 5.4 below and once again these are in general agreement with the actual values for 2000 for the existing exporters. On this basis, Botswana's simulated share of the seaborne steam coal trade would have been $7 \%$ in $1995,12 \%$ in 2000 , $16 \%$ in 2005 and finally $19 \%$ in 2010 . In tonnage terms, this would have been 10.0 million mtce in 1995 and doubling over each five-year interval to end the simulation period at 40.0 million mtce. The country's competitiveness would have ranked it in the second position after South Africa and ahead of Australia, which would have been in the third position, while the United States would have occupied the last position among the four exporters in the model. 


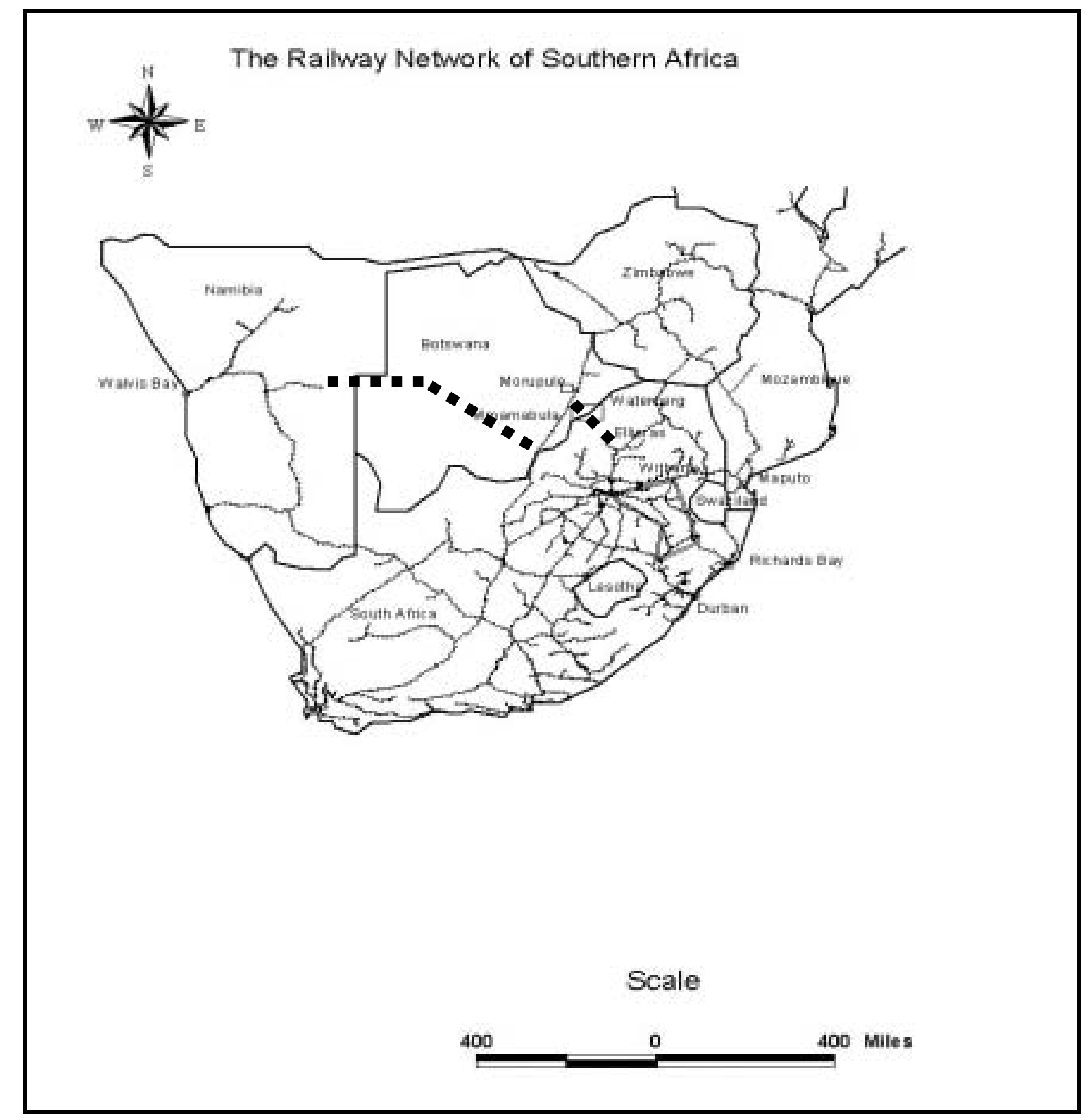

Figure 5.2 Simulated Railway Lines (bold dashed pattern) to Seaports With the Existing Railway Network of Southern Africa

Source: Compiled by author from GIS database files retrieved on April $19^{\text {th }}, 2002$ from: http://www.maproom.psu.edu/dcw/

Note: Coal deposits location is not geo-referenced and is therefore only illustrative. 


\section{Table 5.8 Simulated Gross Steam Coal Exports (000's mtce)}

\begin{tabular}{lrrrr}
\hline & $\mathbf{1 9 9 5}$ & $\mathbf{2 0 0 0}$ & $\mathbf{2 0 0 5}$ & $\mathbf{2 0 1 0}$ \\
\hline Australia & 32759 & 40324 & 32227 & 18887 \\
\hline South Africa & 59736 & 70283 & 82281 & 82231 \\
\hline United States & 19643 & 14163 & 14271 & 29287 \\
\hline Botswana & 10033 & 20033 & 30033 & 40033 \\
\hline
\end{tabular}

Source: Based on model simulations by the author.

Table 5.9 Simulated Flow of Steam Coal From Mine to Export Seaport (000's mtce)

\begin{tabular}{lrrrr}
\hline & $\mathbf{1 9 9 5}$ & $\mathbf{2 0 0 0}$ & $\mathbf{2 0 0 5}$ & $\mathbf{2 0 1 0}$ \\
\hline Queensland to Gladstone & 32755 & 40258 & 32219 & 18886 \\
\hline Appalachia to Hampton Roads & 10743 & 0 & 0 & 14991 \\
\hline Witbank to Richard's Bay & 36000 & 45000 & 57000 & 57000 \\
\hline Mmamabula to Richard's Bay & 0 & 0 & 0 & 0 \\
\hline Mmamabula to Matola & 10000 & 20000 & 30000 & 40000 \\
\hline Mmamabula to Walvis Bay & 0 & 0 & 0 & 0 \\
\hline
\end{tabular}

Source: Based on model simulations by the author.

Note: These coal flows are net of those to rest of world markets. The difference between the gross simulated steam coal flows in table 5.6 and the above simulated net flows is the flows to rest of world markets.

Table 5.10 Simulated Flow of Seaborne Steam Coal From Export to Import Port (000's mtce)

\begin{tabular}{lrrrr}
\hline & $\mathbf{1 9 9 5}$ & $\mathbf{2 0 0 0}$ & $\mathbf{2 0 0 5}$ & $\mathbf{2 0 1 0}$ \\
\hline Gladstone to ARA ${ }^{(1)}$ & & & & \\
\hline Gladstone to Yokohama & 32755 & 40258 & 32219 & 18886 \\
\hline Hampton Roads to ARA & 10743 & 0 & 0 & 14991 \\
\hline Hampton Roads to Yokohama & 0 & 0 & 0 & 0 \\
\hline Richard's Bay to ARA & 7737 & 21342 & 11337 & 0 \\
\hline Richard's Bay to Yokohama & 28263 & 23658 & 45663 & 57000 \\
\hline Matola to ARA & 10000 & 20000 & 0 & 24297 \\
\hline Matola to Yokohama & 0 & 0 & 30000 & 15704 \\
\hline Walvis Bay to ARA & 0 & 0 & 0 & 0 \\
\hline Walvis Bay to Yokohama & 0 & 0 & 0 & 0 \\
\hline
\end{tabular}

Source: Based on model simulations by the author.

Notes: ${ }^{(1)}$ - Amsterdam, Rotterdam and Antwerp, which are taken as in ports of entry for steam coal into the modeled countries in the region. 


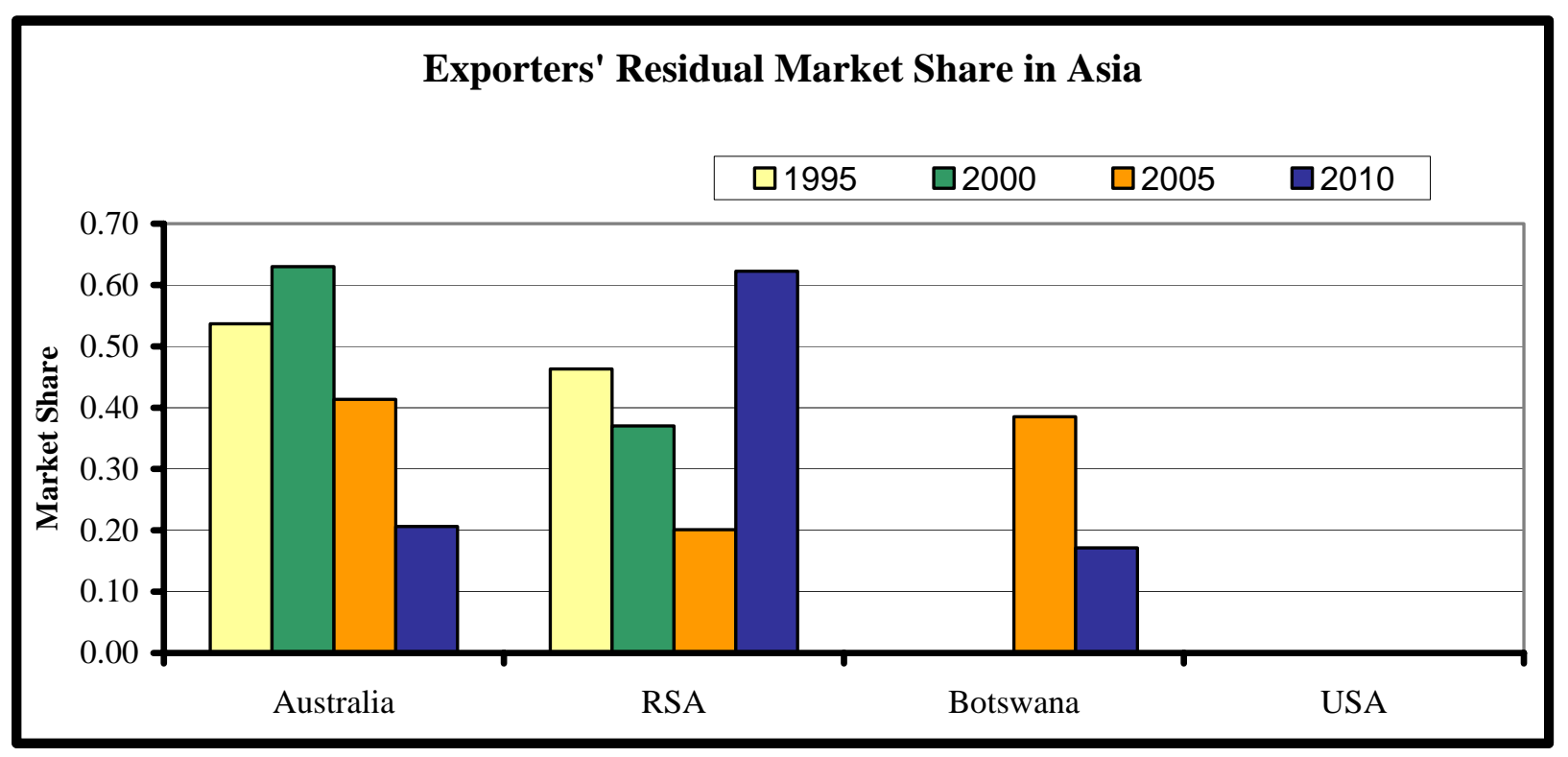

Figure 5.3 Simulation Results of the Base Case Scenario for the Exporters' Residual Market Share in Asia

Source: Based on model simulation by the author.

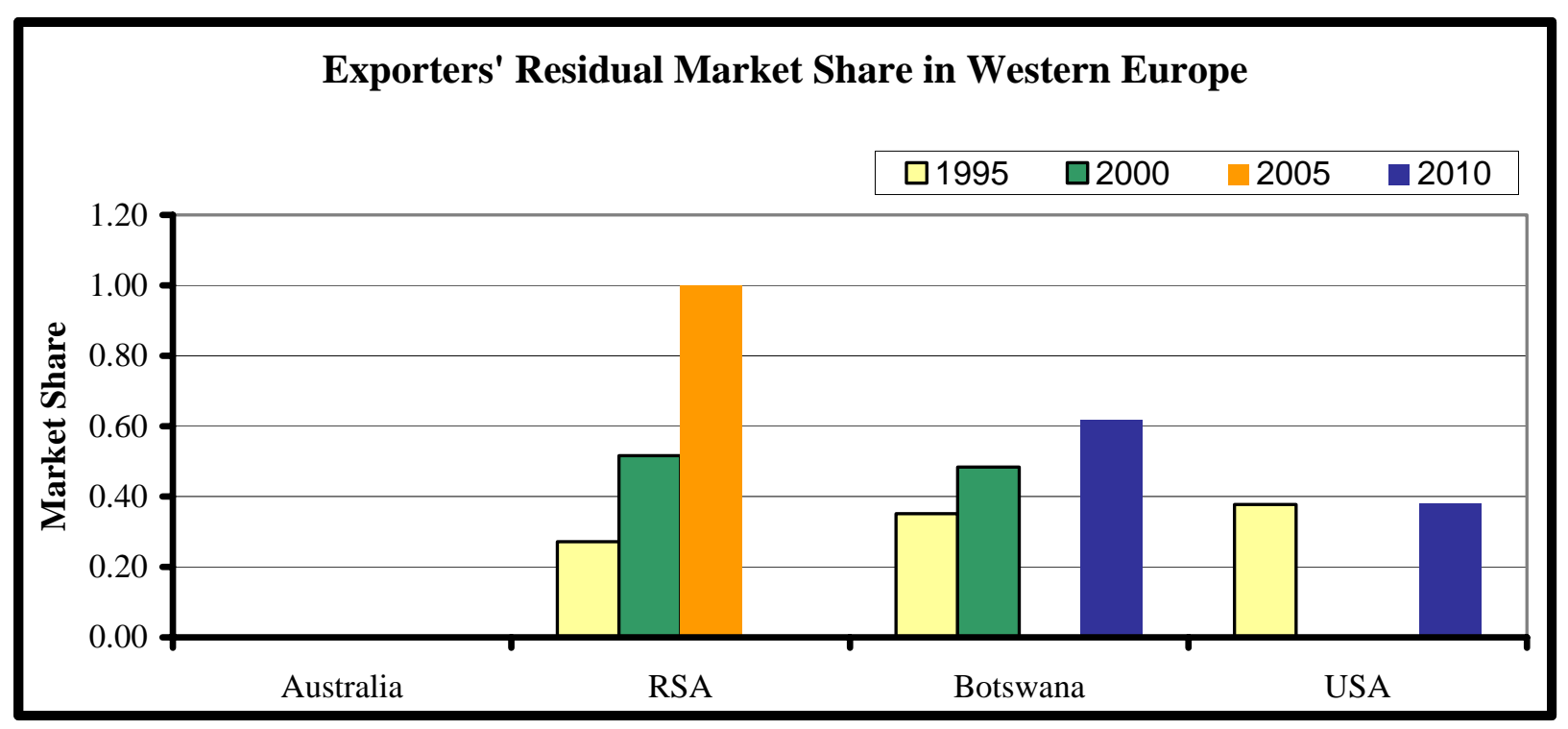

Figure 5.4 Simulation Results of the Base Case Scenario for Exporters' Residual Market Share in Western Europe

Source: Based on model simulation by the author. 


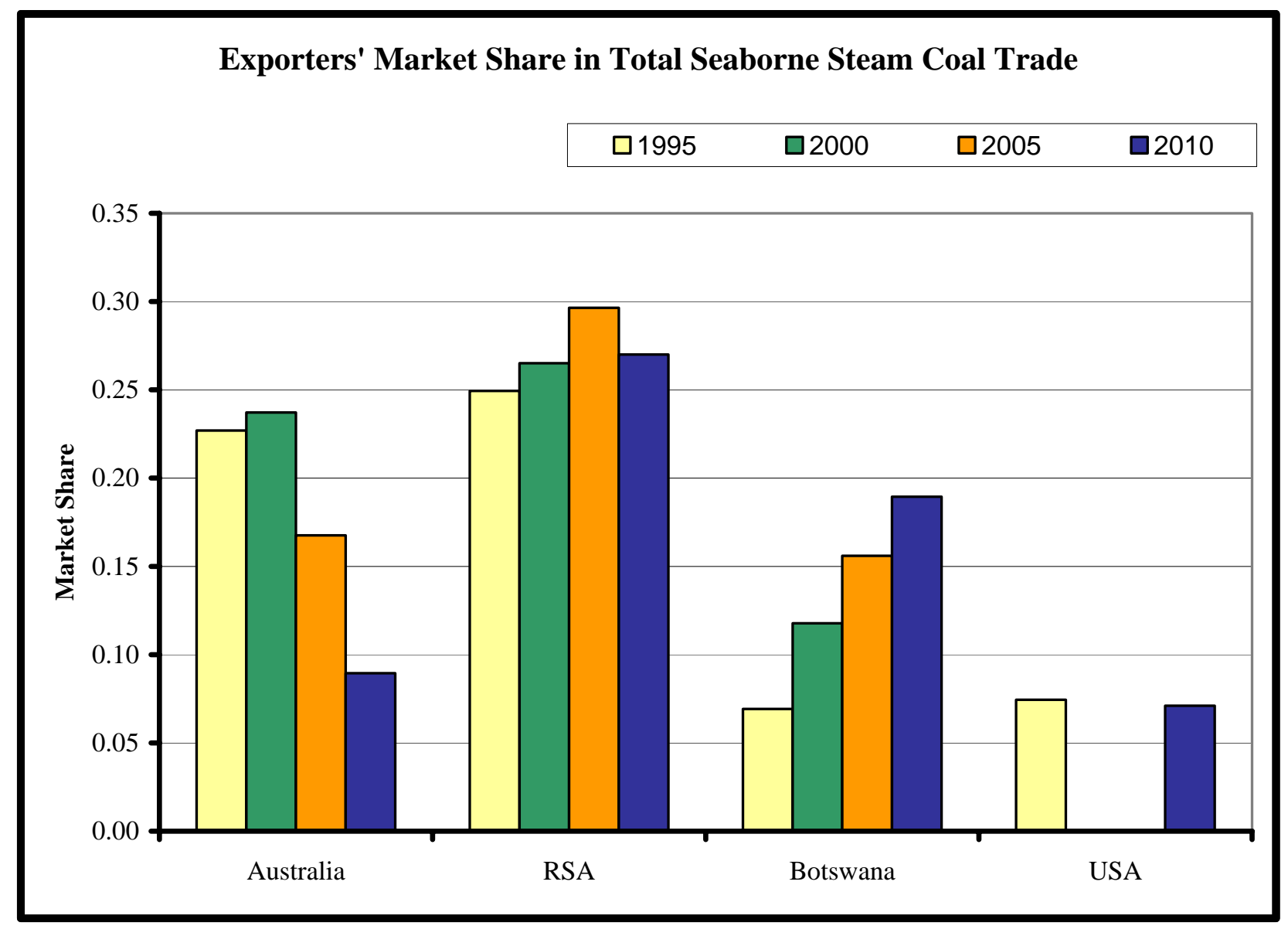

Figure 5.5 Simulation Results of the Base Case Scenario for Exporters' Market Share of the World Seaborne Steam Coal Trade

Source: Based on model simulation by the author. 


\subsubsection{Validation of the Results of the Base Case Simulation Scenario}

To extend the validation process of the model, one useful approach is to assess the response surface of the model. Programming models are difficult to validate and as developed by Yang and Labys (1981), one can confirm with statistical significance the appropriate response qualities of a model. The approach used normally involves analysis of variance based on some form of experimental design. We therefore adopt two approaches for validating the spatial and dynamic optimization model used in this study. The first involves comparison with historical values to determine how closely the model represents the actual activity being modeled (see Gruver and Giarratani, 2002 and Yang, Hwang, and Sohng, 2002). The second approach is based on experimental design methods. The validation of this model proceeds as follows: (1) a comparison of optimal and historical values of exports and their distribution between origindestination pairs and, (2) an experimental design approach that determines the response surface for Botswana's simulated optimal exports to changes in capital expenditure costs, variable supply costs, rail and maritime transportation costs for the years 1995, 2000, 2005 and 2010.

\subsubsection{Comparison With Historical Supplies and Flows}

Tables 5.10 and 5.11 provide comparisons between the optimal and historical values of steam coal exports and their distribution between origin-destination pairs respectively. The exclusion of Botswana from among the suppliers from these tables reproduces the existing state of the world steam coal trade among the selected exporters, Australia, South Africa and the United States. While the validity of the econometric model was first validated in section 5.5 above, one aspect of this exercise included varying the starting period for the estimation period, leading to a new estimation horizon of 1983 to 2000. The price equations for the 1983-2000 are 
shown in Table 5.11 and when these are substituted into the optimization model, they reproduce the base case simulation results shown above in Tables 5.8, 5.9 and 5.10. This is due to the new long run marginal cost functions for South Africa having lower intercepts than in the base case scenario.

The difference between the optimal export volumes and the actual values for 1995 are: Australia (-7\%), South Africa (+24\%) and the United States (-30\%), while in 2000 these are: $4 \%,+24 \%$ and $-27 \%$ for Australia, South Africa and the United States, respectively (see Table 5.12 above). These values indicate good model performance.

Next we determine how well the model predicts the temporal and spatial distribution of this trade by comparing the models optimal trade flow values with the actual values for 1995 and 2000. The temporal and spatial distribution of this trade is provided in Table 5.13 below. The model performs well in depicting trade flows between the major suppliers and demanders and does poorly in explaining trade links with low traded volumes. For instance, the differences between the model's optimal trading volume between South Africa and Western Europe are -7\% and $+38 \%$ in 1995 and 2000 respectively while that to Asia, which is not a major market for South Africa, these differences are $+327 \%$ and $-6 \%$ for 1995 and 2000 respectively. A similar observation is made for differences in Australia's exports to the Asian market where the errors are $3.8 \%$ and $8 \%$ in 1995 and 2000 respectively, while for exports to Western Europe, the errors are as high as $-100 \%$ in both 1995 and 2000. As the United States is a marginal supplier to both markets, by virtue of having the highest marginal cost function among these exporters, its exports volumes are quite erratic. The differences in the model's prediction of exports to Western Europe are $-24 \%$ and $-100 \%$ in 1995 and 2000. The model predicts no US exports to Asian markets. 


\section{Table 5.11 Transformed Long Run Marginal Cost Functions}

(1983 to 2000)

\begin{tabular}{|c|c|}
\hline \multicolumn{2}{|l|}{ Period 1991 - 1995: } \\
\hline Australia: & $\mathrm{P}=44.05+1.37 \times 10^{-4} \mathrm{Q}^{\mathrm{s}}$ \\
\hline South Africa: & $\mathrm{P}=6.37+9.87 \times 10^{-5} \mathrm{Q}^{\mathrm{s}}$ \\
\hline Botswana: & $\mathrm{P}=6.37+9.87 \times 10^{-5} \mathrm{Q}^{\mathrm{s}}$ \\
\hline U.S.A.: & $\mathrm{P}=44.32+5.87 \times 10^{-6} \mathrm{Q}^{\mathrm{s}}$ \\
\hline \multicolumn{2}{|l|}{ Period 1996 - 2000: } \\
\hline Australia: & $\mathrm{P}=19.85+1.37 \times 10^{-4} \mathrm{Q}^{\mathrm{s}}$ \\
\hline South Africa: ${ }^{(a)}$ & $\mathrm{P}=9.87 \times 10^{-5} \mathrm{Q}^{\mathrm{s}}$ \\
\hline Botswana: & $\mathrm{P}=9.87 \times 10^{-5} \mathrm{Q}^{\mathrm{s}}$ \\
\hline U.S.A.: & $\mathrm{P}=33.17+5.87 \times 10^{-6} \mathrm{Q}^{\mathrm{s}}$ \\
\hline
\end{tabular}

Source: Model values based on estimation by the author.

Notes: ${ }^{\text {(a) }}$ - The computed intercept value is negative in 1996, therefore a zero intercept term is used to meet the non-negativity conditions in the mathematical programming model.

Table 5.12 Simulated Gross Steam Coal Exports Excluding Botswana (000's mtce)

\begin{tabular}{lrr|rr}
\hline \multicolumn{3}{c|}{ Historical Period } & \multicolumn{2}{c}{ Forecast Period } \\
\hline & $\mathbf{1 9 9 5}$ & $\mathbf{2 0 0 0}$ & $\mathbf{2 0 0 5}$ & $\mathbf{2 0 1 0}$ \\
\hline Australia & & & & \\
: Actual & 45923 & 62622 & & \\
$\quad$ : Model & 42793 & 60358 & 62222 & 48849 \\
$\quad$ Difference \% & -7.0 & -4.0 & & \\
\hline South Africa & & & & \\
$\quad$ : Actual & 48271 & 59126 & & \\
$\quad$ : Model & 59736 & 70283 & 82281 & 82231 \\
$\quad$ : Difference \% & +24.0 & +19.0 & & \\
\hline U.S.A. & & & & \\
$\quad$ : Actual & 27989 & 19421 & & \\
$\quad$ Model & 19643 & 14163 & 14271 & 39287 \\
$\quad$ : Difference \% & -30.0 & -27.0 & & \\
\hline Botswana & 0 & 0 & 0 & 0 \\
\hline
\end{tabular}

Source: Based on model simulations by the author. 
Table 5.13 Simulated Seaborne Steam Coal Flows Excluding Botswana (000's mtce)

\begin{tabular}{|c|c|c|c|c|}
\hline \multicolumn{3}{|l|}{ Historical Period } & \multicolumn{2}{|c|}{ Forecast Period } \\
\hline & 1995 & 2000 & 2005 & 2010 \\
\hline \multicolumn{5}{|l|}{ Gladstone to ARA $^{(1)}$} \\
\hline : Actual & 4427 & 6674 & \multirow{3}{*}{0} & \multirow{3}{*}{0} \\
\hline : Model & 0 & & & \\
\hline : Difference $\%$ & -100.0 & -100.0 & & \\
\hline \multicolumn{3}{|l|}{ Gladstone to Yokohama } & \multirow{4}{*}{62181} & \multirow{4}{*}{48849} \\
\hline : Actual & 41496 & 55948 & & \\
\hline : Model & 42755 & 60258 & & \\
\hline : Difference $\%$ & +3.0 & +8.0 & & \\
\hline \multicolumn{3}{|l|}{ Hampton Roads to ARA } & \multirow{4}{*}{0} & \multirow{4}{*}{24954} \\
\hline : Actual & 14176 & 2838 & & \\
\hline : Model & 10743 & 0 & & \\
\hline : Difference \% & -24.0 & -100.0 & & \\
\hline \multicolumn{3}{|c|}{ Hampton Roads to Yokohama } & \multirow{4}{*}{0} & \multirow{4}{*}{0} \\
\hline : Actual & 4889 & 3085 & & \\
\hline : Model & 0 & 0 & & \\
\hline : Difference \% & -100.0 & -100.0 & & \\
\hline \multicolumn{3}{|l|}{ Richard's Bay to ARA } & \multirow{4}{*}{41300} & \multirow{4}{*}{14258} \\
\hline : Actual & 19090 & 30059 & & \\
\hline : Model & 17737 & 41342 & & \\
\hline : Difference \% & -7.0 & +38.0 & & \\
\hline \multicolumn{3}{|l|}{ Richard's Bay to Yokohama } & \multirow{4}{*}{15700} & \multirow{4}{*}{42742} \\
\hline : Actual & 5581 & 3877 & & \\
\hline : Model & 18263 & 3658 & & \\
\hline : Difference \% & +327 & -6.0 & & \\
\hline Matola to ARA & 0 & 0 & 0 & 0 \\
\hline Matola to Yokohama & 0 & 0 & 0 & 0 \\
\hline Walvis Bay to ARA & 0 & 0 & 0 & 0 \\
\hline Walvis Bay to Yokohama & 0 & 0 & 0 & 0 \\
\hline
\end{tabular}

Source: Based on model simulations by the author.

Notes: ${ }^{(1)}-$ Amsterdam, Rotterdam and Antwerp, which are taken as entry ports for steam coal imports into the modeled countries in the Western European region. 


\subsubsection{Response Surface Methodology}

The use of experimental design approaches has proven to be a valuable tool for the design and quality improvements of products in many industrial activities. The principal concept is that of the response surface methodology (see Myers and Montgomery, 1995, Kleijnen, 1974 and 1975, Ogawa, 1974 and Naylor, 1971). The response surface methodology permits the observation of interaction factors and therefore extends the sensitivity analysis wherein only one factor is varied at a time. Some typical objectives of response surface methodology as found in Myers and Montgomery include: 1) response optimization, 2) optimal selection of operating conditions to meet product specification and 3) analysis of a response surface of a region of interest. In this study, our objective is more in line with the last of these three (see also Labys and Yang, 1981).

The objective function of the optimization model for the world steam coal trade developed in this study has four cost components and we define a response function that relates the level of Botswana's exports to the four cost components. We adopt a general $2^{\mathrm{k}}$ factorial design to observe the response surface in the vicinity of the forecast optimal values obtained from the optimization model. The steps in this experiment involve screening of factors to select those that have a significant impact on the response, applying OLS regression analysis on transformed variables, and conducting the analysis of variance and the partial F-test to check for factor significance.

The factor symbols for this experimental design are: capital cost, (A), supply costs, (B), rail costs, (C) and maritime costs, (D). Table 5.14 presents the low and high levels for these factors, while Table 5.15 provides the results of the optimization for each of the runs and the effect estimates. The hypothesis testing using the partial F-test is as follows: 


$$
\begin{aligned}
& H_{o}: B_{j}=0 \quad \text { and } \quad H_{A}: B_{j} \neq 0 \\
& F_{o}=\frac{S S_{R}\left(B_{j} \mid B_{o}, B_{1}, . . B_{j-1}, B_{j+1}, . . B_{k}\right) / 1}{S S_{E} /(n-k-1)}
\end{aligned}
$$

where the enumerator represents the regression sum of squares with factor $j$ excluded divided by the degrees of freedom for the single factor $j$, which is 1 . The denominator is the error sum of squares divided by the appropriate degrees of freedom. In tabular form, the partial $F$-test statistic is readily computed by taking the ratio of the mean square error with the factor included to the mean square error of the regression (see Table 5.16 below). To decide the significance of a factor, we compare $F_{o}$ with the critical $\mathrm{F}$ value from statistical tables at the $1 \%$ and $5 \%$ levels and if $F_{o}$ is greater than the $F$ value from the tables, we reject the null hypothesis, $H_{o}$ at the given level of significance.

The partial F-test procedure in this study is equivalent to conducting hypothesis testing using the $t$ test as we are testing the marginal contribution of a single factor at a time (see Gujarat, Chapter 8 and Myers and Montgomery, Chapter 2). This is explained by the connection between the $F$ and $t$ tests, wherein the square of the $t$ value is approximately equal to the $\mathrm{F}$ value for 1 and $v$ degrees of freedom. 
Table 5.14 Factor Level Ratios to Base Case Scenario

\begin{tabular}{lll}
\hline Factor & Low & High \\
\hline Capital Costs & 1.00 & 1.20 \\
\hline Supply Costs & 1.00 & 2.00 \\
\hline Rail Costs & 1.00 & 2.00 \\
\hline Maritime Costs & 1.00 & 1.20 \\
\hline
\end{tabular}

Table 5.15 A $2^{4}$ Simulation Experiment for Botswana's Annual Steam Coal Exports ( for the period 1995 to 2010, in Decimal \%)

\begin{tabular}{|c|c|c|c|c|c|c|c|c|c|c|}
\hline \multicolumn{5}{|c|}{ Factors } & \multicolumn{6}{|c|}{ \% Change from Base Case Scenario } \\
\hline $\begin{array}{l}\text { Run } \\
\text { Number }\end{array}$ & A & B & C & D & $\begin{array}{l}\text { Treatment } \\
\text { Combination }\end{array}$ & 1995 & 2000 & 2005 & 2010 & Totals \\
\hline 1 & - & - & - & - & (l) & 0.000 & 0.000 & 0.000 & 0.000 & 0.000 \\
\hline 2 & + & - & - & - & $\mathrm{a}$ & -1.000 & 0.002 & 0.000 & -0.250 & -1.248 \\
\hline 3 & - & + & - & - & $\mathrm{b}$ & 0.000 & 0.000 & 0.000 & 0.000 & 0.000 \\
\hline 4 & + & + & - & - & $\mathrm{ab}$ & -1.000 & -0.364 & -0.168 & -0.376 & -1.909 \\
\hline 5 & - & - & + & - & $\mathrm{c}$ & 0.000 & 0.000 & 0.000 & 0.000 & 0.000 \\
\hline 6 & + & - & + & - & $\mathrm{ac}$ & 0.000 & -1.000 & -0.801 & -0.850 & -3.651 \\
\hline 7 & - & + & + & - & $\mathrm{bc}$ & -1.000 & 0.000 & 0.000 & 0.000 & 0.000 \\
\hline 8 & + & + & + & - & $a b c$ & 0.000 & -1.000 & -0.999 & -0.998 & -3.997 \\
\hline 9 & - & - & - & + & $\mathrm{d}$ & 0.000 & 0.000 & 0.000 & 0.000 & 0.000 \\
\hline 10 & + & - & - & + & $\mathrm{ad}$ & -1.000 & 0.002 & 0.000 & -0.250 & -1.248 \\
\hline 11 & - & + & - & + & $\mathrm{bd}$ & 0.000 & -0.272 & 0.000 & 0.000 & 0.000 \\
\hline 12 & + & + & - & + & abd & 0.000 & 0.000 & -0.107 & -0.330 & -1.710 \\
\hline 13 & - & - & + & + & $\mathrm{cd}$ & -1.000 & -1.000 & -0.591 & 0.000 & 0.000 \\
\hline 14 & + & - & + & + & acd & 0.000 & 0.000 & 0.000 & -0.693 & -3.284 \\
\hline 15 & - & + & + & + & bcd & 0.000 & -1.000 & -0.999 & 0.000 & -3.997 \\
\hline 16 & + & + & + & + & abcd & -1.000 & 0.000 & 0.000 & -0.998 & 0.000 \\
\hline
\end{tabular}

Source: Based on model simulation by the author.

Table 5.16 Analysis of Variance for the $2^{4}$ Simulation Experiment

\begin{tabular}{lcccccc}
\hline $\begin{array}{l}\text { Source of } \\
\text { Variation }\end{array}$ & $\begin{array}{c}\text { Sum of } \\
\text { Squares }\end{array}$ & $\begin{array}{c}\text { Degrees of } \\
\text { Freedom }\end{array}$ & $\begin{array}{c}\text { Mean } \\
\text { Square }\end{array}$ & $\mathbf{F}_{\mathbf{o}}$ & $\begin{array}{c}\mathbf{F}_{\mathbf{c}} \mathbf{a t} \\
\mathbf{1 \%}\end{array}$ & $\begin{array}{c}\mathbf{F}_{\mathbf{c}} \text { at } \\
\mathbf{5 \%}\end{array}$ \\
\hline $\mathrm{A}$ & 4.089 & 1 & 4.089 & 9.14 & 9.33 & 4.75 \\
\hline $\mathrm{C}$ & 1.214 & 1 & 1.214 & 2.71 & & \\
\hline $\mathrm{A}^{*} \mathrm{C}$ & 1.214 & 1 & 1.214 & 2.71 & & \\
\hline Error & 5.367 & 12 & 0.447 & & & \\
\hline Total & 11.884 & 15 & & & & \\
\hline
\end{tabular}

Source: Based on model simulation by the author. 
The analysis of effects for the above experiment identified capital costs, rail costs and the interaction term between these two variables to be factors that need to be considered in deriving the regression model to explain changes in Botswana's simulated exports over the period 1995 to 2010. The linear regression equation for the export response function is given in equation 5.1 below.

$$
\begin{aligned}
& \hat{y}=-0.390-0.127 x_{1}-0.069 x_{3}-0.069 x_{1} x_{3} \\
& \mathrm{R}^{2} \text { _adjusted }=0.53 \quad \mathrm{~N}=64
\end{aligned}
$$

where $\hat{y}$ is the predicted value of the percentage change in steam coal exports relative to the optimal values from the base case simulation scenario, and $x_{1}$ and $x_{3}$ are transformed capital and rail costs in the range -1.0 to 1.0 , and $x_{1} x_{3}$ is the interaction term for capital and rail costs.

The above response function indicates that the level of exports is a declining function of capital costs, rail transportation costs and their interaction term. Figures 5.6 (a), (b) and (c) provide a graphical presentation of the main effects for capital costs, the interaction effects between capital costs and rail transportation costs, and the response surface for this experimental design. This experiment indicates that rail transportation costs have no main effect on the level of Botswana's steam coal exports but combine with capital costs to negatively impact on exports as shown on Figures 5.6 (a), (b) and (c). The sensitivity analysis that follows will therefore include scenarios for varying capital and rail transportation costs one at a time and analyzing the resulting exports and their distribution. 


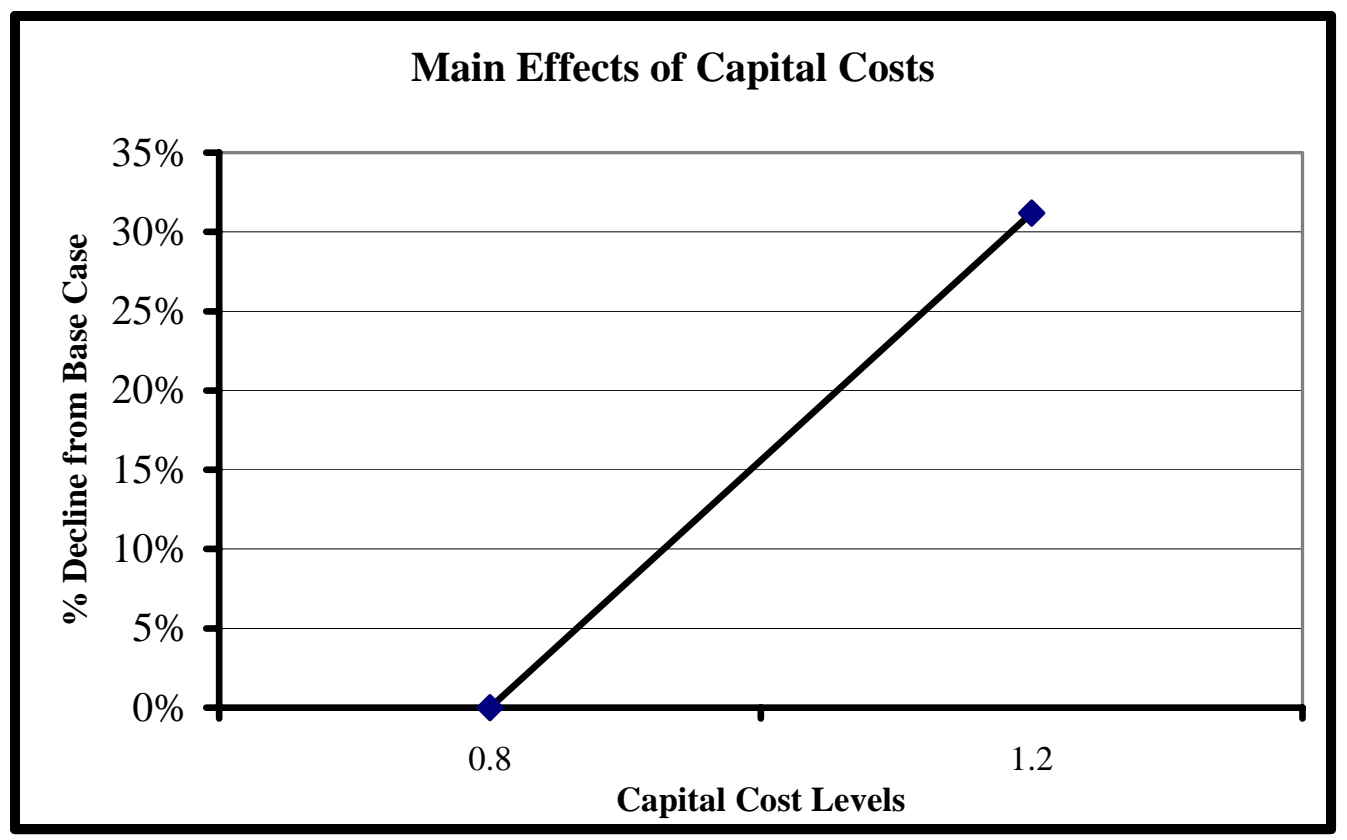

Figure 5.6 (a) Main Effects of Capital Costs on Botswana's Simulated Steam Coal Exports

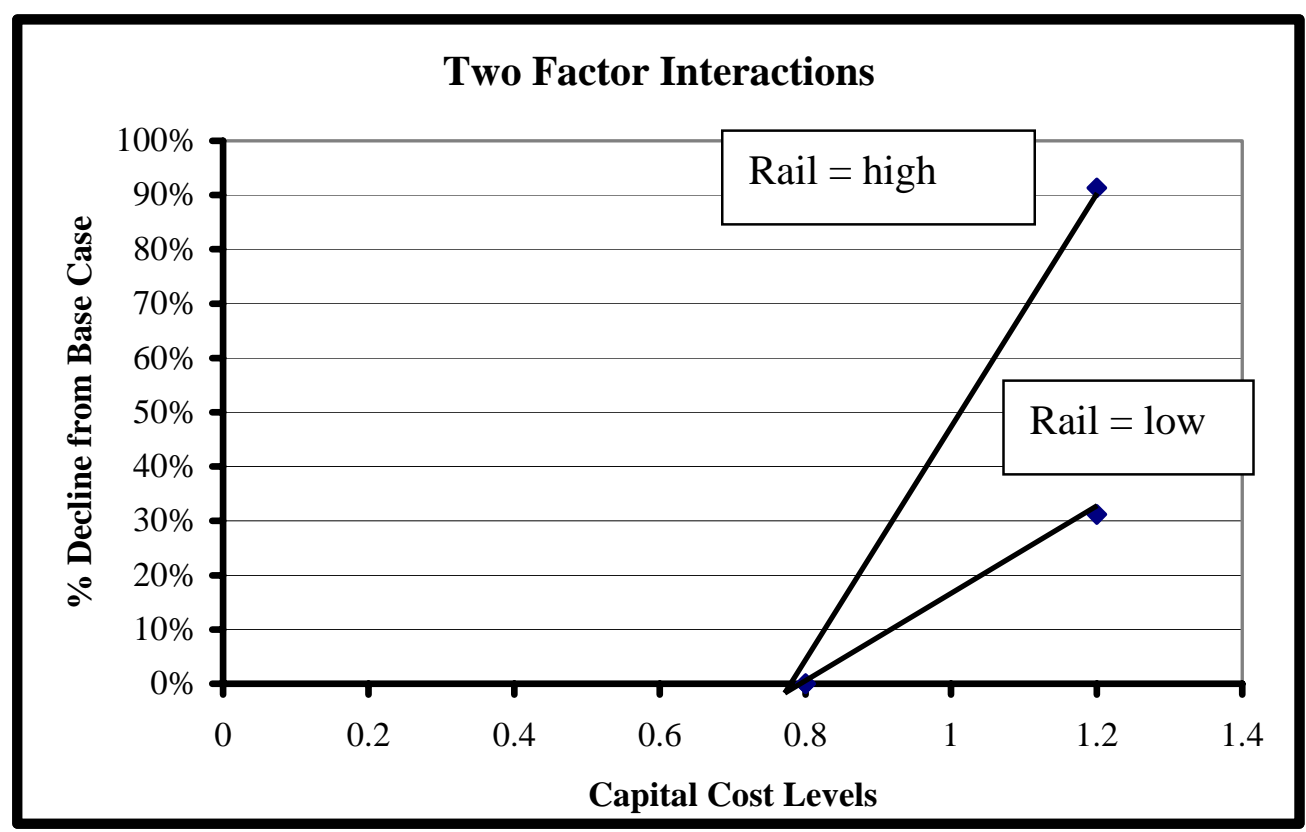

Figure 5.6 (b) Capital and Rail Costs Interaction Effects on Botswana's Simulated Steam Coal Exports 


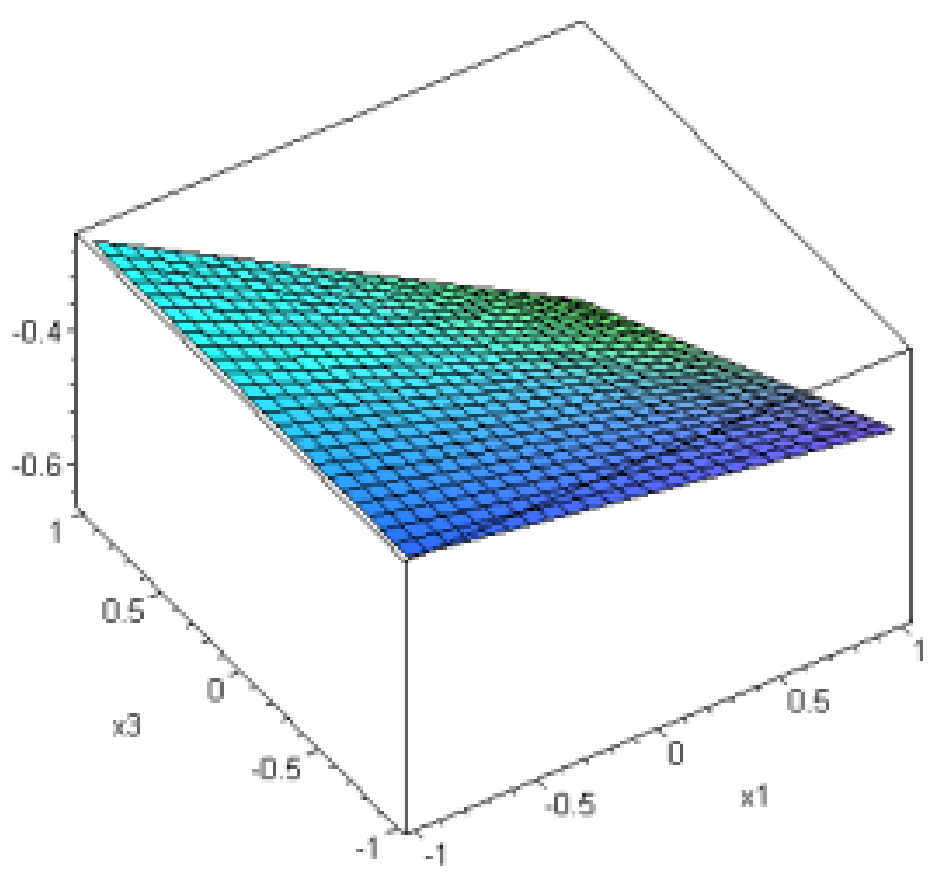

Figure 5.6(c) The Response Surface for Botswana's Simulated Steam Coal Exports 


\subsection{Conclusions}

This chapter presented and validated the results of the econometric model of the world steam coal trade. The forecast values for export and imports from this model compare favorably with those from models by the EIA, IEA and WEFA. While the non-parametric validation tests for the out-of-sample period show low forecast errors for countries that are major coal consumers, the relatively high bias proportion of the Theil coefficient alerted us to the likelihood that the model would perform poorly if used for forecasts that are too far into the future. The relatively large values for the adjusted R-squared indicate that the model has good explanatory power. The long run marginal cost function for the net exporters in the model displayed good properties with respect to the expected signs on the slope coefficients. The validation of these functions successfully demonstrated the robustness of these results over time. As in the country supply and demand equations, these models also had good explanatory power but poor out-ofsample forecasting ability.

The results of the base case simulation scenario show that Botswana's coal would be competitive in the steam coal markets of Western Europe where it becomes the leading supplier among the four exporters in the model. The export port for this trade is Matola in Mozambique. We determined through the experimental design approach that capital costs are the significant factor explaining changes in Botswana's steam coal exports and proceeded to derive a response function that also included rail transportation costs, which were shown to have no effect on exports within the ranges studied.

In summary, the model's ability to depict the temporal and spatial distribution of the seaborne steam coal trade is quite good and is in general agreement with findings by other researchers that support the dominance of Australia and South Africa in models of the seaborne steam coal trade (see Kolstad, Abbey and Bivins, 1982 and Dutton, 1982). 


\section{CHAPTER 6}

\section{POLICY APPLICATIONS}

\subsection{Introduction}

In this chapter, we conduct sensitivity analysis on the simulation results for the base case scenario to check the robustness of the model's solution to changes in capital costs and rail transportation costs. The other cost factors were shown to have little or no effects on the levels of Botswana's exports from the experimental design approach and are therefore not investigated further in this chapter. We then proceed to apply the model to forecast Botswana's future steam coal exports in the years 2005 and 2010 from a base year of 2000 and then determine the country's competitiveness in the steam coal markets in Western Europe and Asia during these years. The simulation results for base case scenario demonstrate that Botswana's coal exports would have been competitive in the Western European markets in the past and that they would remain competitive in this market and Asia in the future. This finding differs from that of the 1983 study, which attributed lack of competitiveness of Botswana's coal in the export markets to the cost of rail transportation to seaports.

\subsection{Sensitivity Analysis}

Theoretically any adverse shift in Botswana's long run marginal cost function would reduce the country's competitiveness as a supplier of steam coal to world markets. In this study, any deterministic shocking of the intercept and slope terms for Botswana's long run marginal cost function would not add any information in this case because of the low intercept and comparable slope terms to those of Australia and the United States (see Figure 5.1 or Table 5.5 above). For instance, in the period 1991-1995, Botswana's intercept term is about one-third those 
of Australia and the United States and the differences grows to about one-sixth in 1996-2000 period. Also recall that supply costs were found to have insignificant effects on the variability in the level of exports. This means that any adverse shifts in Botswana's supply curve would have to be of a magnitude that is not relevant to any policy variable. For instance an intercept shift of up to $200 \%$ still leaves Botswana's supply function below those of Australia and the United States.

The sensitivity analysis will therefore focus on testing the robustness of the base case simulation results on the competitiveness of Botswana's steam coal exports to changes in rail transportation costs and capital costs of expansion or new capacity as these are the factors that were retained to explain the response surface under the model validation in Chapter 5, above. We assume that no single exporter would face maritime transportation costs that diverge from those applying to other exporters once distance and other factors have been taken into account. For this reason they will not be included in the sensitivity analysis. We also know that, the validation experiment failed to select maritime transportation costs as a significant factor in explaining changes in Botswana's simulated steam coal exports. The sensitivity analysis also provides an indication of the long-term competitiveness of each of the two routes described in subsection 5.6.3 above. The scenarios studied are shown in Table 6.1 below.

\subsection{Results of the Sensitivity Analysis of the Base Case Scenario Simulation}

The sensitivity analysis results confirm the results from the response surface methodology that was applied to validate this model which demonstrated that rail transportation costs, at the levels that apply on South Africa's steam coal exports, do not have a significant effect on changes in Botswana's simulated exports. Table 6.2 shows the sensitivity of 
Mmamabula's coal exports to changes in the capital expenditure costs for mine development. These costs were incremented at 10\%,20\% and 25\%. For all increases in capital costs of $10 \%$ or less, there is no change from the results of the base case scenario. When these costs are raised to 20\%, Botswana's 1995 exports are eliminated while they remain unchanged in 2000 and 2005 but decline by $41 \%$ in 2010 relative to the base case. This decline is in the Western European market. As a result of the $20 \%$ increase in capital costs, Botswana's lost market share in Western Europe is gained by South Africa, whose exports increase by $129 \%$ in 1995 relative to their base case levels. South Africa's market share in Western Europe rises to $62 \%$ as compared to $27 \%$ in the base case. It remains unchanged in 2005 and 2010. As South Africa regains its market share in Western Europe, this frees up the Asian market for Australia, which realizes a rise in exports to command 70\%, 94\%, 80\% and 53\% respectively for the years 1995, 2000, 2005 and 2010 . This compares to the base case scenario market shares in Asia of 54\%, 63\%, $41 \%$ and $21 \%$ for the same years respectively.

Finally, when capital costs for Botswana's coal are raised by $25 \%$ relative to the base case scenario, Botswana's coal becomes uncompetitive in both the Asian and Western European markets. South Africa and the United States share the Western European steam coal market in 1995 and 2010 with the intervening years wholly controlled by South Africa. The Asian markets are shared between Australia and South Africa with the share in 2000 very close to the historical level of $90 \%$ for Australia. The elimination of Botswana's exports from the simulation model approximates the existing steam coal trade among the exporters in the model and is depicted on Table 5.12 above. 
Table 6.1 Scenarios for Sensitivity Analyses of the Base Case Simulation Results

\begin{tabular}{ccc}
\hline Scenario & $\begin{array}{c}\text { Rail Transport } \\
\text { Cost }\end{array}$ & Mine Capital Cost \\
\hline 1 & $50 \%$ & \\
\hline 2 & $100 \%$ & \\
\hline 3 & $200 \%$ & $10 \%$ \\
\hline 4 & & $20 \%$ \\
\hline 5 & & $25 \%$ \\
\hline 6 & & \\
\hline
\end{tabular}

Table 6.2 Sensitivity of Trade Flow Patterns to Changes in Botswana's Capital Costs (\% Change from Base Case Scenario)

\begin{tabular}{lrr|rr}
\hline & Historical Period & Forecast Period \\
\hline & $\mathbf{1 9 9 5}$ & $\mathbf{2 0 0 0}$ & $\mathbf{2 0 0 5}$ & $\mathbf{2 0 1 0}$ \\
\hline Botswana's Capital Cost up 10\% & & & & \\
: Gladstone to ARA & 0 & 0 & 0 & 0 \\
: Gladstone to Yokohama & 0 & 0 & 0 & 0 \\
: Hampton Roads to ARA & 0 & 0 & 0 & 0 \\
: Hampton Roads to Yokohama & 0 & 0 & 0 & 0 \\
: Richard's Bay to ARA & 0 & 0 & 0 & 0 \\
: Richard's Bay to Yokohama & 0 & 0 & 0 & 0 \\
: Matola to ARA & 0 & 0 & 0 & 0 \\
: Matola to Yokohama & 0 & 0 & 0 & 0 \\
\hline Botswana's Capital Cost up 20\% & & & & \\
: Gladstone to ARA & 0 & 0 & 0 & 0 \\
: Gladstone to Yokohama & 31 & 0 & 0 & 0 \\
: Hampton Roads to ARA & 0 & 0 & 0 & 66 \\
: Hampton Roads to Yokohama & 0 & 0 & 0 & 0 \\
: Richard's Bay to ARA & 129 & 11 & 0 & 0 \\
: Richard's Bay to Yokohama & -35 & 0 & 0 & 0 \\
: Matola to ARA & -100 & 0 & 0 & -41 \\
: Matola to Yokohama & 0 & 0 & 0 & 0 \\
\hline Botswana's Capital Cost up 25\% & & & & \\
: Gladstone to ARA & 0 & 0 & 0 & 0 \\
: Gladstone to Yokohama & 31 & 50 & 93 & 159 \\
: Hampton Roads to ARA & 0 & 0 & 0 & 66 \\
: Hampton Roads to Yokohama & 0 & 0 & 0 & 0 \\
: Richard's Bay to ARA & 129 & 94 & 0 & + \\
: Richard's Bay to Yokohama & -35 & -85 & 0 & -25 \\
: Matola to ARA & -100 & -100 & 0 & -100 \\
: Matola to Yokohama & 0 & 0 & -100 & -100 \\
\hline
\end{tabular}

Source: Based on model simulations by the author. 
The two major unknowns in this model are the capital costs associated with the development of rail and port infrastructure. These have been accommodated by assuming that the rail charges for transporting coal in South Africa together with the port charges reflect full economic costs in which all of the factors employed in the provision of these services are paid including a provision of profit to the service providers. In the case of the port facilities, this assumption may be sufficient as these are privately owned and operated. In the case of the railway line, which is owned by the South African government, the assumption may not hold as these exporters earn much needed foreign currency and may therefore enjoy government subsidies in the form of lower rail rates to encourage such coal exports. For this reason, the model sensitivity analysis on rail costs is intentionally made to include orders of magnitude increases in these costs in an attempt to accommodate a wider range of "what if" questions on the role of rail transportation costs and hence the geographical location of the country.

\subsection{Forecasting With the Spatial and Dynamic Optimization Model}

The purpose of this section is to apply the spatial and dynamic optimization model to forecast the likely future development of Botswana's coal deposits beginning from a base year of 2000 and extending to 2010 in five-year intervals. The base case forecast assumptions are as follows:

1) Australia's future exports to Asia and South Africa's future exports to Western Europe do not fall below their year 2000 levels while they can take on any positive value in those markets in which these countries are marginal suppliers,

2) exports from the US are free to take on any value in both markets as the country is a marginal supplier to both markets, and

3) Botswana's exports are constrained by export port capacity, which is assumed to be 5.0 million mtce for Matola in 2005 and 20.0 million in 2010. 
The first assumption preserves the existing export quantities, which may be protected from competition by long term contracts, but foresees a situation in which importers would want to minimize their future import bills by buying from the lowest cost entrants into the industry. The last assumption assumes that if a decision to proceed with an export mine where made at the end of 2002, then in the remaining time, 2003 - 2005, from the first period of forecast, Mmamabula coal could be exported through Matola after the necessary investment on mine, rail and port capacity is made. While the model mine is that for a mechanized continuous room and pillar operation, the existence of strippable reserves at Mmamabula presents a possibility for developing an export steam coal mine by 2005. Due to the distance from Mmamabula to Walvis Bay, this route is assumed to be only available in 2010 .

\subsubsection{Results of the Base Case Forecast Scenario}

The results of the base case forecast scenario are provided on Table 6.3 and these predict the following ranking among the four exporters for exports to Western Europe: 1) South Africa, 2) Botswana, 3) the United States and 4) Australia. In the Asian market, the forecast rankings are: 1) Australia, 2) South Africa, 3) Botswana and 4) the United States. Botswana's market share in Asia would be $12 \%$ in 2010 . This translates into 10.772 million mtce 2010 . The export port for this coal is Matola in Mozambique. On the Western European market, Botswana's market share would be $12 \%$ and $23 \%$ in 2005 and 2010 respectively, which translates into 5.0 million and 9.228 million mtce for these years respectively. All of Botswana's coal would be exported through the port of Matola in Mozambique.

In the Asian steam coal markets, Australia's forecast residual market share declines from its actual level of $89 \%$ in 2000 to $73 \%$ and $61 \%$ in 2005 and 2010 respectively while that for South Africa rises from 7\% in 2000 to $27 \%$ for both 2005 and 2010 respectively. The US is 
eliminated from this market, losing its 5\% market share held in 2000. On the Western European markets, both Australia and the United States are eliminated. South Africa's forecast market share is $88 \%$ and $77 \%$ in 2005 and 2010 respectively and during these years, the remainder of this market share is taken up by Botswana. These results were subjected to a sensitivity analysis for scenarios shown on Table 6.5 below.

Table 6.4 provides the forecast f.o.b. steam coal prices for the net exporters in the model together with those for some of the emerging exporters for the year 2000 only. The relative competitiveness ranking based solely on the f.o.b. prices for 2000 and with the export unit value expressed in year 2000 U.S. Dollar per mtce and shown in brackets are: Indonesia (\$24.22), South Africa (\$26.84), Colombia (\$28.10), Botswana (\$28.89), Australia (\$31.10) and the United States (\$38.08). Over the forecast period, the competitiveness ranking of the ports for the net exporters in the model is as follows: 1) Matola, 2) Richard's Bay, 3) Walvis Bay, 4) Gladstone / New Castle and 5) Hampton Roads. 
Table 6.3 Forecast Results of the Base Case Scenario Showing Exporters' Market Shares

\begin{tabular}{lrrrr}
\hline & Australia & South Africa & Botswana & USA \\
\hline Asian Market & & & & \\
Actual 2000 & 89.0 & 7.0 & 0.0 & 5.0 \\
\hline Base Case Forecast Scenario Shares & & & & \\
$: 2005$ & 73.0 & 27.0 & 0.0 & 0.0 \\
$: 2010$ & 61.0 & 27.0 & 12.0 & 0.0 \\
\hline$\quad$ Western European Market & & & & \\
Actual 2000 & 17.0 & 76.0 & 0.00 & 7.0 \\
\hline Base Case Forecast Scenario Shares & & & & \\
$:$ 2005 & 0.0 & 88.0 & 12.0 & 0.0 \\
$: 2010$ & 0.0 & 77.0 & 23.0 & 0.0 \\
\hline
\end{tabular}

Source: Based on model simulations by the author.

Table 6.4 Relative Competitiveness of F.O.B. Prices for Net Exporters (year 2000 US \$ per mtce)

\begin{tabular}{lc|cr}
\hline Historical Period & & Forecast Period & \\
\hline Route & $\mathbf{2 0 0 0}$ & $\mathbf{2 0 0 5}$ & $\mathbf{2 0 1 0}$ \\
\hline Indonesia & 24.22 & na & na \\
\hline South Africa & & & \\
$\quad$ Matola & 24.75 & 22.68 & 23.15 \\
$\quad$ Richard's Bay & 26.84 & 23.92 & 24.39 \\
$\quad$ Walvis Bay & 42.47 & 33.17 & 33.64 \\
\hline Colombia & 28.10 & na & na \\
\hline Botswana & (a) & & \\
$\quad$ Matola & 28.89 & 26.45 & 26.92 \\
$\quad$ Richard's Bay & 30.52 & 27.41 & 27.88 \\
$\quad$ Walvis Bay & 33.09 & 28.93 & 29.40 \\
\hline Gladstone / Newcastle & 31.10 & 40.32 & 41.17 \\
\hline Hampton Roads & 38.08 & 55.83 & 56.37 \\
\hline
\end{tabular}

Source: Based on model simulations by the author.

Notes: ${ }^{(a)}$ - Botswana's f.o.b. prices for 2000 are based on South Africa's f.o.b. prices.

- Indonesia and Colombia are added for comparison in 2000 only

Table 6.5 Scenarios for Sensitivity Analyses of the Base Case Forecast Results

\begin{tabular}{cccc}
\hline Scenario & $\begin{array}{c}\text { Rail Transport } \\
\text { Cost }\end{array}$ & Mine Capital Cost & $\begin{array}{c}\text { Steam Coal Import } \\
\text { Demand }\end{array}$ \\
\hline 1 & $50 \%$ & & \\
\hline 2 & $100 \%$ & & \\
\hline 3 & $200 \%$ & & \\
\hline 4 & & $10 \%$ & \\
\hline 5 & & $20 \%$ & $-20 \%$ \\
\hline 6 & & $25 \%$ & $+20 \%$ \\
\hline 7 & & & \\
\hline 8 & & & \\
\hline
\end{tabular}




\subsubsection{Sensitivity Analysis of the Base Case Forecast Results}

A sensitivity analysis was conducted to observe changes to the forecast optimal market shares, choice of export port, size of mine and timing of development for Botswana's coal deposits that would result from changes in rail transportation costs, capital costs for mine development and the level of import demand (see Table 6.5 above). The results of the sensitivity analyses are as follows:

1. In scenarios 1, 2 and 3, the optimal levels of Botswana's steam coal exports are least sensitive to rail transportation costs to the extent that a $200 \%$ increase in these costs still results in Botswana's market share in Western Europe being at 12\% or 5.0 million mtce, and $23 \%$ or 9.23 million mtce, in 2005 and 2010 respectively. In the Asian market, Botswana's market share declines marginally to $10 \%$ from $12 \%$ in the base case in 2010 . The export tonnage in 2010 is 8.70 million mtce. The size of cumulative export mine capacity declines from 20.05 million mtce under the base case scenario to 17.97 million mtce in 2010.

2. In scenario 4 , when capital costs are $10 \%$ above their base case levels, there is a $10 \%$ decline in Botswana's coal exports in 2010. This decline occurs for exports to the Asia market only. Scenario 5 shows that if these costs are $20 \%$ higher than in the base case forecast scenario, exports decline by $75 \%$ in 2010 . Botswana loses its entire market share in Western Europe while in Asia its share declines to $6 \%$ from the $12 \%$ it held in the base case forecast scenario. The export mine capacity is 5.0 million mtce in 2005 and 5.04 million mtce in 2010 . In scenario 6 , when capital costs are $25 \%$ above the level for base case forecast scenario, Botswana's steam coal is no longer competitive in both markets and the country is eliminated out of the model (see Tables 6.6 and 6.7 below). 
3. In scenario 7 , when the steam coal import demand is $20 \%$ lower than estimated, this does not affect the size of export mine at Mmamabula, which remains at 5.0 million mtce in 2005 and rises to 20.0 million mtce in 2010.

4. In scenario 8, a higher demand than that estimated expectedly shows that the simulated export port capacity for Mmamabula production would become a binding constraint on the size of mine to be developed. Also the port capacity constraint for South Africa means that the additional demand has to be met by other exporters not facing any of these constraints. The model demonstrates the role of marginal supplier that the United States plays in this model. Its exports to Western Europe are 12.32 million mtce in 2010, which is the only time that the model selects US exports.

5. The port of Matola offers the advantage of serving both the Asian and Western European markets and this is the port selected by the model. 
Table 6.6 Distribution of Market Share in Asia Due to Changes in Botswana's Capital Costs (\%)

\begin{tabular}{lrrrr}
\hline & Australia & South Africa & Botswana & USA \\
\hline $\begin{array}{c}\text { Asian Market } \\
\text { Actual 2000 }\end{array}$ & 89.0 & 7.0 & 0.00 & 5.0 \\
\hline Base Case Forecast Scenario Shares & & & & \\
$: 2005$ & 73.0 & 27.0 & 0.0 & 0.0 \\
$: 2010$ & 61.0 & 27.0 & 12.0 & 0.0 \\
\hline Capital costs up 10\% & & & & \\
$:$ 2005 & 73.0 & 27.0 & 0.0 & 0.0 \\
$: 2010$ & 61.0 & 29.0 & 10.0 & 0.0 \\
\hline Capital costs up 20\% & & & & \\
$:$ 2005 & 73.0 & 27.0 & 0.0 & 0 \\
$: 2010$ & 65.0 & 29.0 & 6.0 & 0 \\
\hline Capital costs up 25\% & & & & \\
$:$ :2005 & 80.0 & 20.0 & 0.0 & 0 \\
$: 2010$ & 71.0 & 29.0 & 0.0 & 0 \\
\hline
\end{tabular}

Source: Based on model simulations by the author.

Table 6.7 Distribution of Market Share in Western Europe Due to Changes in Botswana's Capital Costs (\%)

\begin{tabular}{lrrrr}
\hline & Australia & South Africa & Botswana & USA \\
\hline $\begin{array}{l}\text { Western European Market } \\
\text { Actual 2000 }\end{array}$ & 17.0 & 76.0 & 0.00 & 7.0 \\
\hline Base Case Forecast Scenario Shares & & & & \\
$:$ 2005 & 0.0 & 88.0 & 12.0 & 0.0 \\
$: 2010$ & 0.0 & 77.0 & 23.0 & 0.0 \\
\hline Capital costs up 10\% & & & & \\
$:$ 2005 & 0.0 & 88.0 & 12.0 & 0.0 \\
$: 2010$ & 0.0 & 77.0 & 23.0 & 0.0 \\
\hline Capital costs up 20\% & & & & \\
$: 2005$ & 0.0 & 88.0 & 20.0 & 0.0 \\
$: 2010$ & 0.0 & 77.0 & 0.0 & 23.0 \\
\hline Capital costs up 25\% & & & & \\
$:$ 2005 & 0.0 & 100.0 & 0.0 & 0.0 \\
$: 2010$ & 0.0 & 77.0 & 0.0 & 23.0 \\
\hline
\end{tabular}

Source: Based on model simulations by the author. 


\subsection{Conclusions}

In this chapter, sensitivity analyses were conducted to check the robustness of the base case simulation scenario results by varying rail transportation costs and capital expenditure costs for mine development on the Mmamabula coal deposits. The results of the sensitivity analysis confirm those of the response surface methodology wherein rail transportation costs do not have a significant effect on Botswana's exports while these are sensitive to capital costs. If capital costs are $25 \%$ higher than in the base case simulation scenario, this eliminates Botswana's exports from the model.

The spatial and dynamic optimization model was applied to forecast the optimal market shares, choice of export port, size of mine and timing of development for Botswana's coal deposits for the years 2005 and 2010. The forecast mine size and timing of mine development are 5.0 million mtce in 2005 and 20.05 million mtce in 2010. This was followed by a forecast sensitivity analysis of the optimal forecast steam coal exports to changes in rail transportation costs, capital costs for mine development and the level of import demand for the years 2005 and 2010. The sensitivity results confirmed the simulation results by identifying the Western European steam coal markets as the one where Botswana's coal exports would have a competitive advantage. The analysis also selects the port of Matola over Walvis Bay for exports to both Asia and Western Europe. 


\section{CHAPTER 7}

\section{CONCLUSIONS AND FUTURE RESEARCH}

\subsection{Introduction}

In this study, we attempted to analyze the world steam coal trade with the specific objectives of determining the scale of development and time schedule of coal exports likely to be forthcoming from Botswana and the land routes for these exports to existing and simulated ports at Matola in Mozambique, Richard's Bay in South Africa and Walvis Bay in Namibia, and to determine the appropriate policy, where such may be necessary, to encourage the development of infrastructure for exporting Botswana's steam coal.

We constructed a model of the world steam coal trade that included the major exporters and importers who account for a substantial share of this trade. The model consisted of four exporting countries: Australia, South Africa, United States and Botswana, where the latter was included in the model simulation to determine the competitiveness for export of its steam coal deposits. The demand markets for the steam coal trade included two countries in Asia: Japan and South Korea, and seven countries in Western Europe, namely: Belgium, France, Germany, Italy, Netherlands, Spain, and the United Kingdom.

This study involved two stages of analysis, the first of which was to carry out econometric modeling of demand and supply functions for each of the countries in the model and then to compute net import demand for steam coal by countries in Asia and Western Europe as defined above. This stage also involved the estimation of the long run marginal cost functions for the net exporting countries in the model. 
The econometric modeling of country supply, demand and the long run marginal cost functions for the net exporters of the model, were subjected to non-parametric validation techniques involving the following: the mean absolute percent error, MAPE, the Theil inequality coefficient, $\mathrm{U}$, and its bias component of the error, the adjusted R-squared, sensitivity to starting period in the case of the long run marginal cost function, and comparison of the export and import values with both the historical values and also those values obtained by other studies. These econometric models for supply, demand and the long run marginal costs function were found to have good explanatory power but limited forecasting ability. For this reason, the forecasts of supply and demand were conducted for a short out-of-sample forecast period of 10 years from 2000 to 2010 .

The second stage of this study had two purposes: 1) to simulate the competitiveness of Botswana's steam coal exports in the defined markets in Asia and Western Europe, and 2) to forecast the optimal size of capacity development, timing for future mine development on Botswana's coal deposits, choice of export port among Matola in Mozambique, Walvis Bay in Namibia and Richards Bay in South Africa. The first purpose required that the long run marginal cost functions be transformed into the quantity formulation and then substituted into the objective function of the spatial and dynamic optimization model. Additional components of the objective function included: equations for estimating the capital cost of development for a model steam coal mine, rail transportation costs, and maritime transportation costs. The objective function minimizes the sum of the discounted costs of capital expenditure, variable supply costs, rail transportation costs and maritime transportation costs over a given time horizon. The use of discounting is meant to properly account for the time value of money and project risk in the objective function. This model is applied to solve for the temporal and spatial distribution of 
production capacity to meet domestic demand for steam coal in the net exporting countries in the model and also to solve for the flow of steam coal exports to markets in Asia and Western Europe. The model simulation period extends from 1990 to 2010, in five-year intervals as follows: 1991-1995, 1996-2000, 2001-2005 and 2006-2010. The results are stated in both market shares and physical tonnages of coal to determine Botswana's competitiveness in the steam coal markets of Asia and Western Europe.

The second purpose was to apply this spatial and dynamic optimization model to forecast the likely future development of Botswana's coal deposits beginning from a base year of 2000 and extending to 2010 in five-year intervals as in the simulation model.

\subsection{Summary of Results}

The simulation results for the base case scenario demonstrate that Botswana's coal would have been competitive in the Western European steam coal markets in the past and that they would have remained so in the future. The market share, based on the residual steam coal demand in the importing countries of the model, would have grown from $35 \%$ in $1995,48 \%$ in 2000 and $62 \%$ in 2010 in the Western European markets. In 2005, all of Botswana's coal would have been exported to Asia. The country would have been the leading supplier to Western Europe. In the Asian markets, Botswana's exports would have begun in 2005 at $39 \%$ and declining to $17 \%$ in 2010 . The country would have been in third position ahead of the United States in this market with Australia losing the leading position to South Africa. The export capacity for steam coal would have grown from 10.0 million mtce in 1995 to 40.0 million mtce in 2010 . 
An experimental design approach was adopted to validate the model by determining which of the four factors, capital costs, variable supply costs, rail transportation costs and maritime transportation costs would have a significant effect on Botswana's exports. The results indicated that capital costs have a significant effect on the level of competitiveness of Botswana's coal. The traditional sensitivity analysis was conducted on the results of the base case simulation scenario. The results of the sensitivity analysis confirmed those from the experimental design approach which indicate that Botswana's steam coal exports are insensitive to rail transportation costs but are sensitive to changes in capital costs. They also indicate that Matola would be a preferred export port for both the Asian and Western European markets.

The spatial and dynamic optimization model was applied to forecast the likely future development of Botswana's coal deposits beginning from a base year of 2000 and extending to 2010, in five-year intervals. The results of the base case forecast scenario predicts the following ranking among the four exporters for exports to Western Europe: 1) South Africa, 2) Botswana, 3) the United States and 4) Australia. In the Asian market, the forecast rankings are: 1) Australia, 2) South Africa, 3) Botswana and 4) the United States. The model selects the port of Matola for exports to both Asia and Western European over the forecast horizon. The suitability of the port of Matola for exports to both of these markets presents opportunities for Botswana to take advantage of its geographical location in relation to the two major steam coal markets in the world. The size of mine and timing of development in the base case forecast scenario are 5.0 million mtce in 2005 and 20.05 million mtce in 2010. The market shares in Western Europe are $12 \%$ in 2005 and $23 \%$ or 5.0 million and 9.23 million mtce in 2005 and 2010 respectively. The market share in Asia is $12 \%$ or 10.77 million in mtce in 2010. 
The results of the base case forecast scenario were subjected to a sensitivity analysis to observe changes to the forecast optimal market shares, choice of export port, size of mine and timing of development for Botswana's coal deposits that would result from changes in rail transportation costs, capital costs for mine development and the level of steam import demand. The results are summarized below:

1. In scenarios 1, 2 and 3, the optimal levels of Botswana's steam coal exports are least sensitive to rail transportation costs to the extent that a $200 \%$ increase in these costs still results in Botswana's market share in Western Europe being at 12\% or 5.0 million mtce, and $23 \%$ or 9.23 million mtce, in 2005 and 2010 respectively. In the Asian market, Botswana's market share declines marginally to $10 \%$ from $12 \%$ in the base case in 2010 . The export tonnage in 2010 is 8.70 million mtce. The size of cumulative export mine capacity declines from 20.05 million mtce under the base case scenario to 17.97 million mtce in 2010.

2. In scenario 4 , when capital costs are $10 \%$ above their base case levels, there is a $10 \%$ decline in Botswana's coal exports in 2010. This decline occurs for exports to the Asia market only. Scenario 5 shows that if these costs are $20 \%$ higher than in the base case forecast scenario, exports decline by $75 \%$ in 2010 . Botswana loses its entire market share in Western Europe while in Asia its share declines to $6 \%$ from the $12 \%$ it held in the base case forecast scenario. The export mine capacity is 5.0 million mtce in 2005 and 5.04 million mtce in 2010. In scenario 6, when capital costs are $25 \%$ above the base case forecast scenario, Botswana's steam coal is no longer competitive in both markets and the country is eliminated out of the model. 
3. In scenario 7 , when the steam coal import demand is $20 \%$ lower than estimated, this does not affect the size of export mine at Mmamabula, which remains at 5.0 million mtce in 2005 and rises to 20.0 million mtce in 2010.

4. In scenario 8, a higher demand than that estimated expectedly shows that the simulated export port capacity for Mmamabula production would become a binding constraint on the size of mine to be developed. Also the port capacity constraint for South Africa means that the additional demand has to be met by other exporters not facing any of these constraints. The model demonstrates the role of marginal supplier that the United States plays in this model. Its exports to Western Europe are 12.32 million mtce in 2010, which is the only time that the model selects US exports.

5. The port of Matola offers the advantage of serving both the Asian and Western European markets and this is the port selected by the model.

\subsection{Policy Implications}

In the validation section of this study, we demonstrated that the variable supply costs, within the ranges studied, have no significant effect on the level of Botswana's exports. In the event there is a shift in the supply curve due to factors such as a rise in mining wages, such a shift would have to be of an order of magnitude that would not be easy to justify as shift in a policy variable such as wages or other costs of inputs. This suggests that the results of this model would hold under a scenario of rising mining wages for the Southern Africa region. The results of this study can be applied towards policy efforts aimed at encouraging the development of Botswana's coal deposits. We propose the following three areas: 1) the Botswana government policy on the provision of infrastructure, 2) the role of the SADC protocol in regional provision 
of infrastructure and 3) administrative efforts to disseminate information on coal deposits and also to maintain a model of this type for future policy decisions.

\subsubsection{Public Provision of Infrastructure in Botswana}

There are two approaches to the provision of public infrastructure; the passive strategy, in which governments provide infrastructure to eliminate excess demand, and the active strategy, whereby governments provide infrastructure ahead of private investment so as to encourage the latter (Rietveld, 1989 p255).

In the Botswana case, the provision of public infrastructure is planned under the framework of the 5-year National Development Plans. However, the provision of infrastructure for mineral sector projects is provided under the country's mineral development policy. This represents a passive strategy in which infrastructure is provided once its use is definite. This approach has the advantage of lessening the risk of under-utilization of infrastructure. The direct beneficiaries from such infrastructure are then charged user fees that permit the commercial operation and maintenance of the infrastructure. From the mining project's perspective, the provision of infrastructure by government reduces the project's upfront capital cost as it excludes infrastructure costs, resulting in more favorable financial returns to the project.

Other infrastructure projects in the transport sector, specifically the highway network, show the adoption of an active stance by government. For instance, the Trans-Kalahari highway that links South Africa's industrial heartland and traverses about $1000 \mathrm{~km}$ of Botswana territory provides an alternative link to Namibia and Europe through the seaport of Walvis Bay. This highway also provides a good example of a regional approach to planning infrastructure projects as it involves three regional governments. 
This model indicates that Botswana's coal would be competitive in world steam coal markets and that the lack of a rail and seaport infrastructure could be the main impediments to its exploitation. There is merit in the passive approach that the government has adopted towards infrastructure provision for the mineral industry but it now needs, on the strength of a study such as this one, to deliberately encourage the country's sole coal producer, Morupule Colliery, to aggressively seek export markets for the country's coal. For its part, the government could emphasize its current policy of accelerated infrastructure development for specified projects, that have a national benefit, to prospective investors.

\subsubsection{The Role of the SADC Protocol on Transport, Communications and Meteorology}

In Southern Africa, improved political stability has led to regional cooperation under protocols such as the Southern Africa Development Community's (SADC) protocol on Transport, Communications and Meteorology. Articles 3.3 and 3.5 of this protocol provide mechanisms and the institutional framework to facilitate the development of infrastructure through approaches that emphasize regional over national interests. Some experiences in regional cooperation include those in the electricity sub-sector, the Southern Africa Power Pool (SAPP), which was formalized in 1995. This has resulted in inter-connections between national grids in the region, thus minimizing the investment burden that would otherwise have to be met by individual governments. A similar argument can be made to support the merits of a regional approach to the development of railway infrastructure for the exploitation of the region's vast coal deposits.

There would be added advantages in the regional provision of coal transportation infrastructure as this might minimize the selfish rent-seeking behavior that might exist where each country sets their rail tariffs for coal exports. Many researchers have contributed in the 
debates regarding the role of infrastructure in industrialization and economic development. These debates agree in the main that there is a positive relationship between infrastructure and economic development but differ with regard to the magnitude of this impact (see Bell and McGuire, 1997, Munnell, 1992, for a review). These are some of possibilities that need to be factored into a decision to provide railway infrastructure for Botswana's steam coal exports under a regional as opposed to a national approach.

The Botswana government could therefore employ the results of this study towards the justification of a regional approach to the provision of both rail and port infrastructure that would make the development of Botswana's coal possible. The competitiveness results indicate that Botswana would not necessarily be weakening South Africa's export position as the region enjoys a comparative cost advantage in the supply of coal.

The next steps would include the identification by policy makers of those issues of concern to steam coal importing countries and the discovery of ways to address them. The country has accumulated a wealth of experience and success in an approach such as this one due to the recent revision of its mining law, where it was successful in obtaining quite comprehensive input concerning those sections of the law that had stood in the way of these companies' investment in Botswana's minerals sector. The provision of railway infrastructure could encourage mining companies to take advantage of the country's friendly mining law and very competitive fiscal regime to develop Botswana's coal deposits for the export markets.

\subsubsection{Role of Mineral Policy Makers}

The existence of a model such this one would enhance the capabilities of mineral administrators regarding both administrative and mineral policy issues. For instance, as the base forecast results of this model indicate that rail transportation costs at the levels applying to South 
African coal exports would not impede Botswana's exports, this would then force policy makers to hypothesize and identify factors that impede these exports. Also, there would be a need for maintaining current information on the country's coal reserves. The information on the size of coal resources in Botswana is not easily available, and for this reason, it is South Africa and Zimbabwe that are perceived to host coal resources in Africa.

The government has sponsored many studies to investigate the competitiveness of Botswana's coal and it would derive additional benefits if these reports were accessible to researchers and prospective investors.

\subsection{Conclusions}

We draw the following conclusions about the international competitiveness of Botswana's coal:

1. Botswana's coal is competitive in world steam coal markets;

2. Rail transportation costs, at rates that apply on South Africa's steam coal would not discourage exports of coal from Botswana;

3. Variable costs at levels applying to similar mines in South Africa are not a significant factor to the level of exports. Botswana's long run marginal cost function is such that any supply shifts due to factors such as rising wages would have to be of orders of magnitude before this advantage would be eroded;

4. The level of exports is most sensitive to capital costs and therefore this indicates that these costs would need to be defined at a greater level of accuracy to fully determine their role on the variability of exports;

5. The port of Matola is selected by the model for exports to both Western Europe and Asia; 
6. There is merit in applying the results of this study towards justifying Botswana's case for the development of rail and port infrastructure at the regional level and within the terms of the SADC protocol on Transport, Communications and Meteorology, and

7. The spatial and dynamic model developed for this study could act as a base upon which a coal model for Botswana could be built. We have shown in this study that coal models have been applied for a variety of policy issues similar to the ones that concern policy makers in Botswana. For instance, whether or not the market conditions are favorable for developing Botswana's coal and if so what role government could play in encouraging the exploitation of the country's coal deposits.

This study has emphasized the worrisome issue of why the country has met with very little success in developing its coal resource base of about 100 billion metric tons of coal equivalent with about 20 billion metric tons of these in the proven category. Furthermore, some of these proven steam coal reserves are strippable. This resource base translates into two-thirds of all the coal resources in Africa, a fact that should bolster the country's attractiveness for possible new coal development projects.

\subsection{Recommendations for Future Research}

The choice of countries to include in the model was limited by the availability of data and with the passage of time, if data becomes available for what are termed emerging exporting countries such as Colombia, China, Indonesia, India and Venezuela, their inclusion would increase the total market share for simulation.

The model assumption of a perfectly competitive industry facilitates the specification and estimation of the country supply and demand functions, as there is no interaction among these. 
This assumption has been found to hold in the case of the United States steam coal industry (Yang, Huang and Sohng, 2002). But the US steam coal industry is not driven by exports and may therefore not reflect the behavior among those countries for which the industry is export driven. It is therefore very likely that where the steam coal industry is driven by exports and there are a relatively few players of different sizes, then the assumption of a perfectly competitive industry may not hold. For this reason, future research should model the world steam coal trade under other competition models such as the Stackelberg leader follower model or noncooperative Cournot-oligopoly competition. Solution algorithms of the variational inequality problem could then be applied to solve such problems. 


\section{REFERENCES}

1. Abbey, D.S. and Kolstad, C. D., "The Structure of the International Steam Coal Markets", Natural Resources Journal, Vol. 23, no 4, October 1983, p859-891.

2. Burney, N. A., " Socioeconomic Development and Electricity Consumption: A Cross Country Analysis Using Random Coefficient Method", Energy Economics Vol. 17, no.3 Spring 1995 p185-195.

3. Clark, G.C., Lock, N.P. and Smith, R.A., The Coal Resources of Botswana, n.d. printed by the Department of Geological Survey, Lobatse, Botswana.

4. Dammert, A., "Planning Investments in the Copper Sector in Latin America", in Labys, W.C., M.I. Nadiri and J. Nunez del Arco (Ed.), Commodity Markets and Latin American Development: A Modeling Approach, 1980, p65-84, The National Bureau of Economic Research Inc.

5. Demler, F. R. and Tilton, J. E. "Modeling International Trade Flows in Mineral Markets, With Implications for Latin America's Trade Policies”, in Labys, W.C., M.I. Nadiri and J. Nunez del Arco (Ed.), Commodity Markets and Latin American Development: A Modeling Approach, 1980, p85-120, The National Bureau of Economic Research Inc.

6. Dingley, C., "What will it take to meet the need for electricity in sub-equatorial Africa?", Power Economics, May 2000, Vol. 4, Issue 5, p24, 3p. Retrieved January 28 ${ }^{\text {th }}, 2002$ from EBSCOhost:

http://ehostvgw11.epnet.com/ehost.asp?key=204.179.122.140_8000_1930580999\&site=e host\&return=n

7. Drissi-Kaitouni, O. and Florian, M., "An Algorithm for the Spatial Price Equilibrium Problem on a General Network in the Space of Path Flows", Journal of Regional Science, Vol. 31, no.2, May 1991, p171-190

8. Dutton, C.M.J., Modeling the International Trade in Steam Coal, July 15, 1982, Energy Research Group, Department of Physics, Cavendish Laboratory, University of Cambridge, Cambridge CB3 OHE, England.

9. Elliot-Jones, M., "Internationally Traded Coal: Competitiveness", in Bush, W.R.(ed), Economics of Internationally Traded Minerals, 1986, Society of Mining Engineers, Littleton, Colorado.

10. Enke, S., "Equilibrium Among Spatially Separated Markets: Solution by Electric Analogue", Econometrica, Vol. 19, Issue 1, Jan. 1951, p40-47

11. Florian, M. and Los, M. “ A New Look at Static Spatial Price Equilibrium Models”, Regional Science and Urban Economics, Vol. 12, 1982 p579-597.

12. Friesz, T.L., Harker, P.T. and Tobin, R.L., "Alternative Algorithms for the General Network Spatial Price Equilibrium Problem”, Journal of Regional Science, Vol. 24, no.4, Nov. 1984, p475-507

13. Giarratani, F., Gruver, G. and Richmond, C. " The US Regional Ferrous Scrap Model" in Geoffrey, J.D.H., Michael, S. and David, E. B.(Ed.), Trade, Networks and Hierarchies: Modeling Regional and Interregional Economies, 2002 p 159 -175, Springer-Verlag

14. Green, R.J. and Newbury, D.M., "Competition in the British Electricity Spot Market", The Journal of Political Economy, Vol. 100, Issue 5, Oct. 1992, p929-953

15. Judge, G.G. and Takayama, T., Studies in Economic Planning Over Space and Time, 1973, North Holland / American Elsevier. 
16. Harvey, A., "Trends, Cycles and Autoregressions", The Economic Journal, Vol. 107, no.440, January 1997, p192-201.

17. Holloway. M.L., "On Coal Resource Uncertainty and its Importance in Modeling for Public Policy Analysis", in Quirk, J., Terasawa, K. and Whipple D. (Ed), Coal Models and Their Use in Government Planning, 1982 p5-21, Praeger Publishers.

18. Huang, H., Modeling Trade and Environmental Interactions, 2002, West Virginia University, retrieved on December $17^{\text {th }}, 2002$ from: http://etd.wvu.edu//ETDS/E2282/Huang_Haixaio_Dissertation.pdf

19. Hunt, L. C., Judge, G. and Ninomiya, Y., "Underlying Trends and Seasonality in UK Energy Demand: A Sectoral Analysis", Energy Economics, Vol. 25 no.1, January 2003, p93-118.

20. Intriligator, M. D., Econometric Models, Techniques and Applications, 1978, Prentice Hall Inc., Englewood Cliffs, N.J.

21. Kang, K., An Investment Programming Model in the Electric Power Industry, Ph. D. dissertation, May 1981, The University of Texas at Austin.

22. Kendrick, D.A. and Stoutjesdijk, A.J., The Planning of Industrial Investment Programs: A Methodology, 1978, published for the World Bank by the Johns Hopkins University Press, Baltimore.

23. Kleijnen, J. P. C., Statistical Techniques in Simulation: Part I, 1974, Marcel Dekker Inc., New York, NY

24. Statistical Techniques in Simulation: Part II, 1975, Marcel Dekker Inc., New York, NY

25. Kolstad C.D., "Computing Dynamic Spatial Oligopolistic Equilibrium in an Exhaustible Resource Market: The Case of Coal", in Labys, W.C., T. Takayama and N. D. Uri (Ed.), Quantitative Methods for Market-Oriented Economic Analysis Over Space and Time, 1989, p87-104, Gower Publishing Company.

26. Kolstad, C.D., Abbey, D.S. and Bivins, R.L., Modeling International Steam Coal Trade, Los Alamos National Laboratory, LA-9661-MS, UC-98f, issued January 1983.

27. Koopmans, T.C., "Optimum Utilization of the Transportation System", Econometrica, Vol. 17, Issue supplement: Report of the Washington Meeting (July 1949), p136-146.

28. Lai, J. and Chen, C., "A Cost Minimization Model for Coal Import Strategy", Energy Policy, Vol. 24, no.12, 1996, p1111-1117.

29. Labson, B. S., "Changing Patterns of Trade in the World Iron Ore and Steel Market: An Econometric Analysis", Journal of Policy Modeling, 1997, vol. 19, no.3, p237-251

30. Labys, W.C. and Yang, C. W., "Le Chatelier Principle and the Flow Sensitivity of Spatial Commodity Models", in J.C.J.M. van den Bergh, P. Nijkamp and P. Rietveld (Ed.), Recent Advances in Spatial Equilibrium Modeling, 1995, p95 - 110, Springer.

31. _Advances in the Spatial Equilibrium Modeling of Mineral and Energy Issues", International Regional Science Review, 1991, Vol. 14, No. 1, p61-94.

32. __ "A Quadratic Programming Model of the Appalachian Steam Coal Market", Energy Economics, April 1980.

33. Labys, W. C., "Spatial and Temporal Price and Allocation Models of Mineral and Energy Markets", in Labys, W.C., T. Takayama and N. D. Uri (Ed.), Quantitative Methods for Market-Oriented Economic Analysis Over Space and Time, 1989, p17-48, Gower Publishing Company. 
34. "Commodity Models and Their Potential for Latin American Planning", in Labys, W.C., M.I. Nadiri and J. Nunez del Arco (Ed.), Commodity Markets and Latin American Development: A Modeling Approach, 1980, p9- 40, The National Bureau of Economic Research Inc.

35. Labys, W.C., Nadiri, M.I. and Nunez del Arco, J. (Ed.), Commodity Markets and Latin American Development: A Modeling Approach, 1980, The National Bureau of Economic Research Inc.

36. Lin, K., "USDA's World Grain, Oilseeds and Livestock (GOL) Model", in The International agricultural Trade Research Consortium: Agricultural Trade Modeling, the State of Practice and Research Issues, 1987, Economic Research Service, International Economics Division, United States Department of Agriculture, p6-18.

37. Liu, L.N. and Boyce, D.E., "Variational Inequality Formulation of the System-Optimal Travel Choice Problem and Efficient Congestion Tolls for a General Transportation Network With Multiple Time Periods", Regional Science and Urban Economics, Vol. 32, no.5, Sept. 2002, p627-650

38. Mabuza, E., “SADC's trading route derailed", Business Day, October $23^{\text {rd }}, 2001$, First edition. Retrieved on January $28^{\text {th }}, 2002$ from: http://www.bday.co.za/bday/content/direct/1,3523,1003348-6078-0,00.html

39. Manne, A.S. (ed), Investments for Capacity Expansion: Size, Location, and TimePhasing, 1967, The MIT Press, Cambridge Massachusetts

40. Meyers, W.H., Devadoss, S. and Helmar, M., "The Iowa State University FAPRI Model", in The International agricultural Trade Research Consortium: Agricultural Trade Modeling, the State of Practice and Research Issues, 1987, Economic Research Service, International Economics Division, United States Department of Agriculture, p44-56.

41. Mikesell, R.F., The World Copper Industry: Structure and Economic Analysis, 1979, The John Hopkins University Press, Baltimore, Maryland.

42. Mining Cost Service, 2002, published by Western Mine Engineering Inc., Spokane, Washington.

43. Murry, D. A. and Nan, G.D., "A definition of the Gross Domestic ProductElectrification Interrelationship", The Journal of Energy and Development, Vol. XIX, no.2, Spring 1994, p275-283

44. Brooke, A., Kendrick, D., Meeraus, A. and Raman, R., GAMS: A User's Guide, 1998, GAMS Development Corporation, Washington, D.C.

45. Myers, R. H. and Montgomery, D. C., Response Surface Methodology: Process and Product Optimization Using Designed Experiments, 1995, John Wiley and Sons, New York, NY.

46. Nagurney, A., Network Economics: A Variational Inequality Approach, 1999,_Kluwer Academic Publishers, Boston.

47. “Computational Comparisons of Spatial Price Equilibrium Models", Journal of Regional Science, Vol. 27, no. 1, 1987, p55-76.

48. Nagurney, A., Ding, Z. and Dong, J., " Spatial Economic Networks With Multicriteria Producers and Consumers: Statics and Dynamics", Annals of Regional Science, Vol. 36, no.1, Feb. 2002, p79-105

49. Nagurney, A. and Dong, J., “ A Multiclass, Multicriteria Traffic Network Equilibrium Model With Elastic Demand", Transportation Research Part B, Vol. 36, no.1, June 2002, p445-469 
50. Naylor, T.H., Computer Simulation Experiments With Models of economic Systems, 1971, John Wiley \& Sons Inc., New York, NY

51. Newberry, D., "A Template for Power Reform", Public Policy for the Private Sector, Note No.54, September 1995, The World Bank Group.

52. Ogawa, J., Statistical Theory of the Analysis of Experimental Designs, 1974, Marcel Dekker Inc., New York, NY

53. O'Leary, D. T., Charpentier, J.P. and Minogue, D., "Promoting Regional Power Trade: The Southern African Power Pool", Public Policy for the Private Sector, Note No. 145, June 1998, The World Bank Group.

54. Raschke, M. G., "The Structure of the International Coal Trade in Transition", in Bush, W.R.(ed), Economics of Internationally Traded Minerals, 1986, Society of Mining Engineers, Littleton, Colorado.

55. Ross, P. J., Taguchi Techniques for Quality Engineering, 1988, McGraw-Hill Inc., United States

56. Rowse, J., "Solving the Generalized Transportation Problem", Regional Science and Urban Economics, Vol. 11, no.1, Feb. 1981, p57-68

57. Samuelson, P. A., "Spatial Price Equilibrium and Linear Programming", The American Economic Review, Vol. 42, Issue 3, June 1952, p283-303.

58. Senf, D. R. and Fruin, J.E., " An Assessment of the Competitive Position of Great Lakes Ports in the International Steam Coal Trade", University of Minnesota, Staff Paper Series, Staff Paper P86-1, January 1986.

59. Suh, J.S., An Investment Planning Model for the Oil-Refining and Petrochemical Industries in Korea, Ph. D. dissertation, December 1981, The University of Texas at Austin.

60. Takayama, T., "Thirty Years With Spatial and Intertemporal Economics", in J.C.J.M. van den Bergh, P. Nijkamp and P. Rietveld (Ed.), Recent Advances in Spatial Equilibrium Modeling, 1995, p3 - 47, Springer.

61. Takayama, T. and Judge, G. G., Spatial and Temporal Price and Allocation Models, 1971, North Holland Publishing Company, Amsterdam. London

62. __ "Equilibrium Among Spatially Separated Markets: A Reformulation", Econometrica Vol. 32 No. 4, October 1964.

63. Thompson, G.L. and S. Thore, Computational Economics: Economic Modeling with Optimization Software, 1992, The Scientific Press, USA.

64. Toweh, S.H. and Newcomb, R.T., "A Spatial Equilibrium Analysis of World Iron Ore Trade", Resources Policy, September 1991.

65. van den Bergh, J.C.J.M., Nijkamp, P. and Rietveld, P., "Spatial Equilibrium Models: A Survey With Special Emphasis on Transportation", in J.C.J.M. van den Bergh, P. Nijkamp and P. Rietveld (Ed.), Recent Advances in Spatial Equilibrium Modeling, 1995, p48-76, Springer.

66. Wood, D.O. and Mason, M.J., "Analysis of the Energy Information Administration's Coal Supply Model”, in Quirk, J., Terasawa, K. and Whipple D. (Ed), Coal Models and Their Use in Government Planning, 1982 p37-56, Praeger Publishers.

67. Yang, C. and Labys, W.C., "A Sensitivity Analysis of the Linear Complementarity Programming Model: Appalachian Steam Coal and Natural Gas", in Labys, W.C., T. Takayama and N. D. Uri (Ed.), Quantitative Methods for Market-Oriented Economic Analysis Over Space and Time, 1989, p69-86, Gower Publishing Company. 
68. _Stability of Appalachian Coal Shipments Under Policy Variation", The Energy Journal, Vol. 2, No. 3, 1981, p111-128.

69. Yang, C.W., Hwang, M.J., and Sohng, S. N., “ The Cournot Competition in the Spatial Equilibrium Model”, Energy Economics, Vol. 24, no.2, March 2002, p139-154.

70. United States Department of the Interior, U.S. Bureau of Mines. Economic Analysis Tools for the Minerals Industry, (compact disk, SP 17-95), December 1995.

71. United States Department of the Interior, U.S. Bureau of Mines. A Cost Comparison of Selected Coal Mines from Australia, Canada, Colombia, South Africa, and the United

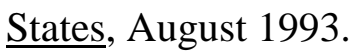

72. U.S. Department of Commerce, International Trade Administration Office of Energy and U.S. Department of Interior, U.S. Bureau of Mines, Division of Resource Evaluation. $\underline{A}$ Cost Comparison of Selected U.S. and South African Coal Mines, April 1990.

73. Future developments, n.d. Retrieved January $28^{\text {th }}, 2002$ from the Chamber of Mines of South Africa world wide web: http://www.bullion.org.za/bulza/educatn/coal.htm\#Future

74. South African Coal Report, Issue no. 13.08, August 2002, p8.

75. South African National Department of Transport, Moving South Africa Report: A Transport Strategy for 2020, retrieved on November 11, 2002 from: http://www.transport.gov.za/projects/msa/msareport/msadraft81,html

76. "Export Coal - End in Sight for Falling Prices, Low Profits?" Mining Engineering Vol. 53, no. 4, April 2001, p11.

77. Coal Age, Chicago Ill. 1996 Vol. 103 no 3, March 1998 20p, retrieved on March $3^{\text {rd }}$, 2002 from: http://wilsontxt.hwwilson.com/pdffull/05456/QJR0Z/8SB.pdf

78. United States Department of the Interior, U.S. Bureau of Mines. Economic Analysis Tools for the Minerals Industry, December 1995. (compact disk).

79. U.S. Department of Interior, U.S. Bureau of Mines, Division of Foreign Data. Mineral Industries of Africa, March 1984. 


\section{Appendix A. Results of the Econometric Estimation of the Country Supply and Demand Functions for Steam Coal (All variables in log first differences).}

\begin{tabular}{|c|c|c|c|c|c|}
\hline Variable & Japan: Demand & Japan: Supply & $\begin{array}{l}\text { Belgium: } \\
\text { Demand }\end{array}$ & $\begin{array}{l}\text { Belgium: } \\
\text { Supply }\end{array}$ & $\begin{array}{l}\text { France: } \\
\text { Demand }\end{array}$ \\
\hline Constant & $\begin{array}{l}0.006 \\
(0.216) \\
\end{array}$ & $\begin{array}{l}-0.216^{* * * *} \\
(-4.058)\end{array}$ & $\begin{array}{l}0.076^{*} \\
(1.775) \\
\end{array}$ & $\begin{array}{l}-0.159 * * \\
(-2.493)\end{array}$ & $\begin{array}{l}-0.042 \\
(-0.641) \\
\end{array}$ \\
\hline Pcoal & $\begin{array}{l}-0.355 \\
(-1.585) \\
\end{array}$ & & $\begin{array}{l}1.507 * * \\
(2.406)\end{array}$ & $\begin{array}{l}0.094 \\
(0.228) \\
\end{array}$ & $\begin{array}{l}1.617^{*} \\
(1.994)\end{array}$ \\
\hline \multicolumn{6}{|l|}{ Pgas } \\
\hline Poil & $\begin{array}{l}0.262 * \\
(1.776) \\
\end{array}$ & & $\begin{array}{l}0.122 \\
(0.852) \\
\end{array}$ & & \\
\hline GDP & $\begin{array}{l}0.204 \\
(1.058) \\
\end{array}$ & & & & $\begin{array}{l}-1.087 * * \\
(-2.342)\end{array}$ \\
\hline Dcoal (-1) & & & $\begin{array}{l}-0.215 \\
(-0.778) \\
\end{array}$ & & $\begin{array}{l}-0.4216 \\
(-1.477) \\
\end{array}$ \\
\hline Trend & $\begin{array}{l}0.361 * * * \\
(4.463) \\
\end{array}$ & $\begin{array}{l}0.868 * * * \\
(3.166) \\
\end{array}$ & & $\begin{array}{l}0.276 \\
(0.891) \\
\end{array}$ & $\begin{array}{l}0.647 \\
(1.118) \\
\end{array}$ \\
\hline Wage & & $\begin{array}{l}0.163 \\
(1.039)\end{array}$ & & $\begin{array}{l}-0.718^{*} \\
(-1.954)\end{array}$ & \\
\hline Interest & & & & $\begin{array}{l}0.1530 \\
(0.626) \\
\end{array}$ & \\
\hline Scoal (-1) & & $\begin{array}{l}(-0.823)^{*} \\
(-1.965)\end{array}$ & & & \\
\hline $\mathrm{R}^{2} \_$adj. & 0.56 & 0.34 & 0.30 & 0.21 & 0.10 \\
\hline M.A.P.E. \% & 5.047 & 13.29 & 25.85 & 16.56 & 23.62 \\
\hline Theil I. C. & 0.031 & 0.093 & 0.134 & 0.096 & 0.140 \\
\hline Bias & 0.008 & 0.163 & 0.255 & 0.358 & 0.172 \\
\hline Variance & 0.956 & 0.322 & 0.295 & 0.261 & 0.171 \\
\hline Covariance. & 0.036 & 0.514 & 0.450 & 0.381 & 0.657 \\
\hline DW & 1.77 & 1.98 & 2.07 & 2.12 & 2.24 \\
\hline $\mathrm{N}$ & 16 & 16 & 14 & 20 & 16 \\
\hline
\end{tabular}

Source: Based on models estimated by the author.

Key: $\quad(* * *),(* *),(*)-1 \%, 5 \%$ and $10 \%$ level of significance respectively. 
Appendix A. (cont'd) Results of the Econometric Estimation of Country Supply and Demand Functions for Steam Coal (All variables in log first differences)

\begin{tabular}{|c|c|c|c|c|c|}
\hline Variable & France: Supply & $\begin{array}{l}\text { Germany: } \\
\text { Demand }\end{array}$ & $\begin{array}{l}\text { Germany: } \\
\text { Supply }\end{array}$ & $\begin{array}{l}\text { Italy: } \\
\text { Demand }\end{array}$ & $\begin{array}{l}\text { Netherlands: } \\
\text { Demand }\end{array}$ \\
\hline Constant & $\begin{array}{l}-0.076 * * * \\
(-2.300)\end{array}$ & $\begin{array}{l}-0.050 * * \\
(-2.533)\end{array}$ & $\begin{array}{l}-0.156 * * * \\
(-5.230)\end{array}$ & $\begin{array}{l}-0.073 \\
(-1.113)\end{array}$ & $\begin{array}{l}-0.032 \\
(-0.391)\end{array}$ \\
\hline Pcoal & $\begin{array}{l}0.295 \\
(1.556)\end{array}$ & $\begin{array}{l}-0.200 * * \\
(-2.595)\end{array}$ & $\begin{array}{l}-0.102 \\
(-1.480)\end{array}$ & $\begin{array}{l}-0.110 \\
(-0.366)\end{array}$ & $\begin{array}{l}-0.014 \\
(-0.031)\end{array}$ \\
\hline Pgas & & $\begin{array}{l}0.314^{*} \\
(1.944)\end{array}$ & & & $\begin{array}{l}0.204 \\
(0.408)\end{array}$ \\
\hline Poil & & $\begin{array}{l}-0.207 * * \\
(-2.118)\end{array}$ & & $\begin{array}{l}0.473^{*} \\
(1.984)\end{array}$ & $\begin{array}{l}0.240 \\
(1.202)\end{array}$ \\
\hline$\overline{\text { GDP }}$ & & $\begin{array}{l}0.295 \\
(1.525)\end{array}$ & & $\begin{array}{l}0.374 \\
(1.180)\end{array}$ & $\begin{array}{l}0.024 \\
(0.059)\end{array}$ \\
\hline Trend & $\begin{array}{l}0.189 \\
(1.589)\end{array}$ & & $\begin{array}{l}0.514 * * * \\
(3.029)\end{array}$ & $\begin{array}{l}0.842 * * \\
(2.827)\end{array}$ & $\begin{array}{l}0.840^{* *} \\
(2.437)\end{array}$ \\
\hline Dcoal (-1) & & $\begin{array}{l}-0.475 * * \\
(-2.635)\end{array}$ & & & \\
\hline Wages & & & $\begin{array}{l}0.398^{* * *} \\
(2.488) \\
\end{array}$ & & \\
\hline \multicolumn{6}{|l|}{ Interest } \\
\hline Scoal (-1) & & & $\begin{array}{l}-0.664 * * * \\
(-3.618) \\
\end{array}$ & & \\
\hline $\mathrm{R}^{2}$ adj. & 0.10 & 0.49 & 0.49 & 0.29 & 0.25 \\
\hline M.A.P.E. $\%$ & 6.74 & 7.40 & 6.045 & 12.225 & 22.72 \\
\hline Theil I. C. & 0.034 & 0.043 & 0.030 & 0.083 & 0.110 \\
\hline Bias & 0.296 & 0.006 & 0.082 & 0.242 & 0.269 \\
\hline Variance & 0.021 & 0.023 & 0.247 & 0.537 & 0.104 \\
\hline Covariance & 0.683 & 0.971 & 0.671 & 0.221 & 0.627 \\
\hline DW & 2.06 & 2.56 & 2.30 & 2.10 & 2.39 \\
\hline $\mathrm{N}$ & 20 & 19 & 19 & 17 & 20 \\
\hline
\end{tabular}

Source: Based on models estimated by the author.

Key: $\quad(* * *),(* *),(*)-1 \%, 5 \%$ and $10 \%$ level of significance respectively. 
Appendix A. (cont'd) Results of the Econometric Estimation of Country Supply and Demand Functions for Steam Coal (All variables in log first differences)

\begin{tabular}{|c|c|c|c|c|}
\hline Variable & $\begin{array}{l}\text { Spain: } \\
\text { Demand }\end{array}$ & $\begin{array}{l}\text { Spain: } \\
\text { Supply }\end{array}$ & UK: Demand & $\begin{array}{l}\text { UK: } \\
\text { Supply }\end{array}$ \\
\hline Constant & $\begin{array}{l}-0.015 \\
(-0.430) \\
\end{array}$ & $\begin{array}{l}0.015 \\
(1.265) \\
\end{array}$ & $\begin{array}{l}0.041 \\
(0.406) \\
\end{array}$ & $\begin{array}{l}-0.115 \\
(-1.051) \\
\end{array}$ \\
\hline Pcoal & $\begin{array}{l}0.060 \\
(0.323)\end{array}$ & $\begin{array}{l}0.134 * \\
(1.751)\end{array}$ & $\begin{array}{l}2.485^{* *} \\
(2.301)\end{array}$ & $\begin{array}{l}0.821 \\
(0.937)\end{array}$ \\
\hline Pgas & $\begin{array}{l}0.151 \\
(1.007)\end{array}$ & & $\begin{array}{l}-0.573 \\
(-1.294)\end{array}$ & \\
\hline Poil & $\begin{array}{l}0.016 \\
(0.082)\end{array}$ & & & \\
\hline GDP & $\begin{array}{l}0.177 \\
(1.131) \\
\end{array}$ & & $\begin{array}{l}0.141 \\
(0.122) \\
\end{array}$ & \\
\hline Trend & $\begin{array}{l}0.399 * * \\
(2.304)\end{array}$ & & & $\begin{array}{l}0.506 \\
(0.924) \\
\end{array}$ \\
\hline Dcoal (-1) & & & $\begin{array}{l}-0.648 * * \\
(-2.709) \\
\end{array}$ & \\
\hline Wage & & $\begin{array}{l}-0.117 \\
(-1.407)\end{array}$ & & $\begin{array}{l}0.841 \\
(1.267)\end{array}$ \\
\hline Interest & & $\begin{array}{l}-0.024 \\
(-1.234)\end{array}$ & & \\
\hline Scoal (-1) & & $\begin{array}{l}.484 * * \\
(2.144)\end{array}$ & & $\begin{array}{l}-0.359 \\
(-1.551) \\
\end{array}$ \\
\hline $\mathrm{R}_{-}^{2}$ adj. & 0.21 & 0.30 & 0.36 & 0.35 \\
\hline M.A.P.E. \% & 12.97 & 8.55 & 7.874 & 4.631 \\
\hline Theil I.C. & 0.082 & 0.057 & 0.058 & 0.026 \\
\hline Bias & 0.390 & 0.398 & 0.174 & 0.017 \\
\hline Variance & 0.116 & 0.504 & 0.054 & 0.047 \\
\hline Covariance. & 0.494 & 0.098 & 0.772 & 0.936 \\
\hline DW & 2.01 & 2.29 & 2.61 & 2.65 \\
\hline $\mathrm{N}$ & 17 & 16 & 16 & 19 \\
\hline
\end{tabular}

Source: Based on models estimated by the author.

Key: $\quad(* * *),(* *),(*)-1 \%, 5 \%$ and $10 \%$ level of significance respectively. 


\section{Appendix A. (cont'd) Results of the Econometric Estimation of Country Supply and Demand Functions for Steam Coal (All variables in log first differences)}

\begin{tabular}{|c|c|c|c|c|c|c|}
\hline Variable & $\begin{array}{l}\text { Australia: } \\
\text { Demand }\end{array}$ & $\begin{array}{l}\text { Australia: } \\
\text { Supply }\end{array}$ & $\begin{array}{l}\text { S. Africa: } \\
\text { Demand }\end{array}$ & $\begin{array}{l}\text { S. Africa: } \\
\text { Supply }\end{array}$ & $\begin{array}{l}\text { U.S.A.: } \\
\text { Demand } \\
\end{array}$ & $\begin{array}{l}\text { U.S.A.: } \\
\text { Supply }\end{array}$ \\
\hline Constant & $\begin{array}{l}0.051 * * * \\
(3.001)\end{array}$ & $\begin{array}{l}0.041 \\
(0.909)\end{array}$ & $\begin{array}{l}0.007 \\
(0.413)\end{array}$ & $\begin{array}{l}0.005 \\
(0.323)\end{array}$ & $\begin{array}{l}0.030 \\
(1.144)\end{array}$ & $\begin{array}{l}0.017 \\
(0.705)\end{array}$ \\
\hline Pcoal & $\begin{array}{l}-0.153^{*} \\
(-1.719) \\
\end{array}$ & $\begin{array}{l}0.135 \\
(0.467) \\
\end{array}$ & $\begin{array}{l}0.0916 \\
(0.860) \\
\end{array}$ & & $\begin{array}{c}-0.0760 \\
(-0.151) \\
\end{array}$ & \\
\hline \multicolumn{7}{|l|}{ Pgas } \\
\hline \multicolumn{7}{|l|}{ Poil } \\
\hline GDP & & & $\begin{array}{l}-0.129 \\
(-0.794) \\
\end{array}$ & & & \\
\hline Trend & $\begin{array}{l}-0.084 \\
(-0.958)\end{array}$ & $\begin{array}{l}0.442 * * * \\
(3.028)\end{array}$ & $\begin{array}{l}0.188^{* *} \\
(2.32)\end{array}$ & & & \\
\hline Dcoal (-1) & $\begin{array}{l}-0.176 \\
(-0.754) \\
\end{array}$ & & & & $\begin{array}{l}-0.649 * * * \\
(-3.150)\end{array}$ & \\
\hline Wage & & $\begin{array}{l}-0.445 \\
(-1.483) \\
\end{array}$ & & & & \\
\hline \multicolumn{7}{|l|}{ Interest } \\
\hline Scoal (-1) & & & & $\begin{array}{l}-0.153 \\
(-0.643) \\
\end{array}$ & & $\begin{array}{l}-0.608 * * \\
(-2.862) \\
\end{array}$ \\
\hline Capacity & & & & $\begin{array}{l}1.109^{* *} \\
(2.482)\end{array}$ & & $\begin{array}{l}0.5976 \\
(0.598) \\
\end{array}$ \\
\hline $\mathrm{R}^{2} \_$adj. & 0.04 & 0.32 & 0.21 & 0.22 & 0.36 & 0.32 \\
\hline M.A.P.E. $\%$ & 1.98 & 6.920 & 3.13 & 1.92 & 4.275 & 4.098 \\
\hline Theil I.C. & 0.011 & 0.041 & 0.016 & 0.010 & 0.022 & 0.022 \\
\hline Bias & 0.233 & 0.001 & 0.286 & 0.293 & 0.145 & 0.109 \\
\hline Variance & 0.023 & 0.004 & 0.001 & 0.660 & 0.072 & 0.008 \\
\hline Covariance & 0.744 & 0.985 & 0.713 & 0.047 & 0.783 & 0.883 \\
\hline DW & 1.68 & 2.46 & 2.1 & 2.15 & 2.22 & 2.13 \\
\hline $\mathrm{N}$ & 19 & 20 & 20 & 20 & 16 & 16 \\
\hline
\end{tabular}

Source: Based on models estimated by the author.

Key: $\quad(* * *),(* *),(*)-1 \%, 5 \%$ and $10 \%$ level of significance respectively. 


\section{Appendix B. Results of the Econometric Estimation of the Long Run Marginal Cost Functions for Steam Coal (1980-1997) (All variables in first differences)}

\begin{tabular}{llll}
\hline Variable & Australia & South Africa & United States \\
\hline Constant & $-7.947^{*}$ & 1.964 & -0.860 \\
& $(-1.793)$ & $(0.671)$ & $(-0.840)$ \\
\hline Wage & $5.534^{* * *}$ & $4.045^{*} *$ & 1.107 \\
& $(3.27)$ & $(2.369)$ & $(0.920)$ \\
\hline Supply & $7.06 \times 10^{-5}$ & $6.51 \times 10^{-5}$ & $7.32 \times 10^{-6}$ \\
& $(0.177)$ & $(0.186)$ & $(0.165)$ \\
\hline Price (-1) & 0.232 & $0.365^{*} *$ & $0.548^{* *}$ \\
& $(1.317)$ & $(2.367)$ & $(2.564)$ \\
\hline Capacity & -0.000172 & -0.000684 & $-2.69 \times 10^{-6}$ \\
& $(-0.257)$ & $(-1.132)$ & $(-0.506)$ \\
\hline & & & \\
\hline & & & 0.32 \\
\hline R ${ }^{2}$ adj. & 0.42 & 0.61 & 2.03 \\
\hline M.A.P.E. $\%$ & 19.32 & 3.26 & 0.013 \\
\hline Theil & 0.158 & 0.026 & 0.345 \\
\hline Bias & 0.326 & 0.327 & 0.653 \\
\hline Variance & 0.023 & 0.001 & 0.002 \\
\hline Covariance & 0.651 & 0.672 & 1.83 \\
\hline DW & 1.83 & 2.30 & 17 \\
\hline N & 17 & 17 & \\
\hline
\end{tabular}

Source: Based on models estimated by the author.

Key: $\quad(* * *),(* *),(*)-1 \%, 5 \%$ and $10 \%$ level of significance respectively. 


\section{Appendix C. Results for Time Series Estimation of Sea Freight Costs Along Trade Routes for Sea Vessels of Size Greater Than 100000 Dead Weight Tons (All variables in log differences except for USA which is in logs)}

\begin{tabular}{|c|c|c|c|c|c|c|}
\hline Variable & $\begin{array}{l}\text { Gladstone } \\
\text { to } \\
\text { Yokohama }\end{array}$ & $\begin{array}{l}\text { Gladstone } \\
\text { to ARA }\end{array}$ & $\begin{array}{l}\text { Richards Bay } \\
\text { (a) to } \\
\text { Yokohama }\end{array}$ & $\begin{array}{l}\text { Richards } \\
\text { Bay to } \\
\text { ARA }\end{array}$ & $\begin{array}{l}\text { Hampton } \\
\text { Roads to } \\
\text { Yokohama }\end{array}$ & $\begin{array}{l}\text { Hampton } \\
\text { Roads to } \\
\text { Yokohama }\end{array}$ \\
\hline Constant & $\begin{array}{l}-0.124 \\
(-1.418) \\
\end{array}$ & $\begin{array}{l}-0.159 * \\
(-2.087)\end{array}$ & $\begin{array}{l}-0.277 * * * \\
(-3.323) \\
\end{array}$ & $\begin{array}{l}-0.258 * * \\
(-2.812) \\
\end{array}$ & $\begin{array}{l}-0.389 \\
(-0.483)\end{array}$ & $\begin{array}{l}-0.370 \\
(-0.375) \\
\end{array}$ \\
\hline Poil & $\begin{array}{l}0.344 \\
(1.601) \\
\end{array}$ & $\begin{array}{l}0.310 \\
(1.771) \\
\end{array}$ & $\begin{array}{l}0.181 \\
(0.744) \\
\end{array}$ & $\begin{array}{l}0.141 \\
(0.538) \\
\end{array}$ & $\begin{array}{l}0.552 * \\
(2.120) \\
\end{array}$ & $\begin{array}{l}0.604 * \\
(1.973) \\
\end{array}$ \\
\hline Freight(-1) & $\begin{array}{l}-0.077 \\
(-0.282) \\
\end{array}$ & $\begin{array}{l}-0.577^{*} \\
(-1.932) \\
\end{array}$ & $\begin{array}{l}-0.638 * * \\
(-2.729) \\
\end{array}$ & $\begin{array}{l}-0.720 * * \\
(-2.379) \\
\end{array}$ & $\begin{array}{l}0.375 \\
(1.690) \\
\end{array}$ & $\begin{array}{l}0.486 * * \\
(2.318) \\
\end{array}$ \\
\hline Trade $^{(b)}$ & $\begin{array}{l}2.280 \\
(1.731) \\
\end{array}$ & $\begin{array}{l}2.608 * * \\
(2.249) \\
\end{array}$ & $\begin{array}{l}4.529 * * \\
(2.962) \\
\end{array}$ & $\begin{array}{l}4.542 * * \\
(2.684) \\
\end{array}$ & & \\
\hline Adj. R-sq. & 0.24 & 0.41 & 0.62 & 0.50 & 0.36 & 0.42 \\
\hline DW & 1.67 & 1.54 & 1.06 & 1.47 & 1.9 & 1.72 \\
\hline $\mathrm{N}$ & 16 & 16 & 12 & 12 & 15 & 15 \\
\hline
\end{tabular}

Source: Based on models estimated by the author.

Key: $\quad(* * *),(* *),(*)-1 \%, 5 \%$ and $10 \%$ level of significance respectively.

Notes: ${ }^{\text {(a) }}$ - This sea freight cost equation will apply to charges exported through the ports of Matola and Walvis Bay after adjusting for distances to destination from these two ports.

(b) - This is the volume of the seaborne steam coal trade.

Appendix D. Sensitivity Results of the Econometric Estimation of the Long Run Marginal Cost Functions for Steam Coal (1983 - 2000) (All variables in first differences)

\begin{tabular}{llll}
\hline Variable & Australia & South Africa & United States \\
\hline Constant & -6.330 & 2.424 & -0.320 \\
& $(-1.392)$ & $(0.829)$ & $(-0.480)$ \\
\hline Wage & $4.184 * *$ & $4.271^{*}$ & 0.893 \\
& $(2.595)$ & $(2.511)$ & $(1.158)$ \\
\hline Supply & 0.000137 & $9.87 \times 10^{-5}$ & $5.87 \times 10^{-6}$ \\
& $(0.340)$ & $(0.385)$ & $(0.855)$ \\
\hline Price (-1) & 0.256 & $0.442^{*} *$ & $0.369 * *$ \\
& $(1.140)$ & $(2.649)$ & $(2.597)$ \\
\hline Capacity & -0.000192 & -0.000755 & $-0.000122^{* * *}$ \\
& $(-0.269)$ & $(-1.256)$ & $(-3.065)$ \\
\hline & & & \\
\hline & & & 0.49 \\
\hline $\mathrm{R}^{2}$ adj. & 0.25 & 0.61 & 1.84 \\
\hline $\mathrm{DW}$ & 1.41 & 2.48 & 17 \\
\hline $\mathrm{N}$ & 17 & 17 &
\end{tabular}

Source: Based on models estimated by the author.

Key: $\quad(* * *),(* *),(*)-1 \%, 5 \%$ and $10 \%$ level of significance respectively. 
Appendix E. Base Case Forecast Residual Market Shares for Exporters

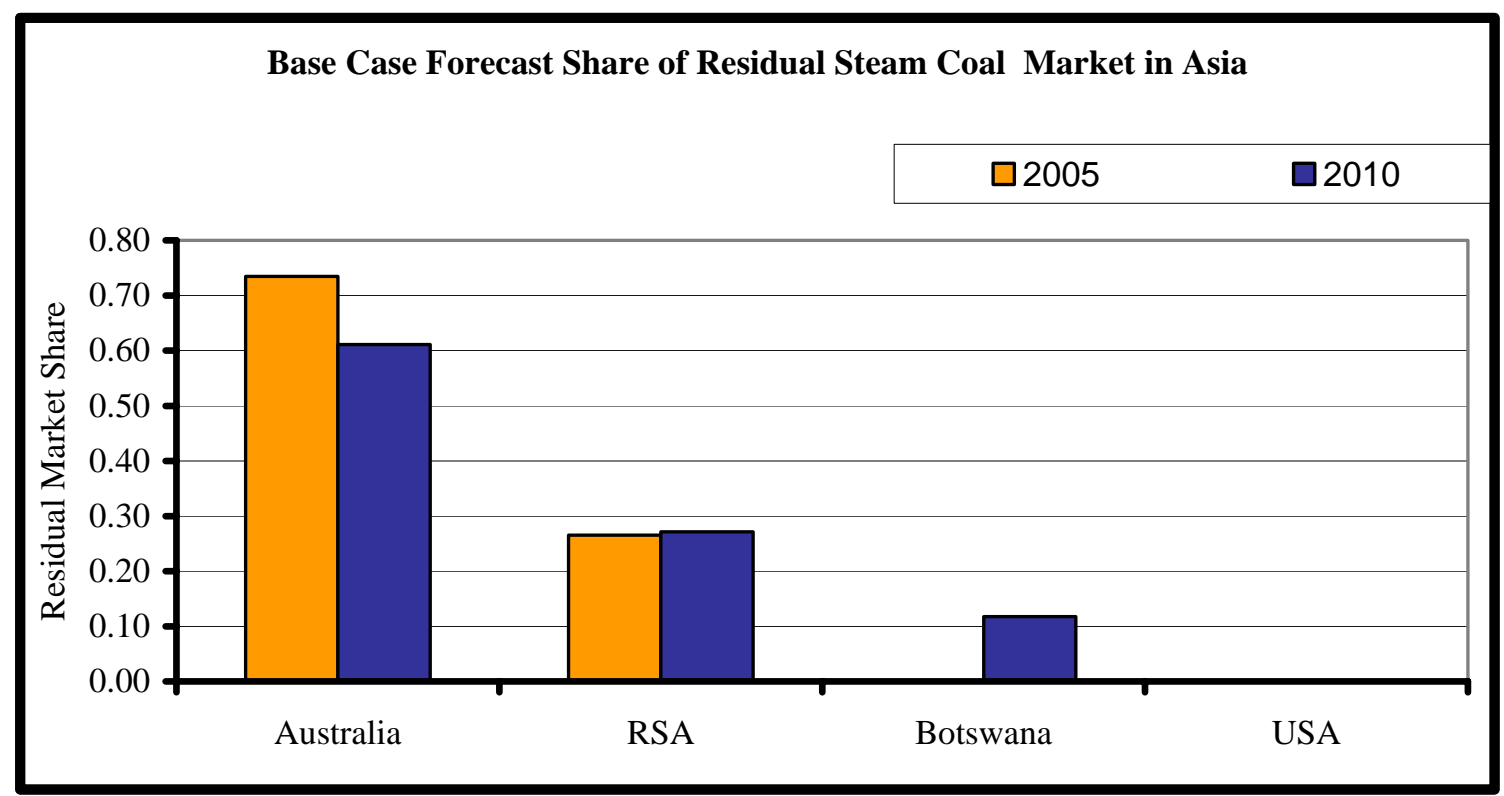

Source: Based on author's model estimation.

Base Case Forecast Share of Residual Steam Coal Market in Western Europe

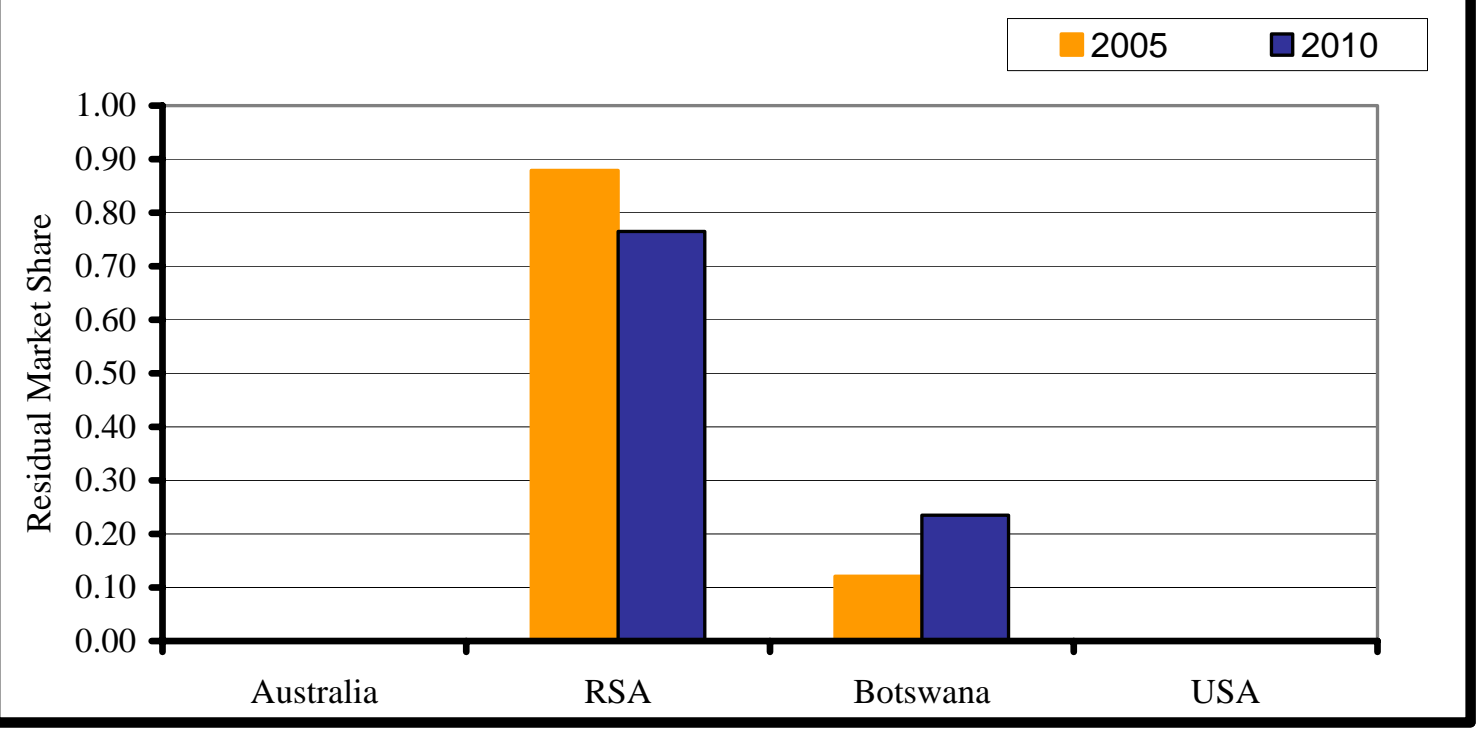

Source: Based on author's model estimation. 
Appendix F. The Resultant Market Shares With Botswana's Capital Costs at 20\% Above Their Base Case Forecast Levels

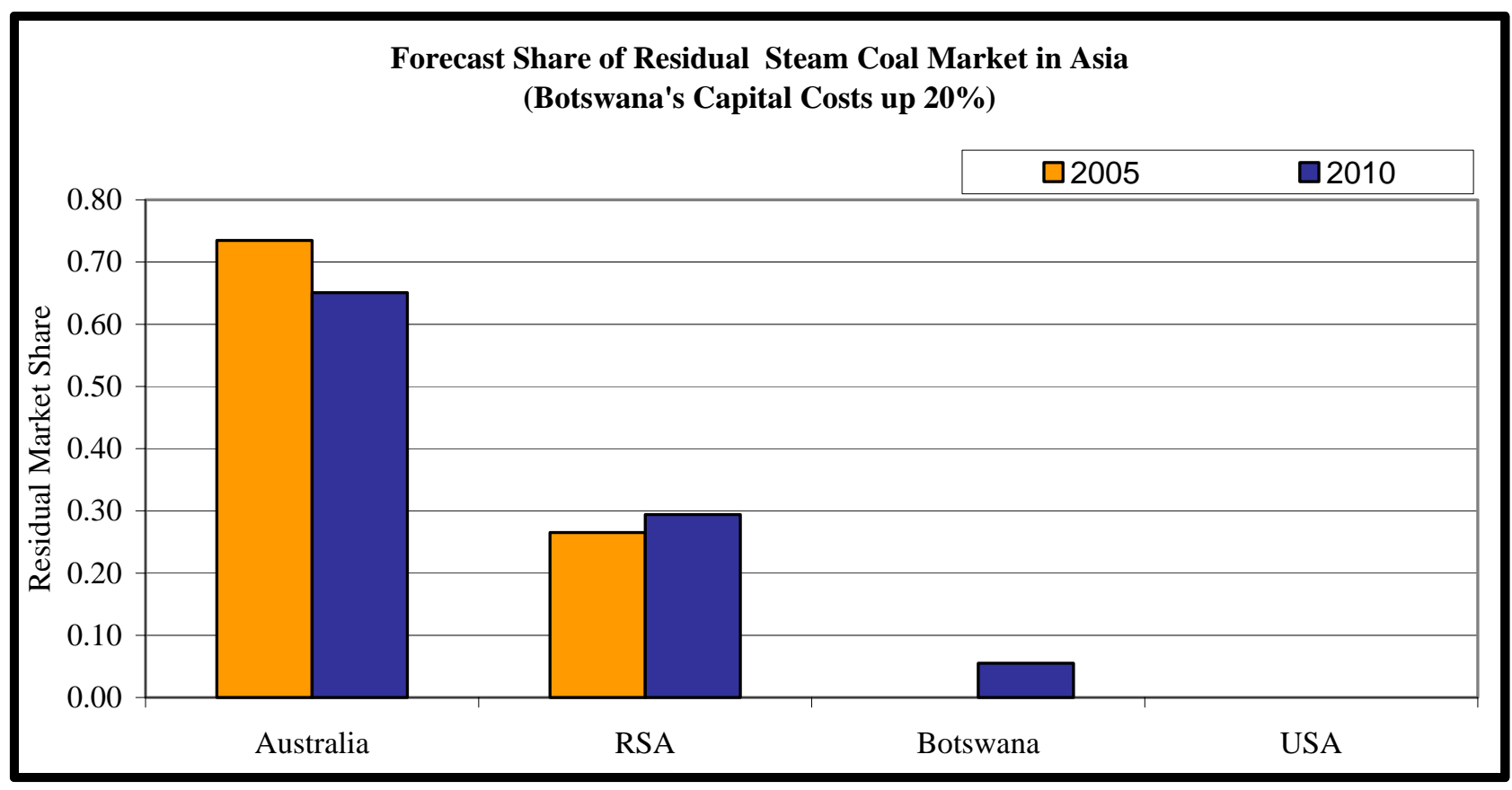

Source: Based on author's model estimation.

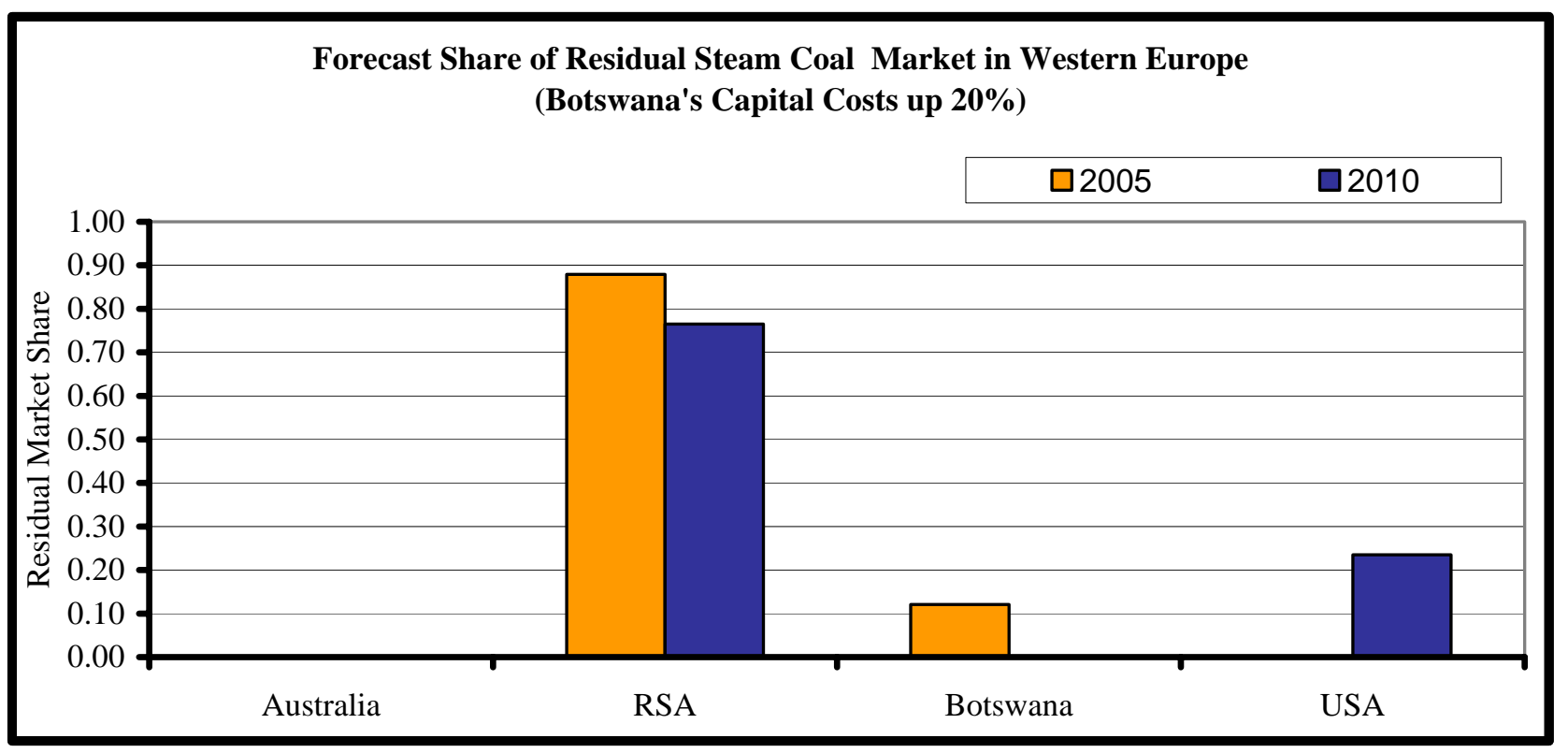

Source: Based on author's model estimation. 


\section{Appendix G. A Simple Multi-period Linear Programming Model of the World Steam Coal Trade}

The logical starting point in the development of a spatial and dynamic model that has the four components of capacity addition, variable supply costs, and distribution costs is to begin with a multi-period linear spatial price equilibrium model. Such a model can be applied to simulate the trade flows only under a decision criterion in which the distribution costs are minimized subject to constraints for the transport problem. This is essentially an application of linear programming over a number of periods all of which are independent and could very easily be programmed individually (see Thompson and Thore 1992, p206). The advantage we gain from such an exercise is that we obtain valuable information from the marginal values, which are the Lagrange Multipliers. In an optimization problem in which the analysis is at the industry level, the marginal values represent shadow market prices at the supply and demand regions. The marginal values also provide a quick indication of the extra costs that would be incurred from an additional unit of supply at a given source and also the additional costs for transporting that unit along a given link between the origin-destination pairs.

The objective function in this cost minimization problem is to minimize the sum of rail transport and maritime transportation costs steam coal traded internationally over the period 1990 to 2010. The typical constraints are for observing material availability at the sources and meeting demand at the destination points. The transfer from land to sea-going vessels adds transshipment points with the added condition that inflows balance out with outflows at these nodes. Figure G.1 shows the existing and simulated regional supply of export coal from the Southern Africa region comprising of Botswana and South African coal mines. Almost all existing export coal mines in South Africa exploit coals on the Witbank coalfield in the Mpumalanga province. There is one large-scale colliery in the Northern province that produces 
coal for both the domestic and export markets. A rail link from the town of Witbank to the Indian Ocean seaport of Richards Bay, where the coal exporting companies operate a private coal handling export terminal by the same name, provides access to the only dedicated coal-handling terminal in the region. The results from this rail transportation and freight cost minimization problem are shown on tables G-1, G-2 and G-3 below.

Table G-1 shows the shadow values, which in this case represent the shadow costs of supply, for possible exports from Mmamabula declining with time so that in the year 2000, there would be no additional cost of a metric ton of coal equivalent shipped through Richards Bay while it would cost an additional \$0.46 and \$2.46 to export the same tonnage through Matola and Walvis Bay respectively due to the binding port capacity constraints. This result means that if there were coal available for export from Mmamabula, this would have been competitive enough to be exported through Richard's Bay in 2000. The model also shows that from 2005 onwards, there is no additional cost for routing Mmamabula's coal output through the port of Walvis Bay while for the other two ports, there is a slight increase in costs as the Richards Bay port capacity constraint is approached. This transportation problem shows that Walvis Bay would be a cheaper route to export to markets in Western Europe than Richards Bay. The reason for this is that while the land distance is longer than that to Richards Bay, the ocean distance is greatly reduced by exporting from Walvis Bay. This could prove to be of significant advantage as importers also value a shorter delivery time, which would be possible through the Mmamabula - Walvis Bay route (South African National Department of Transport, 1997).

In table G-2, the shadow values indicate a gradual convergence in marginal supply costs between producers in South Africa and Australia. On the other hand, an additional unit of coal produced from Appalachia would not lead to a reduction in costs. Table G-3 reflects the cost 
advantage that exports from Botswana would have over those from the United States and Australia in the Asian and Western European steam coal markets respectively. These preliminary results are encouraging and justify a more detailed model to take into account elastic coal supply to meet a growing demand in internationally traded steam coal. A non-linear quadratic programming model is thus used to select the timing and size of capacity additions from among the four possible supply countries in the model that would be necessary to meet the given demand for steam coal in the importing countries of the model. 
$\underline{\text { Supply ( } \mathrm{i}=1 \text { to } \mathrm{n})} \quad \underline{\text { Transshipment }(k=1 \text { to } K)} \quad \underline{\text { Demand }(j=1 \text { to } \mathrm{m})}$

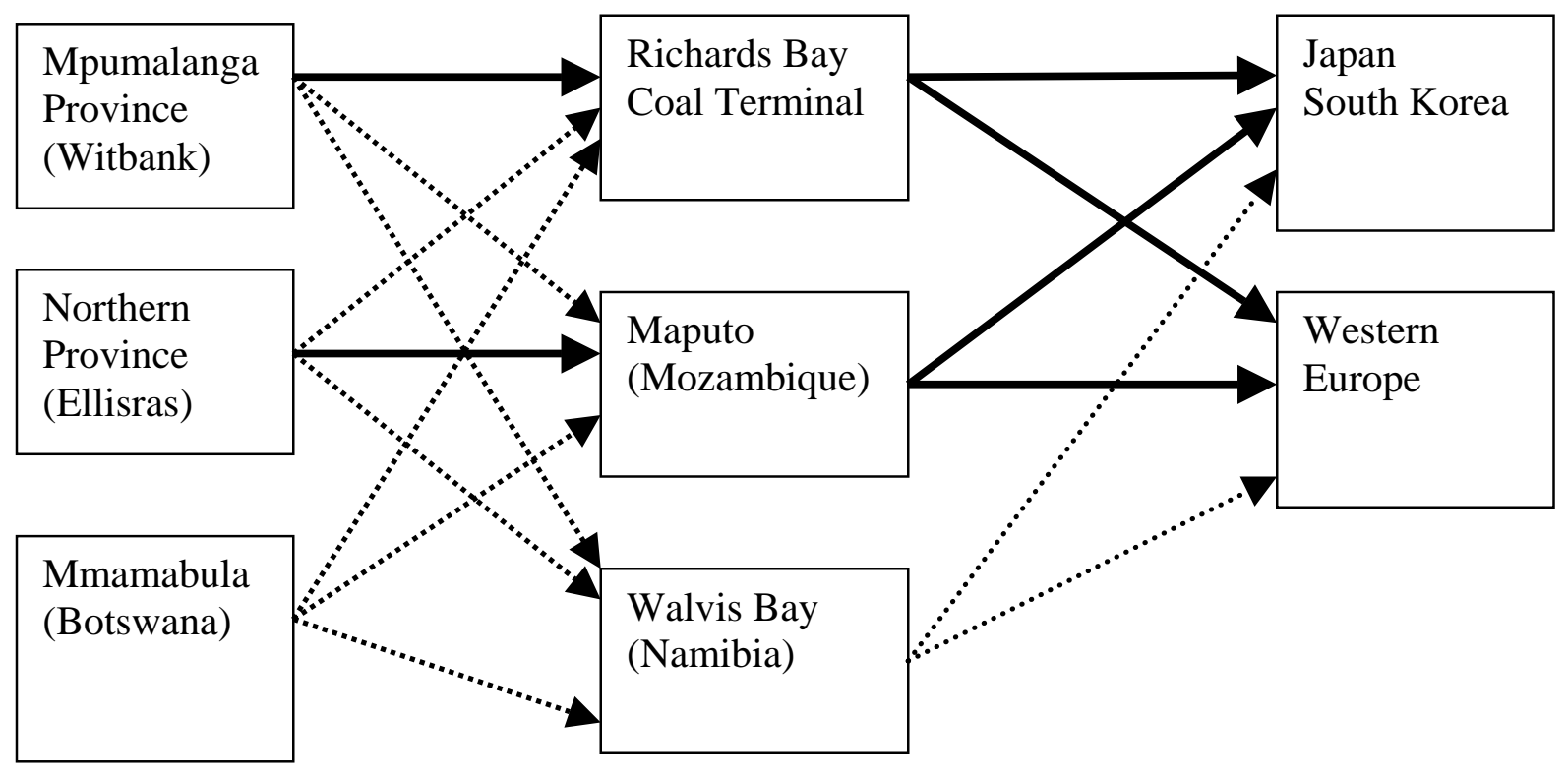

Key: $\rightarrow$ Existing route $\quad \cdots . . \rightarrow$ simulated route

Figure G-1 Existing and Simulated Export Steam Coal Supply and Export Routes for the Southern Africa Region 
Table G-1 Shadow Values for Transporting an Extra Unit of Export Coal

\begin{tabular}{lccccc}
\hline \multicolumn{1}{c}{ From/To } & 1990 & 1995 & 2000 & 2005 & 2010 \\
\hline Witbank - Matola & 0.0 & 0.0 & 0.0 & 0.0 & 0.0 \\
Witbank - Richard's Bay & 0.0 & 0.0 & 0.0 & 0.0 & 0.0 \\
Witbank - Walvis Bay & 52.19 & 25.61 & 15.46 & 6.63 & 5.83 \\
Mmamabula - Matola & 21.48 & 3.47 & 0.46 & 1.38 & 2.18 \\
Mmamabula - Richard's Bay & 19.96 & 2.34 & 0.0 & 1.10 & 1.90 \\
Mmamabula - Walvis Bay & 26.88 & 4.36 & 2.40 & 0.0 & 0.0 \\
Appalachia - Hampton Roads & 0.0 & 0.0 & 0.0 & 0.0 & 0.0 \\
\hline
\end{tabular}

Source: Based on model simulations by author.

Table G-2 Shadow Values for an Additional Unit of Supply

\begin{tabular}{lcccc}
\hline \multicolumn{1}{c}{ Source } & 1990 & 1995 & 2000 & 2005 \\
\hline Witbank & 1.17 & 5.35 & 11.17 & 11.80 \\
Mmamabula & 0.0 & 0.0 & 5.27 & 9.40 \\
Appalachia & 0.0 & 0.0 & 0.0 & 0.0 \\
Australia & 26.31 & 18.36 & 20.55 & 11.72 \\
\hline
\end{tabular}

Source: Based on model simulations by the author.

Table G-3 A Comparison of Shadow Values for Shipping an Extra Unit of Export

\begin{tabular}{lccccc}
\hline \multicolumn{1}{c}{ From / To } & 1990 & 1995 & 2000 & 2005 & 2010 \\
\hline Walvis Bay - ARA & 0.0 & 0.0 & 0.0 & 0.0 & 0.0 \\
Walvis Bay - Yokohama & 4.78 & 6.58 & 11.54 & 4.59 & 5.12 \\
Matola - ARA & 0.0 & 0.0 & 0.0 & 0.0 & 0.0 \\
Matola - Yokohama & 0.0 & 0.0 & 10.04 & 0.0 & 0.0 \\
Gladstone - ARA & 6.56 & 5.77 & 0.0 & 3.38 & 2.04 \\
Gladstone - Yokohama & 0.0 & 0.0 & 0.0 & 0.0 & 0.0 \\
Hampton Roads - ARA & 0.0 & 0.0 & 0.0 & 0.0 & \\
Hampton Roads - Yokohama & 12.04 & 9.98 & 17.37 & 9.74 & 11.05 \\
\hline
\end{tabular}

Source: Based on model simulations by the author. 


\title{
Appendix H. The GAMS Code and Output for the Base Case Simulation Scenario of Spatial and Dynamic Optimization Model of the World Steam Coal Trade
}

\author{
GAMS Rev 121 Windows NT/95/98 \\ 04/18/03 17:50:36 PAGE 1 \\ General Algebraic Modeling System \\ Compilation \\ 3 \\ $4 *$ This nonlinear program solves for international trade flows for the major \\ $5 *$ exporting and importing countries and simulates whether coal exports from \\ $6 *$ Botswana are competitive in this trade. Steam coal demand is econometrically \\ $7 *$ estimated outside the model. The model determines the supply necessary to \\ $8 *$ meet domestic and import demands in the countries of the study. \\ 9 \\ 10 option limcol $=0$; \\ 11 option limrow $=0$; \\ 12 \\ 13 SETS \\ 14 I Coal Supply countries or regions /Australia,USA, Witbank,Mmamabula/ \\ $15 \mathrm{~K}$ Export region ports /Matola,RBCT,Wbay,Gladstone,Hroads/ \\ $16 \mathrm{~J}$ Export and demand region ports /ARA, Yokohama/ \\ 17 T Time period /1990,1995,2000,2005,2010/ \\ 18 Theta Number of years per period $/ 1 * 5 /$ \\ $19 \mathrm{TE}(\mathrm{T})$ Time period for expansion /1995,2000,2005,2010/ \\ 20 M_to_P(I,K) Supply region port combination /Australia .Gladstone, \\ 21 USA .Hroads, \\ 22 Witbank .(Matola,RBCT,Wbay), \\ 23 Mmamabula .(Matola,RBCT,Wbay)/ \\ 24 \\ 25 \\ 26 \\ 27 \\ 28 \\ 29 ALias (K,Ke),(TE,TPE),(T,TP); \\ 30 \\ 31 SCALAR rho discount rate / $/ 0.15 /$ \\ 32 lom life of investment(yrs) / $20 /$ \\ 33 Ecmax Maximum equipment cost for 25000 tpd /26998162.68/ \\ 34 Lcmax Maximum labor cost for 25000 tpd /5581791.254/ \\ 35 Scmax Maximum supply cost for 25000 tpd /3694717.002/ \\ 36 Wd Maximum number of days worked in a year /300/ \\ 37 CI cost index ratio of 2000 to 1994 /0.9090/ \\ 38 share residual demand /0.615/ \\ 39 Sea sea freight sensitivity factor $/ 1.0 /$; \\ 40 PARAMETER \\ 41 Denom expression for the denominator in the period discount \\ factor
}




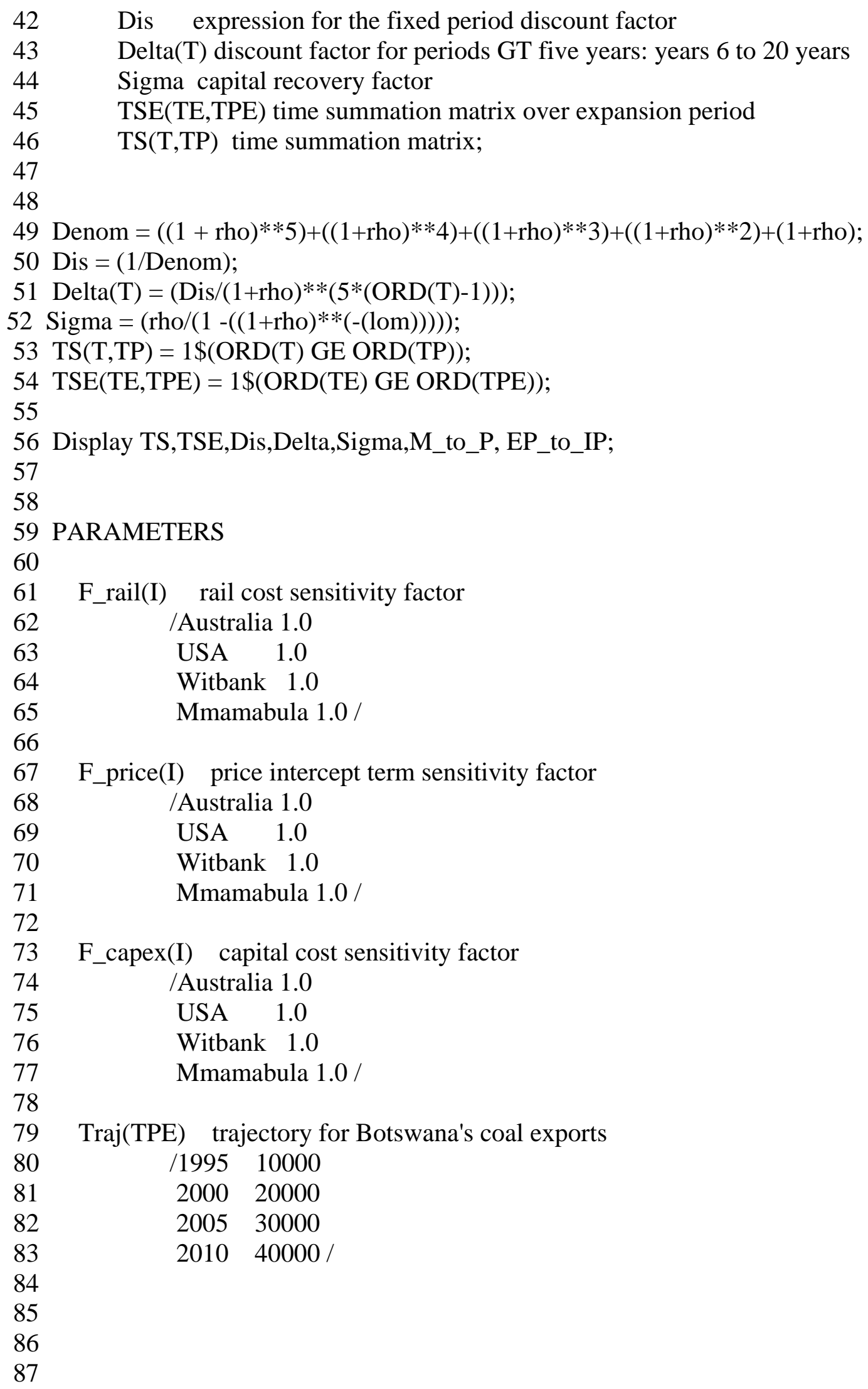

F_capex(I) capital cost sensitivity factor

/Australia 1.0

USA 1.0

Witbank 1.0

Mmamabula 1.0 /

Traj(TPE) trajectory for Botswana's coal exports /1995 10000

$2000 \quad 20000$

200530000

$201040000 /$ 
$88 *$ These go with the original model

89 B(I) supply price slope coefficients

90 / Australia .0000706

91 USA 0.00000732

$92 \quad$ Witbank 0.0000651

93 Mmamabula $0.0000651 /$

94

$95 \mathrm{So}(\mathrm{I})$ supply in base year

96

97

98

99

100

101

$102 *$ This table goes with the base model

103 TABLE

104 A(I,TPE) supply price equation intercepts

$105 \quad 1995 \quad 2000 \quad 2005 \quad 2010$

$\begin{array}{lllll}106 & \text { Australia 50.90 } & 32.31 & 32.31 & 32.31\end{array}$

$\begin{array}{llllll}107 & \text { USA } & 42.97 & 32.19 & 32.19 & 32.19\end{array}$

$108 \quad$ Witbank $15.54 \quad 5.01 \quad 5.01 \quad 5.01$

$109 \quad$ Mmamabula $15.54 \quad 5.01 \quad 5.01 \quad 5.01$;

110

111

$112 *$ This table goes with sensitivty 1983 to 2000

$113 *$ TABLE

$114 *$ A(I,TPE) supply price equation intercepts

$115 * \quad 199520002005 \quad 2010$

$\begin{array}{lllll}116 * & \text { Australia } 44.05 & 19.85 & 19.85 & 19.85\end{array}$

$\begin{array}{llllll}117 * & \text { USA } & 44.32 & 33.17 & 33.17 & 33.17\end{array}$

$118 * \quad$ Witbank $6.37 \quad 0.00 \quad 0.00 \quad 0.00$

$119 * \quad$ Mmamabula $6.37 \quad 0.00 \quad 0.00 \quad 0.00$;

120

121 TABLE

$122 \mathrm{Cap}(\mathrm{K}, \mathrm{T})$ Table of port capacity constraints for period shown

$\begin{array}{llllll}123 & 1990 & 1995 & 2000 & 2005 & 2010\end{array}$

124 Gladstone $200000200000200000200000 \quad 200000$

$125 \quad$ Hroads $200000200000200000200000 \quad 200000$

$126 \quad$ RBCT $22500 \quad 36000 \quad 45000 \quad 57000 \quad 57000$

$127 \quad$ Matola $\quad 0 \quad 10000 \quad 20000 \quad 30000 \quad 40000$

128 Wbay $0 \quad 1000020000 \quad 30000 \quad 40000$; 
129 TABLE

$130 \mathrm{C}(\mathrm{I}, \mathrm{K}, \mathrm{T})$ Table of rail transportation costs US 2000 Dollars per mtce

131

132

$\begin{array}{lllll}1990 & 1995 & 2000 & 2005 & 2010\end{array}$

$\begin{array}{llllllll}133 & \text { USA } & \text {.Hroads } & 28.60 & 20.24 & 19.16 & 17.87 & 17.87\end{array}$

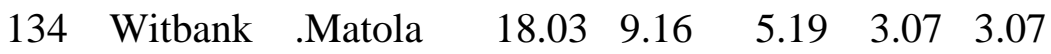

135 Witbank $\quad$. RBCT $\quad 25.28 \quad 12.83 \quad 7.28 \quad 4.31 \quad 4.31$

$\begin{array}{lllllll}136 & \text { Witbank .Wbay } \quad 79.61 & 40.42 & 22.91 & 13.56 & 13.56\end{array}$

$\begin{array}{lllllll}137 & \text { Mmamabula .Matola } & 40.68 & 17.98 & 11.55 & 6.84 & 6.84\end{array}$

138 Mmamabula .RBCT $46.41 \quad 20.52 \quad 13.18 \quad 7.80 \quad 7.80$

139 Mmamabula .Wbay $55.47 \quad 24.52 \quad 15.75 \quad 9.32 \quad 9.32$;

140

141 TABLE

$142 \mathrm{~F}(\mathrm{~K}, \mathrm{~J}, \mathrm{~T})$ Table of Sea freight costs to markets in US 2000 Dollars per mtce

143

144 Matola ARA $\quad 12.97 \quad 12.00 \quad 11.18 \quad 7.94 \quad 7.44$

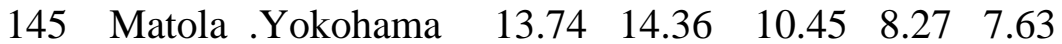

$\begin{array}{llllllll}146 & \text { RBCT } & \text {.ARA } & 12.97 & 12.00 & 11.18 & 7.94 & 7.44\end{array}$

$\begin{array}{llllllll}147 & \text { RBCT } & \text {.Yokohama } & 13.74 & 14.36 & 10.45 & 8.27 & 7.63\end{array}$

$\begin{array}{lllllll}148 & \text { Wbay .ARA } & 10.34 & 9.57 & 8.91 & 6.33 & 5.93\end{array}$

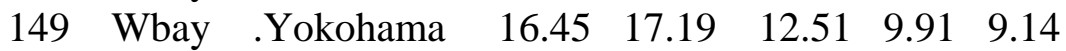

$\begin{array}{lllllll}150 & \text { Gladstone .ARA } & 21.99 & 18.11 & 17.02 & 13.34 & 13.30\end{array}$

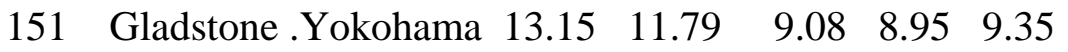

$\begin{array}{lllllll}152 & \text { Hroads .ARA } & 10.33 & 9.47 & 8.37 & 7.19 & 7.36\end{array}$

153 Hroads .Yokohama $26.00 \quad 20.96 \quad 17.80 \quad 15.92 \quad 16.50$;

154

155 Table

156 W(I,TPE) Ratios of other suppliers hourly wages to USA wages

$157 \quad 1995200020052010$

$\begin{array}{llllll}158 & \text { USA } & 1.00 & 1.00 & 1.00 & 1.00\end{array}$

$159 \quad$ Australia $\quad 1.03 \quad 1.14 \quad 1.14 \quad 1.14$

$\begin{array}{llllll}160 & \text { Witbank } & 0.38 & 0.28 & 0.28 & 0.28\end{array}$

$\begin{array}{llllll}161 & \text { Mmamabula } & 0.38 & 0.28 & 0.28 & 0.28 \text {; }\end{array}$

162 TABLE

$163 \mathrm{Z}(\mathrm{I}, \mathrm{T})$ Annual Domestic demand by country or region I in 000s mtce

$\begin{array}{llllll}164 & 1990 & 1995 & 2000 & 2005 & 2010\end{array}$

$165 \quad$ Australia $30243 \quad 33643 \quad 45910 \quad 56230 \quad 69600$

$166 \quad$ USA $\quad \begin{array}{lllllll}627375 & 638844 & 693489 & 774799 & 848535\end{array}$

$167 \quad$ Witbank $96692 \quad 115407 \quad 129710 \quad 142060 \quad 151355$

$168 \quad$ Mmamabula $\quad 800 \quad 837.5 \quad 875 \quad 875 \quad 875$;

169 Table

$170 \mathrm{D}(\mathrm{J}, \mathrm{T})$ Annual import demand by country or region $\mathrm{J}$ in $000 \mathrm{~s}$ mtce: Model

$\begin{array}{llllll}171 & 1990 & 1995 & 2000 & 2005 & 2010\end{array}$

$172 \quad$ ARA $\quad 39950 \quad 46308 \quad 67223 \quad 67215 \quad 63881$

173 Yokohama $10248299217 \quad 103929126637 \quad 148928$; 
176 TABLE

177 Row(I,T) Rest of world exports from country $\mathrm{i}$ in 000s mtce

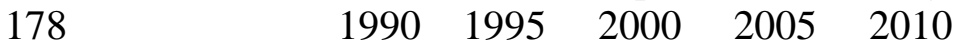

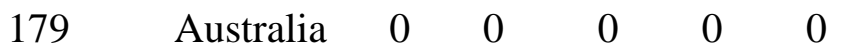

$180 \quad$ USA $\quad \begin{array}{llllll}33200 & 8900 & 14000 & 14000 & 14000\end{array}$

$181 \quad$ Witbank $\quad 14600 \quad 23600 \quad 25200 \quad 25200 \quad 25200$

182 Mmamabula $0 \quad 0 \quad 0000$;

183

$184 *$ Table

$185 *$

$186 * \mathrm{D}(\mathrm{J}, \mathrm{T})$ Annual import demand by country or region J in 000's of mtce: IEA

$187 * \quad 1990 \quad 1995 \quad 2000 \quad 2005 \quad 2010$

$188 * \quad$ ARA $\quad 39950 \quad 46308 \quad 781007580079300$

$189 * \quad$ Yokohama 1024829921790600118300131900 ;

190

191

192 VARIABLES

193 TC Objective function is Present Value of Total Costs: 000's US Dollar 2000;

196 POSITIVE VARIABLES

197

198 VC(I,TPE) operating costs at mine i in period t: 000's US Dollar

199 S(I,TPE) quantity of coal supplied by country I in period t: 000's mtce

$200 \mathrm{X}(\mathrm{I}, \mathrm{K}, \mathrm{TPE})$ quantity shipped from supply $\mathrm{S}$ to port $\mathrm{K}$ in period t: 000's mtce

$201 \mathrm{H}(\mathrm{I}, \mathrm{TE})$ capacity addition at source $\mathrm{i}$ in period $\mathrm{t}: 1000 \mathrm{tpd}$

$202 \mathrm{Y}(\mathrm{Ke}, \mathrm{J}, \mathrm{TPE})$ quantity shipped from port $\mathrm{K}$ to demand $\mathrm{J}$ in period t: 000's mtce

203 Cumcapex(I,TPE) cumulative annualized capital expenditure: 000's US 2000 \$;

205 EQUATIONS

OBJECTIVE Minimize the discounted sum of development, supply plus delivery costs

208 Supply(I,TPE) supply constraint at time t

209 Minesize(I,TPE) constranit on capacity expansion: 000's mtce

210 Demand(J,TPE) demand constraint at time t: Residual demand facing exporters

211 Trans(K,TPE) transshipment constraint at all ports at time $t$

212 Capconstr(K,TPE) port capacity constraint

213 Cap_rbct(K,TPE) port constraint at RSA ports net of ROW tonnage

214 RSAcapex1(I,TPE) annulized capital costs of expansion:1995 RSA

215 RSAcapex2(I,TPE) annualized capital costs of expansion:2000 RSA

216 RSAcapex3(I,TPE) annualized capital costs of expansion:2005 RSA

217 RSAcapex4(I,TPE) annualized capital costs of expansion:2010 RSA

219 Auscapex1(I,TPE) annualized capital costs of expansion:1995 Australia 
Auscapex2(I,TPE) annualized capital costs of expansion:2000 Australia

221 Auscapex3(I,TPE) annualized capital costs of expansion:2005 Australia

222 Auscapex4(I,TPE) annualized capital costs of expansion:2010 Australia

261 S.lo("Australia",TPE)= Z("Australia",TPE)+Row("Australia",TPE); 
GAMS Rev 121 Windows NT/95/98

04/18/03 17:50:36 PAGE 6

General Algebraic Modeling System

Compilation

262 S.lo("USA",TPE)= Z("USA",TPE)+Row("USA",TPE);

263 S.lo("Mmamabula",TPE)= Z("Mmamabula",TPE)+Row("Mmamabula",TPE);

264 S.lo("Witbank",TPE)=Z("Witbank",TPE)+Row("Witbank",TPE);

265

266

267 H.lo(I,TPE $)=.125$;

268

269 OBJECTIVE.. TC =E $=\left(\operatorname{SUM}(\mathrm{I}, \mathrm{Cumcapex}(\mathrm{I}, " 2010 "))^{*} \mathrm{CI}\right)+\mathrm{SUM}((\mathrm{I}, \mathrm{TPE}), \mathrm{VC}(\mathrm{I}, \mathrm{TPE}))+$

270 SUM((I,K,TPE)\$M_to_P(I,K),Delta(TPE)*F_rail(I)*C(I,K,TPE)*X(I,K,TPE))

$271+$ SUM(Ke,J,TPE)\$EP_to_IP(Ke,J),Delta(TPE)*Sea*F(Ke,J,TPE)*Y(Ke, J,TPE $)$ );

272

273

274 RSAper1("Witbank","1995").. S("Witbank","1995")=e= So("Witbank")+

275 Wd*H("Witbank","1995");

276 RSAper2("Witbank","2000").. S("Witbank","2000")=e= S("Witbank","1995")+

277 Wd*H("Witbank","2000");

278 RSAper3("Witbank","2005").. S("Witbank","2005")=e= S("Witbank","2000")+

279 Wd*H("Witbank","2005");

280 RSAper4("Witbank","2010").. S("Witbank","2010")=e= S("Witbank","2005")+

Wd*H("Witbank","2010");

282

283 Botsper1("Mmamabula","1995").. S("Mmamabula","1995")=e= So("Mmamabula")+

284 Wd*H("Mmamabula","1995");

285 Botsper2("Mmamabula","2000").. S("Mmamabula","2000")=e= S("MMamabula", "1995")+

286

Wd*H("MMamabula","2000");

287 Botsper3("Mmamabula","2005").. S("Mmamabula","2005")=e= S("Mmamabula", "2000")+

288

Wd*H("Mmamabula","2005");

289 Botsper4("Mmamabula","2010").. S("Mmamabula","2010")=e= S("Mmamabula", "2005")+

290

Wd*H("Mmamabula","2010");

291

292 AUSper1("Australia","1995").. S("Australia","1995")=e= So("Australia")+

293

294 AUSper2("Australia","2000").. S("Australia","2000")=e= S("Australia", "1995")+

295

Wd*H("Australia","2000");

296 AUSper3("Australia","2005").. S("Australia","2005")=e= S("Australia", "2000")+

Wd*H("Australia","2005"); 
298 AUSper4("Australia","2010").. S("Australia","2010")=e= S("Australia",

$$
\text { "2005")+ }
$$

Wd*H("Australia","2010");

301 USAper1("USA","1995").. S("USA","1995")=e= So("USA")+ Wd*H("USA","1995");

302 USAper2("USA","2000").. S("USA","2000")=e= S("USA","1995")+ Wd*H("USA", "2000");

303 USAper3("USA","2005").. S("USA","2005")=e= S("USA","2000")+ Wd*H("USA", "2005");

304 USAper4("USA","2010").. S("USA","2010")=e= S("USA","2005")+ Wd*H("USA", "2010");

305

306

307

308 Supply(I,TPE).. -SUM(K\$M_to_P(I,K),X(I,K,TPE))=G= -S(I,TPE)+Z(I,TPE)

$+\operatorname{Row}(\mathrm{I}, \mathrm{TPE})$

309 Demand(J,TPE).. SUM(Ke\$EP_to_IP(Ke,J),Y(Ke,J,TPE))=G= share*D(J,TPE);

310 Capconstr(K,TPE).. -SUM(I\$M_to_P(I,K),X(I,K,TPE))=G=-Cap(K,TPE);

311 Trans(K,TPE)..SUM(I\$M_to_P(I,K),X(I,K,TPE))-SUM(J\$EP_to_IP(K,J),Y(K,J,TPE) )$=\mathrm{E}=0$;

$312 \mathrm{Mbal}(\mathrm{TPE}) . . \mathrm{SUM}(\mathrm{I}, \mathrm{S}(\mathrm{I}, \mathrm{TPE}))-\mathrm{SUM}(\mathrm{I}, \mathrm{Z}(\mathrm{I}, \mathrm{TPE}))-\mathrm{SUM}(\mathrm{I}, \mathrm{Row}(\mathrm{I}, \mathrm{TPE}))-$

$313 \quad \mathrm{SUM}(\mathrm{J}, \mathrm{share} * \mathrm{D}(\mathrm{J}, \mathrm{TPE}))=\mathrm{E}=0$;

314 Minesize(I,TPE).. -H(I,TPE) $=\mathrm{g}=-100000$;

315

316 Cap_rbct("RBCT",TPE).. -SUM(I\$M_to_P(I,"RBCT"),X(I,"RBCT",TPE))=G=

$317 \quad-$ Cap("RBCT",TPE);

318 RSA_map("Witbank","Matola",TPE).. X("Witbank","Matola",TPE)=E=0;

319 RSA_wbay("Witbank","Wbay",TPE).. X("Witbank","Wbay",TPE)=E=0;

320 Bots_mat("Mmamabula","Matola",TPE).. -X("Mmamabula","Matola",TPE)-

321 X("Mmamabula","Wbay",TPE)-X("Mmamabula","RBCT",TPE)=G= -Traj(TPE)

322

323 Bots_rich("Mmamabula","Wbay",TPE).. -X("Mmamabula","Matola",TPE)-

324 X("Mmamabula","Wbay",TPE)-X("Mmamabula","RBCT",TPE)=G= -Traj(TPE)

325

326 Bots_walv("Mmamabula","RBCT",TPE).. -X("Mmamabula","Matola",TPE)-

327 X("Mmamabula","Wbay",TPE)-X("Mmamabula","RBCT",TPE)=G= -Traj(TPE)

328

329 Phi(I,TPE).. V VC(I,TPE)=E= Delta(TPE)*F_price(I)*(A(I,TPE)*S(I,TPE)

$330+0.5 * \operatorname{Delta}(\mathrm{TPE}) * \mathrm{~B}(\mathrm{I}) *(\mathrm{~S}(\mathrm{I}, \mathrm{TPE}) * \mathrm{~S}(\mathrm{I}, \mathrm{TPE}))$;

331

332 RSAcapex1("Witbank","1995").. Cumcapex("Witbank","1995")=e=

333 F_capex("Witbank")*(Delta("1995")*sigma*Ecmax*(H("Witbank","1995")/25)+

334 Delta("1995")*W("Witbank","1995")*sigma*Lcmax*(H("Witbank","1995")/25)+ 
335 Delta("1995")*sigma*Scmax*(H("Witbank","1995")/25));

336

337 RSAcapex2("Witbank","2000").. Cumcapex("Witbank","2000")=E=

338 Cumcapex("Witbank","1995")+

339 F_capex("Witbank")*(Delta("2000")*sigma*Ecmax*(H("Witbank","2000")/25)+

340 Delta("2000")*W("Witbank","2000")*sigma*Lcmax*(H("Witbank","2000")/25)+

341 Delta("2000")*sigma*Scmax*(H("Witbank","2000")/25));

342

343 RSAcapex3("Witbank","2005").. Cumcapex("Witbank","2005")=E=

344 Cumcapex("Witbank","2000")+

345 F_capex("Witbank")*(Delta("2005")*sigma*Ecmax*(H("Witbank","2005")/25) +

346 Delta("2005")*W("Witbank","2005")*sigma*Lcmax*(H("Witbank","2005")/25) +

347 Delta("2005")*sigma*Scmax*(H("Witbank","2005")/25));

348

349 RSAcapex4("Witbank","2010").. Cumcapex("Witbank","2010")=E=

350 Cumcapex("Witbank","2005")+

351 F_capex("Witbank")*(Delta("2010")*sigma*Ecmax*(H("Witbank","2010")/25)+

352 Delta("2010")*W("Witbank","2010")*sigma*Lcmax*(H("Witbank","2010")/25)+

353 Delta("2010")*sigma*Scmax*(H("Witbank","2010")/25));

354

355

356 AUScapex1("Australia","1995").. Cumcapex("Australia","1995")=e=

357 F_capex("Australia")*(Delta("1995")*sigma*Ecmax*(H("Australia","1995")/25)

$+$

358 Delta("1995")*W("Australia","1995")*sigma*Lcmax*(H("Australia","1995")/25)

$+$

359 Delta("1995")*sigma*Scmax*(H("Australia","1995")/25));

360

361 AUScapex2("Australia","2000").. Cumcapex("Australia","2000")=E=

362 Cumcapex("Australia","1995")+

363 F_capex("Australia")*(Delta("2000")*sigma*Ecmax*(H("Australia","2000")/25)

$+$

364 Delta("2000")*W("Australia","2000")*sigma*Lcmax*(H("Australia","2000")/25) $+$

365 Delta("2000")*sigma*Scmax*(H("Australia","2000")/25));

366

367 AUScapex3("Australia","2005").. Cumcapex("Australia","2005")=E=

368 Cumcapex("Australia","2000")+

369 F_capex("Australia")*(Delta("2005")*sigma*Ecmax*(H("Australia","2005")/25)

$+$

370 Delta("2005")*W("Australia","2005")*sigma*Lcmax*(H("Australia","2005")/25)

$+$

371 Delta("2005")*sigma*Scmax*(H("Australia","2005")/25));

372

373 AUScapex4("Australia","2010").. Cumcapex("Australia","2010")=E=

374 Cumcapex("Australia","2005")+ 
375 F_capex("Australia")*(Delta("2010")*sigma*Ecmax*(H("Australia","2010")/25)

$+$

376 Delta("2010")*W("Australia","2010")*sigma*Lcmax*(H("Australia","2010")/25)

$+$

377 Delta("2010")*sigma*Scmax*(H("Australia","2010")/25));

378

379

380 USAcapex1("USA","1995").. Cumcapex("USA","1995")=e=

381 F_capex("USA")*(Delta("1995")*sigma*Ecmax*(H("USA","1995")/25)+

382 Delta("1995")*W("USA","1995")*sigma*Lcmax*(H("USA","1995")/25)+

383 Delta("1995")*sigma*Scmax*(H("USA","1995")/25));

384

385 USAcapex2("USA","2000").. Cumcapex("USA","2000")=E=

386 Cumcapex("USA","1995")+

387 F_capex("USA")*(Delta("2000")*sigma*Ecmax*(H("USA","2000")/25)+

388 Delta("2000")*W("USA","2000")*sigma*Lcmax*(H("USA","2000")/25)+

389 Delta("2000")*sigma*Scmax*(H("USA","2000")/25));

390

391 USAcapex3("USA","2005").. Cumcapex("USA","2005")=E=

392 Cumcapex("USA","2000")+

393 F_capex("USA")*(Delta("2005")*sigma*Ecmax*(H("USA","2005")/25)+

394 Delta("2005")*W("USA","2005")*sigma*Lcmax*(H("USA","2005")/25)+

395 Delta("2005")*sigma*Scmax*(H("USA","2005")/25));

396

397 USAcapex4("USA","2010").. Cumcapex("USA","2010")=E=

398 Cumcapex("USA","2005")+

399 F_capex("USA")*(Delta("2010")*sigma*Ecmax*(H("USA","2010")/25)+

400 Delta("2010")*W("USA","2010")*sigma*Lcmax*(H("USA","2010")/25)+

401 Delta("2010")*sigma*Scmax*(H("USA","2010")/25)**.904);

402

403 Botscapex1("Mmamabula","1995").. Cumcapex("Mmamabula","1995")=e=

404 F_capex("Mmamabula")*(Delta("1995")*sigma*Ecmax*(H("Mmamabula","1995")/25)

$+$

405 Delta("1995")*W("Mmamabula","1995")*sigma*Lcmax*(H("MMamabula","1995")/25)

$+$

406 Delta("1995")*sigma*Scmax*(H("Mmamabula","1995")/25));

407

408 Botscapex2("Mmamabula","2000").. Cumcapex("Mmamabula","2000")=E=

409 Cumcapex("Mmamabula","1995")+

410 F_capex("Mmamabula")*(Delta("2000")*sigma*Ecmax*(H("Mmamabula","2000")/25)

$+$

411 Delta("2000")*W("Mmamabula","2000")*sigma*Lcmax*(H("Mmamabula","2000")/25)

$+$

412 Delta("2000")*sigma*Scmax*(H("Mmamabula","2000")/25));

413 
414 Botscapex3("Mmamabula","2005").. Cumcapex("Mmamabula","2005")=E= 415 Cumcapex("Mmamabula","2000")+

416 F_capex("Mmamabula")*(Delta("2005")*sigma*Ecmax*(H("Mmamabula","2005")/25) $+$

417 Delta("2005")*W("Mmamabula","2005")*sigma*Lcmax*(H("Mmamabula","2005")/25) $+$

418 Delta("2005")*sigma*Scmax*(H("Mmamabula","2005")/25));

419

420 Botscapex4("Mmamabula","2010").. Cumcapex("Mmamabula","2010")=E=

421 Cumcapex("Mmamabula","2005")+

422 F_capex("Mmamabula")*(Delta("2010")*sigma*Ecmax*(H("Mmamabula","2010")/25) $+$

423 Delta("2010")*W("Mmamabula","2010")*sigma*Lcmax*(H("Mmamabula","2010")/25) $+$

424 Delta("2010")*sigma*Scmax*(H("Mmamabula","2010")/25));

425

426 MODEL PEM /ALL/;

427 SOLVE PEM USING NLP MINIMIZING TC;

428 option decimals $=2$;

429 option solprint $=$ off;

430 option reslim $=200000$;

431 option iterlim $=500000$;

432 option optcr $=0.1$;

433

434

435

436 PARAMETERS E(I,TPE) exports from supply region or country I in period T

437 Capcost(I,TPE) cost of expansion in period $t$ in nominal dollars

438 FOB_Mmbla(I,K,TPE) free on board price for Mmamabula coal

439 FOB_Wit(I,K,TPE) free on board price for South AFrica coal

440 FOB_USA(I,K,TPE) free on board price for Appalachia coal

$441 \quad$ Price(I,TPE) supply price in country $i$ in time $t$;

442

443 Price $(\mathrm{I}, \mathrm{TPE})=$ F_price $(\mathrm{I}) * \mathrm{~A}(\mathrm{I}, \mathrm{TPE})+\mathrm{B}(\mathrm{I}) * \mathrm{~S} .1(\mathrm{I}, \mathrm{TPE})$;

$444 \mathrm{E}(\mathrm{I}, \mathrm{TPE})=$ s.l(I,TPE $)+\mathrm{H} .1(\mathrm{I}, \mathrm{TPE})-\mathrm{Z}(\mathrm{I}, \mathrm{TPE})$;

445 Capcost $(\mathrm{I}, \mathrm{TPE})=\mathrm{w}(\mathrm{I}, \mathrm{TPE}) * 405.8 *(\mathrm{H} .1(\mathrm{I}, \mathrm{TPE}) * * 0.941)+2943 *(\mathrm{H} .1(\mathrm{I}, \mathrm{TPE})$

446

$* * 0.901)+$

447

$$
390.7 *(\mathrm{H} .1(\mathrm{I}, \mathrm{TPE}) * * 0.904) \text {; }
$$


GAMS Rev 121 Windows NT/95/98

04/18/03 17:50:36 PAGE 10

General Algebraic Modeling System

Compilation

448 FOB_Mmbla("Mmamabula",K,TPE)=C("Mmamabula",K,TPE)+Price("Witbank",TPE);

449 FOB_Wit("Witbank",K,TPE)=C("Witbank",K,TPE)+Price("Witbank",TPE);

450 FOB_USA("USA",K,TPE)=C("USA",K,TPE)+ Price("USA",TPE);

451

452 display E,S.1,Price,FOB_Mmbla, FOB_Wit, FOB_USA,

453 Cumcapex.1,H.1,X.1,Y.1;

COMPILATION TIME $=0.000$ SECONDS $\quad 0.7 \mathrm{Mb} \quad$ WIN200-121

GAMS Rev 121 Windows NT/95/98 04/18/03 17:50:36 PAGE 11

General Algebraic Modeling System

Execution

GAMS Rev 121 Windows NT/95/98

04/18/03 17:50:36 PAGE 13

General Algebraic Modeling System

S OLVE S UMMAR Y

MODEL PEM OBJECTIVE TC

TYPE NLP

DIRECTION MINIMIZE

SOLVER MINOS TROM LINE 427

$\begin{array}{lc}* * * * \text { SOLVER STATUS } & \text { 1 NORMAL COMPLETION } \\ \text { **** MODEL STATUS } & \text { 2 LOCALLY OPTIMAL } \\ * * * * \text { OBJECTIVE VALUE } & 10612441.9746\end{array}$

RESOURCE USAGE, LIMIT $\quad 0.328 \quad 1000.000$

ITERATION COUNT, LIMIT $98 \quad 10000$

EVALUATION ERRORS $\quad 0 \quad 0$

MINOS-Link Mar 21, 2001 WIN.M5.M5 20.0 019.043.039.WAT GAMS/MINOS 5.5

GAMS/MINOS, Large Scale Nonlinear Solver

B. A. Murtagh, University of New South Wales

P. E. Gill, University of California at San Diego,

W. Murray, M. A. Saunders, and M. H. Wright,

Systems Optimization Laboratory, Stanford University 
Work space allocated $\quad--\quad 1.84 \mathrm{Mb}$

EXIT - Optimal Solution found.

\section{LOWER LEVEL UPPER MARGINAL}

---- EQU OBJECTIVE . . . . 1.000

OBJECTIVE Minimize the discounted sum of supply plus delivery costs

---- EQU Supply supply constraint at time t

\section{LOWER LEVEL UPPER MARGINAL}

\begin{tabular}{|c|c|c|}
\hline Australia.1995 33643.00033643 .000 & $+\mathrm{INF}$ & 4.064 \\
\hline Australia.2000 45910.00045910 .000 & $+\mathrm{INF}$ & 2.511 \\
\hline Australia.2005 56230.00056230 .000 & $+\mathrm{INF}$ & 1.394 \\
\hline Australia.2010 69600.00069600.000 & $+\mathrm{INF}$ & 0.822 \\
\hline USA $\quad .19956 .4774 \mathrm{E}+56.4774 \mathrm{E}+5$ & $+\mathrm{INF}$ & 2.764 \\
\hline $.20007 .0749 \mathrm{E}+57.0749 \mathrm{E}+5$ & $+\mathrm{INF}$ & 2.236 \\
\hline $.20057 .8880 \mathrm{E}+57.8880 \mathrm{E}+5$ & $+\mathrm{INF}$ & 1.272 \\
\hline $.20108 .6254 \mathrm{E}+5$ 8.6254E+5 & $+\mathrm{INF}$ & 0.695 \\
\hline Witbank .1995 1.3901E+5 1.3901E+5 & $+\mathrm{INF}$ & 0.685 \\
\hline Witbank .2000 $1.5491 \mathrm{E}+5$ 1.5491E+5 & $+\mathrm{INF}$ & 0.372 \\
\hline Witbank .2005 $1.6726 \mathrm{E}+5 \quad 1.6726 \mathrm{E}+5$ & $+\mathrm{INF}$ & 0.200 \\
\hline Witbank .2010 $1.7656 \mathrm{E}+5 \quad 1.7656 \mathrm{E}+5$ & $+\mathrm{INF}$ & 0.099 \\
\hline Mmamabula.1995 $837.500 \quad 837.500$ & $+\mathrm{INF}$ & \\
\hline Mmamabula.2000 $875.000 \quad 875.000$ & $+\mathrm{INF}$ & \\
\hline Mmamabula.2005 $875.000 \quad 875.000$ & $+\mathrm{INF}$ & \\
\hline Mmamabula.2010 $875.000 \quad 875.000$ & $+\mathrm{INF}$ & \\
\hline
\end{tabular}

---- EQU Demand demand constraint at time t: Residual demand facing exporters

\section{LOWER LEVEL UPPER MARGINAL}

$\begin{array}{lllll}\text { ARA } & .199528479 .42028479 .420 & \text { +INF } & 4.669 \\ \text { ARA } & .200041342 .14541342 .145 & \text { +INF } & 2.824 \\ \text { ARA } & .200541337 .22541337 .225 & \text { +INF } & 1.531 \\ \text { ARA } & .201039286 .81539286 .815 & \text { +INF } & 0.894 \\ \text { Yokohama.1995 61018.455 61018.455 } & \text { +INF } & 4.820 \\ \text { Yokohama.2000 63916.33563916.335 } & \text { +INF } & 2.800 \\ \text { Yokohama.2005 77881.75577881.755 } & \text { +INF } & 1.536 \\ \text { Yokohama.2010 91590.72091590.720 } & \text { +INF } & 0.896\end{array}$


---- EQU Capconstr port capacity constraint

LOWER LEVEL UPPER MARGINAL

\begin{tabular}{|c|c|c|c|}
\hline Matola & $.1995-1.000 \mathrm{E}+4-1.000 \mathrm{E}+4$ & $+\mathrm{INF}$ & 0.264 \\
\hline Matola & $.2000-2.000 \mathrm{E}+4-2.000 \mathrm{E}+4$ & + INF & 0.062 \\
\hline Matola & $.2005-3.000 \mathrm{E}+4-3.000 \mathrm{E}+4$ & $+\mathrm{INF}$ & 0.014 \\
\hline Matola & $.2010-4.000 \mathrm{E}+4-4.000 \mathrm{E}+4$ & $+\mathrm{INF}$ & 0.008 \\
\hline RBCT & $.1995-3.600 \mathrm{E}+4-3.600 \mathrm{E}+4$ & $+\mathrm{INF}$ & 2.391 \\
\hline RBCT & $.2000-4.500 \mathrm{E}+4-4.500 \mathrm{E}+4$ & $+\mathrm{INF}$ & 1.864 \\
\hline RBCT & $.2005-5.700 \mathrm{E}+4-5.700 \mathrm{E}+4$ & $+\mathrm{INF}$ & 1.137 \\
\hline RBCT & $.2010-5.700 \mathrm{E}+4-5.700 \mathrm{E}+4$ & $+\mathrm{INF}$ & 0.703 \\
\hline Wbay & $.1995-1.000 \mathrm{E}+4 \quad . \quad+\mathrm{INF}$ & & \\
\hline Wbay & $.2000-2.000 \mathrm{E}+4$ & & \\
\hline Wbay & $.2005-3.000 \mathrm{E}+4$ & & \\
\hline Wbay & $.2010-4.000 \mathrm{E}+4 \quad . \quad+\mathrm{INF}$ & & \\
\hline Gladstor & e. $1995-2.000 \mathrm{E}+5-3.276 \mathrm{E}+4$ & $+\mathrm{INF}$ & \\
\hline Gladstor & e. $2000-2.000 E+5-4.026 E+4$ & $+\mathrm{INF}$ & \\
\hline Gladstor & e. $2005-2.000 \mathrm{E}+5-3.222 \mathrm{E}+4$ & $+\mathrm{INF}$ & \\
\hline Gladstor & 1e. $2010-2.000 E+5-1.889 E+4$ & $+\mathrm{INF}$ & \\
\hline Hroads & $.1995-2.000 \mathrm{E}+5-1.074 \mathrm{E}+4$ & $+\mathrm{INF}$ & \\
\hline Hroads & $.2000-2.000 \mathrm{E}+5 \quad . \quad+\mathrm{INF}$ & & \\
\hline Hroads & $.2005-2.000 \mathrm{E}+5 \quad . \quad+\mathrm{INF}$ & & \\
\hline Hroads & $.2010-2.000 \mathrm{E}+5-1.499 \mathrm{E}+4$ & $+\mathrm{INF}$ & 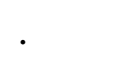 \\
\hline
\end{tabular}

---- EQU Bots_mat constrains Mmamabula exports to export trajectory

\section{LOWER LEVEL UPPER MARGINAL}

$\begin{array}{llll}\text { Mmamabula.Matola.1995 -1.000E+4 -1.000E+4 } & \text { +INF } & 2.483 \\ \text { Mmamabula.Matola.2000 -2.000E+4 -2.000E+4 } & \text { +INF } & 2.037 \\ \text { Mmamabula.Matola.2005 -3.000E+4 -3.000E+4 } & \text { +INF } & 1.283 \\ \text { Mmamabula.Matola.2010 -4.000E+4 -4.000E+4 } & \text { +INF } & 0.774\end{array}$

\section{LOWER LEVEL UPPER MARGINAL}

$\begin{array}{llll}---- \text { VAR TC } \quad \text {-INF } & 1.0612 \mathrm{E}+7 \quad \text { +INF }\end{array}$

TC Objective function is Present Value of Total Costs: 000's US Dollar 2000

---- VAR VC operating costs at mine $\mathrm{i}$ in period t: 000's US Dollar

\section{LOWER LEVEL UPPER MARGINAL}

Australia.1995 - 2.2669E+5 +INF .

Australia.2000 . $97111.300+\mathrm{INF}$. 


\begin{tabular}{|c|c|c|}
\hline Australia.2005 & 49672.131 & $+\mathrm{INF}$ \\
\hline Australia.2010 & 24707.222 & $+\mathrm{INF}$ \\
\hline USA $\quad .1995$ & $1.9161 \mathrm{E}+6$ & $+\mathrm{INF}$ \\
\hline .2000 & $7.8443 E+5$ & $+\mathrm{INF}$ \\
\hline .2005 & $4.3854 \mathrm{E}+5$ & + INF \\
\hline USA $\quad .2010$ & $2.4480 \mathrm{E}+5$ & $+\mathrm{INF}$ \\
\hline Witbank .1995 & $2.3831 \mathrm{E}+5$ & $+\mathrm{INF}$ \\
\hline Witbank .2000 & 73398.468 & $+\mathrm{INF}$ \\
\hline Witbank .2005 & 43754.148 & $+\mathrm{INF}$ \\
\hline Witbank .2010 & 23212.001 & $+\mathrm{INF}$ \\
\hline Mmamabula.1995 & . 11044.043 & $3+\mathrm{INF}$ \\
\hline Mmamabula.2000 & 3786.253 & $+\mathrm{INF}$ \\
\hline Mmamabula.2005 & 2943.490 & $+\mathrm{INF}$ \\
\hline Mmamabula.2010 & 2042.265 & $+\mathrm{INF}$ \\
\hline
\end{tabular}

---- VAR S quantity of coal supplied by country I in period t: 000's mtce

\section{LOWER LEVEL UPPER MARGINAL}

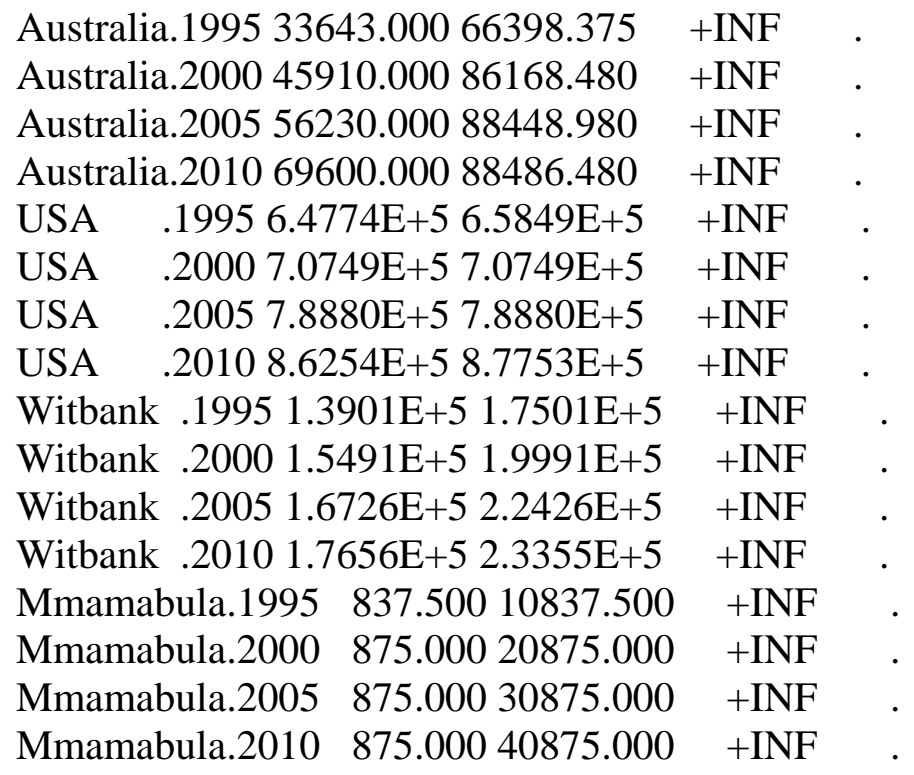

---- VAR X quantity shipped from supply $S$ to port $K$ in period t: 000's mtce

\section{LOWER LEVEL UPPER MARGINAL}

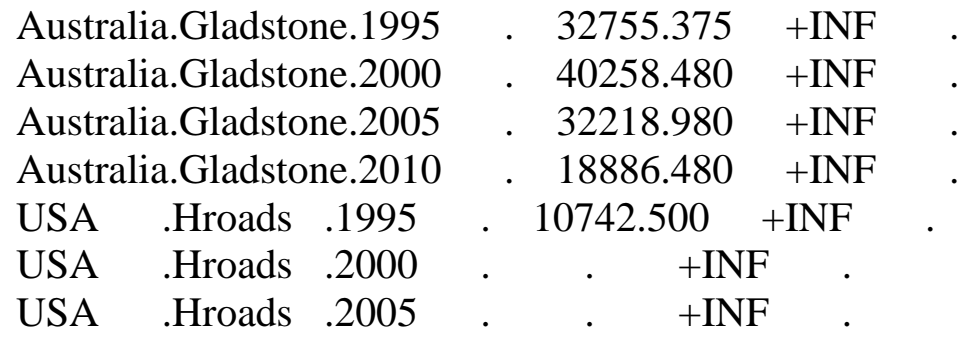


VAR X quantity shipped from supply $S$ to port $K$ in period $t$ : 000 's mtce

\section{LOWER LEVEL UPPER MARGINAL}

USA .Hroads .2010 . $14991.055+\mathrm{INF}$.

Witbank .Matola .1995 . . . +INF .

Witbank .Matola .2000 . . + +INF .

Witbank .Matola .2005 . . + +INF .

Witbank .Matola .2010 . . + +INF .

Witbank .RBCT $.1995 \quad$. $36000.000+\mathrm{INF}$.

Witbank .RBCT $.2000 \quad$. $45000.000+\mathrm{INF}$.

Witbank .RBCT .2005 . $57000.000+\mathrm{INF}$.

Witbank .RBCT .2010 . $57000.000+\mathrm{INF}$.

Witbank .Wbay .1995 . . . +INF .

Witbank .Wbay .2000 . . . + +INF .

Witbank .Wbay .2005 . . + +INF .

Witbank .Wbay .2010 . . + +INF .

Mmamabula.Matola $.1995 \quad$. $10000.000+$ +INF

Mmamabula.Matola $.2000 \quad$. $20000.000+$ INF

Mmamabula.Matola .2005 . $30000.000+$ INF .

Mmamabula.Matola .2010 . $40000.000+\mathrm{INF}$.

$\begin{array}{llllll}\text { Mmamabula.RBCT } & .1995 & \text {. } & \text {. } & \text { +INF } & 2.291\end{array}$

$\begin{array}{llllllllll}\text { Mmamabula.RBCT } & .2000 & \text {. } & \text {. } & \text { +INF } & 1.854\end{array}$

$\begin{array}{llllll}\text { Mmamabula.RBCT } & .2005 & \text {. } & \text {. } & \text { +INF } & 1.139\end{array}$

$\begin{array}{llllllllll}\text { Mmamabula.RBCT } & .2010 & \text {. } & \text {. } & \text { +INF } & 0.703\end{array}$

Mmamabula.Wbay .1995 . . + +INF .

Mmamabula.Wbay $\quad .2000$. . . $\quad$ +INF .

Mmamabula.Wbay .2005 . . . $\quad$ + INF .

Mmamabula.Wbay .2010 . . $\quad+$ INF .

---- VAR H capacity addition at source $\mathrm{i}$ in period t:1000 tpd

LOWER LEVEL UPPER MARGINAL

\begin{tabular}{|c|c|c|c|c|}
\hline Australia.1995 & 0.125 & 3.835 & $+\mathrm{INF}$ & \\
\hline Australia.2000 & 0.125 & 65.900 & $+\mathrm{INF}$ & \\
\hline Australia.2005 & 0.125 & 7.602 & $+\mathrm{INF}$ & \\
\hline Australia.2010 & 0.125 & 0.125 & $+\mathrm{INF}$ & 46.167 \\
\hline USA $\quad .1995$ & 0.125 & 0.125 & $+\mathrm{INF}$ & 322.456 \\
\hline .2000 & 0.125 & 163.342 & $+\mathrm{INF}$ & \\
\hline .2005 & 0.125 & 271.033 & $+\mathrm{INF}$ & \\
\hline .2010 & 0.125 & 295.757 & $+\mathrm{INF}$ & \\
\hline Witbank .1995 & 0.125 & 135.973 & $+\mathrm{INF}$ & \\
\hline Witbank .2000 & 0.125 & 83.010 & $+\mathrm{INF}$ & \\
\hline Vitbank .2005 & 0.125 & 81.167 & $+\mathrm{INF}$ & \\
\hline
\end{tabular}


Witbank $.2010 \quad 0.125 \quad 30.983 \quad+\mathrm{INF}$

Mmamabula.1995 $0.125 \quad 33.458 \quad$ +INF

Mmamabula.2000 $0.125 \quad 33.458 \quad+$ INF

Mmamabula.2005 $0.125 \quad 33.333 \quad+$ INF

Mmamabula.2010 $0.125 \quad 33.333+\mathrm{INF}$.

---- VAR Y quantity shipped from port $\mathrm{K}$ to demand $\mathrm{J}$ in period t: 000's mtce

LOWER LEVEL UPPER MARGINAL

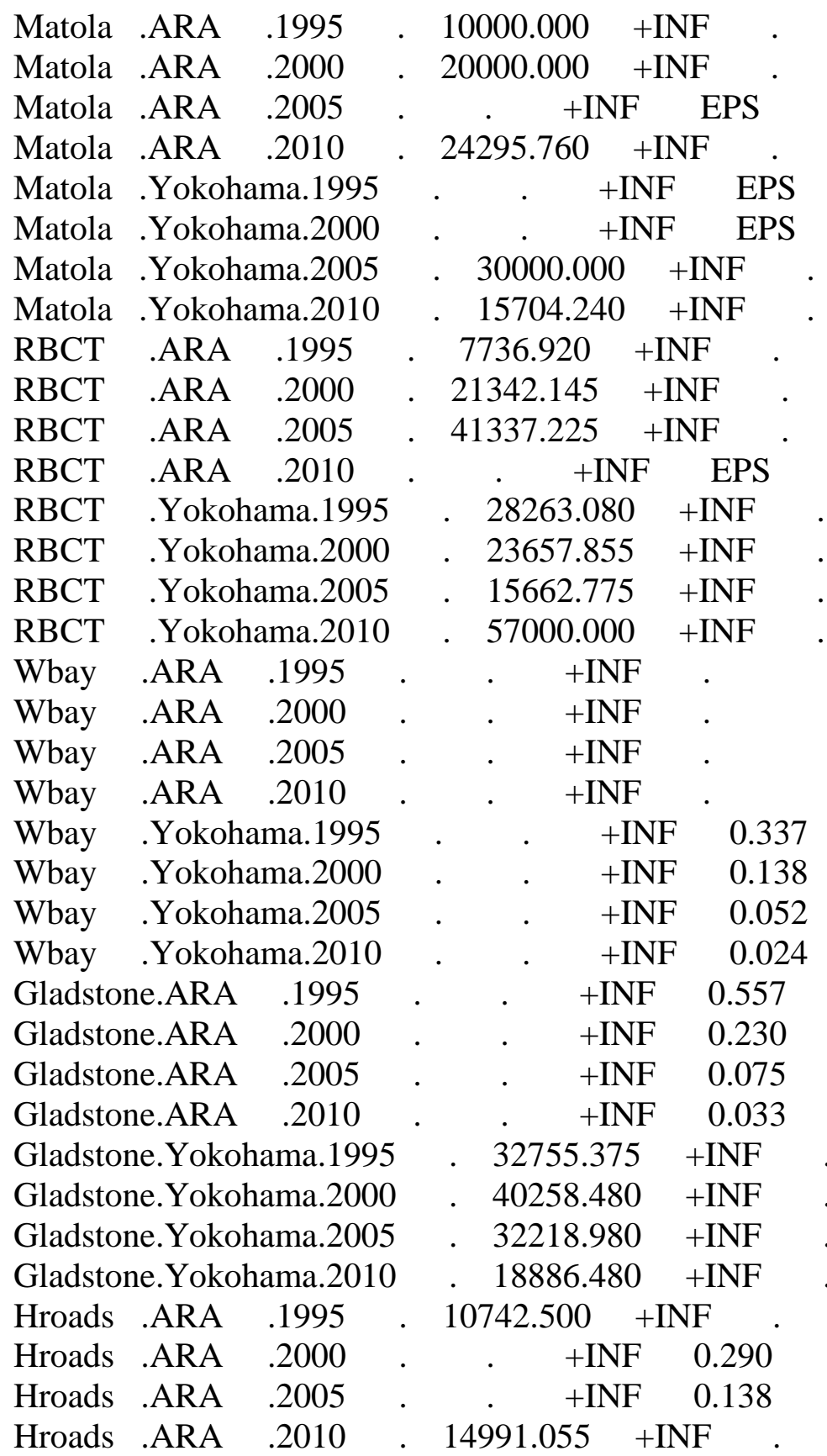


Hroads .Yokohama.1995 . . . $\quad$ +INF 0.585

Hroads .Yokohama.2000 . . . $\quad$ +INF 0.614

Hroads .Yokohama.2005 . . . $\quad$ +INF 0.272

Hroads .Yokohama.2010 . . . $\quad$ +INF 0.071

**** REPORT SUMMARY : $\quad 0 \quad$ NONOPT

0 INFEASIBLE

0 UNBOUNDED

0 ERRORS

GAMS Rev 121 Windows NT/95/98

04/18/03 17:50:36 PAGE 26

General Algebraic Modeling System

Execution

---- 452 PARAMETER E exports from supply region or country I in period T

$19952000 \quad 2005 \quad 2010$

$\begin{array}{lllll}\text { Australia } & 32759.21 & 40324.38 & 32226.58 & 18886.60\end{array}$

$\begin{array}{lllll}\text { USA } & 19642.62 & 14163.34 & 14271.03 & 29286.81\end{array}$

Witbank $\quad 59735.97 \quad 70283.01 \quad 82281.17 \quad 82230.98$

Mmamabula $\quad 10033.46 \quad 20033.46 \quad 30033.33 \quad 40033.33$

---- 452 VARIABLE S.L quantity of coal supplied by country I in period t: 000's mtce

$1995 \quad 2000 \quad 2005 \quad 2010$

$\begin{array}{lllll}\text { Australia } & 66398.37 & 86168.48 & 88448.98 & 88486.48\end{array}$

$\begin{array}{llllll}\text { USA } & 658486.50 & 707489.00 & 788799.00 & 877526.05\end{array}$

$\begin{array}{llllll}\text { Witbank } & 175007.00 & 199910.00 & 224260.00 & 233555.00\end{array}$

$\begin{array}{lllll}\text { Mmamabula } & 10837.50 & 20875.00 & 30875.00 & 40875.00\end{array}$

---- 452 PARAMETER Price supply price in country $\mathrm{i}$ in time $\mathrm{t}$

$1995 \quad 2000 \quad 2005 \quad 2010$

$\begin{array}{llrrr}\text { Australia } & 55.59 & 38.39 & 38.55 & 38.56\end{array}$

$\begin{array}{lllll}\text { USA } & 47.79 & 37.37 & 37.96 & 38.61\end{array}$

$\begin{array}{lllll}\text { Witbank } & 26.93 & 18.02 & 19.61 & 20.21\end{array}$

$\begin{array}{lllll}\text { Mmamabula } & 16.25 & 6.37 & 7.02 & 7.67\end{array}$ 
---- 452 PARAMETER FOB_Mmbla free on board price for Mmamabula coal

$\begin{array}{lcccc} & 1995 & 2000 & 2005 & 2010 \\ \text { Mmamabula.Matola } & 44.91 & 29.57 & 26.45 & 27.05 \\ \text { Mmamabula.RBCT } & 47.45 & 31.20 & 27.41 & 28.01 \\ \text { Mmamabula.Wbay } & 51.45 & 33.77 & 28.93 & 29.53 \\ \text { Mmamabula.Gladstone } & 26.93 & 18.02 & 19.61 & 20.21 \\ \text { Mmamabula.Hroads } & 26.93 & 18.02 & 19.61 & 20.21\end{array}$

---- 452 PARAMETER FOB_Wit free on board price for South AFrica coal

$\begin{array}{lcccc} & 1995 & 2000 & 2005 & 2010 \\ \text { Witbank.Matola } & 36.09 & 23.21 & 22.68 & 23.28 \\ \text { Witbank.RBCT } & 39.76 & 25.30 & 23.92 & 24.52 \\ \text { Witbank.Wbay } & 67.35 & 40.93 & 33.17 & 33.77\end{array}$

---- 452 PARAMETER FOB_USA free on board price for Appalachia coal

$\begin{array}{lllll} & 1995 & 2000 & 2005 & 2010 \\ \text { USA.Hroads } & 68.03 & 56.53 & 55.83 & 56.48\end{array}$

---- 452 VARIABLE Cumcapex.L cumulative annualized capital expenditure: 000's US $2000 \$$

$\begin{array}{lccccc} & 1995 & 2000 & 2005 & 2010 \\ \text { Australia } & 57260.29 & 554756.96 & 583288.29 & 583521.55 \\ \text { USA } & 1858.00 & 1208957.18 & 2204774.04 & 2733414.24 \\ \text { Witbank } & 1828285.80 & 2373767.85 & 2638946.51 & 2689273.36 \\ \text { Mmamabula } & 449877.88 & 669742.00 & 778644.94 & 832788.95\end{array}$

---- 452 VARIABLE H.L capacity addition at source $\mathrm{i}$ in period $\mathrm{t}: 1000 \mathrm{tpd}$

$\begin{array}{llccc} & 1995 & 2000 & 2005 & 2010 \\ \text { Australia } & 3.83 & 65.90 & 7.60 & 0.12 \\ \text { USA } & 0.12 & 163.34 & 271.03 & 295.76 \\ \text { Witbank } & 135.97 & 83.01 & 81.17 & 30.98 \\ \text { Mmamabula } & 33.46 & 33.46 & 33.33 & 33.33\end{array}$


---- 452 VARIABLE X.L quantity shipped from supply $\mathrm{S}$ to port $\mathrm{K}$ in period t: 000 's mtce

\begin{tabular}{lcccc} 
& 1995 & 2000 & 2005 & 2010 \\
Australia.Gladstone & 32755.37 & 40258.48 & 32218.98 & 18886.48 \\
USA .Hroads & 10742.50 & \multicolumn{4}{c}{14991.05} \\
Witbank .RBCT & 36000.00 & 45000.00 & 57000.00 & 57000.00 \\
Mmamabula.Matola & 10000.00 & 20000.00 & 30000.00 & 40000.00
\end{tabular}

---- 452 VARIABLE Y.L quantity shipped from port $\mathrm{K}$ to demand $\mathrm{J}$ in period t: 000 's mtce

\begin{tabular}{llllll} 
& \multicolumn{1}{c}{1995} & 2000 & 2005 & 2010 \\
Matola & .ARA & 10000.00 & 20000.00 & 24295.76 \\
Matola & .Yokohama & \multicolumn{5}{c}{30000.00} & 15704.24 \\
RBCT & .ARA & 7736.92 & 21342.14 & 41337.22 \\
RBCT & .Yokohama & 28263.08 & 23657.85 & 15662.77 & 57000.00 \\
Gladstone.Yokohama & 32755.37 & 40258.48 & 32218.98 & 18886.48 \\
Hroads .ARA & 10742.50 & & 14991.05 &
\end{tabular}

GAMS Rev 121 Windows NT/95/98 04/18/03 17:50:36 PAGE 28

General Algebraic Modeling System

Execution

EXECUTION TIME $=0.050$ SECONDS $\quad 1.4 \mathrm{Mb} \quad$ WIN200-121

USER: Division of Resource Management

G010529:1803AP-WIN

West Virginia University

DC2709

**** FILE SUMMARY

INPUT C:IMY DOCUMENTSIGENERALIEXP_DESIGN_SIM90.GMS

OUTPUT C:IWINDOWSIGAMSDIRIEXP_DESIGN_SIM90.LST 


\section{Vita}

\section{Khaulani Fichani}

Khaulani Fichani was born on August $6^{\text {th }}, 1958$ at Masunga in Botswana. He completed his secondary school education in 1977 from Moeding College and was awarded a scholarship under the Canadian International Development Agency to study towards a degree in mining engineering. In 1980 he graduated with a two year Mining Technician's Diploma from the Haileybury School of Mines in Ontario, Canada and proceeded to study at the University of British Columbia where he graduated in 1984 with a B.A.Sc. Degree in Mining and Mineral Processing Engineering.

His work experience includes more than ten years in both the private and government sectors. He spent one year as a production supervisor for underground mining operations at Botswana's large scale copper and nickel mine, BCL Ltd, in 1985/86 and two years as production foreman at the now largest diamond mine operation in Botswana, the Orapa and Letlhakane Mines from 1986 to 1988. By the time he went back for his Doctoral studies, he was a Principal Minerals Officer in Botswana's Ministry of Minerals, Energy and Water Affairs.

From mid 1990 to December 1991, Khaulani completed an MS program in Mineral Economics from the Colorado School of Mines in Golden, Colorado. Upon graduation he played key roles in the restructuring and subsequent sale of Amax Inc.'s interest in BCL in 1992; securing Sysmin assistance to Botswana's base metal mining industry in 1994; leading the first phase of the project to review Botswana's mineral legislation and policy that culminated in his presentation of the proposed fiscal regime to a select group of international mining executives in 1996 and chairing some of the roundtable discussions; secretary of the drafting committee for the new mining law in 1997, and an attachment to the Commonwealth Secretariat's Economic and Legal Advisory Services Division in London in 1998.

Since January 1999, Khaulani has been a student in the Ph.D. program in Agriculture and Resource Economics at West Virginia University. In this time, he has worked part-time as a GIS technician for the Division's Natural Resource Analysis Center and also as adjunct faculty at Fairmont State College in Fall 2002 and Potomac State College of West Virginia University in Spring 2003. I taught introductory microeconomics and principles of macroeconomics.

His areas of interest are in modeling primary fossil fuel trade at both the regional and international levels; applying economic theory to the solution to problems on global warming, and issues to do with energy, the environment, development and welfare. 